\author{
UNIVERSIDADE DE SÃO PAULO \\ PROGRAMA DE PÓS-GRADUAÇÃO EM ENGENHARIA MECÂNICA
}

FELIPE ALCARPE CODA

\title{
ARQUITETURA PARA AQUISIÇÃO DE BIG DATA VOLTADA PARA INDÚSTRIA 4.0
}



UNIVERSIDADE DE SÃO PAULO

PROGRAMA DE PÓS-GRADUAÇÃO EM ENGENHARIA MECÂNICA

FELIPE ALCARPE CODA

\title{
ARQUITETURA PARA AQUISIÇÃO DE BIG DATA VOLTADA PARA INDÚSTRIA 4.0
}

\author{
Versão Corrigida
}

Dissertação apresentada à Escola Politécnica da Universidade de São Paulo, como parte dos requisitos para a obtenção do título de Mestre em Ciências.

Programa: Engenharia Mecânica

Área de concentração: Controle e Automação

Orientador: Prof. Dr. Paulo Eigi Miyagi

Coorientador: Prof. Dr. Fabrício Junqueira

São Paulo 
Autorizo a reprodução e divulgação total ou parcial deste trabalho, por qualquer meio convencional ou eletrônico, para fins de estudo e pesquisa, desde que citada a fonte.

Este exemplar foi revisado e corrigido em relação à versão original, sob responsabilidade única do autor e com a anuência de seu orientador.

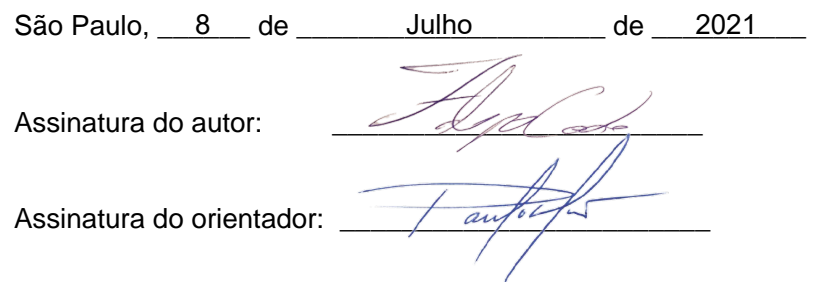

\section{Catalogação-na-publicação}

Coda, Felipe Alcarpe

Arquitetura para aquisição de big data voltada para indústria 4.0 / F. A.

Coda -- versão corr. -- São Paulo, 2021.

$189 \mathrm{p}$.

Dissertação (Mestrado) - Escola Politécnica da Universidade de São

Paulo. Departamento de Engenharia Mecatrônica e de Sistemas Mecânicos.

1.Indústria 4.0 2.Big Data I.Universidade de São Paulo. Escola

Politécnica. Departamento de Engenharia Mecatrônica e de Sistemas

Mecânicos II.t. 


\section{AGRADECIMENTOS}

Ao professor Dr. Paulo Eigi Miyagi pela orientação, paciência e sabedoria. Durante todo o estudo suas sugestões, ensinamentos e críticas foram compartilhados com maestria, melhorando imensamente todos os aspectos deste trabalho e contribuindo com a minha formação, tanto técnica como pessoal.

Ao professor Dr. Fabrício Junqueira pela coorientação, pelo apoio técnico e por todas as discussões. Ao longo deste projeto diversas dúvidas e questionamentos surgiram, mas sempre foram respondidos prontamente.

Ao Dr. Marcosiris Pessoa por todo o auxílio e contribuições feitas nas produções cientificas que decorreram deste estudo.

A todos os colaboradores da Escola Politécnica da USP que contribuíram de alguma forma com este trabalho, em especial ao Prof. Dr. Marcos Tsuzuki, responsável pelo programa de pós-graduação em Engenharia Mecânica, e as Sras. Regianne e Marisa da secretaria do programa de pós-graduação por todo o suporte acadêmico e administrativo.

Às agências de fomento Coordenação de Aperfeiçoamento de Pessoal no Nível Superior (CAPES), Fundação de Amparo à Pesquisa do Estado de São Paulo (FAPESP) e ao Conselho Nacional de Desenvolvimento Científico e Tecnológico (CNPq) por toda a infraestrutura fornecida. Em especial a última, por todo o suporte financeiro prestado durante este estudo.

Aos colegas de laboratório por todas as dicas e contribuições que foram feitas a este estudo.

Aos meus familiares, por todo o incentivo. 


\section{RESUMO}

O desenvolvimento de novas tecnologias e formas de se adquirir e processar dados obtidos em todas as etapas de um processo industrial é percebido por especialistas como um dos pilares de uma nova revolução industrial, denominada de "Indústria 4.0". A Indústria 4.0 pode ser compreendida como o resultado da implementação, de fato, de fábricas inteligentes onde os sistemas produtivos são autônomos, versáteis e associados a serviços para atender as diferentes necessidades de cada consumidor. Essa nova revolução industrial se apoia em conceitos como a Internet das Coisas (IoT), onde todos os dispositivos envolvidos nos sistemas produtivos estão conectados entre si, compondo sistemas ciber-fisicos (CPS) de modo que se pode processar uma quantidade muito grande de dados relacionados direta e indiretamente a esse sistema tanto no mundo virtual como no mundo real.

Em paralelo ao desenvolvimento desses sistemas produtivos estão sendo consideradas novas formas de tratar um conjunto muito grande de dados, conhecidos como big data. Estes estudos exploram técnicas e abordagens multidisciplinares, isto é, o aprimoramento na capacidade de adquirir e analisar potencialmente qualquer dado relacionado com processos e produtos é interpretado como uma oportunidade para revisar os paradigmas associados a sistemas produtivos.

A grande quantidade e variedade de dados do sistema produtivo, no contexto do big data, é evidentemente uma fonte de informações fundamental para controlar e otimizar todas as etapas do processo produtivo e os serviços associados. Neste contexto, este trabalho tem como objetivo desenvolver (i) a modelagem do processo de aquisição de dados de um sistema produtivo e, (ii) uma proposta de arquitetura do sistema de aquisição de dados.

Com base na natureza do sistema produtivo, a abordagem de sistema a eventos discretos é adotada para a representação/descrição dos processos envolvidos, de modo que se utiliza a técnica PFS (Production Flow Schema) / RdP (Rede de Petri) para o desenvolvimento dos modelos. A arquitetura do sistema de aquisição de big data é proposta levando em consideração os conceitos presentes no RAMI 4.0 que é uma arquitetura de referência para a Indústria 4.0.

Palavras-chaves: Indústria 4.0, Big data, Internet das Coisas, Sistema Ciber-Físico, RAMI 4.0, Production Flow Schema, Rede de Petri. 


\begin{abstract}
The development of new technologies and ways of acquiring and processing data obtained at all stages of an industrial process is perceived by experts as one strategic pillar of a new industrial revolution, called "Industry 4.0". Industry 4.0 can be understood as the result of the implementation, in fact, of intelligent factories where production systems are autonomous, versatile and associated with services to meet the different needs of each consumer. This new industrial revolution relies on concepts such as the Internet of Things (IoT), where all the devices involved in productive systems are connected together, composing cyber-physical systems (CPS) so that a very large amount of data directly and indirectly related to this system can be processed both in the virtual world, and in the real world.

In parallel with the development of these productive systems, new methods of handling a very large set of data known as big data are being considered. These studies explore multidisciplinary techniques and approaches, that is, enhancing the ability to acquire and potentially analyze any data related to processes and products is interpreted as an opportunity to review the paradigms associated with production systems.

The large amount and variety of data in the productive system, in the context of big data, is evidently a fundamental source of information to control and optimize all stages of the production process and associated services. In this context, this work has as objectives to develop (i) the modeling of the data acquisition process of a productive system and, (ii) a data acquisition system architecture proposal.

Based on the nature of the production system, the system approach to discrete events is adopted for the representation / description of the processes involved, using the PFS (Production Flow Schema) / Petri Net technique. The architecture of the big data acquisition system is proposed taking into consideration the concepts present in RAMI 4.0 which is a reference architecture for Industry 4.0.
\end{abstract}

Keywords: Industry 4.0, Big data, Internet of Things, Cyber-Physical System, RAMI 4.0, Production Flow Schema, Petri Net. 



\section{LISTA DE FIGURAS}

Figura 1 - Inovação tecnológica nas revoluções industriais. ........................................... 19

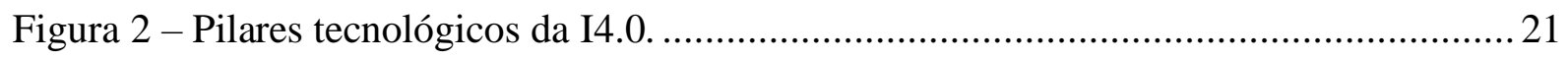

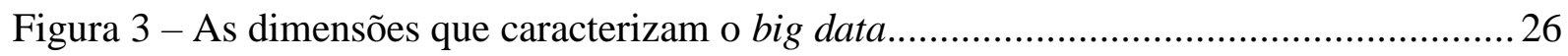

Figura 4 - Diagrama funcional para aquisição de dados dentro de um sistema de controle.... 28

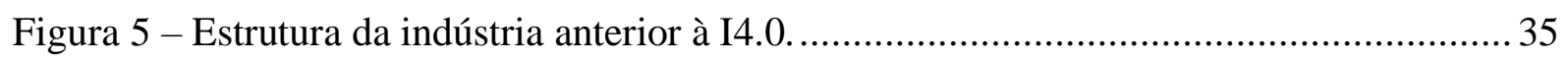

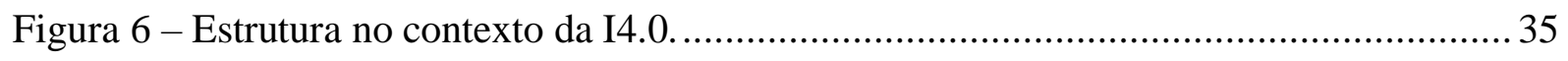

Figura 7 - Estrutura básica de um CPS.................................................................. 37

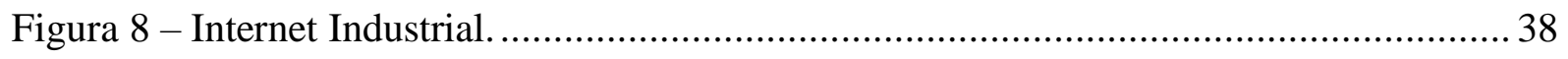

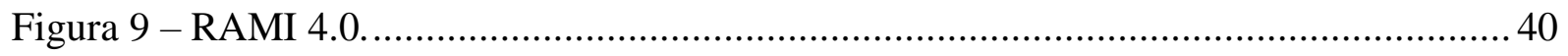

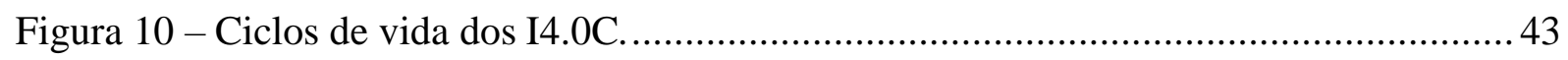

Figura 11 - Derivação dos níveis hierárquicos do RAMI 4.0 ......................................... 44

Figura 12 - NIST Big data Reference Architecture (NBDRA). ....................................... 48

Figura 13 - Exemplo da modelagem em KAOS. .................................................... 51

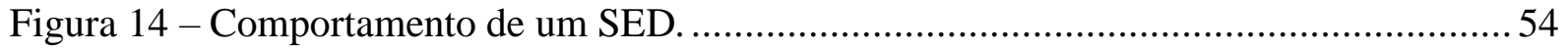

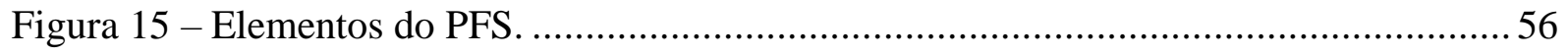

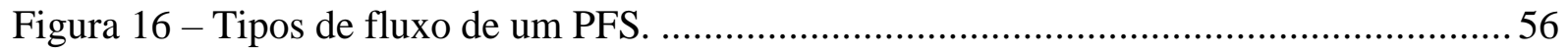

Figura 17 - Exemplo da modelagem top-down com o PFS onde (a) é o esquema do processo;

(b) são os modelos em PFS da estrutura geral do processo; (c) é o modelo em RdP derivado do

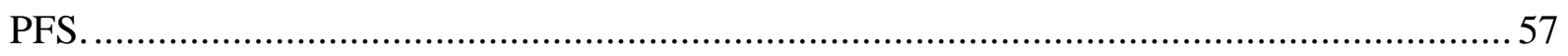

Figura 18 - Representação gráfica em RdP da sequência de duas transições $\left(t_{1}\right.$ e $\left.t_{2}\right) \ldots \ldots \ldots \ldots . . .58$

Figura 19 - Representação gráfica em RdP do paralelismo de três transições $\left(t_{1}, t_{2}\right.$ e $\left.t_{3}\right)$......59

Figura 20 - Representação gráfica em RdP da sincronização de três transições $\left(t_{1}, t_{2}\right.$ e $\left.t_{3}\right)$...59

Figura 21 - Representação gráfica em RdP do conflito entre três transições $\left(t_{1}, t_{2}\right.$ e $\left.t_{3}\right) \ldots \ldots . . .60$

Figura 22 - Representação gráfica em RdP de dois processos compartilhando um recurso. .. 61

Figura 23.1 - (a), (b), (c), (d): Análise de um modelo em RdP e obtenção da ...................... 63

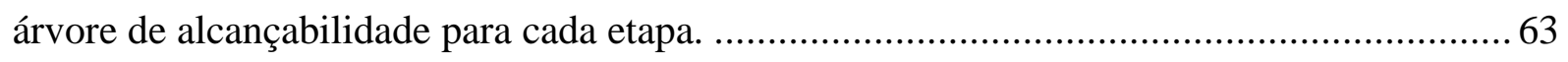

Figura 23.2 - (e), (f), (g): Análise de um modelo em RdP e obtenção da árvore de

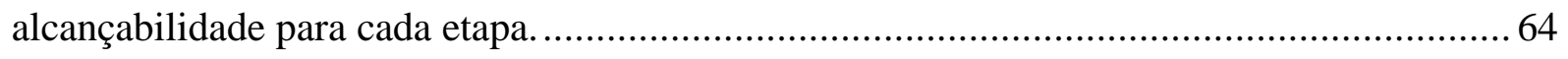

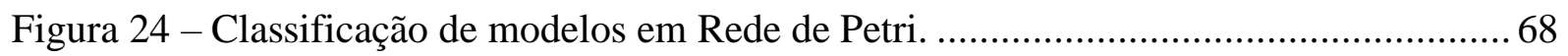

Figura 25 - Empresas onde os dados alimentam ferramentas de otimização. ....................... 71

Figura 26 - Empresas onde os dados são seu próprio negócio. .......................................... 74

Figura 27 - Empresas onde os dados motivam a estratégia competitiva.............................. 77 
Figura 28 - Estrutura da arquitetura sobre o eixo Camadas do RAMI 4.0........................ 83

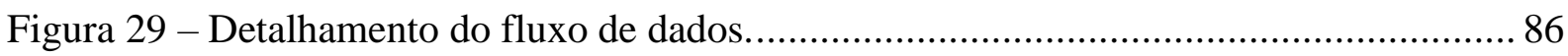

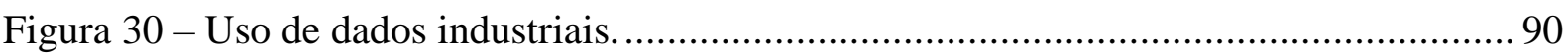

Figura 31 - Detalhamento da aquisição de dados em tempo real....................................... 90

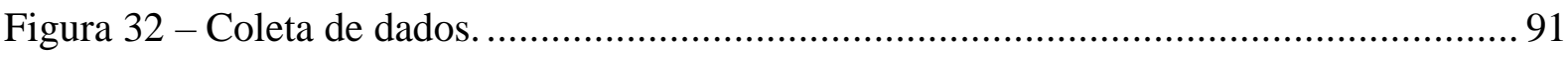

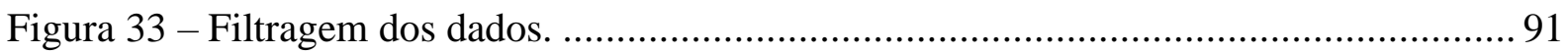

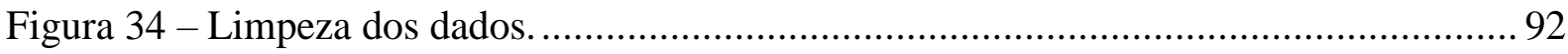

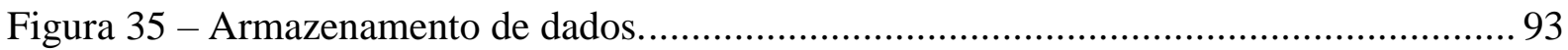

Figura 36 - Interação entre sistemas de controle e supervisão corporativos e a "solução de

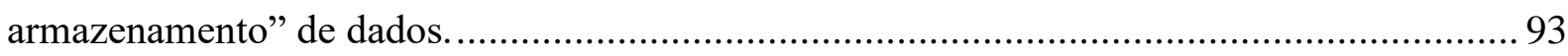

Figura 37 - Modelo em PFS do processo geral de aquisição de dados industriais. ............... 95

Figura 38 - Modelo em PFS do processo geral de aquisição de dados na I4.0...................... 96

Figura 39 - Modelo em RdP da coleta de dados na camada “Ativo Técnico". ..................... 97

Figura 40 - Modelo em RdP da virtualização dos ativos na camada "Integração"................. 98

Figura 41 - Modelo em RdP da transferência dos dados na camada "Comunicação"............ 99

Figura 42 - Modelo em RdP das funcionalidades na camada "Informação"....................... 100

Figura 43 - Modelo em RdP das funcionalidades na camada "Funcional". ........................ 101

Figura 44 - Modelo em RdP das funcionalidades na camada "Regra do Negócio". ............ 102

Figura 45 - Modelo em RdP do envio de comandos na camada "Comunicação". ................ 102

Figura 46 - Modelo em RdP do envio de comandos na camada "Integração". .................... 103

Figura 47 - Modelo em RdP do envio de comandos na camada "Ativo Técnico". .............. 104

Figura 48 - Modelo em RdP do processo de aquisição de dados na I4.0........................... 105

Figura 49 - Atividades em sequência no modelo em RdP.............................................. 106

Figura 50 - Atividades em paralelismo no modelo em RdP....................................... 107

Figura 51 - Atividades em sincronismo no modelo em RdP......................................... 108

Figura 52 - Atividades com recursos em compartilhamento no modelo em RdP. .............. 109

Figura 53 - Árvore de alcançabilidade dos componentes do modelo RdP......................... 111

Figura 54 - Resultado do módulo de classificação de tipos no modelo em RdP................. 113

Figura 55 - Interpretação do módulo de classificação de tipos no modelo em RdP............. 113

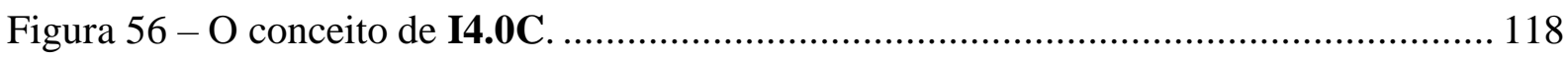

Figura 57 - Representação de um I4.0C, seu relacionamento com os Ativos, AAS e um tipo

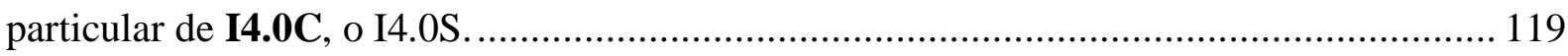

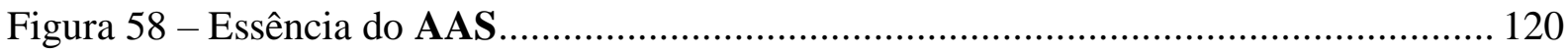

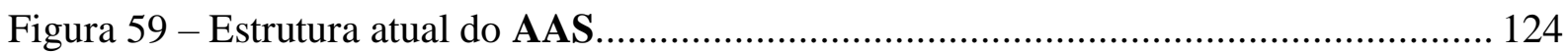




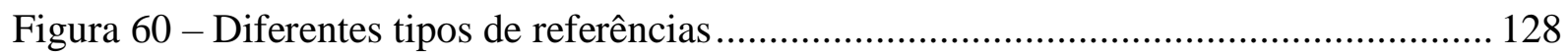

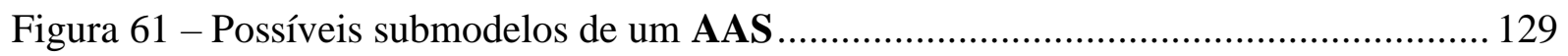

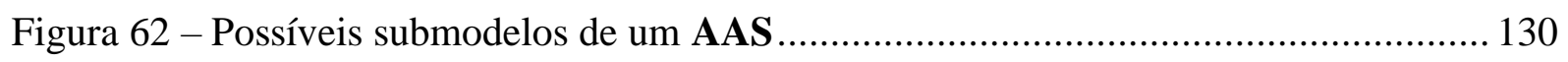

Figura 63 - Exemplo de submodelos para o cenário apresentado em (BEDENBENDER et al.,

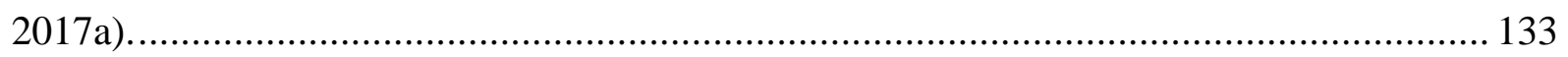

Figura 64 - Exemplo de visualização de um submodelo em um cliente OPC-UA............... 140

Figura 65 - Atividades do Exemplo 1 na arquitetura proposta. ........................................ 141

Figura 66 - Vários I4.0Cs com relacionamentos constituem um novo I4.0C com um AAS

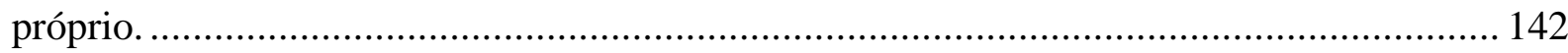

Figura 67 - A estrutura de um sistema em diferentes níveis de granularidade..................... 142

Figura 68 - As relações entre Ativos são descritas por meio de relações de propriedade..... 143

Figura 69 - No mundo físico, os Ativos são conectados $\left(c_{i}\right)$ por meio de suas propriedades $(M n)$

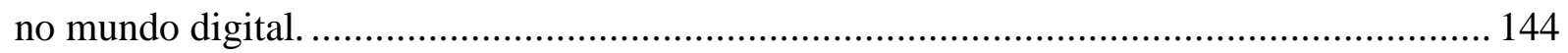

Figura 70 - No mundo digital, as conexões entre os Ativos são representadas pelos relacionamentos $(r)$ entre propriedades $(M n)$ registradas nos AASs dos I4.0C $\ldots \ldots \ldots \ldots \ldots \ldots . . . . . . .145$

Figura 71 - Exemplo de uma montagem que conecta vários componentes para formar um

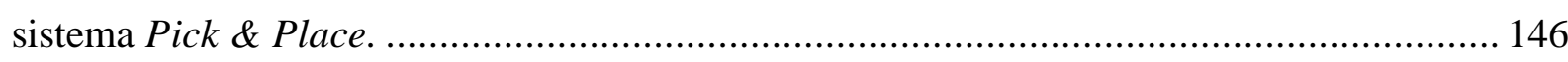

Figura 72 - Exemplo de relacionamentos entre Ativos baseados em um PLC e uma impressora

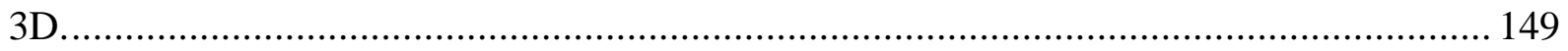

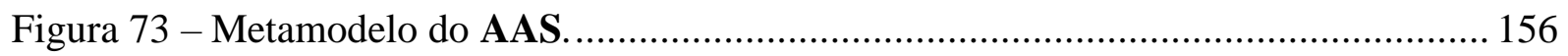

Figura 74- Visão geral do metamodelo para subelementos............................................ 157

Figura 75 - Representação dos atributos mínimos do Ativo “servo motor de corrente contínua",

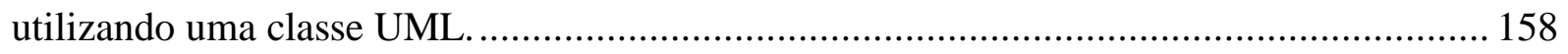

Figura 76 - Representação dos atributos mínimos do AAS relacionado ao Ativo da Figura 74,

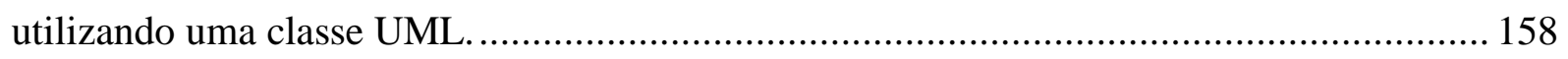

Figura 77 - Referência entre o AAS (Figura 76) e seu Ativo (Figura 75), utilizando um

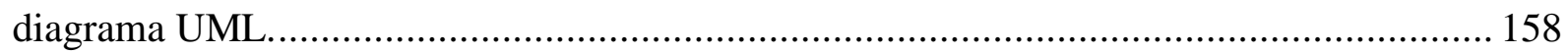

Figura 78 - Representação dos atributos mínimos do submodelos de dados técnicos do AAS da Figura 76, utilizando um diagrama UML

Figura 79 - Referência entre o AAS (Figura 76) e seu submodelo (Figura 78), utilizando um diagrama UML

Figura 80 - Referência a um elemento que não faz parte do contexto deste AAS para dar uma definição à propriedade "semanticId" da Figura 78, utilizando um diagrama UML 159 
Figura 81 - Propriedade "velocidade máxima de rotação" referente ao submodelo "dados técnicos", utilizando um diagrama UML. 160

Figura 82 - Referência a um elemento do contexto deste AAS para dar uma definição à propriedade "semanticId" da Figura 81, utilizando um diagrama UML. ........................... 160 Figura 83 - Descrição do conceito "velocidade máxima de rotação", pertencente a um dicionário de conceitos do AAS, utilizando um diagrama UML. 160 Figura 84 - Representação de todos os elementos que compõem o exemplo do motor de passo de corrente contínua. 161

Figura 85 - Atividades do Exemplo 2 na arquitetura proposta. 162

Figura 86 - Estrutura inicial para a base de dados. 163 


\section{LISTA DE TABELAS}

Tabela 1 - Análise de modelos GORE. .52

Tabela 2 - Análise do modelo em KAOS da Figura 25 (tipo 1)........................................ 71

Tabela 3 - Análise do modelo em KAOS da Figura 26 (tipo 2). ......................................... 74

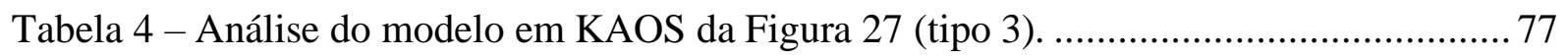

Tabela 5 - Legenda do modelo na Figura 39........................................................... 98

Tabela 6 - Legenda do modelo na Figura 40 ........................................................... 99

Tabela 7 - Legenda do modelo na Figura 41 ............................................................ 99

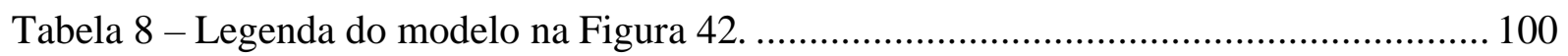

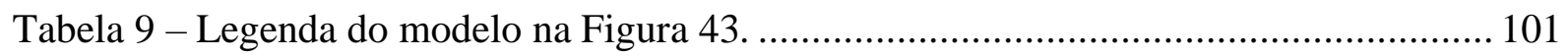

Tabela 10 - Legenda do modelo na Figura 44. .......................................................... 102

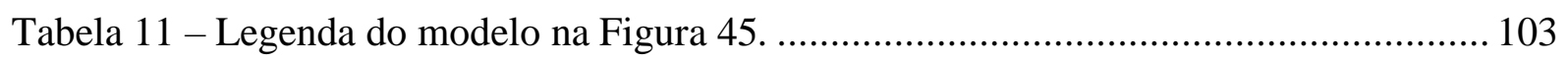

Tabela 12 - Legenda do modelo na Figura 46. ......................................................... 103

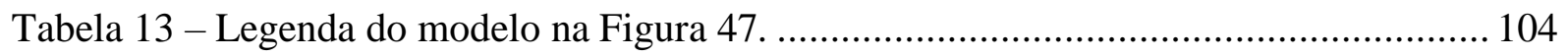

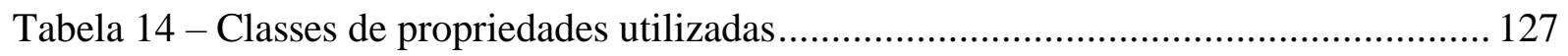

Tabela 15 - Views básicas definidas para os AASs pela DIN SPEC 91345 ....................... 132

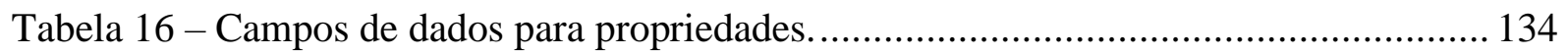

Tabela 17 - Campos de dados para submodelos. ....................................................... 135

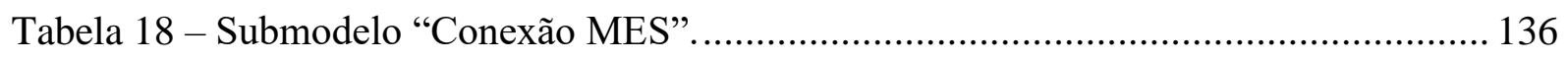

Tabela 19 - Submodelo "Eficiência energética". .......................................................... 137

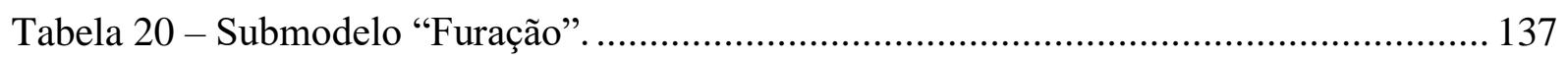

Tabela 21 - Exemplo de classificação de materiais, utilizado na Tabela 20. ...................... 138

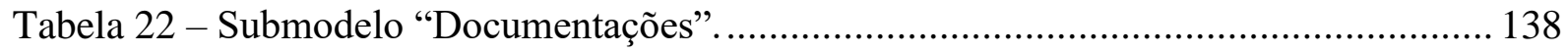

Tabela 23 - Exemplo de classificação dos tipos de campo de documento, utilizado na Tabela 22 .

Tabela 24 - Exemplo de classificação de tipos de arquivos para itens do documento utilizados

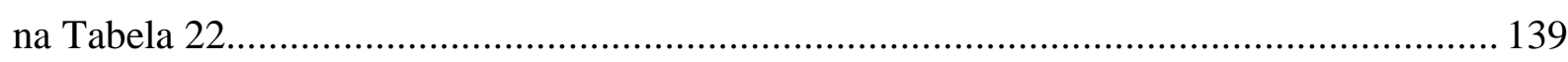

Tabela 25 - Classificações de propriedades para diferentes disciplinas de engenharia. ....... 148

Tabela 26 - Possíveis declarações de valor de propriedade.............................................. 148

Tabela 27 - Características determinadas para os Ativos compatíveis com a Indústria 4.0.. 154

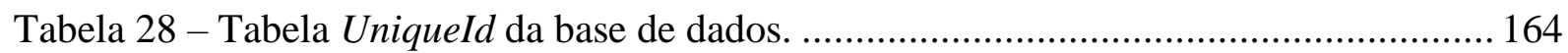

Tabela 29 - Tabela IdentifiableElements da base de dados. ........................................... 165 
VIII

Tabela 30 - Tabela SubModelElement da base de dados.............................................. 165

Tabela 31 - Tabela Reference. da base de dados.............................................................. 166

Tabela 32- Tabela Attributes da base de dados............................................................. 166

Tabela 33 - Tabela Data da base de dados. .................................................................. 170

Tabela 34 - Tabela LangStringSet da base de dados................................................... 173 


\title{
LISTA DE SIGLAS, ACRÔNIMOS E ABREVIATURAS
}

\author{
Sigla Descrição \\ ACID Atomicity, Consistency, Isolation, Durability \\ AMQP Advanced Message Queuing Protocol \\ CIM Computer-Integrated Manufacturing \\ CPS Sistemas Ciber-Fisicos \\ DAQ Sistema de aquisição de dados \\ DFKI Deutsches Forschungszentrum für Künstliche Intelligenz \\ DFS Distributed File System \\ ERP Enterprise Resource Planning \\ EV Empresas Virtuais \\ GBRAM Goal-Based Requirements Analysis Method \\ GORE Goal Oriented Requirements Engineering \\ HDFS Hadoop Distributed File System \\ I4.0 Indústria 4.0 \\ I4.0C Industry 4.0 Component \\ ICT Information and Comunication Technologies - Tecnologias da Informação \\ e Comunicação \\ IEC International Electrotechnical Commission \\ IEEE Institute of Electrical and Electronics Engineers \\ IHM Interface Homem-Máquina \\ IoT Internet of Things - Internet das Coisas \\ IP Internet Protocol address \\ ISA International Society of Automation \\ ISO International Organization for Standardization \\ JSON JavaScript Object Notation \\ KAOS Knowledge Acquisition in automated specification \\ LTE Long-Term Evolution \\ MQTT Message Queuing Telemetry Transport \\ MRP Material Requirement Planning \\ NDBRA NIST Big data Reference Architecture \\ NFR Non-Functional Requirement
}


NIST National Institute of Standards and Technology

NoSQL Not only SQL

OPC-UA OPC Unified Architecture

PFS Production Flow Schema

PIPE Platform Independent Petri net Editor

PLM Product Lifecycle Management

QoS Quality of Service

RAMI 4.0 Reference Architectural Model for Industry 4.0

RdP Rede de Petri

RFID Radio Frequency IDentification

SEBoK Systems Engineering Body of Knowledge

SEDs Sistemas a Eventos Discretos

SGAM Smart Grid Architecture Model

SOA Service-Oriented Archtecture

SQL $\quad$ Structured Query Language

TCP Transmission Control Protocol

USB Universal Serial Bus

Wi-Fi Wireless Fidelity

XML eXtensible Markup Language

ZVEI Zentralverband Elektrotechnik- und Elektronikindustrie e.V. - Associação alemã de fabricantes de elétricos e eletrônicos 


\section{SUMÁRIO}

1 INTRODUÇÃO

1.1 ОВJETIVO.......................................................................................................... 23

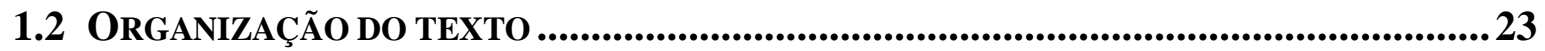

2 FUNDAMENTOS 25

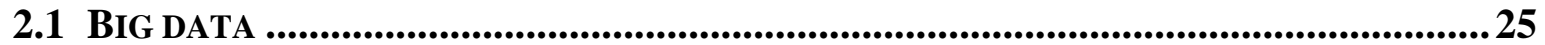

2.1.1 Sistemas de aquisição de dados (DAQ) .....................................................2 28

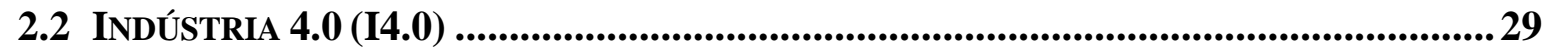

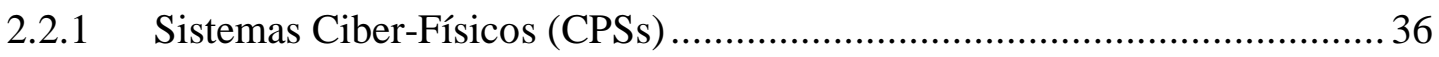

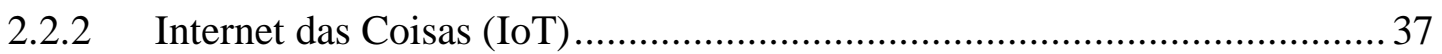

2.3 ARQUITETURAS DE SISTEMAS ........................................................................................ 38

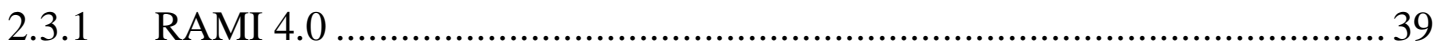

2.3.2 Eixo 1: Categorização dos ativos......................................................... 41

2.3.3 Eixo 2: Etapas do Ciclo de vida e Cadeia de valor................................... 42

2.3.4 Eixo 3: Níveis Hierárquicos ................................................................. 43

2.3.5 NBDRA - NIST Big data Reference Architecture................................. 45

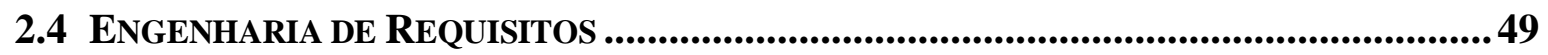

2.4.1 Engenharia de requisitos orientada ao objetivo (GORE) ......................... 49

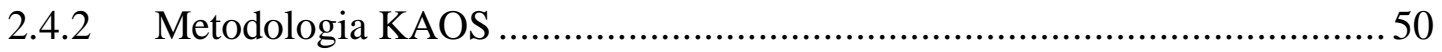

2.4.3 Técnica de análise de requisitos .........................................................51

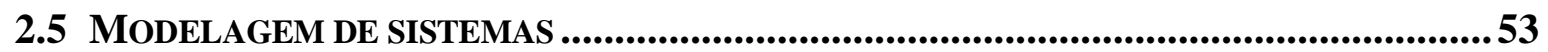

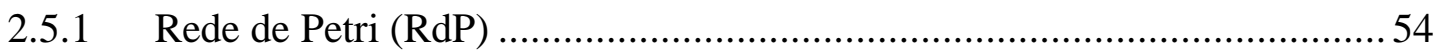

2.5.2 Características da Rede de Petri .................................................................58

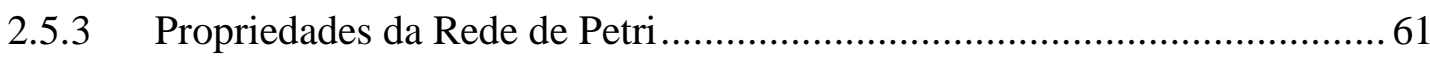

2.5.4 Classificação de tipos de Rede de Petri .....................................................66

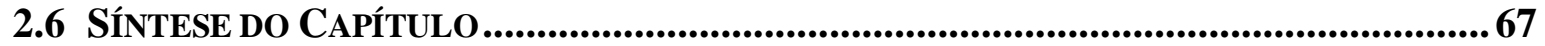

3 MODELAGEM DOS REQUISITOS PARA SISTEMAS DE BIG DATA 69

3.1 TIPO 1: EMPRESAS ONDE OS DADOS ALIMENTAM FERRAMENTAS DE OTIMIZAÇÃO .. 69

3.2 TIPO 2: EMPRESAS ONDE OS DADOS SÃO O SEU PRÓPRIO NEGÓCIO ........................... 73

3.3 TIPO 3: EMPRESAS ONDE OS DADOS MOTIVAM A ESTRATÉGIA DE COMPETITIVIDADE 75

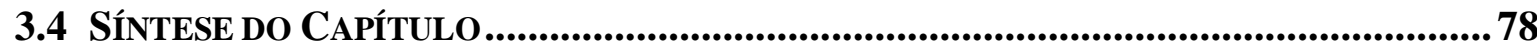


4 ARQUITETURA PARA A AQUISIÇÃO DE BIG DATA

4.1 ESTRUTURA DA ARQUITETURA................................................................................. 81

4.2 INTERAÇÃO ENTRE OS COMPONENTES DA ARQUITETURA...................................... 84

4.3 SÍNTESE dO CAPÍTULO........................................................................................ 87

MODELAGEM E ANÁLISE DO PROCESSO DE AQUISIÇÃO DE BIG DATA 89

5.1 Modelagem Conceitual do Processo de Aquisição de Big data 89

5.2 Modelagem Funcional da ARQuitetura Proposta ......................................99

5.3 ANÁlISE DOS MODELOS EM RDP ...................................................................... 104

5.3.1 Análise das características estruturais do modelo em RdP ..................... 106

5.3.2 Análise das propriedades do modelo em RdP ...................................... 110

5.3.3 Análise dos tipos do modelo em RdP ............................................... 113

5.4 Resultados da AvaliaÇÃo do Modelo..................................................... 113

6 CONCLUSÕES $\quad 115$

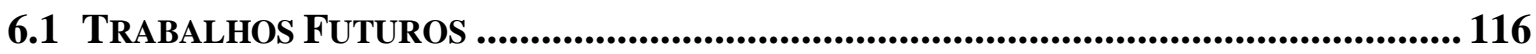

$\begin{array}{lll}7 & \text { APÊNDICE } & 117\end{array}$

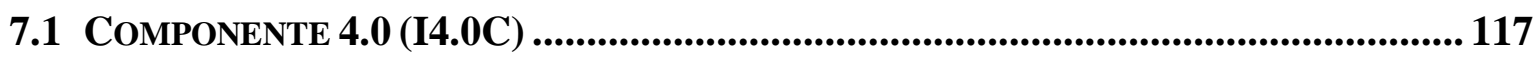

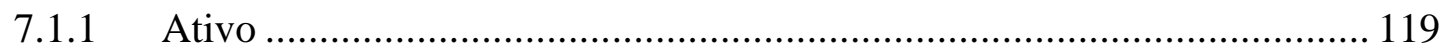

7.1.2 Asset Administration Shell (AAS) …............................................. 121

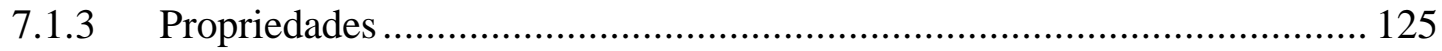

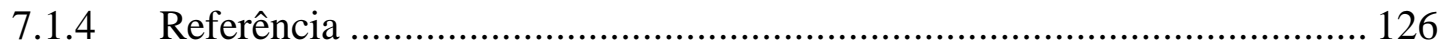

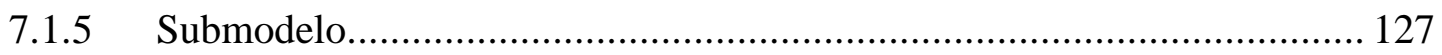

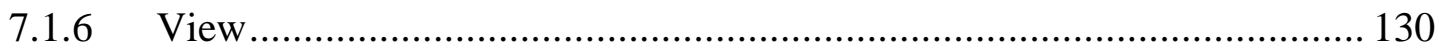

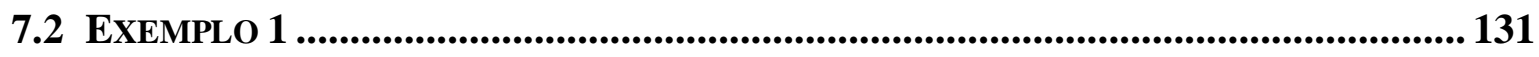

7.3 COMPOSIÇÃO E COOPERAÇÃ̃ ENTRE ATIVOS ................................................ 140

7.4 EXEMPLO DE APLICAÇÃO DE RELACIONAMENTO ENTRE ATIVOS ............................ 147

7.5 CRITÉRIOS PARA UM ATIVO SER CONSIDERAdO COMPATÍVEL COM A I4.0 ............. 151

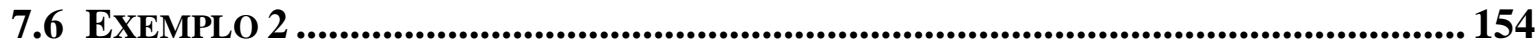

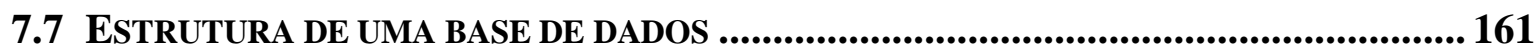

8 REFERÊNCIAS $\quad 175$ 




\section{INTRODUÇÃO}

No início no século XVIII, três grandes “ondas” de mudanças tecnológicas modificaram o cenário mundial de produção de bens e que aumentaram a produtividade (IMTIAZ; JASPERNEITE, 2013). Essas ondas são conhecidas como revoluções industriais.

Tais revoluções industriais foram influenciadas pelos avanços tecnológicos, pelas demandas de mercado e pelo surgimento de novas técnicas e modelos de negócios que, de alguma forma, alavancaram o progresso humano por meio de novas formas de geração de energia, produção em grande quantidade e processamento de informações (CHANTANAYINGYONG, 2016; SCHWAB, 2016).

A primeira revolução industrial se caracteriza pelo uso da máquina a vapor para geração de energia e a mecanização do trabalho manual no século XVIII. Um exemplo de equipamento dessa época é o tear mecânico. A segunda revolução se caracteriza pela disseminação da energia elétrica e a implantação de técnicas de produção em massa a partir do início do século XIX, como a linha de montagem da empresa Ford, em 1870. A terceira revolução industrial se caracteriza pelo desenvolvimento da microeletrônica (circuitos integrados) e automação dos processos de manufatura onde o primeiro controlador industrial, baseado em memória programável, foi desenvolvido em 1969 (GIERSBERG, 2014; PISCHING, 2018).

A Figura 1 mostra como, para Schuh et al., (2014), cada revolução industrial anterior foi caracterizada pelo desenvolvimento tecnológico e inovações organizacionais marcantes para cada época.

Figura 1 - Inovação tecnológica nas revoluções industriais.

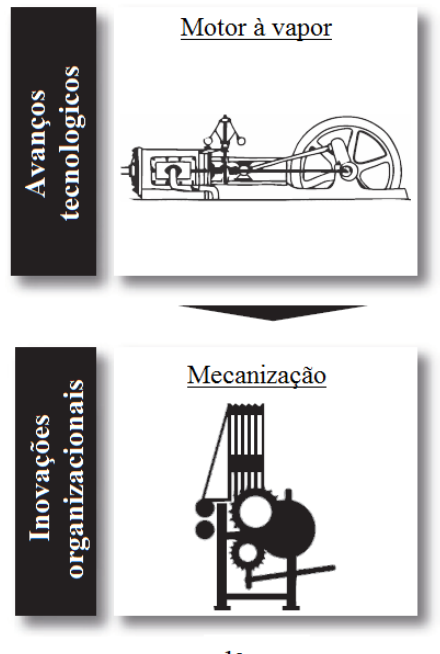

1a rev.
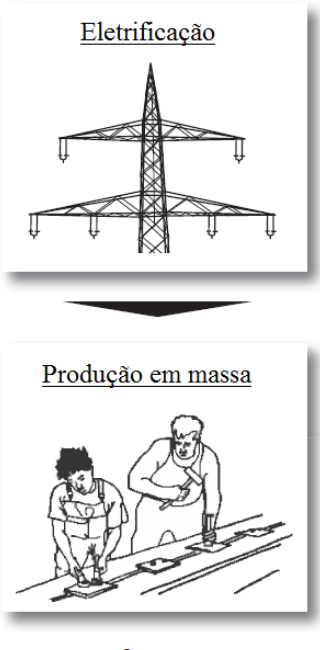

2a rev.
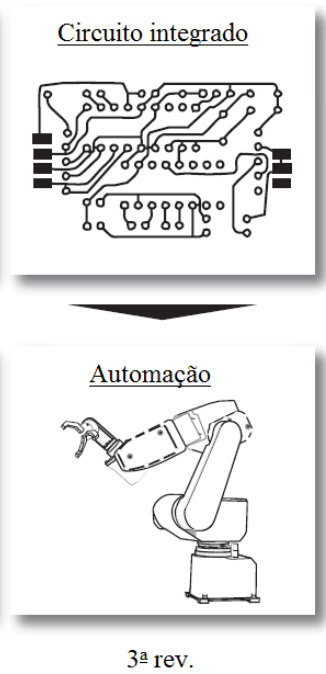

Fonte: Adaptado de Schuh et al., (2014). 
Para Bangemann et al. (2016), a quarta revolução, denominada de Indústria 4.0 (I4.0), representa um novo cenário de produção mundial, caracterizada por três aspectos principais:

- Uma nova forma de organizar e controlar toda a cadeia de valor ${ }^{1}$ considerando todo o ciclo de vida dos produtos;

- A disponibilidade de informações em tempo real dos processos envolvidos na cadeia de valor;

- A estruturação de cadeias de valor entre empresas considerando a interconectividade de humanos, dispositivos e sistemas, de acordo com suas habilidades/capacidades de interesse para o processo produtivo.

Rüssmann et al. (2015) reconhecem que a I4.0 é uma revolução sustentada por nove pilares tecnológicos. Esses nove pilares são ilustrados pela Figura 2 onde o sistema produtivo industrial é caracterizado pela interação de diversas e diferentes entidades:

1. Internet das Coisas (IoT): que envolve a capacidade de conectar todos os dispositivos que compõem as entidades (i.e. dispositivos, usuários, sistemas) envolvidas, tornando-os capazes de enviar, receber e processar dados;

2. Big data: que considera a disponibilidade de uma quantidade muito grande de dados coletados pelas entidades envolvidas, com a intenção de usá-los para aprimorar os processos;

3. Computação na nuvem: que considera a disponibilidade permanente de recursos computacionais (independentemente de onde fisicamente estes estejam), e que possibilita o armazenamento e o processamento de dados com desempenho e velocidade compatível com as necessidades;

4. Simulação: que é a técnica de análise que "espelha" (num mundo virtual) os processos físicos (no mundo real) a partir dos dados coletados em tempo real de modo a permitir testes que aprimoram e otimizam os processos. Esta réplica entre o mundo virtual e mundo físico é fruto da implementação do que é chamado de digital twin;

5. Robôs autônomos: onde se considera a disponibilidade de robôs com capacidade para tomar decisões e executar tarefas de uma maneira cada vez mais autônoma, flexível e cooperativa de modo que possam atuar lado a lado com humanos e aprender com eles;

\footnotetext{
${ }^{1}$ A cadeia de valor (value chain) é uma referência ao conjunto de atividades que uma empresa, operando em um contexto industrial, realiza para entregar um produto ou serviço ao mercado consumidor (PORTER, 1998).
} 
6. Integração horizontal e vertical: que representa a efetiva conexão entre os diferentes sistemas utilizados numa empresa (integração vertical) para o controle de seus processos internos e por conexões entre sistemas com funcionalidades similares (integração horizontal) envolvendo uma rede de empresas, consumidores ou fornecedores parceiros;

7. Realidade aumentada: que é a tecnologia considerada para uma revisão e inovação dos procedimentos dos operadores humanos que envolvem interação com máquinas, sistemas e outras pessoas, incluindo os consumidores;

8. Manufatura aditiva: que é a tecnologia considerada para aumentar a flexibilidade na fabricação de componentes, considerando inclusive peças que não têm como serem manufaturadas com técnicas convencionais de fabricação, assim como uma revisão das técnicas de gestão de estoques;

9. Ciber-segurança: que assegura que mesmo com o abrupto aumento da conectividade a comunicação entre as entidades ocorre com a devida confiabilidade, protegendo as propriedades críticas de sistemas industriais.

Figura 2 - Pilares tecnológicos da I4.0.

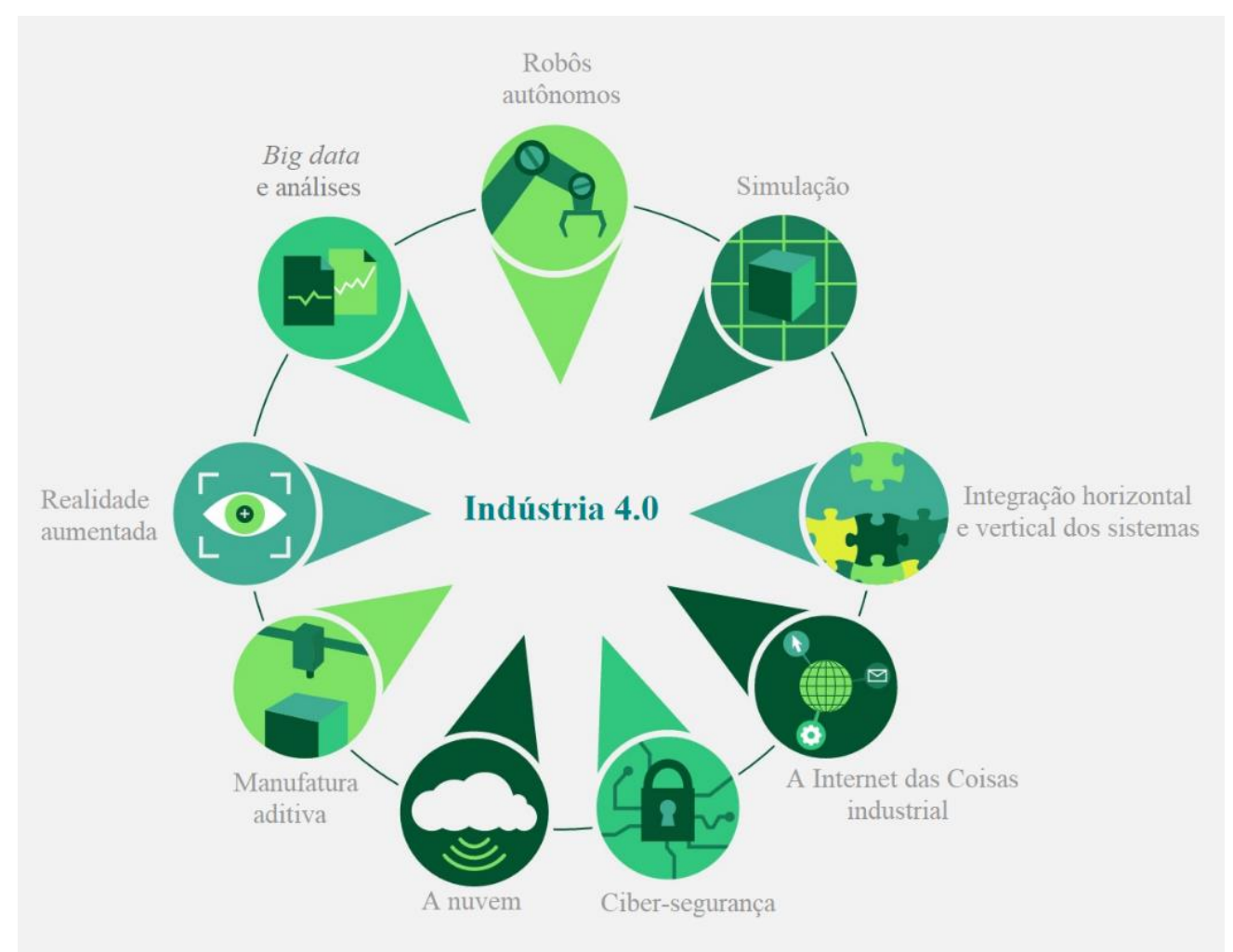

Fonte: Adaptado de Rüssmann et al., (2015). 
Existem trabalhos que sugerem outras abordagens e visões para a I4.0, às vezes como sendo este apenas um caso de aplicação de CPS ou IoT com computação na nuvem² (AAZAM; ZEADALLY; HARRAS, 2018; JAZDI, 2014) e/ou com outros conjuntos de pilares tecnológicos. Apesar desta dificuldade de se ter uma visão comum para o estudo da integração das diferentes tecnologias envolvidas, publicações relacionadas como Ploner (2014), Lee et al., (2015), Lee; Kao; Yang (2014) e Sun et al., (2016) confirmam o big data como fundamental na implantação da I4.0, isto é, em todos os trabalhos publicados nessa área o big data sempre está presente como uma tecnologia fundamental para viabilizar e oferecer o suporte necessário para a I4.0. No entanto, essas mesmas publicações não definem ou especificam claramente o que é o big data na I4.0, isto é, qual é a natureza e características dessa quantidade muito grande de dados a ser processada, quais os sistemas que armazenam e disponibilizam esses dados, e quais devem ser os atributos de um sistema de análise dos dados neste ambiente.

Numa visão mais conceitual e genérica, o big data (ou o sistema de big data) envolve processos que podem ser vistos como de mesma natureza que os sistemas a eventos discretos (SEDs) (WANG; TÖRNGREN; ONORI, 2015) de modo que técnicas de modelagem, análise e caracterização de soluções de controle de SEDs podem ser utilizadas. Nesse contexto, identifica-se um caminho para desenvolver modelos e especificações de um sistema de big data para a I4.0, via técnicas como rede de Petri (RdP) (ZHANG et al., 2017), e consequentemente, suas extensões e interpretações como por exemplo o Production Flow Schema (PFS).

Outro ponto de destaque é que já existem alguns trabalhos que orientam a organização dos sistemas na I4.0. Dentre eles se destaca o RAMI 4.0 (Reference Architectural Model for Industry 4.0) que é uma arquitetura de referência para a implementação da I4.0 (ADOLPHS et $a l ., 2015)$. Todos os sistemas da I4,0, inclusive os relacionados com o big data devem atender o RAMI 4.0.

Do ponto de vista de implementação da I4.0, fica claro que apesar da significativa contribuição de vários especialistas, o big data envolve dados que antes de tudo devem ser devidamente coletados para serem armazenados e utilizados, e os trabalhos publicados até o momento não têm focado este problema.

\footnotetext{
${ }^{2} \mathrm{O}$ conceito de computação em nuvem é descrito por Gartner (2008) como uma referência à utilização da memória e capacidades de armazenamento e processamento de computadores e servidores interligados pela internet. Atualmente, o termo faz referência a utilização, por usuários, de serviços e recursos computacionais através de uma rede de comunicação (e.g. internet).
} 


\subsection{Objetivo}

Neste contexto, este trabalho foca o processo de aquisição de dados no contexto de big data para I4.0, isto é, o objetivo é desenvolver a modelagem dos processos envolvidos e com isso obter os subsídios para especificar uma arquitetura deste sistema (de coleta de dados de processos industriais).

A abordagem adotada é de SEDs para a descrição dos processos envolvidos usando técnicas como o PFS e a RdP.

$\mathrm{Na}$ especificação desta arquitetura do sistema de coleta de dados, o cerne está no conjunto de funcionalidades, componentes e serviços necessários para a coleta de dados, estabelecendo os procedimentos para que os dados coletados sejam devidamente preparados para aplicações de análise do sistema produtivo e seu controle.

A partir do objetivo deste trabalho, foram estabelecidas as seguintes metas a serem alcançadas:

1. Contextualizar o big data na I4.0, definindo e especificando o que é um sistema que utiliza o big data;

2. Estabelecer os requisitos para sistemas de big data com base nos pontos de vista de stakeholders ligados à I4.0;

3. Conceber uma arquitetura preliminar para sistemas de big data em consonância com o RAMI 4.0, definindo os componentes necessários para a aquisição de dados na I4.0;

4. Desenvolver a modelagem conceitual e funcional dos processos de aquisição de dados dentro da arquitetura concebida anteriormente utilizando a técnica PFS/RdP;

5. Avaliação do modelo desenvolvido para aprimoramento e especificação de uma arquitetura para sistemas de big data no contexto da I4.0.

\subsection{Organização do texto}

Seguinte ao capítulo introdutório, o corpo do texto está organizado em mais cinco capítulos.

No Capítulo 2 são apresentados os fundamentos considerados neste trabalho.

No Capítulo 3 é apresentada a modelagem dos requisitos para sistemas de big data.

No Capítulo 4 é apresentada a proposta de arquitetura para sistemas de big data no contexto da I4.0. 
No Capítulo 5 é apresentada a modelagem e a análise da arquitetura proposta e que confirmam suas funcionalidades.

No Capítulo 6 são feitas as considerações finais sobre o trabalho desenvolvido.

Finalmente, são discutidos em uma seção à parte os trabalhos futuros. 


\section{FUNDAMENTOS}

Neste capítulo são apresentados os conceitos relevantes para esta pesquisa, isto é: (1) os conceitos de big data e sistemas de aquisição de dados; (2) a I4.0 em conjunto com CPS e IoT; (3) arquiteturas de referência como o RAMI 4.0 e o NDBRA (NIST Big data Reference Architecture); (4) práticas da Engenharia de Requisitos para o projeto de sistemas; e (5) técnicas de modelagem, análise e especificação de sistemas. A compreensão destes conceitos facilita o entendimento do procedimento adotado e das contribuições deste estudo, sendo elas a elicitação dos requisitos para big data, a proposta de uma arquitetura que estruture o processo de aquisição de big data e a modelagem e avaliação desta arquitetura.

\subsection{Big data}

Uma das primeiras definições para o big data desdobra o termo como conjuntos de dados com três dimensões características: volume, velocidade e variedade (LANEY, 2001). Atualmente, autores como Gil e Song (2016) adicionam outras duas dimensões: veracidade e

valor. Existe ainda uma discussão entre os pesquisadores sobre a necessidade de adicionar a dimensão do "valor", mas neste trabalho assume-se que este representa uma característica que na prática é desejada para os dados.

Uma descrição de cada dimensão segue:

- Volume: trata da quantidade dos dados coletados (nos sistemas atuais, na ordem de exabytes, ou seja, $10^{18}$ bytes) (CHEN; LI; WANG, 2015; YIN; KAYNAK, 2015);

- Variedade: trata dos diferentes tipos de formatos e fontes dos dados extraídos e que podem referenciar diversas variáveis mensuráveis;

- Velocidade: trata da capacidade dos dispositivos de transmissão de dados de passar os dados extraídos pelos dispositivos detectores para os dispositivos de realização do controle a uma velocidade compatível com as necessidades da tomada de decisões;

- Veracidade: trata da confiabilidade dos dados e está associada à disponibilidade de ferramentas para garantir isso;

- Valor: trata das informações que os dados contêm para uma perspectiva de melhoria, ou seja, vantagens para os processos/serviços associados.

Em resumo, o big data, além de envolver uma grande massa de dados envolve a ideia de um sistema que inclui recursos que garantem a velocidade de processamento e serviços que adicionam valor (DE MAURO; GRECO; GRIMALDI, 2015). 
A Figura 3 mostra as dimensões que caracterizam o big data.

Figura 3 - As dimensões que caracterizam o big data.

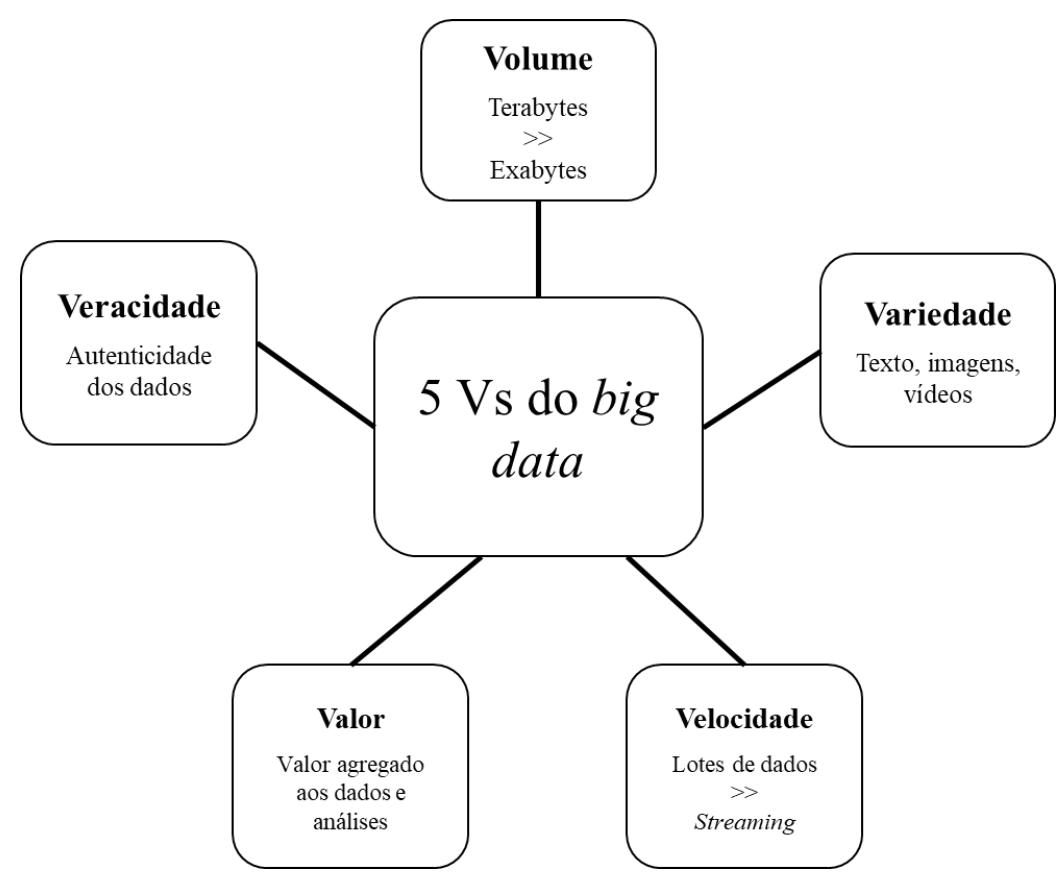

Fonte: Adaptado de Yin e Kaynak (2015).

Dados ou mesmo big data por si mesmos são apenas os registros de fatos que ocorreram, necessitando de métodos (e.g. algoritmos de data mining, machine learning, etc.) para inferir conhecimento (CHEN; MAO; LIU, 2014).

Com base nessa definição em (CHEN; MAO; LIU, 2014), argumenta-se que tal entidade (ou big data application) deve ser interpretado como um sistema que aplica algoritmos a conjuntos de dados considerando as cinco dimensões (Vs), para geração de informação, conhecimento, inteligência e, finalmente, sabedoria (LIEW, 2013).

Sobre o armazenamento do big data, segundo Strohbach et al. (2016), o estado da arte das suas tecnologias está dividido entre os seguintes tipos de sistemas:

- Distributed File Systems (DFS): é um sistema de arquivos como o Hadoop File System (HDFS) que é capaz de armazenar grandes quantidades de dados não estruturados de forma confiável e em hardwares de relativamente baixo custo (commodity hardware). Ele foi projetado para arquivos de dados relativamente grandes e é adequado para a rápida inclusão de dados e processamento em massa.

- Bancos de dados NoSQL: são considerados como a família de sistemas mais importante das tecnologias de armazenamento de big data. Esses bancos consideram 
dados não-relacionais ${ }^{3}$ que não são aderentes às propriedades de atomicidade, consistência, isolamento e durabilidade (ACID), responsáveis por garantir a precisão, a totalidade e a integridade dos dados durante as operações em bancos de dados relacionais $(\mathrm{SQL})$.

- Bancos de dados NewSQL: é um sistema com formato de bancos de dados relacional que visa escalabilidade comparável aos bancos de dados NoSQL, mantendo as propriedades ACID, ou seja, combinando a velocidade e desempenho de NoSQL e a confiabilidade de SQL.

- Big data Querying Platforms: é um sistema com recursos que permitem consultas em grandes bases de armazenamento de dados como os sistemas de arquivos distribuídos (DFS) ou bancos NoSQL. A principal característica é uma interface de alto nível (i.e., via SQL) como linguagem, para assegurar baixas latências de consulta.

Um exemplo da magnitude dos dados gerados e coletados a partir da conectividade entre a indústria moderna, soluções baseadas em computação na nuvem e a gestão das áreas de negócio empresariais é o relatório publicado por Gantz, Reinsel, Shadows, (2012), que prevê um aumento na geração de dados de 130 para 40.000 exabytes entre 2005 e 2020. Yin e Kaynak (2015) estimavam que esta quantidade dobraria a cada dois anos, no entanto, o estudo mais recente publicado pela empresa Statista (2021) mostra que os números superaram as estimativas anteriores, alcançando 59.000 exabytes de dados gerados no mundo todo ao final de 2020 e com uma estimativa de crescimento deste volume em $26 \%$ ao ano para os próximos cinco anos.

No entanto, em adição à definição de big data, é também fundamental identificar um procedimento para seu projeto e implementação. Assim, é necessário que os requisitos para o big data sejam propriamente identificados, permitindo que o desenvolvimento de sistema relacionados sejam efetivamente orientados à solução das necessidades dos atores envolvidos, nesse caso, stakeholders $^{4}$ da I4.0.

\footnotetext{
${ }^{3}$ Dados não-relacionais não usam a estrutura de dados tradicional onde os dados estão relacionados em tabelas de linhas e colunas. Em vez disso os dados não-relacionais são armazenados de forma otimizada para os requisitos específicos do tipo de dado armazenado (e.g.: dados armazenados em pares "chave" para identificação e "valor" para o dado armazenado).

${ }^{4} \mathrm{O}$ termo stakeholders no contexto desta pesquisa diz respeito aos indivíduos envolvidos / comprometidos com o sucesso do negócio da empresa associados com o cenário da I4.0.
} 


\subsubsection{Sistemas de aquisição de dados (DAQ)}

Lei et al. (2018) descrevem o processo de aquisição de dados como a captura e armazenamento de conjuntos de dados relevantes de processos dos sistemas produtivos. Além disso, os autores acrescentam que um DAQ (Data Acquisition System - sistema de aquisição de dados) é geralmente composto por: (1) dispositivos de detecção (por exemplo, chaves fimde-curso, acelerômetros, sensores acústicos, termômetros, sensores de corrente, strain gages, etc.); (2) dispositivos de transmissão de dados; e (3) dispositivos de armazenamento de dados.

Em resumo, o DAQ é um sistema onde sinais físicos dos processos de interesse são convertidos em dados conforme os passos a seguir (MEASUREMENT COMPUTING CORPORATION, 2012):

1. Uma variável de um elemento físico do processo de interesse produz um sinal físico;

2. O sinal físico é convertido em um sinal elétrico por um dispositivo de detecção (sensor, isto é, um transdutor);

3. O sinal elétrico, que na prática sempre inclui algum nível de ruído, passa por um dispositivo para condicionamento de sinal e remoção do ruído;

4. O sinal resultante é transmitido para um conversor analógico/digital;

5. O sinal digital é convertido para um dado digital para ser armazenado e processado em um computador para análise e tomada de decisão.

A Figura 4 ilustra o diagrama para aquisição de dados e controle de sistemas, mostrando o caminho percorrido pelo sinal coletado de um elemento físico até sua conversão em dados e processamento por um dispositivo de realização do controle. A parte inferior da Figura 4 ilustra o fluxo de sinais de atuação a partir de uma tomada de decisão do dispositivo de realização do controle.

Figura 4 - Diagrama funcional para aquisição de dados dentro de um sistema de controle.

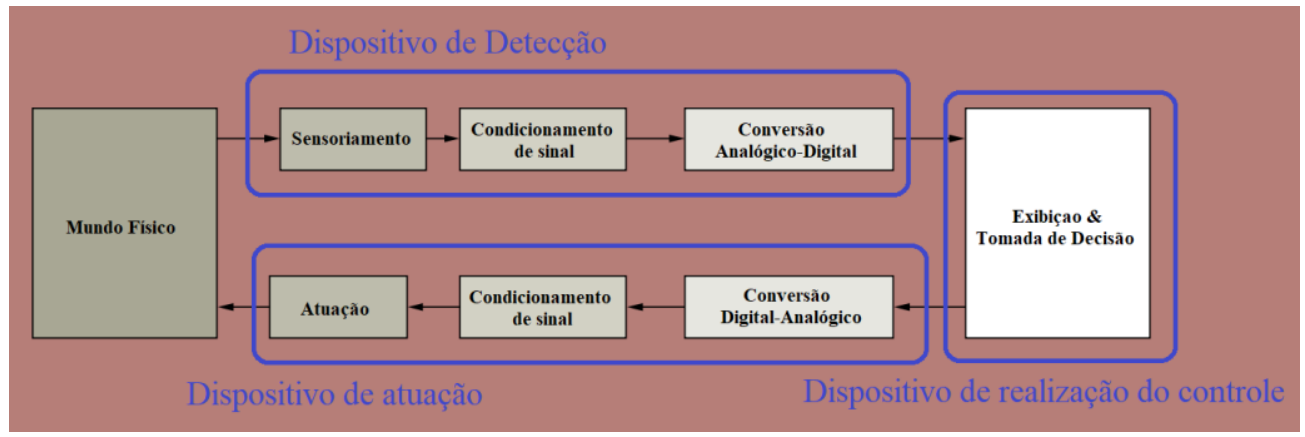

Fonte: Adaptado de Omega Engineering INC (2000). 
Com o tempo, os dispositivos de detecção evoluíram de sensores eletromecânicos com uma única variável para sistemas eletrônicos capazes de medir centenas de variáveis simultaneamente (MEASUREMENT COMPUTING CORPORATION, 2012).

Em relação aos conceitos sobre DAQs, os manuais de empresas como a Omega Engineering INC (2000) e a Measurement Computing Corporation (2012) apresentam os principais fundamentos, e outras publicações relacionadas focam em aplicações específicas (FERRERO MARTÍN et al., 2014). Entretanto, na I4.0 as funcionalidades envolvidas no DAQ requerem uma revisão dos conceitos em função não só da ordem de grandeza da quantidade de dados envolvida, mas principalmente do que efetivamente deve ser extraído e processado para aprimoramento dos processos.

A Figura 4 ilustra o fluxo básico para coleta de dados que, em princípio, mantém-se mesmo no caso de I4.0 e big data. A análise deste fluxo indica que um DAQ pode, portanto, ser caracterizado como um sistema com um conjunto de estados discretos alcançáveis e que a transição entre esses estados é resultante da ocorrência de eventos que podem ser tratados como instantâneos. De fato, esta descrição é do funcionamento de um SED (CURY, 2001; MIYAGI, 1996), e assim entende-se que as metodologias e técnicas que têm sido desenvolvidas para estudo, análise e especificação do controle de SEDs podem ser exploradas para identificar as propriedades de um DAQ, analisar suas capacidades operacionais e para gerar uma especificação para sua implementação.

No contexto da I4.0, a habilidade de analisar grandes quantidades e diferentes formatos de dados é fundamental. A conectividade entre os componentes da I4.0 explora esse volume de dados coletados de consumidores, fornecedores, operadores, etc. e dos dispositivos envolvidos (e.g. máquinas, produtos, sensores) para monitoração, controle e suporte à tomada de decisão (KAGERMANN; WAHLSTER; HELBIG, 2013).

\subsection{Indústria 4.0 (I4.0)}

A Indústria 4.0 (I4.0) é a transformação digital da manufatura/processo produtivo e dos processos de criação de valor. Nesse contexto, (PLATORM INDUSTRIE 4.0, 2020) associa a I4.0 a criação de uma rede inteligente de máquinas e processos para a indústria através de tecnologias da informação e comunicação (ICT - Information and Communication Technology).

Como mencionado anteriormente, a I4.0 está embasada em várias tecnologias sendo que três se destacam por terem uma abrangência maior do ponto de vista de interação entre 
entidades: Sistemas Ciber-Físicos (CPS - Cyber-Physical Systems), Internet das Coisas (IoT Internet of Things) e Tecnologias da Informação e Comunicação.

Os CPS são sistemas de entidades computacionais colaborativas que estão conectadas com os processos físicos ao seu redor (MONOSTORI, 2018). Assim, eles são responsáveis pela integração do mundo real com o mundo virtual. Desta forma, é necessário que os módulos CPS sejam capazes de identificar, por meio de tecnologias digitais de comunicação, as máquinas e instalações físicas e suas condições operacionais por meio de sensores (no mundo real), avaliar essas condições com base em modelos computacionais (no mundo virtual), e atuar nos processos físicos, compondo assim laços de realimentação em que o ambiente físico afeta o ambiente virtual e vice-versa.

Os módulos CPS devem ter recursos para serem controlados por meio de interfaces interativas homem-máquina, e estarem disponíveis globalmente por meio de serviços de Internet (BORNSCHLEGL et al., 2013; DOMBROWSKI; WAGNER; RIECHEL, 2013; PLONER, 2014).

Já a IoT permite a comunicação entre "coisas", incluindo produtos e máquinas, o que possibilita a troca de dados de forma ampla, autônoma e personalizada (PISCHING et al., 2015a, 2015b). Segundo Bassi et al. (2013), o advento IoT pode ser dividido em três momentos. O primeiro está relacionado às tecnologias de código de barras e de identificadores por radiofrequência (RFID), que ajudam a automatizar o rastreamento, o inventário e a identificação de "coisas". O segundo momento, o qual está sendo vivenciado, é caracterizado pela conexão de sensores, dispositivos, dados e aplicativos. O terceiro momento, o qual poderá se chamar de "IoT cognitiva", tende a facilitar o reaproveitamento de informações de "coisas" e dados, potencializando a interconectividade e as soluções interoperáveis com a distribuição de informação enriquecida em semântica (PISCHING, 2018).

A I4.0 assume a interação com autonomia para tomada de decisão entre máquinas e matérias-primas por meio da IoT, o que é chamado de manufatura inteligente (smart manufacturing) (UNGUREAN; GAITAN; GAITAN, 2014). Para isso materiais e produtos devem ter um identificador único (como por exemplo uma tag RFID - Radio Frequency IDentification) por meio do qual é possível rastreá-los e obter informações a respeito dos processos exigidos, sejam eles durante a manufatura ou durante as demais etapas do ciclo de suas vidas (GORECKY et al., 2014; KAGERMANN; WAHLSTER; HELBIG, 2013).

$\mathrm{Na}$ I4.0 os recursos físicos devem ser tratados/vistos no correspondente mundo virtual como serviços, os quais precisam ser criados, publicados e compartilhados em uma infraestrutura baseada em ICT que inclui a computação na nuvem, para serem então utilizados 
por uma empresa ou grupo de parceiros que visam atender a uma demanda específica. Neste contexto os serviços representam as funções ou os processos de manufatura e outros serviços envolvidos, os quais podem ser utilizados por diferentes empresas com interesses comuns, e assim contribuir para a formação de empresas virtuais (EVs), por meio das quais, qualquer parceiro, mesmo que geograficamente disperso, pode se unir ao sistema para atender a demandas de acordo com suas habilidades, capacidades e disponibilidade.

Para Kagermann (2014) a formação de EVs vem se destacando cada vez mais no setor industrial, e sua complexidade implica na demanda de serviços inteligentes e colaborativos que sejam disponibilizados e compartilhados sobre a infraestrutura da Internet, essencialmente sobre uma infraestrutura baseada em ICT, em especial a computação na nuvem e, assim sendo, preocupações sobre as formas de localização e pesquisa de serviços acabam sendo evidenciadas.

Do ponto de vista de interação entre entidades (e.g. objetos, máquinas, sistemas, pessoas), a I4.0 resulta da aplicação de CPS, IoT e ICT para a automação dos processos. Os principais requisitos para esta automação incluem (BORNSCHLEGL et al., 2013; IMTIAZ; JASPERNEITE, 2013):

- Objetos inteligentes, que são dispositivos mecatrônicos com inteligência descentralizada;

- Rede de comunicação de dados universal, que garante uma ampla capacidade de comunicação de cada um desses objetos inteligentes em uma rede de comunicação;

- Sistema produtivo disperso, ágil e conversível, formado por um conjunto de objetos inteligentes;

- Sistema de sistemas, com mudanças dinâmicas das fronteiras do sistema - aplicação do conceito de EV;

- Sistemas totalmente ou parcialmente autônomos e adaptativos ao contexto com controle ativo em tempo real;

- Sistemas cooperativos com controle distribuído;

- Internet baseada em padrões comprovados para comunicação via cabo ou sem fío (por exemplo, TCP/IP, Ethernet, Bluetooth, Wi-Fi, etc.);

- $\quad$ Fusão entre os mundos real e virtual;

- Integração vertical na rede de comunicação por meio da substituição de uma arquitetura estritamente horizontal e uma arquitetura de controle hierárquico, por 
uma integração vertical robusta e consistente entre estruturas de rede de comunicação;

- Mudança do papel do ser humano, munindo-o de tecnologia móvel para acessar os dados da planta e da produção, por exemplo, via tablets, smartphones óculos/visores de realidade aumentada, etc.

Entende-se que os objetos inteligentes são resultantes da crescente disponibilidade de microprocessadores, unidades de armazenamento, sensores e transmissores que estão sendo incorporados em quase todos os tipos imagináveis de máquinas, produtos (em todos os seus estágios de fabricação) e materiais, bem como ferramentas inteligentes.

Todas essas inovações permitirão que os produtos e máquinas se comuniquem uns com os outros e troquem informações. Em outras palavras, as fábricas do futuro irão otimizar e controlar seus processos de fabricação em grande parte por eles mesmos (NIKOLAUS, 2013; SIBUM, 2014).

As fronteiras entre as estações de trabalho tendem a ser mais flexíveis, criando internamente uma zona de transição permitindo uma distribuição inteligente das operações com base no status das estações disponíveis e em operação, desta forma otimizando a utilização do sistema produtivo.

Os sistemas totalmente ou parcialmente autônomos e adaptativos podem assim distribuir as atividades entre os colaboradores baseado no status de cada estação de trabalho. Desta forma, pode-se adaptar a sequência de atividades de forma interativa para cada colaborador e equipamento (DOMBROWSKI; WAGNER; RIECHEL, 2013).

Nesse contexto, Rüssmann et al., (2015) avaliam os benefícios da I4.0 ao longo de quatro áreas:

- Produtividade: espera-se que a I4.0 traga melhorias na produtividade. Pela implementação dos pilares tecnológicos da I4.0, os autores argumentam que os sistemas produtivos podem, dependendo da sua área de atuação, alcançar ganhos em produtividade de até $30 \%$ em relação aos números anteriores a implementação destas tecnologias;

- Crescimento da receita: espera-se que a I4.0 incentive o crescimento da receita gerada pela atividade econômica. Com a crescente demanda por equipamentos inteligentes e aplicações utilizando dados coletados pelos setores de manufatura e o aumento na demanda por produtos personalizados por consumidores, impulsionando um crescimento extra nas receitas; 
- Empregabilidade: espera-se que a I4.0 leve a um aumento na geração de empregos. À medida que os sistemas produtivos e de serviços se tornem cada vez mais complexos, espera-se que a I4.0 aumente a demanda por profissionais das áreas de engenharia, desenvolvimento de software e tecnologia da informação;

- Investimentos: espera-se que a I4.0 aumente a quantidade de investimentos aportados na área industrial. Esperam-se na Alemanha aportes de até $€ 250$ bilhões entre 2015 e 2025 feitos por empresas buscando incorporar a I4.0 nos seus processos de produção.

Assim como uma porta USB pode ser usada para conectar diferentes tipos de dispositivos em um computador, usando o princípio "plug \& play", o mesmo se espera que ocorra com os objetos inteligentes - dispositivos de campo, máquinas, e outros equipamentos no contexto da I4.0 - sem qualquer necessidade de novas parametrizações ou programações (NIKOLAUS, 2013). Neste contexto, tudo deve ser compatível entre si. Todas as entidades, como por exemplo, sistemas produtivos ou máquinas que participam da produção podem ser retiradas e repostas em segundos (DEUTSCHLAND MAGAZINE, 2014). Uma fábrica pode ser desmontada e remontada de uma nova forma (SIBUM, 2014).

Um aspecto importante da I4.0 é a descentralização da tomada de decisões, de modo que os funcionários, máquinas e produtos devam ter mecanismos para facilitar a comunicação uns com os outros, além do que se deve permitir que dispositivos, máquinas e objetos distribuídos, porém interligados, possam interagir também uns com os outros, sem depender de intervenção humana para configurar e comissionar a inteligência embarcada.

Para atingir este objetivo, são necessários tanto a miniaturização do hardware como o desenvolvimento e adoção de interfaces de comunicação apropriadas. Enquanto as tecnologias de rede de comunicação, como Ethernet, Wireless ou Bluetooth estão amplamente disseminadas, a integração entre softwares ainda é relativamente cara e complexa devido à grande variedade de interfaces existentes. Ao lado de outras tecnologias, a OPC-UA (OPC Unified Architecture) é uma abordagem que oferece uma interface genérica de comunicação, independente da tecnologia de rede de comunicação e do software. Ela tem sido vista como uma das tecnologias-chave para a representação/transmissão transparente de dados entre componentes de sistemas heterogêneos (IMTIAZ; JASPERNEITE, 2013).

Ao contrário de conceitos semelhantes que foram propagados no passado - e.g., a manufatura integrada por computador (CIM - Computer-Integrated Manufacturing) - a I4.0 está se desenvolvendo por meio da fusão e refinamento das tecnologias existentes. Além disso, 
a I4.0 reúne grandes empresas industriais, institutos acadêmicos de pesquisa e governos em busca de um objetivo comum (GIERSBERG, 2014; NIKOLAUS, 2013).

$\mathrm{Na}$ I4.0 cada ativo $^{5}$ inteligente relacionado com os processos produtivos tem um endereço IP para obter e gerenciar individualmente informações em tempo real (PLONER, 2014).

Para cada ativo real existe o seu respectivo ativo virtual. Cada produto e cada máquina tem de ser incluído digitalmente num sistema de gestão e controle, para que possa se comunicar posteriormente com outros produtos e máquinas (GIERSBERG, 2014).

A interação entre os elementos (i.e. ativos) do sistema em diferentes níveis de controle deve ser mais transparente e flexível, o que pode ser conseguido por meio do uso da mesma tecnologia no nível de controle de processo, assim como na área da gestão da produção. Portanto, é importante pesquisar os métodos de transferência de dados existentes que atendam aos requisitos da I4.0 (MAKAROV; LANGMANN; FRANK, 2014).

Para Kagermann, Wahlster e Helbig (2013) as empresas poderão estabelecer redes globais de comunicação possibilitando maior colaboração e integração de maquinário, estoques e aspectos intelectuais como conhecimentos, competências e habilidades.

A Figura 5 mostra os paradigmas da indústria anterior à I4.0, segundo o conceito de "pirâmide da automação":

- A integração vertical (interna) da fábrica envolve a interação apenas com as camadas imediatamente adjacentes;

- A estrutura é baseada em hardware, que reflete a capacidade funcional de dispositivos e ferramentas da empresa;

- As informações derivadas das funcionalidades dos produtos são isoladas do resto do sistema.

Na Figura 6 tem-se os novos paradigmas da I4.0:

- A integração vertical neste caso deve permitir a comunicação entre elementos de diversas camadas, não apenas os imediatamente adjacentes;

${ }^{5}$ A definição de um ativo na I4.0 é sintetizada por Bader et al. (2019) como qualquer objeto (real ou virtual) de valor para a empresa. Essa definição é explorada de maneira mais extensa na seção 7.1.1. 
- A estrutura visa a integração horizontal, com o foco em serviços onde diferentes empresas parceiras interagem possibilitando que uma empresa utilize os serviços que não dispõe, mas que pode ser realizado por parceiros;

- Os produtos são parte da rede, retornando ao processo produtivo informações sobre suas condições de uso, que por sua vez influenciam no projeto de novas versões do produto.

Figura 5 - Estrutura da indústria anterior à I4.0.

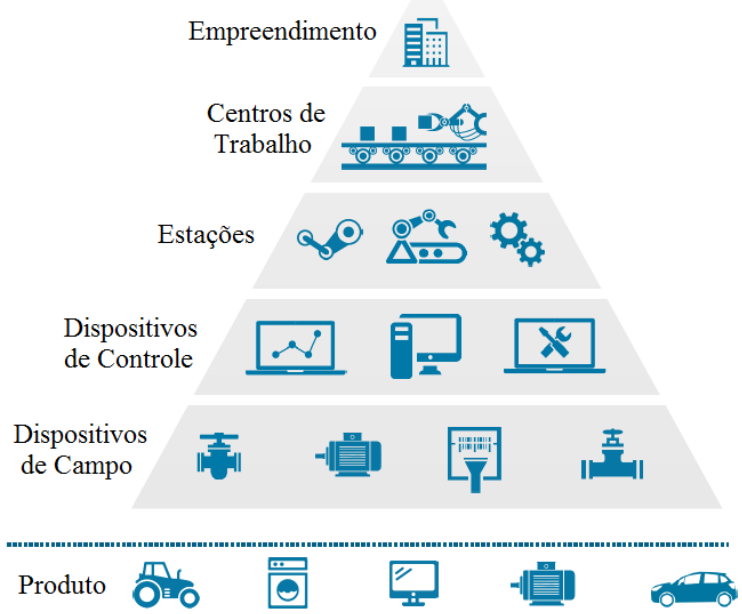

Fonte: Adaptado de Schweichhart (2016).

Figura 6 - Estrutura no contexto da I4.0.

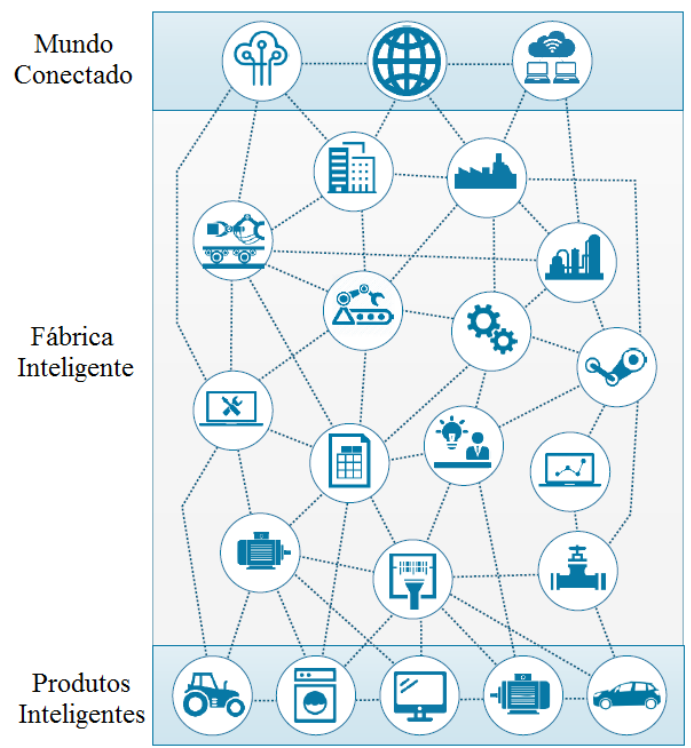

Fonte: Adaptado de Schweichhart (2016). 
Em relação a sua implementação, empresas como Siemens, Bosch, Festo e ZVEI entre outras, e associações como VDI associadas a iniciativa alemã Platform Industrie 4.0 são pioneiras no desenvolvimento da I4.0 (ADOLPHS et al., 2015). Há fábricas-modelo, como no Centro Alemão de Pesquisa da Inteligência Artificial (DFKI) (DEUTSCHLAND MAGAZINE, 2014).

\subsubsection{Sistemas Ciber-Físicos (CPSs)}

Os sistemas ciber-físicos (CPSs) podem ser definidos como sistemas onde existe a integração entre processos computacionais e processos físicos, e essa integração entre eles melhora a capacidade dos sistemas físicos existentes (WANG; TÖRNGREN; ONORI, 2015). Kang et al. (2016) definem os CPSs de forma similar, mas complementando a definição afirmando que esses sistemas utilizam e fornecem serviços de acesso e processamento de dados disponíveis na Internet.

Em um contexto de manufatura, o desenvolvimento e aplicação de microcomputadores cada vez mais poderosos e autônomos e, utilizados na forma de sistemas embarcados ${ }^{6}$, torna possível a conexão entre os diversos elementos que compõem um CPS (por exemplo: o maquinário, sistemas de estoque, sistemas de distribuição, sistemas produtivos) e, consequentemente, a troca de informações e a ocorrência de eventos de modo que estes elementos possam mutuamente influenciar suas operações (KAGERMANN; WAHLSTER; HELBIG, 2013).

Para Pisching (2018) a implantação de CPSs é um dos fundamentos da fábrica inteligente, onde os produtos, recursos e processos se comunicam mutuamente para realizar as operações produtivas de forma autônoma e atendendo os requisitos da produção. Neste cenário, a comunicação entre os recursos (e.g. peças, máquinas) é essencial para a manufatura de produtos personalizados que atendem as necessidades individuais dos consumidores.

A Figura 7 ilustra a estrutura básica de um CPS. Os sistemas físicos devem possuir interfaces que permitam a interação entre usuários e outros sistemas de forma autônoma por via local ou via rede de comunicação. A partir destas interfaces é realizada a interação com os sistemas embarcados, presentes nos dispositivos físicos na forma de sistemas de controle que interagem com sensores e atuadores (BRETTEL et al., 2014; BROY, 2010; MONOSTORI,

\footnotetext{
${ }^{6}$ Steve (2003) define um sistema embarcado como um sistema que possui um microprocessador dedicado a executar uma funcionalidade ou um conjunto de funcionalidades. Um sistema embarcado é desenvolvido para realizar uma tarefa particular embora considerando escolhas e opções diferentes para tal.
} 
2014). Quando conectados em uma rede de comunicação, os sistemas embarcados do CPS monitoram e controlam os processos físicos. Assim os processos físicos afetam o mundo virtual $^{7}$ e vice-versa.

Figura 7 - Estrutura básica de um CPS.

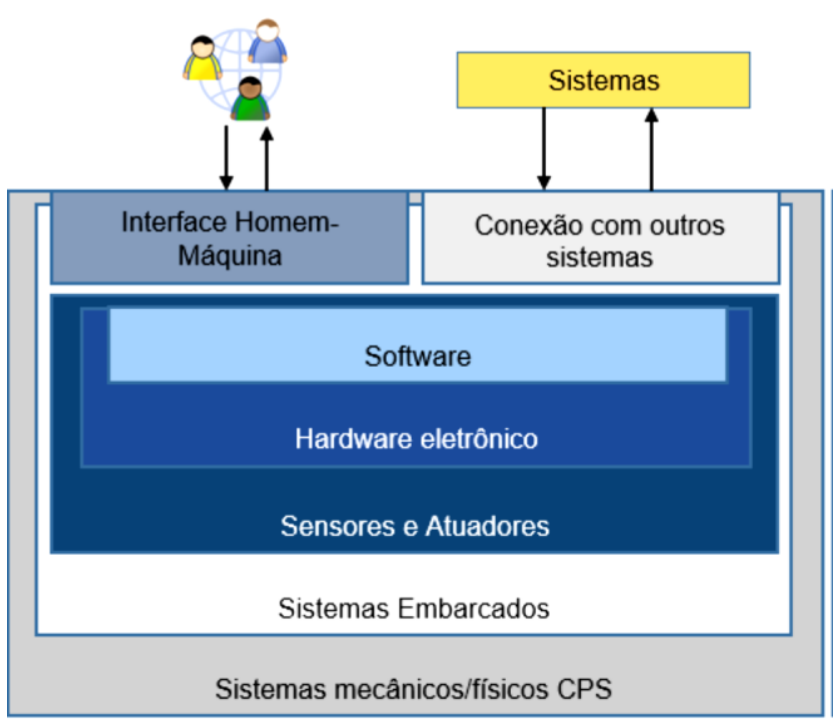

Fonte: Adaptado de Broy (2010).

\subsubsection{Internet das Coisas (IoT)}

A "Internet das Coisas" (Internet of Things - IoT) é entendida como uma infraestrutura de rede de comunicação global, onde "coisas" físicas e virtuais possuem identificadores e são integradas via redes de comunicação (PISCHING, 2018; VAN KRANENBURG, 2008).

Lee J. et al. (2015) definem a IoT de forma similar, acrescentando que a rede de comunicação é capaz de juntar, separar, sincronizar e organizar informações de diferentes fontes.

Na Figura 8, Evans e Annunziata (2012) demonstram como IoT viabiliza a análise de big data no ambiente industrial e como estes sistemas estão relacionados, isto é:

- Máquinas industriais executam suas funções e geram dados referentes aos processos produtivos e das suas próprias condições;

- Dados são armazenados e analisados;

\footnotetext{
${ }^{7}$ Kagermann (2014) descreve o mundo virtual como uma representação do mundo real possibilitada por técnicas de virtualização e onde são feitas análises das condições dos processos do mundo real.
} 
- Da análise desses dados são tomadas decisões retornando comandos que conduzem as máquinas para novas entradas/condições e dando sequência ao ciclo.

Figura 8 - Internet Industrial.

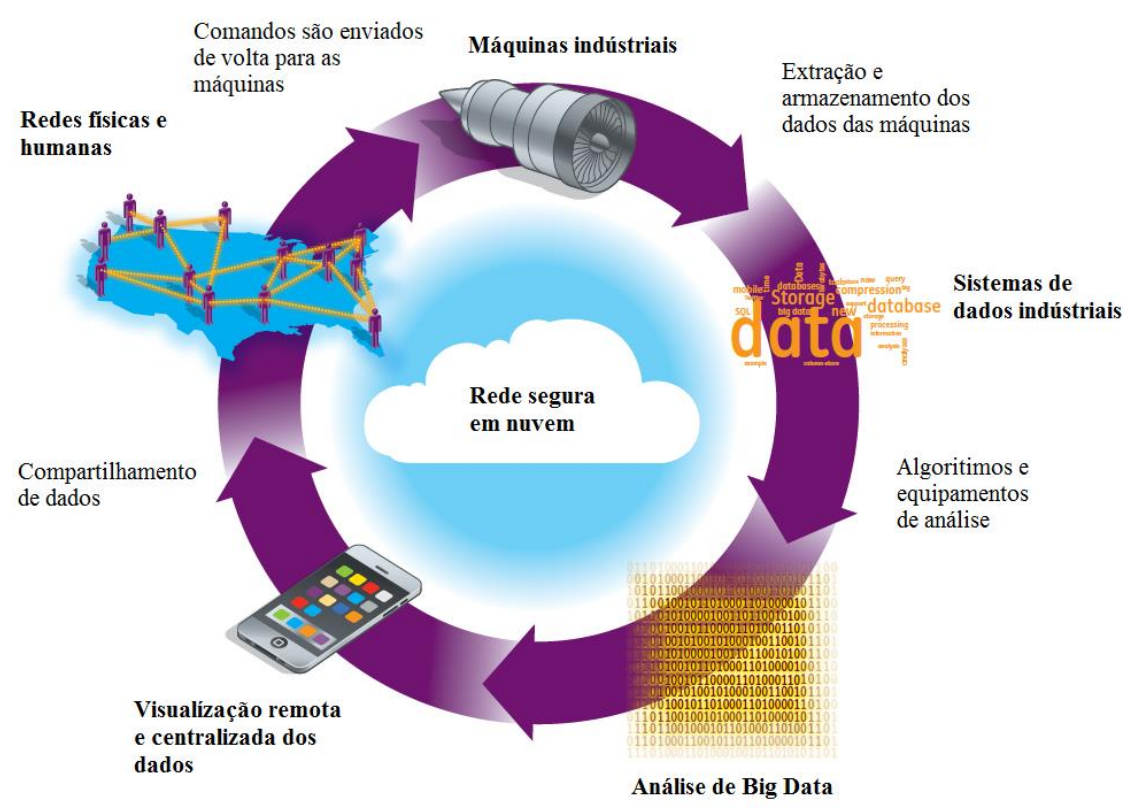

Fonte: Adaptado de Evans e Annunziata, (2012).

Essa relação entre o big data e a IoT faz parte do escopo de CPSs onde os equipamentos estão conectados entre si e com um banco de dados, trocando dados em tempo real (KAGERMANN, 2014).

A IoT é o meio que garante que todos os equipamentos sejam capazes de se comunicarem entre si, de modo que todas as "coisas" devem adotar alguma linguagem comum para sua comunicação.

\subsection{Arquiteturas de Sistemas}

Uma "arquitetura" é definida como uma estrutura organizacional de um sistema, contendo suas partes, seus relacionamentos, princípios e orientações que servem para controlar seu projeto, implementação e evolução ao longo do tempo (GERACI et al., 1991; INTERNATIONAL ORGANIZATION OF STANDARDIZATION, 2011; PISCHING, 2018).

De forma similar, Pressman (2007) define a arquitetura de um sistema como um framework (esquema) que representa a forma, a estrutura, os componentes e as interações entre os componentes desse sistema. Nesse contexto, do ponto de vista de sistema, uma arquitetura 
deve abordar sua estrutura fundamental definida a partir da perspectiva de componentes, propósitos, relacionamentos, interfaces, processos, restrições, comportamentos, princípios e regras, características e propriedades físicas e lógicas.

A empresa Hewlett Packard (2018) define uma "arquitetura de referência" como um documento ou conjunto de documentos que representam a estrutura e integração de produtos e serviços recomendados para formar uma solução (a arquitetura do sistema), incorporando as práticas aceitas em um setor, assim respondendo às perguntas que surgem durante o seu desenvolvimento.

Uma "arquitetura de referência" é um documento estável, abrangente e a partir do qual são derivadas arquiteturas especificas para finalidades concretas (BANGEMANN et al., 2016). Adolph et al., (2016) afirmam que arquiteturas de referência têm um papel importante pois descrevem os principais aspectos da estrutura do sistema e representam o ponto de partida para o desenvolvimento de ferramentas necessárias para a implantação efetiva da arquitetura de um sistema (PISCHING, 2018).

A arquitetura de referência orienta soluções estruturais e organizacionais do sistema conforme as necessidades e exigências dos stakeholders, assim garante-se que as soluções desenvolvidas estão focadas em resolver problemas existentes.

\subsubsection{RAMI 4.0}

O RAMI 4.0 é um modelo de arquitetura de referência ${ }^{8}$ para a I4.0 (PISCHING, 2018) (ADOLPHS et al., 2015) desenvolvida pela German Eletrical and Eletronic Manufacturers' Association (ZVEI) e seus parceiros (GØTZE, 2016).

Ele é uma adaptação e expansão do SGAM (Smart Grid Architecture Model) para atender os requisitos da I4.0 (ADOLPH et al., 2016) e foi concebido a partir de normas vigentes do setor produtivo visando atender diferentes especificações em uma única estrutura tridimensional envolvendo a integração vertical, horizontal e a engenharia fim-a-fim ${ }^{9}$ (PISCHING, 2018) (ADOLPHS et al., 2015).

\footnotetext{
${ }^{8}$ Nesse contexto, o modelo de arquitetura de referência contém uma descrição da estrutura geral dos sistemas ou processos na I4.0. A partir desse modelo, podem ser derivadas arquiteturas de referência para sistemas ou processos específicos.

${ }^{9}$ Engenharia fim-a-fim é um termo usado como referência a ligação (a partir da digitalização) entre todas as etapas do ciclo de vida de um ativo, da aquisição de matéria-prima até seu descarte. Desta maneira, todos os ativos que
} 
Gøtze (2016) descreve o RAMI4.0 como uma estrutura com coordenadas tridimensionais que representa todos os aspectos da I4.0, de modo que relações relativamente complexas possam ser separadas em agrupamentos menores.

A Figura 9 mostra os eixos do RAMI 4.0.

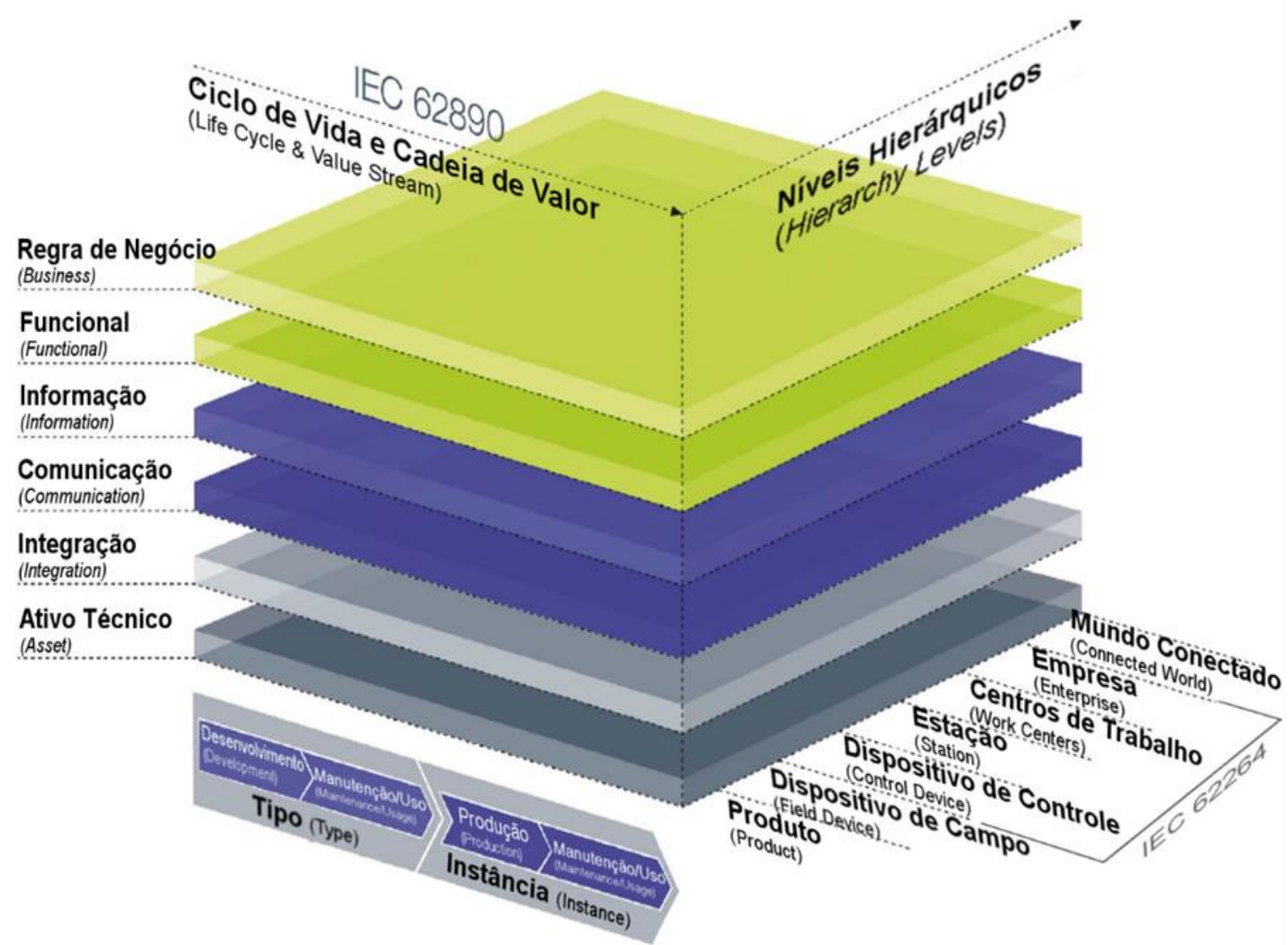

Fonte: Adaptado de Adolphs et al. (2015).

Um dos benefícios do RAMI 4.0 é ele ser orientado a serviços (SOA - Service-Oriented Archtecture), considerando também que podem existir elementos externos a uma empresa. Além disso, o RAMI 4.0 também garante que todos os participantes envolvidos na I4.0 compreendam uns aos outros (SCHWEICHHART, 2016).

Dentro dos três eixos, todos os aspectos da I4.0 podem ser mapeados permitindo que os elementos sejam classificados de acordo com esta visão tridimensional. Os conceitos

fazem parte do processo produtivo receberão informações relevantes em tempo real que podem ser incorporadas a sua cadeia de valor, otimizando seu processo produtivo (BLUNCK, WERTHMANN, 2017). 
envolvidos na I4.0 podem ser explorados e implementados usando o RAMI 4.0, possibilitando uma migração passo a passo do presente para o mundo da I4.0 (HANKEL, 2015).

\subsubsection{Eixo 1: Categorização dos ativos}

O eixo vertical do RAMI 4.0 é utilizado para representar as propriedades dos ativos, tornando possível que eles sejam mapeados tanto física como virtualmente. Essa forma de representação das propriedades em camadas tem origem na área de ICT, onde é uma prática comum a decomposição de relações e propriedades complexas das entidades envolvidas em camadas, facilitando seu entendimento (GØTZE, 2016).

Segundo Pisching (2018) este eixo é dividido em seis camadas para descrever a decomposição de máquinas e entidades físicas de tal forma que possam ser mapeadas para suas respectivas representações virtuais sob a forma de componentes da I4.0 (I4.0C).

Adolphs et al. (2015) descrevem cada uma das camadas individualmente e as suas interrelações como:

- Regra de Negócio: é a camada responsável por conter as regras que o sistema deve seguir assim como as condições legais e regulatórias. Esta camada é responsável por mapear o modelo de negócios do sistema, orquestrando ${ }^{10}$ os serviços da camada funcional;

- Funcional: nesta camada está a interface para a comunicação entre ativos de empresas (i.e. parceiros). Assim, as atividades do sistema podem ser direcionadas para as funcionalidades que as completam da forma mais eficiente. Nesse contexto, esta é a camada responsável pela integração horizontal das funcionalidades do sistema;

- Informação: nesta camada está a fonte de dados necessária para o controle dos ativos, garantindo que os dados sobre os ativos sejam tratados, disponibilizados e fornecidos. Nesta camada são realizadas as análises e todas as operações relacionadas à big data de acordo com as suas aplicações especificas;

\footnotetext{
${ }^{10}$ A orquestração de um sistema é um conceito discutido com frequência no contexto de arquiteturas orientadas a serviços. Este conceito diz respeito à configuração e coordenação das partes de um sistema, além de ser responsável por alinhar as solicitações (e.g pedidos de clientes) às funcionalidades necessárias para a sua execução no sistema
} (MENYCHTAS; GATZIOURA; VARVARIGOU, 2011). 
- Comunicação: esta camada garante que todos os dados direcionados às camadas anteriores possuem formato uniforme, permitindo amplo acesso das informações e fornecendo um canal de comunicação entre os ativos da empresa (integração virtual);

- Integração: nesta camada está o mapeamento virtual do sistema real. Aqui são provisionadas as informações sobre os ativos (componentes físicos, hardware, documentos, software, etc.) coletadas por sensores como leitores RFID (RadioFrequency IDentification) e a IHM (Interface Homem-Máquina);

- Ativo técnico: esta camada representa a realidade, isto é, os componentes físicos como as máquinas, atuadores, peças, documentos e as pessoas.

Essa dimensão/eixo do RAMI 4.0 representa a principal mudança na forma de compreender um ativo. Aqui o ativo é visto como um CPS e o IoT é o recurso que possibilita a conexão entre ativos físicos e sua contraparte digital na camada de Integração.

\subsubsection{Eixo 2: Etapas do Ciclo de vida e Cadeia de valor}

A I4.0 considera melhorias ao longo do ciclo de vida dos produtos, máquinas, fábricas, etc. O segundo eixo do RAMI 4.0 é utilizado para visualização e normalização das relações dos componentes da I4.0 com o ciclo de vida de produtos e equipamentos ao longo de uma cadeia de valor $^{11}$ (ADOLPHS et al., 2015).

O eixo de Ciclo de Vida e Cadeia de Valor é concebido com base na norma IEC 62890, que trata de instruções referentes ao gerenciamento do ciclo de vida dos produtos e equipamentos (PISCHING, 2018).

É feita uma distinção entre "tipo" e "instância" no eixo como uma forma de diferenciar as etapas de projeto e fabricação. Um "tipo" se torna uma "instância" quando são completadas as suas etapas de projeto e prototipagem e se iniciam as etapas de manufatura do produto (HANKEL, 2015).

Segundo Zezulka et al. (2016) o "tipo" de um produto ou máquina representa sua ideia inicial, cobrindo o pedido de projeto do cliente, o desenvolvimento e as simulações do

\footnotetext{
${ }^{11}$ Pela digitalização e integração de diferentes cadeias de valor os clientes podem acompanhar o progresso da produção de itens durante a manufatura, e para que os benefícios dessa integração sejam alcançados é necessário que o ciclo de vida seja visualizado em conjunto com o processo de adição de valor de forma coletiva entre todas as fábricas e parceiros envolvidos (ADOLPHS et al., 2015).
} 
protótipo. A etapa de "instância" cobre a produção seriada dos produtos finais e sua manutenção. Os produtos seriados podem ser usados como "tipos", ou seja, a base para novos produtos. Assim, a mudança de um elemento entre as etapas de "tipo" e "instância" pode ocorrer diversas vezes.

A Figura 10 ilustra algumas das etapas relevantes do ciclo de vida de alguns elementos da I4.0. Nesta figura percebe-se que são mapeados o ciclo de vida do produto, dos pedidos recebidos e da fábrica como um todo, elementos internos a um sistema produtivo, e também são mapeados os ciclos de vida das máquinas e de peças de fornecedores, elementos externos ao processo da fábrica, devidamente integrados ao seu sistema produtivo.

Figura 10 - Ciclos de vida dos I4.0C.

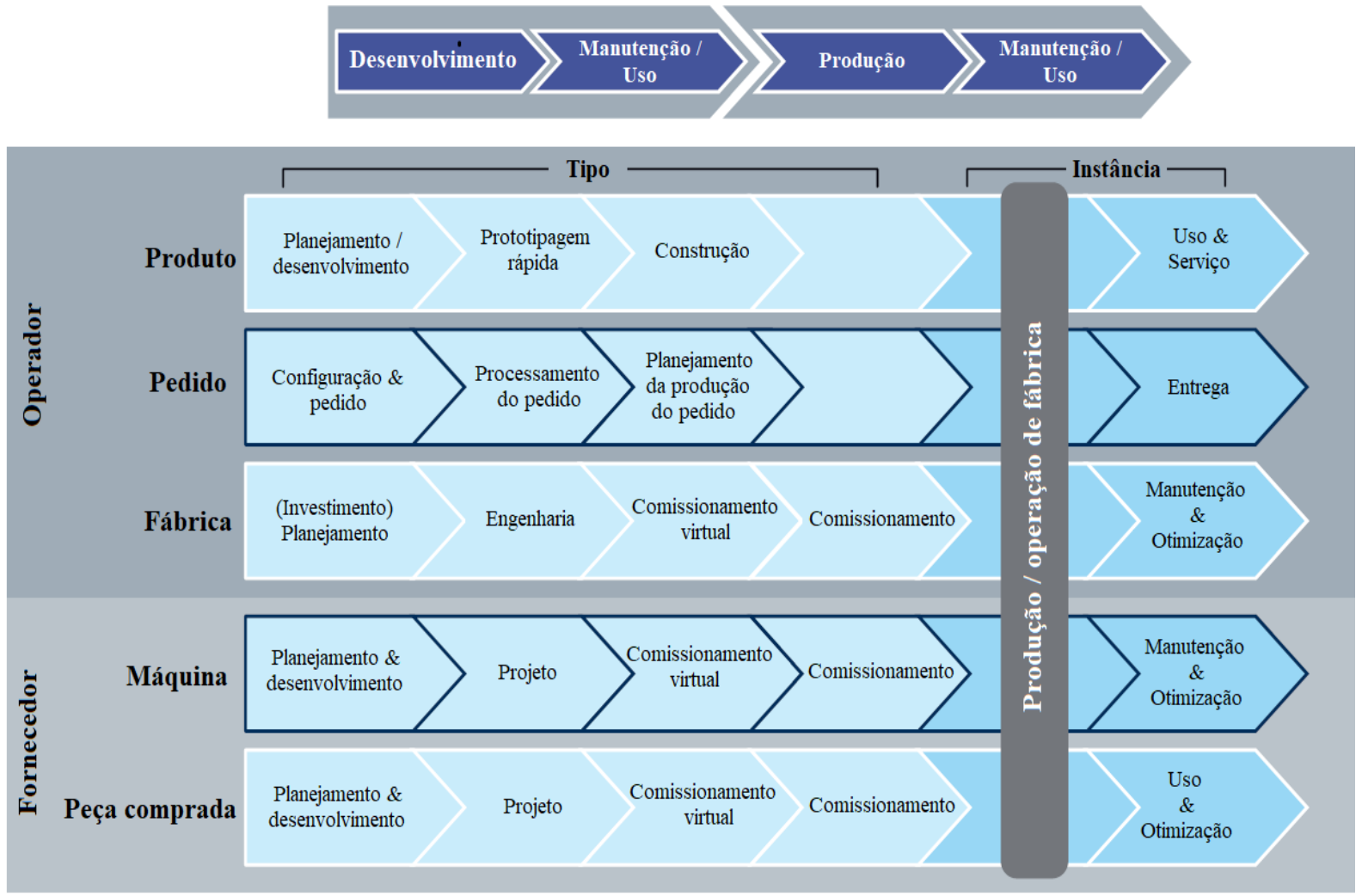

Fonte: Adaptado de Adolphs et al. (2015).

\subsubsection{Eixo 3: Níveis Hierárquicos}

O terceiro eixo do RAMI 4.0 descreve a integração dos sistemas empresariais de controle (PISCHING, 2018). O eixo foi concebido com base na norma ISA-95, que define a interface entre as funções de controle e as outras funções da empresa. A norma define por meio de níveis hierárquicos os sistemas de controle de uma empresa, desde os processos físicos reais 
(máquinas e componentes) até os sistemas responsáveis pelo controle da gestão e planejamento do negócio da empresa (GØTZE, 2016; ISA, 2019).

Para classificação dos sistemas dentro de uma fábrica, o terceiro eixo do RAMI 4.0 segue os padrões estabelecidos nas normas IEC 62264 e IEC 61512. Para atender o maior número de setores possível do ambiente industrial, foram destacados os termos "Empresa", "Centros de trabalho", "Estação" e "Dispositivo de controle" (ADOLPHS et al., 2015).

A Figura 11 mostra o desdobramento do eixo de níveis hierárquicos do RAMI 4.0, mostrando as definições herdadas das normas IEC 62264, IEC 61512 e ISA-95, além dos conceitos considerados para referenciar aspectos da I4.0. Para Adolph et al. (2016) e Dorst et al. (2015) esses níveis representam aspectos fundamentais da I4.0.

Figura 11 - Derivação dos níveis hierárquicos do RAMI 4.0.

Acréscimo para Indústria 4.0

Mundo Conectado

IEC 62264-1:2013 integração de sistemas de controle

empresarial - Parte 1: Modelos e terminologia

IEC 61512-1:1997 Controle de lotes

Parte 1: Modelos e terminologia

Esboço ISA 88/95 Relatório Técnico

Usando ISA-88 e ISA-95 em conjunto

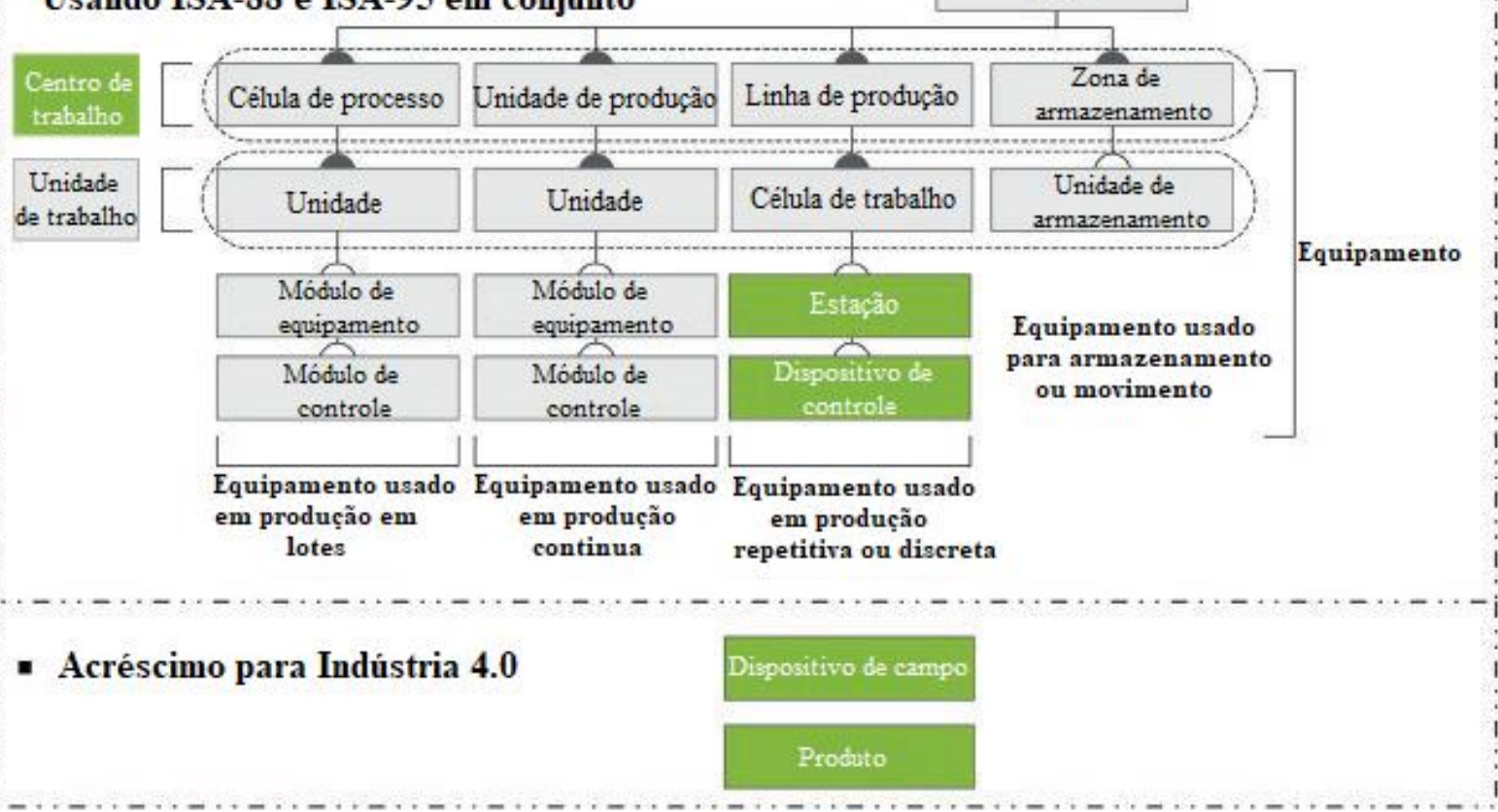

Fonte: Adaptado de Adolphs et al. (2015). 
Para a I4.0, além do dispositivo de controle de máquinas e equipamentos, deve-se considerar também as ações de controle de cada componente (dispositivo, produto ou sistema) de modo que, para considerar essa característica, foram adicionados os níveis de "Dispositivo de campo" (sensores inteligentes) e de "Produto", resultando em uma estrutura que permite uma forma homogênea de considerar o produto a ser manufaturado e o ambiente de produção com as suas interdependências (ADOLPHS et al., 2015).

Outra adição à norma é o nível de "Mundo conectado", relacionado com a função de gestão entre empresas, como uma forma da fábrica ir além das suas fronteiras individuais alcançando parceiros externos (PISCHING, 2018).

\subsubsection{NBDRA - NIST Big data Reference Architecture}

Fundado em 1901, o NIST (National Institute of Standards and Technology) é um dos mais antigos laboratórios científicos dos Estados Unidos. Na época, o Congresso Americano estabeleceu esta agência com a intenção de prover ao país uma infraestrutura de metrologia de mesmo nível às existentes no Reino Unido e na Alemanha. Atualmente a agência se destaca pelo seu suporte ao desenvolvimento tecnológico dos Estados Unidos (NIST, 2017).

Em 29 de março de 2012 a Casa Branca americana anunciou uma iniciativa intitulada: "Big data Research and Development Initiative", contando com fundos e incentivos governamentais para pesquisas em ciências e engenharias, fortalecendo a segurança nacional, transformando técnicas de aprendizado e melhorando a habilidade de extrair conhecimento de grandes e complexos conjuntos de dados (NBD-PWG, 2015).

Dentre os projetos desenvolvidos no NIST por esta iniciativa está o NIST Big data Interoperability Framework, que gerou uma coletânea de estudos em 7 volumes com o objetivo de criar uma "arquitetura de referência" capaz de facilitar a compreensão das complexidades operacionais em lidar com big data, proporcionando uma ferramenta para a descrição, discussão e desenvolvimento de arquiteturas especificas a partir de uma estrutura comum.

No quinto volume (NBD-PWG, 2015), o NIST realizou uma pesquisa respondida por nove participantes com as próprias arquiteturas:

- 9 sight Consulting, Barry Devlin;

- $\quad$ EMC/Pivotal, Milind Bhandarkar;

- $\quad$ ET Strategies, Robert Marcus;

- IBM, James Kobielus; 
- LexisNexis, Tony Middleton;

- Microsoft, Orit Levin;

- $\quad$ Oracle, Harry Foxwell;

- $\quad$ SAP, Sanjay Patil;

- University of Amsterdam, Yuri Demchenko.

No sexto volume (NBD-PWG, 2018) o NIST compilou os conceitos abordados pelas arquiteturas apresentadas no volume anterior e por outros subgrupos ligados ao NIST para a formação da própria "arquitetura de referência" para o big data (NBDRA - NIST Big data Reference Architecture) que é independente de fornecedores, tecnologias ou infraestruturas especificas.

A Figura 12 mostra a NBDRA que considera um sistema de big data com cinco componentes funcionais lógicos ("Orquestrador do sistema", "Fornecedor dos dados", "Fornecedor das aplicações de big data", "Consumidor dos dados" e "Fornecedor da Estrutura de big data") conectados por interfaces de interoperabilidade (i.e., serviços) e envolvidos por duas estruturas ("Segurança e privacidade" e "Gestão") que representam a natureza entrelaçada do gerenciamento e da segurança e privacidade em todos os componentes.

A NBDRA está alinhada por dois eixos representando as cadeias de valor associadas o big data, a "cadeia de valor das informações" (eixo horizontal) e a "cadeia de valor de ICTs" (eixo vertical). Ao longo do eixo da "cadeia de valor das informações" entende-se que o valor é criado a partir da coleta, integração, análise e aplicação dos dados. Ao longo do eixo de ICT, o valor é criado com base nas redes de comunicação, infraestrutura, plataformas, ferramentas e outros serviços de ICT para hospedar e operar o big data (NBD-PWG, 2018).

A relação entre os componentes da NBDRA está indicada por três tipos de setas: a seta tipo "DATA" mostra o fluxo de dados entre as funções principais do sistema, tanto fisicamente (transmitindo os dados) como fornecendo sua localização ou meios para os acessar; a seta tipo "SW" é uma referência às ferramentas de software para processamento de big data in situ (i.e., onde eles - os dados - estão); a seta tipo "Uso de serviços" representa a transmissão do acesso a interfaces programáveis por software.

Os cinco componentes (itens 1 a 5) e as duas estruturas (itens 6 e 7) que compõem a NBDRA são detalhados a seguir (NBD-PWG, 2018): 
1. Orquestrador do sistema: a função nesta arquitetura inclui definir e integrar os dados necessários a cada atividade de aplicação, orquestrando o funcionamento do sistema. Também compete ao orquestrador do sistema configurar e gerir, a partir da estrutura de gestão, as cargas de trabalho de todos os componentes do sistema, provisionando recursos físicos e virtuais para garantir que essa carga é capaz de suprir os requisitos de qualidade das funcionalidades do sistema, além de provisionar recursos adicionais em casos de surtos no número de dados ou acessos;

2. Fornecedor dos dados: a função aqui é incorporar ao sistema novos dados que possam ser transformados e analisados. O "fornecedor de dados" pode ser desde um sensor, uma pessoa inserindo dados manualmente ou outro sistema de big data. As funções do "fornecedor dos dados" e das aplicações podem pertencer a empresas diferentes. Consequentemente, uma característica importante de um sistema de big data é a habilidade de importar e utilizar dados de fontes variadas. Para atender esta função, muitas vezes o "fornecedor dos dados” é encarregado de criar abstrações dos dados, potencialmente limpando, corrigindo e armazenando os dados em um formato que é acessível ao sistema de big data;

3. Fornecedor de aplicações de big data: a função aqui é executar um conjunto específico de operações ao longo do ciclo de vida dos dados para atender as especificações determinadas pelo orquestrador do sistema. Esse componente da arquitetura encapsula as funcionalidades a serem executadas pelo sistema, e essas atividades incluem acessar, coletar, preparar e analisar os dados, além de visualizar os resultados;

4. Fornecedor da estrutura de big data: a função aqui tipicamente consiste em uma ou mais componentes da cadeia de valor de ICT hierarquicamente organizados, proporcionando plataformas, infraestrutura e processamento que atendam aos requisitos da análise de big data (ou seja, atendendo ao volume, a variedade, a velocidade e a veracidade dos dados);

5. Consumidor dos dados: a função aqui é similar a um "espelho" do "fornecedor dos dados" e pode, em um contexto sistêmico, representar tanto o "consumidor dos dados" de um sistema quanto o "fornecedor dos dados" para outro (respectivamente importando os dados e os resultados de análises de um sistema e os incorporando a outro). O "consumidor dos dados" utiliza os serviços proporcionados pelo “fornecedor de aplicações" para conseguir acesso a informações de interesse; 
6. Segurança e privacidade: a função da "camada de segurança e privacidade" que cerca os cinco componentes principais da arquitetura indicam que todos os componentes são afetados pelas considerações do sistema para segurança e privacidade;

7. Gestão: a função da "camada de gestão" compreende dois grupos de atividades: a gestão do sistema e a gestão do ciclo de vida dos dados (BDLM - Big data Life cycle Management). A gestão do sistema inclui atividades como gerir os softwares, a configuração, os backups, os recursos e o desempenho do sistema. BDLM envolve as atividades de gestão da coleta, preparação, análise, visualização e acessos aos dados ao longo de todas as etapas do seu ciclo de vida.

Figura 12 - NIST Big data Reference Architecture (NBDRA).

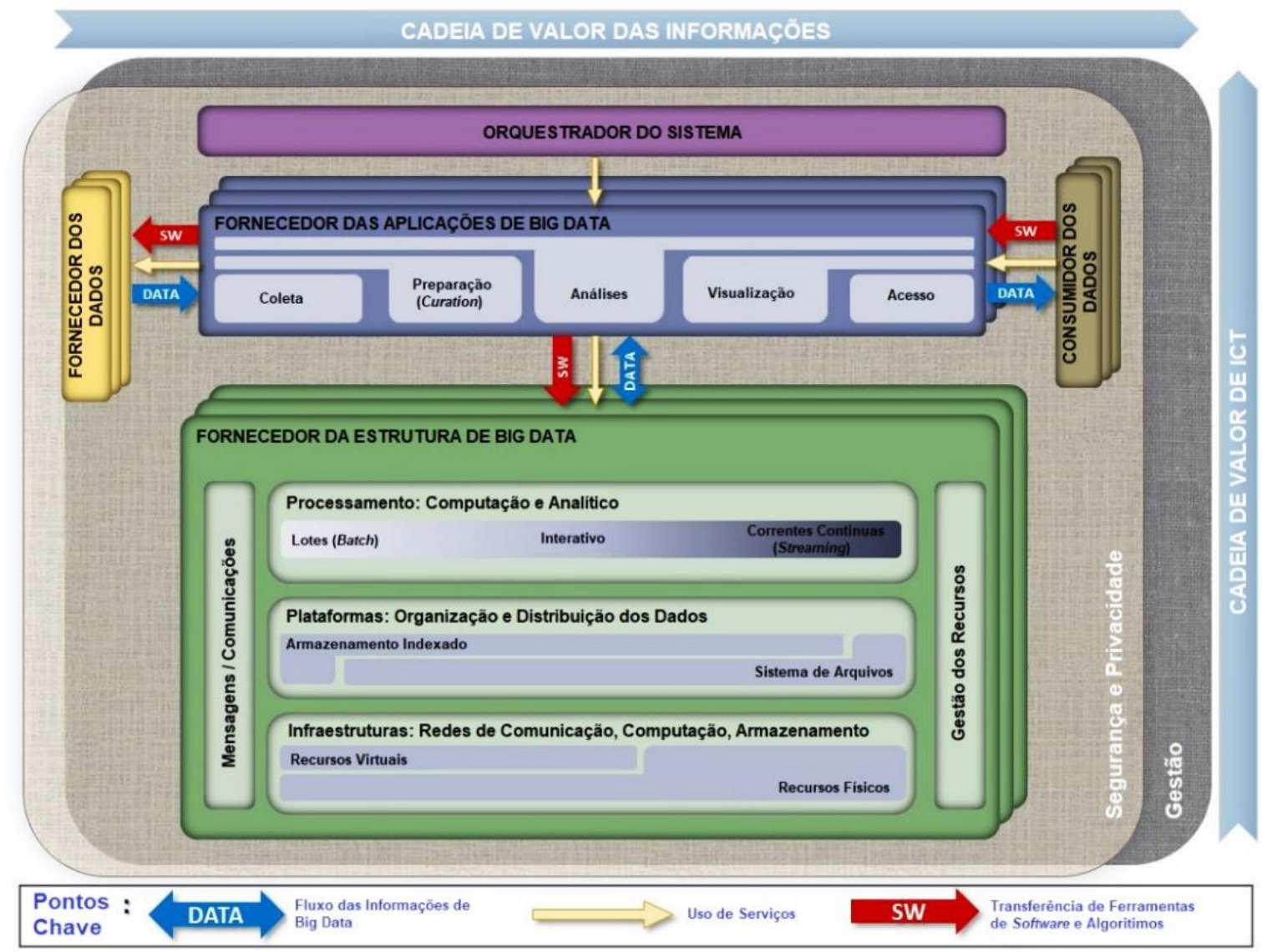

Fonte: Adaptado de NBD-PWG (2018).

A NBDRA representa desde soluções corporativas fortemente integradas por interfaces padronizadas até sistemas fracamente acoplados, mantidos por convenções ou acordos entre as 
partes interessadas. Portanto, diferentes soluções técnicas podem ser derivadas da NBDRA para aplicações diferentes.

\subsection{Engenharia de Requisitos}

Nuseibeh e Easterbrook (2000) afirmam que a Engenharia de Requisitos é um ramo da Engenharia de software que considera objetivos do mundo real para caracterizar funções, restrições e a evolução ao longo do tempo de soluções de software.

Considerando que este conceito pode ser estendido a outros tipos de sistemas, assumese aqui que as técnicas derivadas da Engenharia de Requisitos podem ser aplicadas na modelagem e análise das necessidades envolvidas na implementação de sistemas em geral.

As etapas para definir os requisitos de um sistema são:

1. Elicitação de requisitos: é o estágio em que usuários e / ou stakeholders são questionados na tentativa de entender suas necessidades. Um dos objetivos mais importantes da elicitação é descobrir o problema que precisa ser resolvido pelo sistema (NUSEIBEH; EASTERBROOK, 2000).

2. Modelagem e análise de requisitos: visa entender as funções do sistema, estruturando os requisitos e as necessidades envolvidas em sua operação. Os modelos desenvolvidos nesta etapa devem ser precisos, incluindo detalhes esquecidos no estágio de elicitação (CHENG; ATLEE, 2007).

3. Documentação: o foco aqui é registrar a descrição dos requisitos de uma maneira que possa ser entendida para manutenção e atualização dos sistemas.

4. Validação de requisitos: nesta fase é assegurado que o modelo e a documentação especificam adequadamente as necessidades das partes interessadas (CHENG; ATLEE, 2007). Os requisitos estabelecidos devem continuar a ser validados e revisados à medida que o ambiente e as operações em que estão envolvidos mudam.

\subsubsection{Engenharia de requisitos orientada ao objetivo (GORE)}

GORE (Goal Oriented Requirements Engineering) é uma área específica de Engenharia de Requisitos (SILVA, 2016) interessada em orientar o desenvolvimento de sistemas relacionando-os com as necessidades que precisam cumprir (LAPOUCHNIAN, 2005; VAN LAMSWEERDE, 2000). 
Em geral, GORE adota modelos que permitem uma representação das necessidades (objetivos) de um ou mais stakeholders para um sistema e suas associações para objetivos secundários além dos agentes responsáveis por classificá-los (HORKOFF; YU, 2011).

Alguns exemplos de métodos para a modelagem orientada aos objetivos incluem:

- GBRAM (Goal-Based Requirements Analysis Method): este método orienta a elicitação dos objetivos das atividades do sistema, classificando objetivos e os associando a restrições e cenários (ANTON; POTTS, 1998; HORKOFF; YU, 2011).

- NFR (Non-Functional Requirement): este método visa representar as intenções humanas em sistemas técnicos (CHUNG et al., 2012). Ele começa com softgoals, que são as expectativas do uso, desempenho ou flexibilidade de um sistema. Esses softgoals são decompostos e refinados, estruturando os objetivos em uma árvore hierárquica (CHUNG et al., 2012; HORKOFF; YU, 2011).

- $\quad \mathbf{i}^{*}$ : este método é uma tentativa de trazer a compreensão social para a Engenharia de Sistemas, colocando conceitos sociais selecionados no núcleo da atividade diária de um sistema (YU, 2009). Faz uso das notações usadas no NFR, incluindo softgoals, decomposições e refinamentos, além de adicionar tarefas, hardgoals (preocupações gerais e estratégicas para um sistema que pode ser compartilhado por suas diferentes versões), recursos e relações de dependência entre os agentes para a modelagem (HORKOFF; YU, 2011; YU, 1997).

\subsubsection{Metodologia KAOS}

A metodologia KAOS (Knowledge Acquisition in automated Specification também conhecida como Keep All Objectives Satisfied) é uma das abordagens GORE que foi desenvolvida nas Universidades de Oregon (Estados Unidos) e de Louvain (Bélgica) e possui um conjunto de técnicas para análise (ALMISNED; KEPPENS, 2010; LAPOUCHNIAN, 2005).

A vantagem do KAOS em relação aos outros métodos mencionados anteriormente é a sua capacidade de alinhar os objetivos aos seus requisitos, aumentando as chances da modelagem do sistema agregar, de fato, valor ao negócio (LAPOUCHINIAN, 2005).

A modelagem de um sistema pela metodologia KAOS utiliza um grafo com:

- "Objetivos" ou "objetivos secundários" (graficamente indicados por paralelogramos brancos) esperados para o sistema; 
- "Requisitos" (graficamente indicados por paralelogramos brancos em negrito) para alcançar os objetivos;

- "Expectativas" (graficamente indicados por paralelogramos cinzas) são especificações dos "objetivos" ou "requisitos" diretamente ligados aos agentes responsáveis;

- “Agentes" (graficamente indicados por hexágonos) envolvidos;

- “Operações” (graficamente indicadas por elipses) que mostram os procedimentos para obter os resultados;

- "Eventos" (graficamente indicados por pentágonos) que representam os efeitos da operação ou dos requisitos;

- "Setas" com elos (esferas) representando a relação (i.e., sequência) entre esses elementos.

A Figura 13 mostra um exemplo de um modelo KAOS.

Figura 13 - Exemplo da modelagem em KAOS.

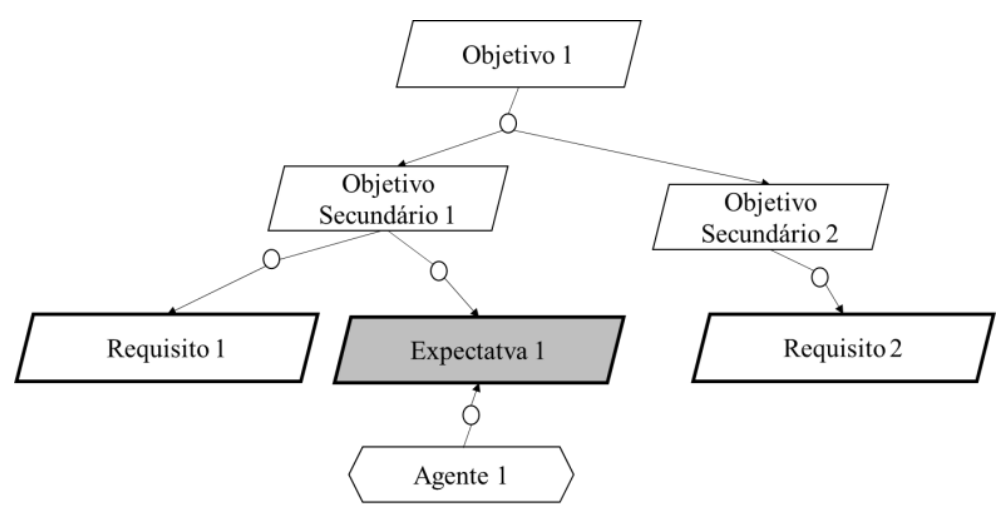

Fonte: Adaptado de Coda et al. (2018).

\subsubsection{Técnica de análise de requisitos}

Uma pesquisa realizada por Horkoff e Yu (2011) apresenta um guia para técnicas analíticas e uma proposta de orientação baseada em perguntas e respostas para avaliar e melhorar os modelos GORE. A análise dos modelos é realizada considerando sete abordagens: 
1) Compreensão do domínio: as questões buscam definir se o modelo faz uma "boa" representação do domínio de atuação do sistema (ambiente e contexto de um sistema);

2) Comunicação: as questões buscam confirmar se o modelo pode ser usado como uma forma de comunicar aos interessados todas as informações sobre o domínio, planejar alternativas ou validar as decisões tomadas. As perguntas aqui também se destinam a verificar se esta comunicação existe;

3) Melhoria do modelo: as questões buscam confirmar se o modelo pode ser melhorado pela interação com os usuários para identificar e corrigir deficiências. As perguntas aqui visam verificar a precisão do modelo e apontar onde ele pode ser melhorado;

4) Escopo: o foco é identificar os limites dos agentes do modelo. As questões buscam delimitar o escopo das atividades dos sistemas;

5) Elicitação de requisitos: para melhorar a precisão de um modelo é necessário encontrar requisitos de alto nível que melhor descrevam os interesses do sistema. As questões visam aumentar os detalhes do modelo, apontando a necessidade de novos requisitos;

6) Melhoria de requisitos: com base no modelo resultante, as perguntas buscam garantir que os requisitos existentes sejam atendidos e garantir que as funcionalidades do sistema cubram todos os cenários possíveis de falhas;

7) Design: o modelo resultante também deve ser usado para encontrar modelos alternativos. As questões visam confrontar o design inicial procurando alternativas melhores.

A Tabela 1 apresenta as questões propostas por Horkoff e Yu (2011) para a análise e melhoria de modelos GORE.

Tabela 1 - Análise de modelos GORE.

\begin{tabular}{|c|l|}
\hline Categoria & \multicolumn{1}{c|}{ Questão } \\
\hline \multirow{3}{*}{$\begin{array}{c}\text { Compreensão } \\
\text { do domínio }\end{array}$} & $\begin{array}{l}\text { QU1: O domínio contém um alto grau de interação social, múltiplos stakeholders com } \\
\text { objetivos distintos ou envolve vários sistemas interagindo? }\end{array}$ \\
\cline { 2 - 2 } & $\begin{array}{l}\text { QU2: É necessário compreender os detalhes do sistema neste momento? Existem } \\
\text { informações como custo, probabilidades e condições? É possível expressar as } \\
\text { propriedades necessárias ou desejadas para o domínio? }\end{array}$ \\
\hline
\end{tabular}




\begin{tabular}{|c|c|}
\hline Comunicação & $\begin{array}{l}\text { QC1: É necessário se comunicar com os stakeholders, validar os requisitos do modelo } \\
\text { e justificar as recomendações? }\end{array}$ \\
\hline \multirow{2}{*}{$\begin{array}{l}\text { Melhoria } \\
\text { do modelo }\end{array}$} & QM1: Você está confiante em conhecer com precisão o domínio e os modelos? \\
\hline & QM2: Você gostaria de verificar propriedades críticas do modelo? \\
\hline Escopo & QS1: É necessário determinar o escopo do sistema? \\
\hline \multirow{4}{*}{$\begin{array}{c}\text { Elicitação } \\
\text { dos Requisitos }\end{array}$} & $\begin{array}{l}\text { QE1: É necessário encontrar mais requisitos de alto nível? Você está à procura de } \\
\text { formas de progredir a elicitação? }\end{array}$ \\
\hline & QE2: O modelo precisa encontrar requisitos detalhados do sistema? \\
\hline & $\begin{array}{l}\text { QE3: O modelo precisa considerar requisitos não-funcionais do sistema difíceis de ser } \\
\text { quantificados? }\end{array}$ \\
\hline & QE4: O modelo considera premissas do domínio? \\
\hline \multirow{2}{*}{$\begin{array}{c}\text { Melhoria } \\
\text { dos Requisitos }\end{array}$} & $\begin{array}{l}\text { QR1: Você está trabalhando em um sistema onde segurança / privacidade / riscos / ou } \\
\text { outras propriedades são criticamente consideradas? }\end{array}$ \\
\hline & QR2: É necessário encontrar erros ou inconsistências nos requisitos? \\
\hline \multirow{4}{*}{ Projeto } & QD1: Você está ciente de um número suficiente de alternativas de design? \\
\hline & QD2: Você precisa avaliar e escolher entre alternativas de design? \\
\hline & QD3: É necessário encontrar processos de desenvolvimento aceitáveis? \\
\hline & QD4: Você precisa simular as operações antes da sua implementação? \\
\hline
\end{tabular}

Fonte: Adaptado de Horkoff e Yu (2011).

\subsection{Modelagem de sistemas}

Segundo (BKCASE EDITORIAL BOARD, 2016), o modelo de um sistema é uma representação dos aspectos desse sistema e do seu ambiente. A criação de modelos de um sistema é feita para "analisar" o seu desempenho e funcionamento, ou para "controlar", isto é, assegurar o funcionamento do sistema fazendo com que ele atue de determinada forma.

A modelagem de um sistema, como apresentado em (HAUSE, 2007), possui dois conceitos chaves para a descrição deste sistema, tornando possível a sua abstração, ou seja, a redução deste sistema para os detalhes que valem a pena modelar. São eles a definição das visões e pontos de vista relevantes ao sistema modelado.

De acordo com Miyagi (1996), Cury (2001), Chung (2003) e Cassandras e Lafortune (2008), um sistema a eventos discretos (SED) é uma forma de ver um sistema com comportamento determinado pela ocorrência de eventos que alteram de forma discreta e instantânea o estado do sistema.

Villani (2004) adiciona que as variáveis que representam o estado do sistema permanecem constantes entre a ocorrência de eventos. Este comportamento é apresentado em 
sistemas concebidos com base em regras e procedimentos definidos pelo homem (man-made systems), como é o caso para sistemas de manufatura, redes de comunicação, entre outros. Nesses exemplos de SED, os eventos caracterizam o início do funcionamento de uma máquina, a chegada de uma mensagem, etc.

A Figura 14 ilustra graficamente o comportamento de um SED ao longo do tempo.

Figura 14 - Comportamento de um SED.

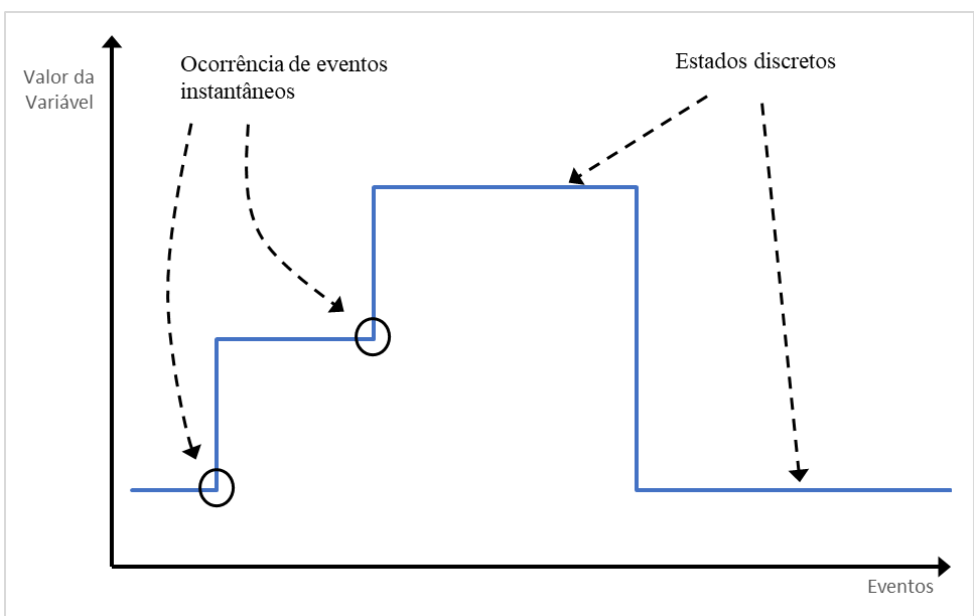

Fonte: Adaptado de Villani (2004).

\subsubsection{Rede de Petri (RdP)}

Dentre as várias técnicas utilizadas para a modelagem de SED, destaca-se a rede de Petri (RdP) (MICHAEL; WAGNER; MOLDT, 2018; MIYAGI, 1996), em princípio, pela sua forma gráfica de representar processos e sistemas e que reconhecidamente é útil e efetiva para a análise estrutural e funcional de processos e sistemas. Além disso, um modelo em RdP é relativamente fácil de ser convertido em programas que são carregados e executados em controladores programáveis industriais. Entende-se que esta é uma técnica efetiva de especificação de soluções de controle, isto é, é confiável e eficiente como um guia para a implementação prática da automação de processos ou de sistemas (MIYAGI, 1996).

Junqueira (2006, apud MOORE; BRENNAN, 1996) descreve a RdP como uma técnica de modelagem gráfica e matemática desenvolvida por Carl Adam Petri em meados de 1960 para caracterizar operações de concorrência em computadores.

Esta técnica tem sido usada desde então na modelagem de sistemas dinâmicos em diversas áreas (SRINIVASAN; VENKATASUBRAMANIAN, 1998) como, por exemplo, 
protocolos de comunicação, algoritmos distribuídos, arquiteturas de computadores, interação homem/máquina (ELKOUTBI; KELLER, 1998).

Chen, Li e Wang (2015) descrevem como a literatura sobre RdP sustenta a sua utilização na modelagem relacionada ao big data em três aspectos:

1. Modelos em RdP proporcionam mecanismos de controle e gestão dos dados. Simonet; Fedak; Ripeanu (2015) utilizaram a RdP para construir um modelo que descreve as atividades do ciclo de vida dos dados. Com base nesse estudo os autores propuseram um modelo de programação chamado "Active Data" para automatizar e melhorar a gestão dos dados nos ambientes de programação Hadoop e MapReduce;

2. Modelos em RdP são utilizados na simulação de sistemas multiagente (multi-agent systems) como uma ferramenta de validação do sistema. Ma, Wu e Xie (2005) projetaram serviços $w e b^{12}$ e utilizaram uma combinação de modelos RdP para garantir que seus usuários alcancem seus objetivos;

3. A RdP é uma ferramenta efetiva para simulações de cenários para avaliar a qualidade dos serviços (QoS - Quality of Service) de sistemas com computação distribuída. Yang et al. (2011) propuseram um serviço web com base em modelos em RdP consciente da sua QoS. Além disso os autores propuseram um método de cálculo da QoS baseado no uso e na probabilidade de uso.

Um modelo em RdP é interpretado para cada caso, e diferentes abordagens podem ser adotadas, o que é efetivo para análise de casos específicos e oferece maior liberdade ao desenvolvedor dos modelos. Entretanto, isso, em geral, acarreta diferentes modelos de acordo com a visão do desenvolvedor, e esta falta de uniformidade compromete o estudo e desenvolvimento de sistemas de grande porte e relativamente complexos onde muitos atores e diferentes formas e níveis de interação entre eles estão envolvidos. Assim, na final da década de 80 o PFS (Production Flow Schema) foi proposto e desenvolvido para sistematizar o

\footnotetext{
12 Os serviços web (web services) são tecnologias que permitem a comunicação entre entidades de uma maneira independente de linguagem de programação ou do seu sistema operacional, permitindo que os dados entre eles sejam compartilhados usualmente nos formatos XML ou JSON. Para Pisching (2018) os serviços web oferecem um padrão de interoperabilidade entre aplicações, permitindo sua combinação de forma flexível alcançando operações complexas.
} 
desenvolvimento de modelos de sistemas produtivos (HASEGAWA; TAKAHASHI; MIYAGI, 1988; MIYAGI; ARATA; 1997).

O modelo em PFS é um grafo interpretado derivado de RdP para representar processos e sistemas em diferentes níveis de abstração. Segundo Pisching et al. (2018) o PFS permite detalhar gradativamente, segundo uma abordagem top-down, as funcionalidades envolvidas e os fluxos de itens (materiais ou informação) relacionados. Devido à sua linguagem intuitiva, os modelos gerados podem ser facilmente entendidos por diferentes especialistas (por exemplo, engenheiros, designers ou arquitetos).

Os elementos do PFS são chamados de "atividades", "distribuidores" e "arcos orientados". A atividade é uma representação de componentes ativos, o distribuidor representa as entidades passivas e os arcos orientados definem o caminho dos itens no sistema. A Figura 15 ilustra um modelo em PFS com seus elementos estruturais.

Figura 15 - Elementos do PFS.

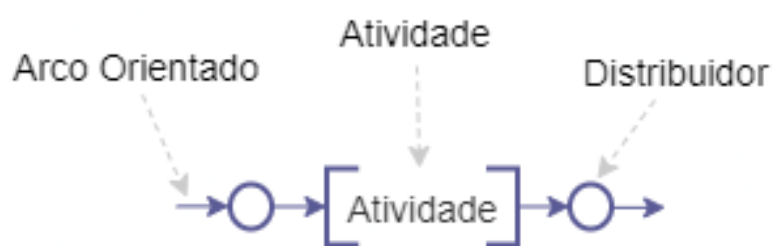

Fonte: Adaptado de Pisching et al. (2018).

O tipo de fluxo em um modelo em PFS pode ser classificado como um dos três tipos "primário", "secundário" e, de acordo com Melo et al. (2010) e Junqueira, Villani e Miyagi, (2005), um terceiro tipo também pode ser considerado para representar a "interação" entre componentes de um sistema de informações como operações de solicitação e resposta. A Figura 16 mostra cada tipo de fluxo.

Figura 16 - Tipos de fluxo de um PFS.

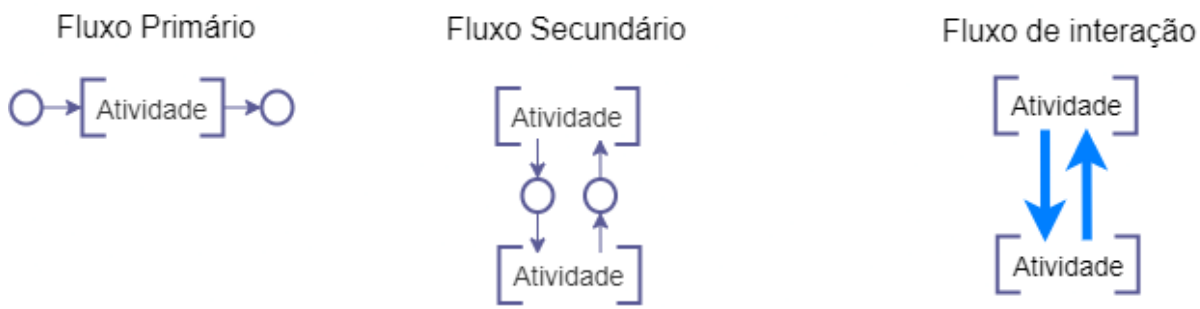

Fonte: Adaptado de Pisching et al. (2018). 
A Figura 17 ilustra o procedimento top-down de modelagem com o PFS onde uma descrição de um processo ou sistema num certo nível de abstração é gradualmente detalhada até que um modelo em RdP é obtido.

Os trabalhos publicados sobre o PFS focam na sua aplicação em sistemas e processos e na avaliação de sua efetividade na derivação de modelos em RdP. A formalização desta técnica (PFS) não é tratada nesses trabalhos, entretanto, pode-se citar outros trabalhos como o de Ezpeleta, Colom; Martinez (1995) que tem o foco na formalização de uma técnica denominada $S^{3} \mathrm{PR}$ (Systems of Simple Sequential Processes with Resources) que é análoga ao PFS.

Figura 17 - Exemplo da modelagem top-down com o PFS onde (a) é o esquema do processo; (b) são os modelos em PFS da estrutura geral do processo; (c) é o modelo em RdP derivado do PFS.

(a)
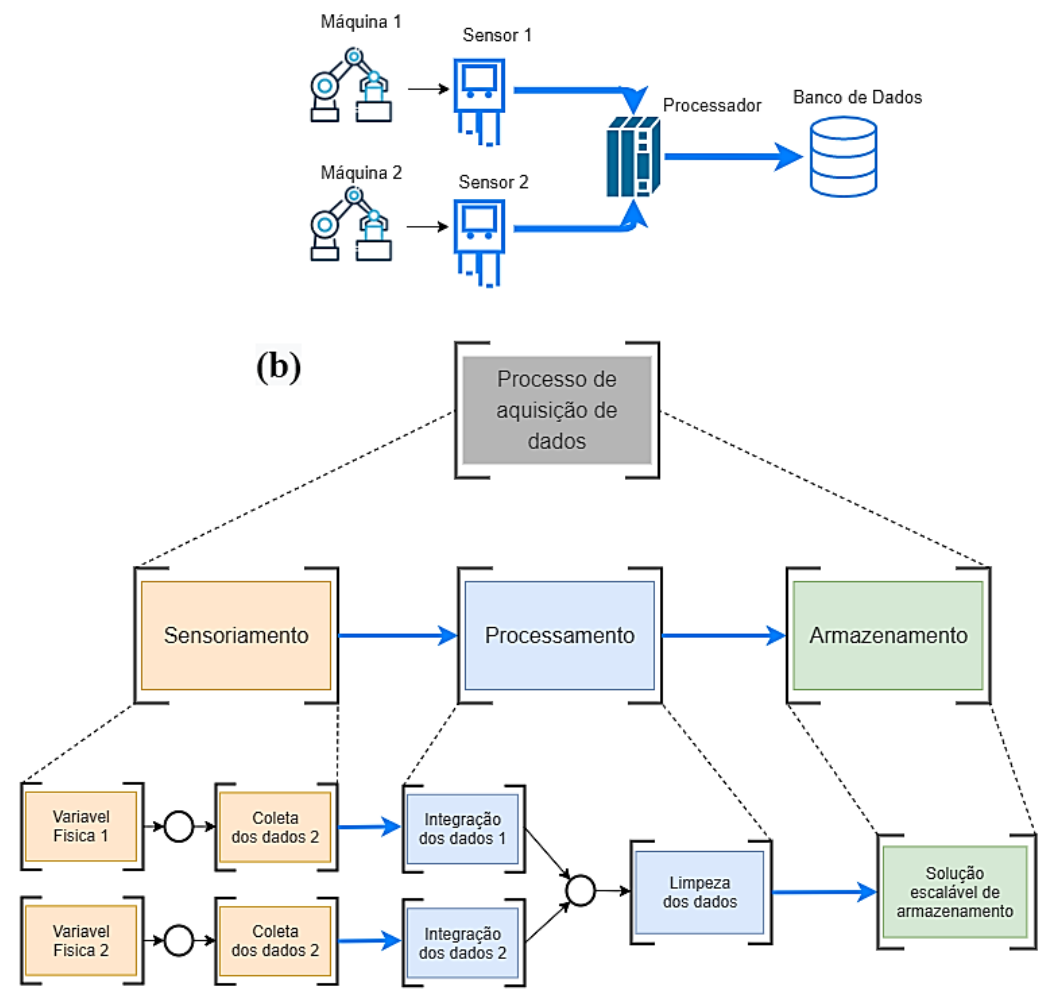

(c)

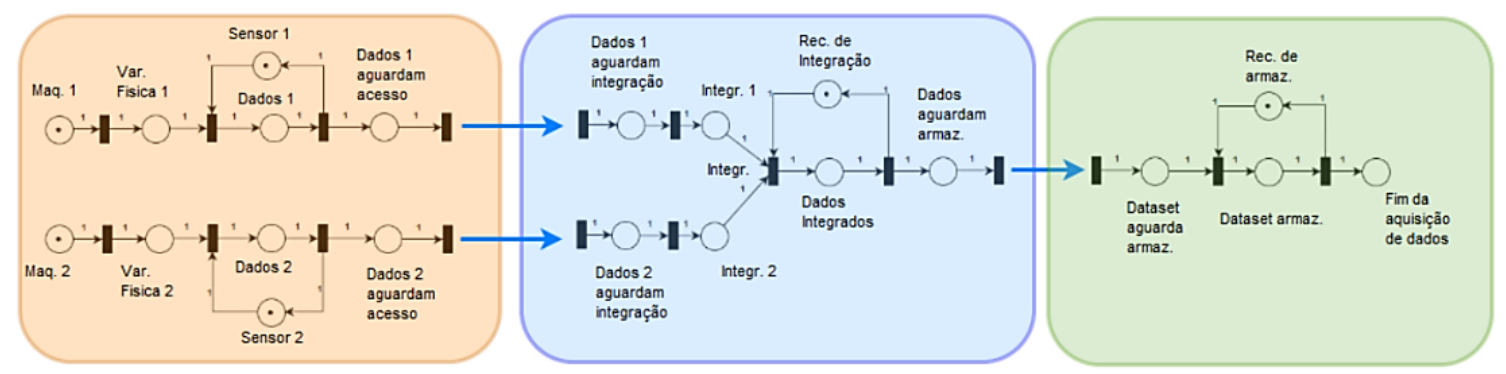

Fonte: autor. 
Portanto, a RdP se destaca como uma ferramenta adequada para a modelagem e análise do processo de aquisição de big data.

\subsubsection{Características da Rede de Petri}

O comportamento dinâmico de um SED pode ser compreendido e estudado a partir da evolução dos seus processos. Esse comportamento deriva de características estruturais especificas, as quais uma ferramenta adequada para a modelagem de SEDs deve ser capaz de representar. Algumas das características estruturais mais importantes em SEDs são:

\section{- $\quad \underline{\text { Sequência }}$}

A sequência é uma característica estrutural de SEDs que indica uma ordem de realização das atividades envolvidas, isto é, qual conjunto de atividades deve ser concluído para que outro seja iniciado.

Em RdP, esta sequência de atividades é representada por transições (os termos específicos relacionados à RdP estão em Ariel Narrow). Assim, a relação de sequência entre duas atividades $t_{1}$ e $t_{2}$, pode ser representada adicionando-se um lugar $p_{1}$ e arcos orientados. Para que a transição $t_{2}$ seja habilitada, é necessário que a transição $t_{1}$ tenha sido disparada anteriormente. A Figura 18 mostra duas atividades em uma relação de sequência.

Figura 18 - Representação gráfica em RdP da sequência de duas transições $\left(t_{l}\right.$ e $\left.t_{2}\right)$.

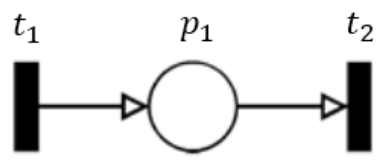

Fonte: Adaptado de Fattori et al. (2019).

\section{- $\quad$ Paralelismo}

O paralelismo é uma característica estrutural de SED que indica atividades que podem ser executados ao mesmo tempo sem que haja interferência da execução de um em outro, mas ambos com a mesma origem, isto é, uma única condição (estado) inicial.

Em RdP, o paralelismo de duas atividades pode ser modelado por dois lugares $p_{1}$ e $p_{2}$, por três transições $t_{1}, t_{2}$ e $t_{3}$ e arcos orientados. A Figura 19 representa a condição de paralelismo, 
onde após o disparo de $t_{1}$, ambas as transições $t_{2}$ e $t_{3}$ ficam habilitadas e o disparo delas independe da outra.

Figura 19 - Representação gráfica em RdP do paralelismo de três transições $\left(t_{1}, t_{2} \mathrm{e} t_{3}\right)$.

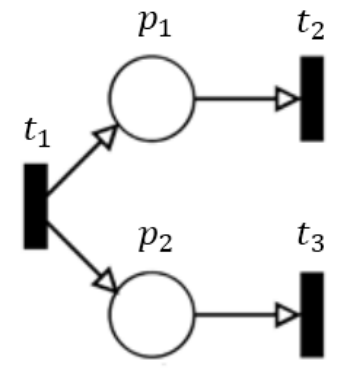

Fonte: Adaptado de Fattori et al. (2019).

\section{- $\quad \underline{\text { Sincronizacãa }}$}

A sincronização é uma característica estrutural de SED em que uma atividade depende da execução de outras atividades. Em geral, a sincronização ocorre entre atividades em paralelo, mas também pode ocorrer entre duas atividades com origens (processos) totalmente independentes.

Em RdP, a sincronização de duas atividades pode ser modelada por dois lugares $p_{1}$ e $p_{2}$, por três transições $t_{1}, t_{2}$ e $t_{3}$ e arcos orientados. A Figura 20 ilustra esta situação em que é necessário que as transições $t_{1}$ e $t_{2}$ tenham sido disparadas anteriormente para que a transição $t_{3}$ seja habilitada (e.g. dando a ideia de convergência entre as atividades do sistema).

Figura 20 - Representação gráfica em RdP da sincronização de três transições $\left(t_{1}, t_{2}\right.$ e $\left.t_{3}\right)$.

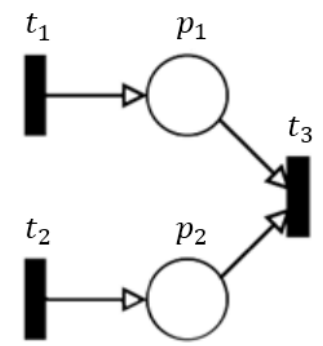

Fonte: Adaptado de Fattori et al. (2019). 


\section{- $\quad \underline{\text { Conflito }}$}

O conflito é uma característica estrutural de SEDs associada a escolha. Quando as atividades estão em conflito, significa que apenas uma delas pode ser executada, e a execução de uma dessas atividades inibe a execução das outras atividades que estavam em conflito.

Em RdP, o conflito entre duas atividades pode ser modelado por um lugar $p_{1}$, por três transições $t_{1}, t_{2}$ e $t_{3}$ e arcos orientados. A Figura 21 ilustra uma situação de conflito, onde após o disparo da transição $t_{1}$, apenas uma das transições seguintes pode ser disparada, e seu disparo desabilita a outra transição.

Figura 21 - Representação gráfica em RdP do conflito entre três transições $\left(t_{1}, t_{2} \mathrm{e} t_{3}\right)$.

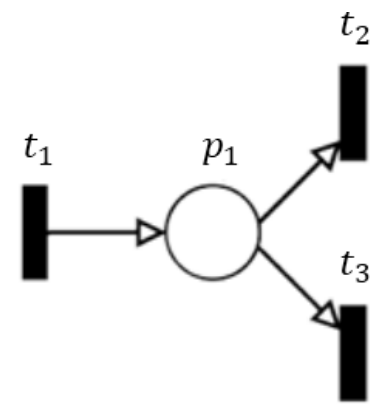

Fonte: Adaptado de Fattori et al. (2019).

\section{- Compartilhamento de recursos}

O compartilhamento de recursos é uma característica estrutural de SED em que atividades diferentes dependem de um mesmo recurso para serem executadas. Um recurso pode ser um equipamento usado em diferentes atividades em um sistema produtivo, a escrita de informações na memória de um sistema operacional, uma linha de transmissão em um sistema de comunicação, uma máquina ou ferramenta entre outros de diferentes áreas.

Em RdP o compartilhamento pode ser modelado utilizando quatro transições $t_{1}, t_{2}, t_{3}$, e $t_{4}$, três lugares $p_{1}, p_{2}$ e $p_{3}$ e arcos orientados. A Figura 22 ilustra dois processos (1 e 2) que compartilham um recurso (lugar $p_{1}$ ). Os processos 1 e 2 só podem ter sequência (i.e., suas transições habilitadas) caso o recurso compartilhado $p_{1}$ esteja disponível. E uma vez que um processo esteja em operação, o outro fica desabilitado até que o recurso $p_{1}$ seja disponibilizado novamente. 
Figura 22 - Representação gráfica em RdP de dois processos compartilhando um recurso.

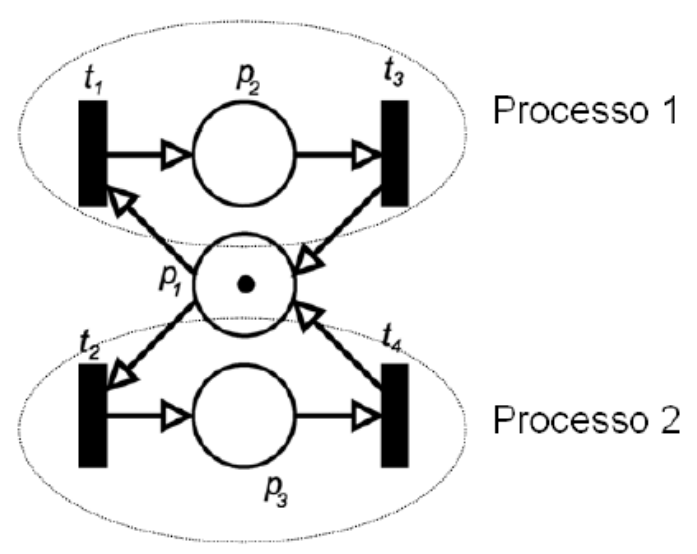

Fonte: Adaptado de Fattori et al. (2019).

\subsubsection{Propriedades da Rede de Petri}

De acordo com Murata (1989), modelos em RdP podem ser analisados com base nas propriedades qualitativas e intrínsecas dos elementos que compõem o modelo e sua estrutura, caracterizando o comportamento dinâmico do sistema ou processo modelado. Neste caso, um modelo em RdP pode ser descrito por um vetor $\left\{P, T_{N}, T_{T}, F_{N}, F_{I}, M_{0}\right\}$, onde:

$P$ é o conjunto de lugares. Cada lugar tem capacidade de receber certo número de marcas. Quando não se tem uma indicação explícita, essa capacidade é infinita;

$T_{N}$ é o conjunto de transições instantâneas, isto é, não temporizadas;

$T_{T}$ é o conjunto de transições temporizadas;

$F_{N}$ é o conjunto de arcos orientados que só podem conectar elementos distintos, isto é, transições a lugares ou, lugares a transições. Cada arco orientado tem um peso $w$ que indica 0 número de arcos orientados em paralelo (que conectam os mesmos elementos distintos). Quando não se tem uma indicação explícita, esse peso é 1;

$F_{I}$ é o conjunto de arcos inibidores que ligam lugares a transições;

$M_{0}$ é a marcação inicial, isto é, um vetor onde cada elemento representa a quantidade inicial de marcas nos lugares do modelo, e que tem respeita a capacidade de cada lugar.

Por fim, regras de habilitação, desabilitação e disparo de transições que alteram a marcação do modelo em RdP, isto é, o estado do sistema/processo modelado. Para mais detalhes, ver Murata (1998) onde se tem uma definição formal da RdP. 
As principais propriedades de um modelo em RdP segundo Murata (1989) são:

\section{- Alcancabilidade}

A identificação dos estados que podem ser alcançados durante o funcionamento de um sistema é uma propriedade fundamental para o estudo da sua dinâmica. Ao serem disparadas, transições mudam a distribuição das marcas em uma RdP, logo, uma sequência de disparos precede uma sequência de marcações.

Um estado específico, com marcações denominado $M_{n}$, é alcançável se e somente se, a partir de uma marcação inicial $M_{0}$, ele pode ser alcançado após uma sequência de disparos. Esta sequência de disparos pode ser apresentada como $\sigma=M_{0} t_{1} M_{1} t_{2} M_{2} \ldots t_{n} M_{n}$, assim, $M_{n}$ é alcançável após uma sequência $\sigma$ de disparos a partir de $M_{0}$.

A Figura 23 exemplifica a "árvore de alcançabilidade" em modelos RdP. Definindo um vetor de marcação como $M=\left(p_{1}, p_{2}, p_{3}, p_{4}\right)$ e, portanto $M_{0}=(1,0,0,0)$. A Figura 23 também mostra o vetor de marcação $M$ ao longo dos disparos das transições do modelo, construindo sua árvore de alcançabilidade.

O conjunto de marcações alcançáveis a partir de $M_{0}$ é denominado $R\left(M_{0}\right)$.

\section{- $\quad$ Limitabilidade e Seguranca}

Um modelo em RdP é dito $k$-limitado ou simplesmente limitado se o número de marcas em cada lugar do modelo não exceder um número finito $k$ para qualquer marcação alcançável a partir de $M_{0}$. Um modelo em RdP é dita segura se esta for 1-limitada. Na prática, os lugares do modelo em RdP são frequentemente usados para representar buffers e/ou registradores de dados, itens ou materiais. Assim, assegurar que o modelo do sistema é limitado ou seguro, é uma forma de garantir que não haverá overflow (i.e., acúmulo) nos buffers ou registradores, não importando qual sequência de eventos (disparos de transições) ocorra.

Utilizando o modelo da Figura 23 como exemplo, percebe-se que ela é não limitada, uma vez que existe a possibilidade de ocorrer um acúmulo de marcas no lugar $p_{4}$. Assim, o modelo em RdP também não é seguro.

\section{- Vivacidade}

Um modelo em RdP é considerado como vivo se para qualquer marcação $M \in R\left(M_{0}\right)$ sempre existir pelo menos uma transição habilitada para disparo. A vivacidade está intimamente 
relacionada à ausência de deadlocks (situações de auto travamento) na operação de um processo.

Figura 23.1 - (a), (b), (c), (d): Análise de um modelo em RdP e obtenção da árvore de alcançabilidade para cada etapa.

\section{Análise da \\ RdP}

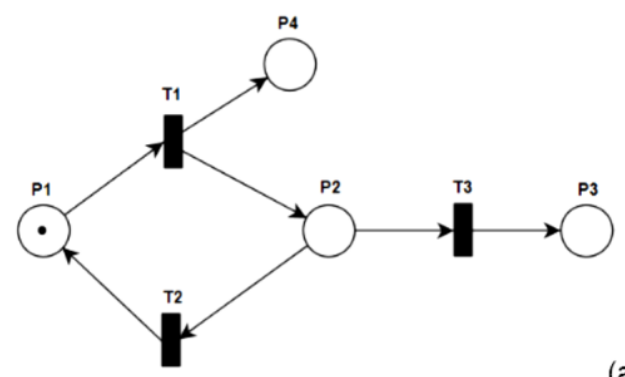

(a)

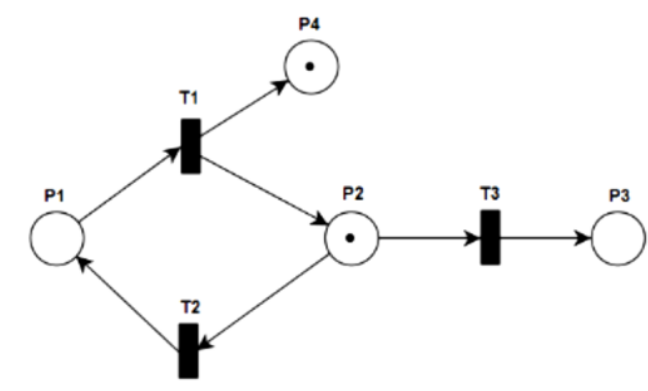

(b)

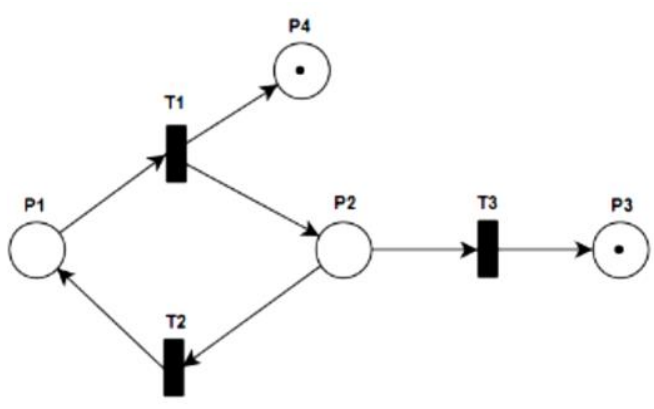

(c)

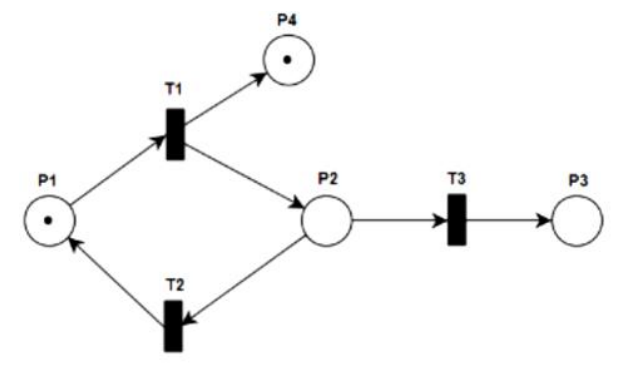

Árvore de

Alcançabilidade

$(1,0,0,0)$

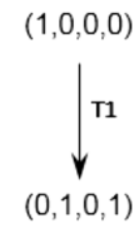

$(1,0,0,0)$

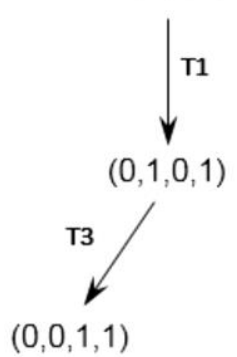

$(1,0,0,0)$

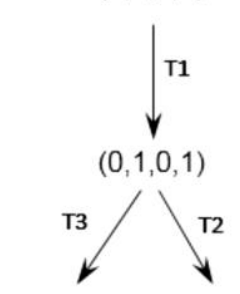

$(0,0,1,1) \quad(1,0,0,1)$

(d)

Fonte: Adaptado de Fattori et al. (2019). 
Figura 23.2 - (e), (f), (g): Análise de um modelo em RdP e obtenção da árvore de alcançabilidade para cada etapa.
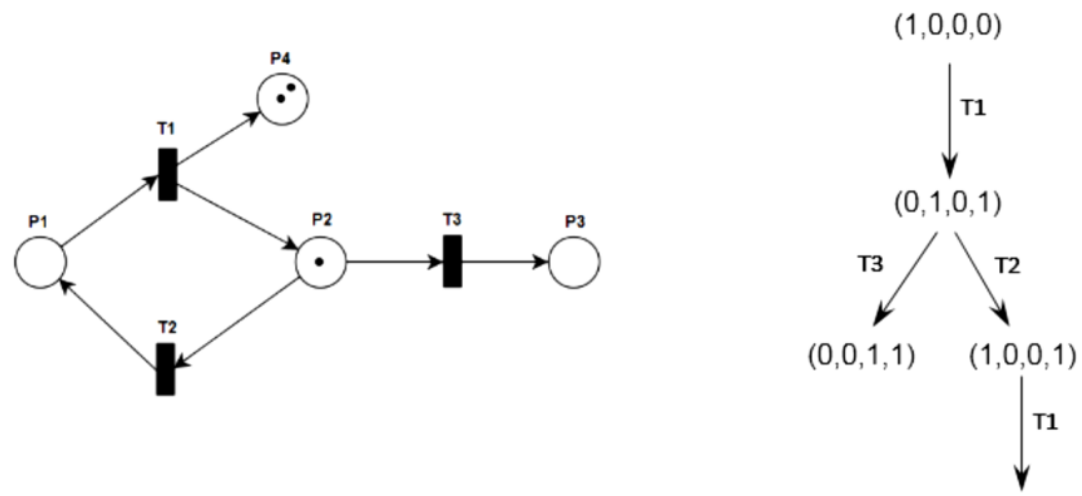

(e)
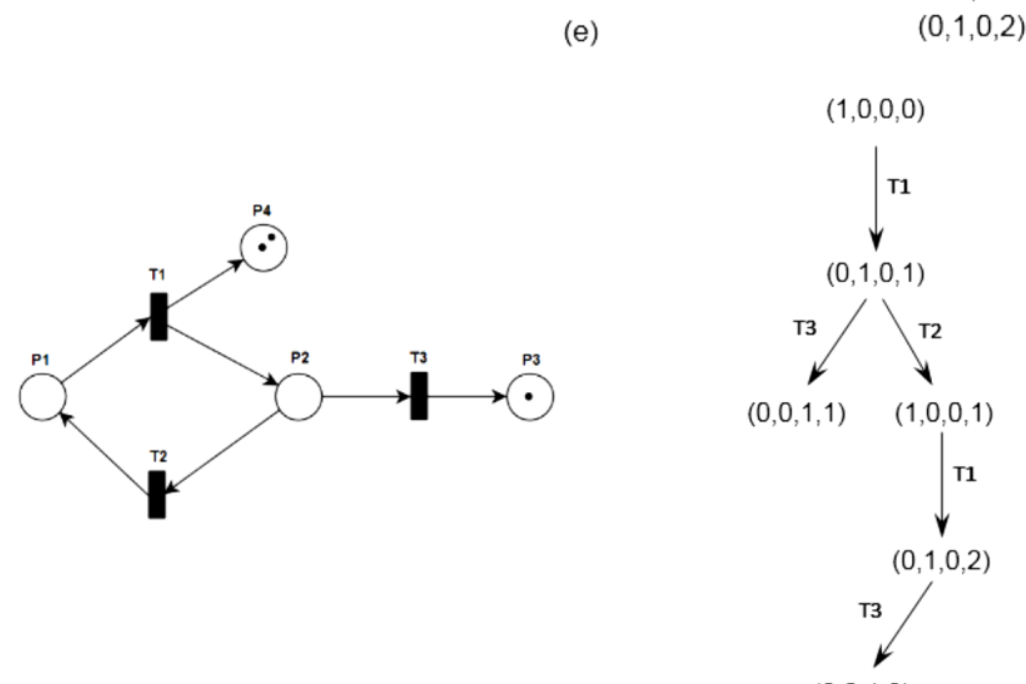

(f)

$$
(0,0,1,2)
$$
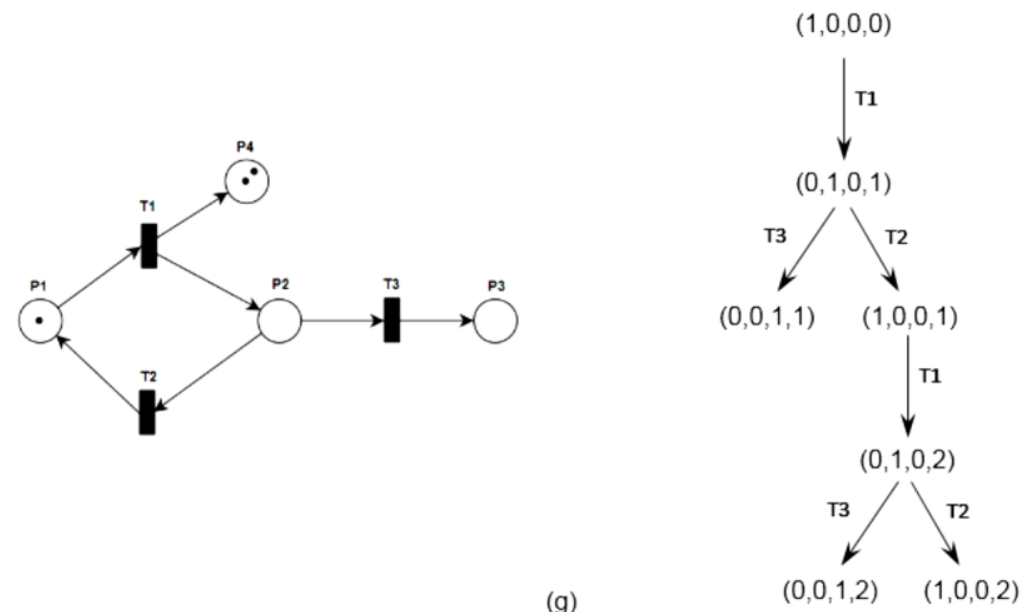

(g)

Fonte: Adaptado de Fattori et al. (2019).

Vivacidade é uma propriedade fundamental para a operação regular de muitos processos. Entretanto, a identificação desta propriedade nem sempre é simples e o custo de 
verificação para alguns processos pode ser muito elevado. Nesse sentido, são definidos diferentes níveis de vivacidade, de modo que uma transição $t$ em um modelo em RdP é dita:

1. L0-viva (morta) se nunca pode ser disparada em qualquer sequência de disparos a partir de $M_{0}$;

2. L1-viva (ou potencialmente disparável) se $t$ pode ser disparada apenas uma vez em alguma sequência de disparos a partir de $M_{0}$;

3. L2-viva se, dado um número inteiro positivo $k, t$ pode ser disparada $k$ vezes em alguma sequência de disparos a partir de $M_{0}$;

4. L3-viva se $t$ aparece infinitamente, em alguma sequência de disparos a partir de $M_{0}$;

5. L4-viva se $t$ é L1-viva para cada marcação $M$ em $R\left(M_{0}\right)$, ou seja, $t$ pode ser disparada pelo menos uma vez em todas as sequências de disparos a partir de $M_{0}$.

\section{- $\quad \underline{\text { Reversibilidade }}$}

Um modelo em RdP é dito reversível se, para qualquer marcação $M$ em $R\left(M_{0}\right), M_{0}$ é alcançável a partir de $M$. Assim, em um modelo reversível é sempre possível retornar para a marcação inicial ou estado inicial. Em muitas aplicações não é necessário retornar ao estado inicial, mas é esperado o retorno a um estado desejado ${ }^{13}$. Portanto, a condição de reversibilidade pode ser descrita pela definição do estado desejado. Uma marcação $M^{\prime}$ é considerada um estado desejado se, para cada marcação $M$ em $R\left(M_{0}\right), M^{\prime}$ é alcançável a partir de $M$.

\section{- $\quad$ Cobertura}

Segundo Reisig (2013), existe cobertura em um modelo em $\operatorname{RdP}\left(R, M_{0}\right)$ se existir um vetor de marcação $M^{\prime}$ alcançável a partir de $M_{0}$ tal que este vetor seja maior ou igual que todos os vetores de marcação alcançáveis por qualquer estado do modelo.

Ou seja, se $\exists M^{\prime} \in R\left(M_{0}\right) \mid M^{\prime}(p) \geq M_{i}(p) / \forall p \in P, \forall M_{i} \in R\left(M_{0}\right)$, o modelo é dito coberto, e neste caso a cobertura do modelo em RdP é $M^{\prime}$.

\section{- $\quad$ Persistência}

${ }^{13}$ Exemplo: Uma máquina executa setup ao ser ligada. Depois da sua operação, ela não realiza o setup novamente. 
Um modelo em RdP é dito persistente se, para quaisquer duas transições habilitadas, o disparo de uma delas não desabilita a outra. Uma transição em um modelo em RdP persistente, uma vez habilitada, permanece habilitada até que dispare. A noção de persistência é útil no contexto de sistemas assíncronos. A persistência é fortemente relacionada a um sistema/processo sem conflitos.

No exemplo de modelo em RdP da Figura 23, verifica-se que após o disparo da transição $t_{1}$, as transições $t_{2}$ e $t_{3}$ ficam habilitadas, mas se a transição $t_{2}$ dispara, a transição $t_{3}$ é desabilitada, e se a transição $t_{3}$ dispara, a transição $t_{2}$ é desabilitada. Portanto, este modelo em RdP não é persistente.

\section{- $\quad$ Equidade}

Diferentes noções de equidade foram propostas na literatura de RdP. Aqui são abordados dois conceitos de equidade: equidade limitada e equidade incondicional (ou global).

Duas transições $t_{1}$ e $t_{2}$ possuem uma relação "igual-limitada" se o máximo de vezes que uma disparar, enquanto a outra não disparar, é limitada. Um modelo em RdP é dita igual-limitada se cada par de transições desta mantém uma relação igual limitada. Uma sequência de disparos $\sigma$ é dita incondicionalmente igual se esta é finita ou todas as transições do modelo aparecem infinitamente em $\sigma$. Um modelo em RdP é dito incondicionalmente igual se todas as sequências de disparos $\sigma$, a partir de $M$ em $R\left(M_{0}\right)$, forem incondicionalmente iguais.

Utilizando a Figura 23 como exemplo, percebe-se que ao comparar as transições $t_{1}$ e $t_{2}$, para cada disparo da transição $t_{1}$ é necessário um disparo de $t_{2}$ para que $t_{1}$ volte a ser habilitada e igualmente entre $t_{2}$ e $t_{1}$. Desta forma, as transições $t_{1}$ e $t_{2}$ são incondicionalmente iguais. Entretanto, comparando as transições $t_{1}$ e $t_{3}$, ou $t_{2}$ e $t_{3}$, percebe-se que as transições $t_{1}$ e $t_{2}$ podem ser disparadas infinitamente dada certa sequência de eventos sem que ocorra o disparo de $t_{3}$, logo, estes pares de transições não são iguais.

\subsubsection{Classificação de tipos de Rede de Petri}

Com base no trabalho de Bonet e Lladó (2007) é possível classificar um modelo em RdP com base na conexão entre seus lugares e transições. A classificação segue:

- RdP ordinária - É um modelo em RdP onde o peso dos seus arcos é sempre 1, as transições $t$ são todas instantâneas e a capacidade de todos os lugares para receber marcas é infinita (BERNARDINELLO; CINDIO, 1992); 
- State machine - É um modelo em RdP ordinária tal que $\left.\right|^{\bullet} t|=| t^{\bullet} \mid=1$ para todo $t$, isto é, uma RdP em que cada transição tem exatamente um lugar na sua entrada e um lugar na sua saída (MURATA, 1989);

- $\quad$ Marked graph - É um modelo em RdP ordinária tal que $\left.\right|^{\bullet} p|=| p^{\bullet} \mid=1$, para todo $p \in P$, isto é, uma RdP ordinária em que cada lugar possui exatamente uma transição na sua entrada e uma transição na sua saída (MURATA, 1989);

- $\quad$ Free choice net - É um modelo em RdP ordinária tal que para todo $p_{1}, p_{2} \in P, p_{1}^{*} \cap$ $p_{2}^{\bullet} \neq \emptyset \Rightarrow\left|p_{1}^{\bullet}\right|=\left|p_{2}^{\bullet}\right| \leq 1$, isto é, uma RdP ordinária em que todo arco saindo de um lugar é o único de entrada para uma transição (MURATA, 1989);

- Extended free choice net - É um modelo em RdP ordinária tal que $p_{1}^{\bullet} \cap p_{2}^{\bullet} \neq \emptyset \Rightarrow$ $p_{1}^{\bullet}=p_{2}^{\bullet}$, para todo $p_{1}, p_{2} \in P$, isto é, uma RdP ordinária em que todas as transições em conflito que compartilham um lugar de entrada, possuem necessariamente os mesmos lugares de entrada (Murata, 1989);

- Simple net ou Asymmetric choice net - É um modelo em RdP ordinária tal que no caso de existência de transições com dois ou mais conflitos na entrada: $p_{1} \neq p_{2} \Rightarrow$ $p_{1}^{\bullet} \cap p_{2}^{\bullet} \neq \varnothing$ e $\left\{\left|p_{1}^{\bullet}\right| \leq 1\right.$ ou $\left.\left|p_{2}^{\bullet}\right| \leq 1\right\}$, para todo $p_{1}, p_{2} \in P$, isto é, podem existir transições de saída de $p_{1}$ e $p_{2}$ em comum sendo que neste caso, existe no máximo uma transição de saída para o lugar $p_{1}$ ou para o lugar $p_{2}$ (BAUSE; KRITZINGER, 1998);

- Extended simple net - É um modelo em RdP ordinária tal que no caso de existência de transições em conflito: $p_{1}^{\bullet} \cap p_{2}^{\bullet} \neq \varnothing$ ou $p_{1}^{\bullet} \subseteq p_{2}^{\bullet}$ ou $p_{1}^{\bullet} \supseteq p_{2}^{\bullet}$, para todo $p_{1}, p_{2} \in P$, isto é, uma RdP ordinária em que existem transições de saída de $p_{1}$ e $p_{2}$ em comum ou, o conjunto de transições de saída de $p_{1}$ está contido ou, é igual ao conjunto de transições de saída de $p_{2}$ (ou vice-versa) (BAUSE; KRITZINGER, 1998).

A Figura 24 ilustra os tipos de um modelo em Rede de Petri.

\subsection{Síntese do Capítulo}

Este capítulo discutiu os fundamentos que envolvem este estudo. Desta forma, as definições de big data e I4.0 são vistas aqui como alinhadas.

A definição de arquitetura de um sistema, assim como os modelos de arquiteturas de referência como RAMI 4.0 e NBDRA foram apresentadas, pois estes formam a base para 
desenvolvimento de uma arquitetura de um sistema que implementa o processo de aquisição de big data no contexto da I4.0.

O contexto da engenharia de requisitos junto com a metodologia KAOS foram explorados para orientar o estudo dos requisitos de stakeholders ligados à I4.0. Isto é, procurou-se identificar e caracterizar as necessidades do mercado para sistemas que utilizam big data, de modo que a arquitetura desenvolvida seja orientada a atender estas demandas.

Figura 24 - Classificação de modelos em Rede de Petri.

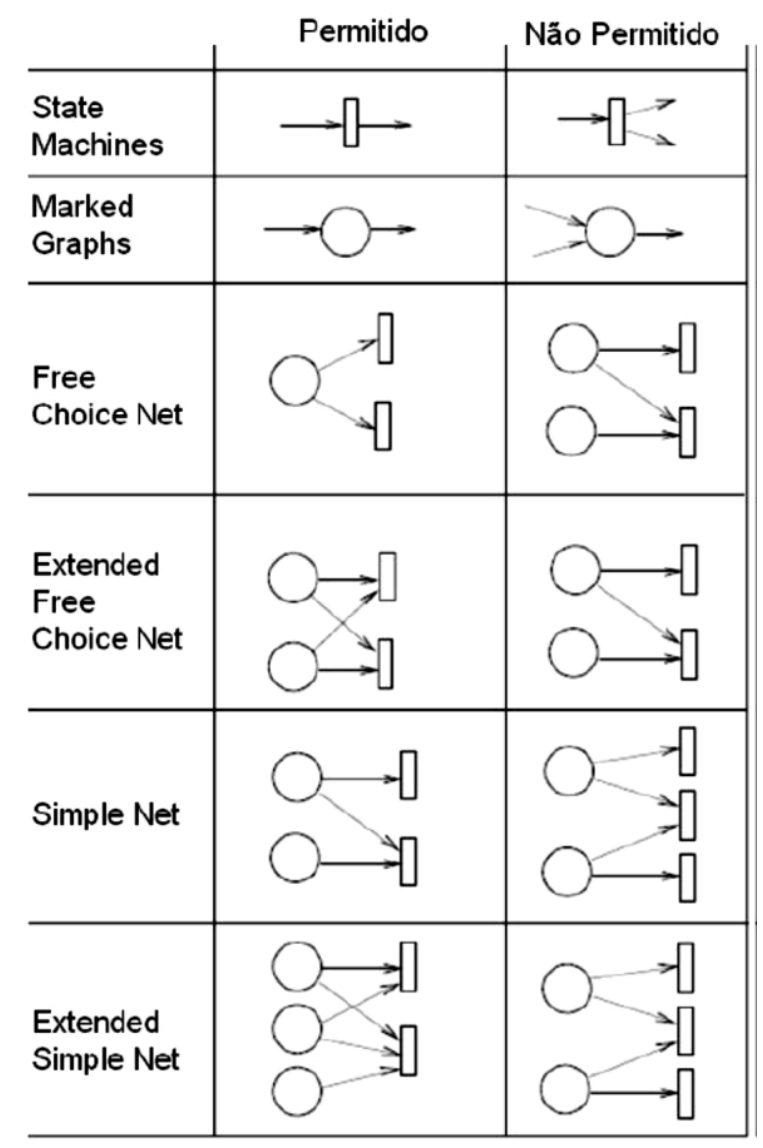

Fonte: Adaptado de Fattori et al. (2019).

A verificação das funcionalidades e validação da arquitetura pode ser realizada com base na análise de seus modelos estruturais e funcionais. Assim, em relação a modelagem de sistemas, foi apresentada a técnica PFS/RdP. Por meio da aplicação desta técnica se deriva o modelo do processo de aquisição de big data e se verifica, por exemplo, se o processo estabelecido pela arquitetura evolui do seu início ao fim sem nenhum impasse, além da avaliação de suas características, propriedades e classificações. 


\section{MODELAGEM DOS REQUISITOS PARA SISTEMAS DE BIG DATA}

Considerando a contextualização do tema "big data" que foi desenvolvida, este Capítulo apresenta a elucidação dos requisitos para sistemas de big data por parte de stakeholders ligados à I4.0.

Uma modelagem acurada do DAQ (Data Acquisition System - sistema de aquisição de dados) é fundamental para uma avaliação sobre o desempenho do processo de coleta de dados na I4.0 descritas em publicações como (LEE et al., 2015; LEE; KAO; YANG, 2014; SUN et al., 2016).

De acordo com Lyko, Nitzschke e Ngonga Ngomo (2016), a maioria dos sistemas de aquisição de dados emprega algoritmos para garantir que apenas os fragmentos do que é considerado valioso nos dados coletados. Por outro lado, algumas empresas consideram a maioria de seus dados como potencialmente de alto valor e procuraram DAQs capazes de lidar com big data. Assim, entende-se que é relevante fazer a elucidação dos requisitos para sistemas de big data.

Gittler et al. (2019) apresentam uma abordagem para a aquisição de dados voltada para sistemas de monitoração na I4.0. No entanto, publicações com descrições mais detalhadas das funcionalidades dos DAQs e sua implementação no contexto de big data na I4.0 não foram identificadas até o momento da redação deste texto.

$\mathrm{Na}$ primeira etapa deste estudo os requisitos para sistemas que utilizam big data foram modelados com base nos viewpoints de stakeholders ligados ao contexto da I4.0. Os resultados alcançados foram publicados em Coda et al. (2018) e Coda et al. (2019).

Do ponto de vista da conexão entre as entidades da I4.0, a modelagem dos requisitos com base nos pontos de vista de stakeholders é entendida como um compromisso temporário para a ação colaborativa de um grupo de empresas de diferentes tipos, para que a caracterização do big data considere o ponto de vista de diferentes stakeholders.

Com base no trabalho de Mazzei e Noble (2017) são considerados três tipos básicos para empresas e as respectivas expectativas para sistemas de big data dos seus stakeholders. A metodologia KAOS é utilizada na modelagem pois se considera que os stakeholders estão comprometidos com a valorização das suas empresas.

\subsection{Tipo 1: Empresas onde os dados alimentam ferramentas de otimização}

Uma das aplicações mais facilmente identificadas para análise de big data é a oportunidade de melhorar o desempenho da função principal de um sistema. Esse tipo engloba 
as indústrias que são o núcleo da I4.0, ou seja, indústrias de fabricação comprometidas em coletar dados relevantes por meio da tecnologia de conectividade e comunicação disponível.

Empresas como Coca-Cola, Etihad Airways, Walt Disney e Intel buscam reunir a maior quantidade de dados gerados por seus produtos e processos para alimentar seus procedimentos analíticos utilizados na melhoria dos seus processos, produtos e serviços (ALHARTHI; KROTOV; BOWMAN, 2017; MAZZEI; NOBLE, 2017; VAN RIJMENAM, 2014).

Essas empresas são consideradas para este trabalho porque existem dados disponíveis sobre os pontos de vista de seus stakeholders para sistemas de big data.

Coca-Cola é uma empresa que utiliza o big data para gerenciar seus produtos e processos de acordo com a percepção de seus consumidores. Para alimentar essas análises, a empresa difundiu inovações como as Freestyle Machines, que permitem mais de 100 combinações de bebidas reunindo dados sobre preferência, sazonalidade, disposição geográfica e a necessidade de reabastecer seus produtos (MAZZEI; NOBLE, 2017).

A Etihad Airways é uma companhia aérea que voa para mais de 89 destinos e transporta cerca de 10 milhões de passageiros anualmente. A empresa desde a sua criação, em 2003, utiliza centenas de sensores em todos os seus aviões para gerar dados sobre sua frota, em um arranjo onde computadores e sensores em aeronaves são conectados por uma rede de comunicação e trocam informações em tempo real. Essa monitoração permite a manutenção preditiva de aeronaves, economizando em custos de manutenção (ALHARTHI; KROTOV; BOWMAN, 2017; VAN RIJMENAM, 2014).

A Walt Disney também utiliza o big data como uma ferramenta para conhecer melhor seus clientes e melhorar seus produtos. Desde 2013, todas as pulseiras de usuários / clientes em seus parques foram equipadas com RFID utilizados para coletar informações do cliente sobre comportamento, histórico de compras, tempo de espera e preferências para melhorar a experiência do usuário e as estratégias de marketing da empresa (ALHARTHI; KROTOV; BOWMAN, 2017; VAN RIJMENAM, 2014).

Anteriormente todos os processadores da Intel eram submetidos a até 19.000 testes de qualidade, depois de deixar a linha de produção, mas mais recentemente, com a análise preditiva de big data, a empresa conseguiu reduzir o tempo e número de testes, economizando mais de 30 milhões de dólares em custos de fabricação (MAZZEI; NOBLE, 2017).

Nota-se que o maior interesse de tais empresas é melhorar a eficiência de seus processos, usando o conhecimento sobre os desejos e expectativas de seus consumidores por meio da análise de big data e, assim, modificam os parâmetros do processo para os tornar mais rentáveis. 
A Figura 25 apresenta a modelagem obtida a partir das relações entre "objetivos", "expectativas" e "requisitos".

Figura 25 - Empresas onde os dados alimentam ferramentas de otimização.

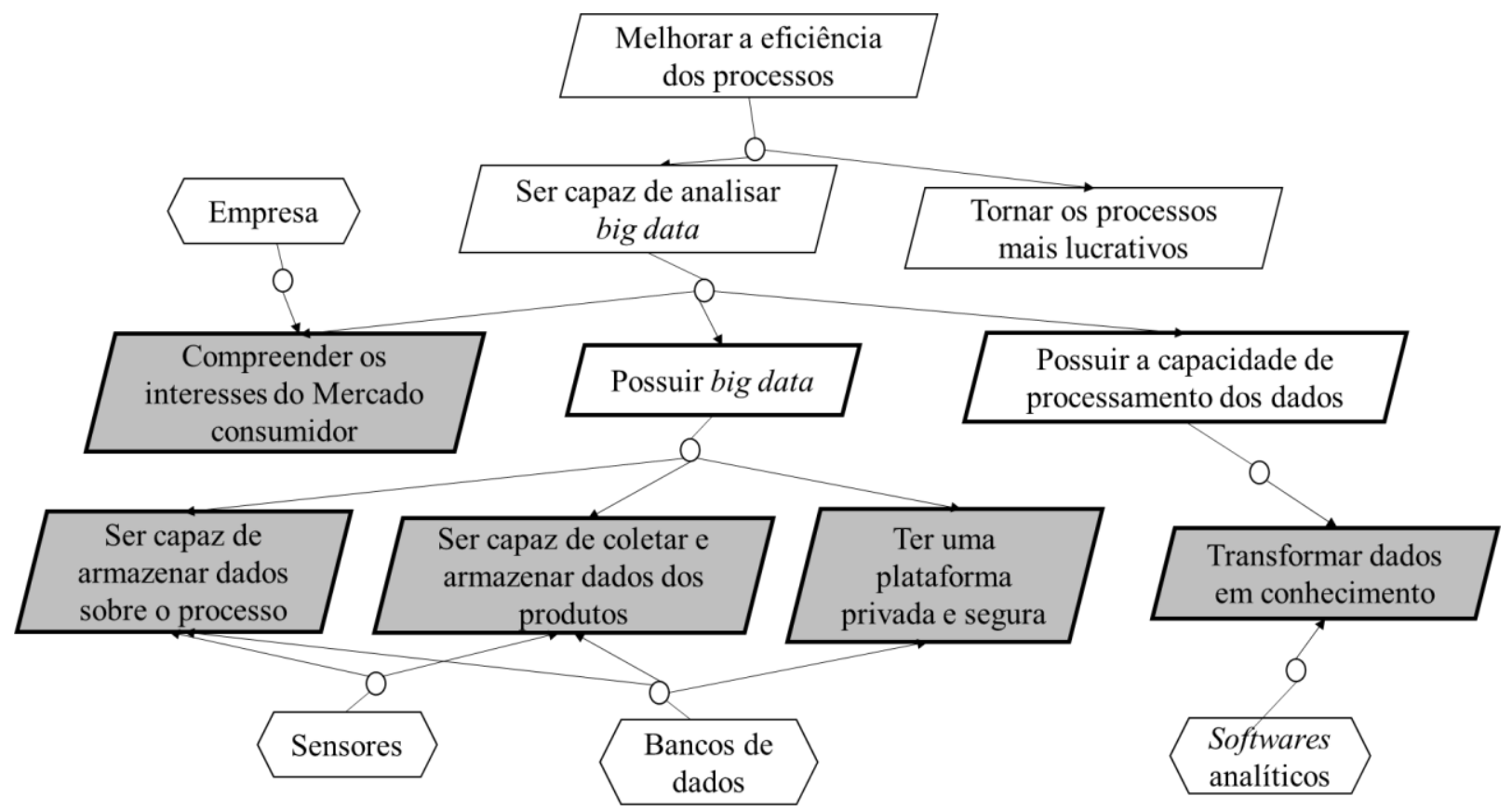

Fonte: Adaptado de Coda et al. (2018).

Respondendo às questões propostas por Horkoff e Yu (2011), o modelo resultante foi avaliado, e a Tabela 2 apresenta as respostas obtidas.

Comparando o modelo da Figura 25 com o de (ERIDAPUTRA; HENDRADJAYA; DANAR SUNINDYO, 2014), observa-se que ambos os modelos se referem ao mesmo tipo de sistema, mas neste estudo o foco está nos pontos de vista e expectativas dos stakeholder para suas funcionalidades, enquanto o modelo dos autores correlatos se preocupa com as características dos dados e das suas bases de dados.

Tabela 2 - Análise do modelo em KAOS da Figura 25 (tipo 1).

\begin{tabular}{|c|l|}
\hline Categoria & \multicolumn{1}{|c|}{ Tipo 1 } \\
\hline $\begin{array}{c}\text { Compreensão } \\
\text { do domínio }\end{array}$ & $\begin{array}{l}\text { QU1: O modelo oferece uma visão das necessidades e expectativas semelhantes de } \\
\text { stakeholders de múltiplos domínios de atuação, mas não um detalhamento de } \\
\text { particularidades de cada domínio específico. }\end{array}$ \\
\hline
\end{tabular}




\begin{tabular}{|c|c|}
\hline & $\begin{array}{l}\text { QU2: Não, o momento da modelagem inclui uma primeira visão das funcionalidades } \\
\text { que os sistemas devem conter para atender as necessidades dos sistemas produtivos na } \\
\text { Indústria 4.0. Espera-se que essas informações sejam expressas durante o } \\
\text { desenvolvimento dos sistemas e com particularidades para cada domínio de atuação. }\end{array}$ \\
\hline Comunicação & $\begin{array}{l}\text { QC1: Sim, como a Indústria } 4.0 \text { envolve novos paradigmas, é necessária a existência } \\
\text { de canais de comunicação com stakeholders para validar o modelo. }\end{array}$ \\
\hline \multirow{2}{*}{$\begin{array}{l}\text { Melhoria } \\
\text { do modelo }\end{array}$} & $\begin{array}{l}\text { QM1: A modelagem inclui as semelhanças nos interesses para sistemas de big data em } \\
\text { domínios diferentes. O modelo pode ser detalhado para representar domínios } \\
\text { específicos conforme necessidade. }\end{array}$ \\
\hline & $\begin{array}{l}\text { QM2: Como o modelo se refere a uma fase inicial do projeto de sistemas para Indústria } \\
\text { 4.0, não é necessária a verificação das propriedades neste momento. }\end{array}$ \\
\hline Escopo & $\begin{array}{l}\text { QS1: A modelagem busca encontrar semelhanças em domínios diferentes para sistemas } \\
\text { de big data. Espera-se que um sistema que contenha as características do modelo atenda } \\
\text { diferentes áreas de atuação. }\end{array}$ \\
\hline \multirow{4}{*}{$\begin{array}{c}\text { Elicitação } \\
\text { dos Requisitos }\end{array}$} & $\begin{array}{l}\text { QE1: Não. A modelagem realizada visa encontrar semelhanças nos interesses de } \\
\text { stakeholders, possibilitando o desenvolvimento de sistemas que atendam às exigências } \\
\text { de diversos sistemas produtivos. Requisitos de mais alto nível podem ser usados para } \\
\text { detalhar o modelo com as necessidades de processos produtivos específicos. }\end{array}$ \\
\hline & $\begin{array}{l}\text { QE2: Não, apenas quando existir interesse em elaborar modelos dedicados a sistemas } \\
\text { produtivos específicos, representando suas particularidades. }\end{array}$ \\
\hline & $\begin{array}{l}\text { QE3: Não, requisitos não-funcionais detalham não o que um sistema deve fazer, mas } \\
\text { como ele deve fazer. Estes devem ser considerados nas etapas efetivas de } \\
\text { desenvolvimento dos sistemas. }\end{array}$ \\
\hline & $\begin{array}{l}\text { QE4: O modelo não contém uma descrição de um domínio específico, mas sim uma } \\
\text { interseção entre domínios diferentes. }\end{array}$ \\
\hline \multirow{2}{*}{$\begin{array}{c}\text { Melhoria } \\
\text { dos Requisitos }\end{array}$} & $\begin{array}{l}\text { QR1: A segurança dos dados é uma característica considerada no modelo e esperada } \\
\text { para manter a integridade dos sistemas de big data. }\end{array}$ \\
\hline & $\begin{array}{l}\text { QR2: É necessário que as propriedades do modelo sejam revistas por stakeholders de } \\
\text { processos produtivos específicos. }\end{array}$ \\
\hline \multirow{4}{*}{ Projeto } & $\begin{array}{l}\text { QD1: Não, nesta etapa não foi considerado o projeto específico de um sistema, mas os } \\
\text { interesses nele. }\end{array}$ \\
\hline & $\begin{array}{l}\text { QD2: Não nesta etapa do projeto. Espera-se que durante o desenvolvimento dos } \\
\text { sistemas considerem-se alternativas de Projeto que melhor se encaixem nas } \\
\text { expectativas de stakeholders de áreas diferentes. }\end{array}$ \\
\hline & $\begin{array}{l}\text { QD3: Sim, devem-se encontrar processos aceitáveis que possibilitem o } \\
\text { desenvolvimento de sistemas com as características do modelo. }\end{array}$ \\
\hline & $\begin{array}{l}\text { QD4: Nesta fase, tem-se a concepção do sistema. A simulação da operação do sistema } \\
\text { deve ser considerada durante seu desenvolvimento. }\end{array}$ \\
\hline
\end{tabular}




\subsection{Tipo 2: Empresas onde os dados são o seu próprio negócio}

Muitas empresas, principalmente no setor manufatureiro, consideram que seu foco deveria estar apenas no sistema produtivo. Assim, nessas empresas, o interesse não está nos serviços de processamento de dados. Essas empresas tendem a ter interesse em adquirir esse tipo de serviço de parceiros (outras empresas) onde o processamento de dados é o foco, ou seja, empresas em que os dados são o seu próprio negócio. Empresas deste tipo não são o núcleo da I4.0, mas são componentes dela, fornecendo na forma de serviços às funcionalidades que as empresas do núcleo precisam, mas não possuem. Neste caso, existem empresas como a Pivotal Software, Cloudera e Oracle, que fornecem serviços sob a forma de plataformas para processamento de dados (MAZZEI; NOBLE, 2017).

Empresas como a Pivotal Software e a Cloudera são aqui consideradas porque existem dados disponíveis sobre os pontos de vista de seus stakeholders para sistemas de big data.

A Pivotal Software, uma empresa derivada da EMC e da VmWare, concentra-se em big data, fornecendo serviços para seus clientes criarem aplicativos de código aberto em um ambiente de computação na nuvem. Um de seus maiores clientes, a Ford Motor Company, usa a plataforma de programação e a metodologia da Pivotal para desenvolver o FordPass, um aplicativo que permite que os motoristas encontrem vagas de estacionamento e monitorem seus veículos via dispositivos inteligentes (MAZZEI; NOBLE, 2017).

A Cloudera, uma empresa de serviços, oferece uma plataforma de análise e gerenciamento de dados de alto desempenho e baixo custo para clientes de vários setores, como Samsung, Cisco e Allstate (MAZZEI; NOBLE, 2017).

Para este tipo de empresa, os objetivos do negócio estão relacionados à sua capacidade de fornecer serviços aos seus clientes na forma de plataformas capazes de armazenar e processar grandes quantidades de dados.

A Figura 26 apresenta a modelagem obtida a partir dos requisitos deste tipo de empresa para o big data.

Respondendo às questões propostas por Horkoff e Yu (2011), o modelo resultante é analisado e a Tabela 3 apresenta as respostas obtidas.

Por meio da comparação do modelo da Figura 26 com o modelo em (ERIDAPUTRA; HENDRADJAYA; DANAR SUNINDYO, 2014), observa-se que os sistemas de big data exigidos pelas empresas desse domínio específico devem ter a forma de uma plataforma que pode ser alugada a um cliente, mas essa funcionalidade não é descrita pelos autores. 
Figura 26 - Empresas onde os dados são seu próprio negócio.

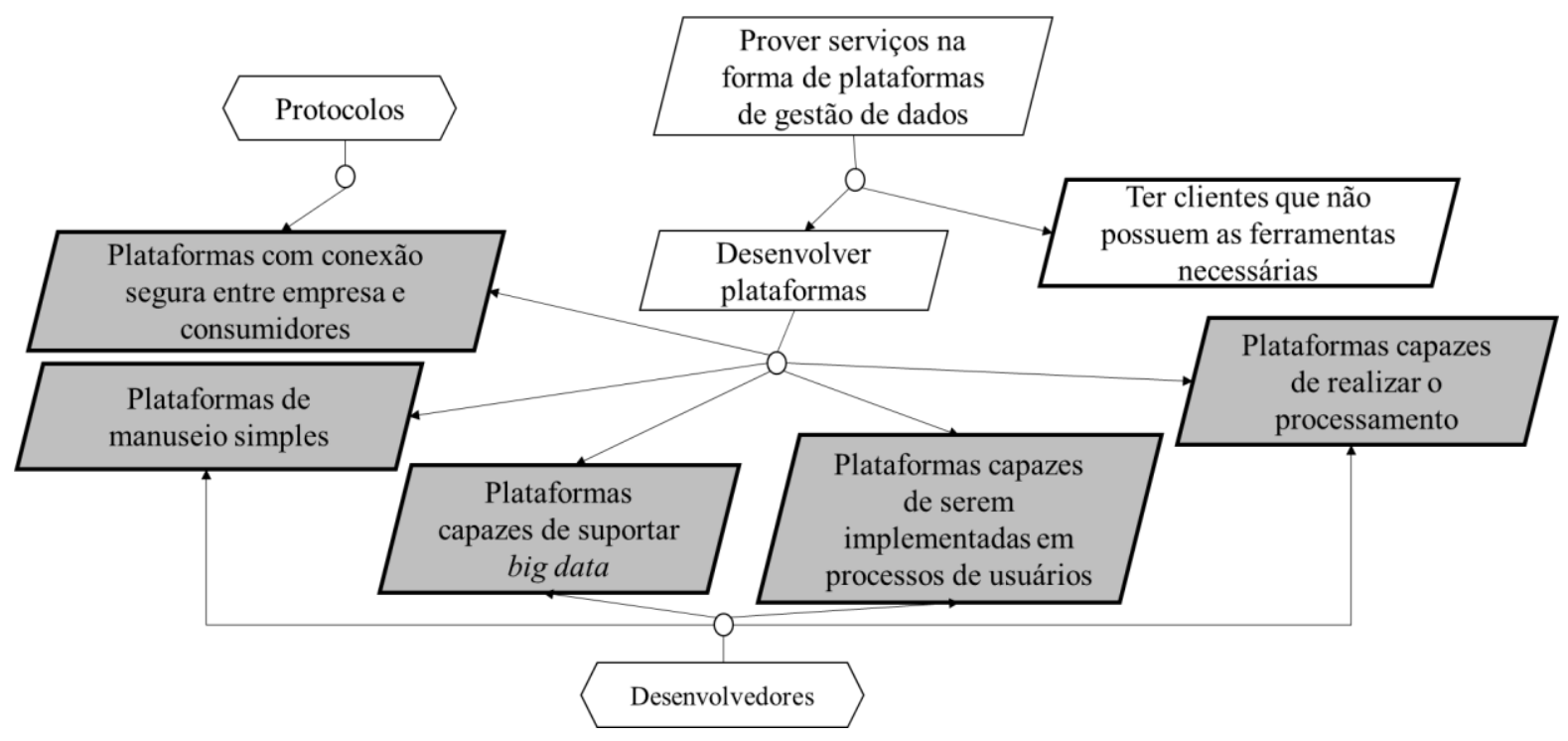

Fonte: Adaptado de Coda et al. (2018).

Tabela 3 - Análise do modelo em KAOS da Figura 26 (tipo 2).

\begin{tabular}{|c|l|}
\hline Categoria & \multicolumn{1}{c|}{ Tipo 2 } \\
\hline \multirow{2}{*}{$\begin{array}{c}\text { Compreensão } \\
\text { do domínio }\end{array}$} & $\begin{array}{l}\text { QU1: O modelo proposto para empresas do tipo 2 reúne os interesses de múltiplos } \\
\text { stakeholders de um mesmo domínio, e pela semelhança nas suas áreas de atuação } \\
\text { mostra como um mesmo sistema com estas características estaria adequado para } \\
\text { diversas empresas. }\end{array}$ \\
\cline { 2 - 3 } & $\begin{array}{l}\text { QU2: A conectividade proporcionada pela internet das coisas no contexto de Indústria } \\
\text { 4.0 torna possível que os requisitos dessa área de atuação sejam atendidos, mas nesse } \\
\text { momento da modelagem não é necessário o modelo conter informações sobre custos e } \\
\text { condições. }\end{array}$ \\
\hline \multirow{2}{*}{ Comunicação } & $\begin{array}{l}\text { QC1: Sim, a comunicação constante com stakeholders deve existir para que se garanta } \\
\text { que suas necessidades seriam representadas em um sistema com as características do } \\
\text { modelo. }\end{array}$ \\
\hline \multirow{2}{*}{ Escopo } & $\begin{array}{l}\text { QM1: Sim, pela semelhança nas expectativas de diferentes empresas neste tipo, pode- } \\
\text { se afirmar que o modelo e o domínio são representados com precisão. }\end{array}$ \\
\cline { 2 - 3 } do modelo & $\begin{array}{l}\text { QM2: Como o modelo se refere a uma fase inicial do projeto de sistemas para Indústria } \\
\text { 4.0, não é necessária a verificação das propriedades neste momento. } \\
\text { QS1: Não, a verificação do escopo do sistema deve ser realizada durante a etapa de } \\
\text { especificas de cada empresa. }\end{array}$ \\
\hline &
\end{tabular}




\begin{tabular}{|c|c|}
\hline \multirow{4}{*}{$\begin{array}{c}\text { Elicitação } \\
\text { dos Requisitos }\end{array}$} & $\begin{array}{l}\text { QE1: Não. A modelagem realizada visa encontrar semelhanças nos interesses de } \\
\text { stakeholders, possibilitando o desenvolvimento de um sistema que atenda às exigências } \\
\text { de diversas empresas. Encontrar requisitos mais específicos só seria necessário para } \\
\text { adequar o modelo às necessidades especificas de cada empresa. }\end{array}$ \\
\hline & $\begin{array}{l}\text { QE2: Não, apenas quando existir interesse em elaborar modelos dedicados a sistemas } \\
\text { produtivos específicos, representando suas particularidades. }\end{array}$ \\
\hline & $\begin{array}{l}\text { QE3: Não, requisitos não-funcionais detalham não o que um sistema deve fazer, mas } \\
\text { como ele deve fazer. Estes devem ser considerados nas etapas efetivas de } \\
\text { desenvolvimento dos sistemas. }\end{array}$ \\
\hline & $\begin{array}{l}\text { QE4: O modelo pode ser melhor detalhado para representar premissas existentes no } \\
\text { domínio com as características da Indústria } 4.0 \text {. }\end{array}$ \\
\hline \multirow{2}{*}{$\begin{array}{c}\text { Melhoria } \\
\text { dos Requisitos }\end{array}$} & $\begin{array}{l}\text { QR1: O modelo considera como exigência que existam protocolos responsáveis por } \\
\text { garantir a segurança e privacidade dos dados desenvolvidos no sistema modelado. }\end{array}$ \\
\hline & $\begin{array}{l}\text { QR2: É necessário que as propriedades do modelo sejam revistas por stakeholders de } \\
\text { processos produtivos específicos. }\end{array}$ \\
\hline \multirow{4}{*}{ Projeto } & $\begin{array}{l}\text { QD1: Não, nesta etapa não foi considerado o design específico de um sistema, mas os } \\
\text { interesses nele. }\end{array}$ \\
\hline & $\begin{array}{l}\text { QD2: Não nesta etapa do projeto. Espera-se que durante o desenvolvimento dos } \\
\text { sistemas considerem-se alternativas de projeto que se encaixem melhor nas } \\
\text { expectativas de stakeholders de áreas diferentes. }\end{array}$ \\
\hline & $\begin{array}{l}\text { QD3: Sim, devem-se encontrar processos aceitáveis que possibilitem o } \\
\text { desenvolvimento de sistemas com as características do modelo. }\end{array}$ \\
\hline & $\begin{array}{l}\text { QD4: Nesta fase, tem-se a concepção do sistema. A simulação da operação do sistema } \\
\text { deve ser considerada durante seu desenvolvimento. }\end{array}$ \\
\hline
\end{tabular}

Fonte: Adaptado de Coda et al. (2018).

\subsection{Tipo 3: Empresas onde os dados motivam a estratégia de competitividade}

Há também empresas dedicadas ao desenvolvimento de modelos de negócios inovadores, com foco não no acúmulo de dados, mas no fluxo desses dados (DAVENPORT; BARTH; BEAN, 2012). Empresas deste tipo não estão efetivamente no contexto da I4.0, mas compartilham um interesse mútuo com as entidades que compões o I4.0 porque o fluxo de dados tem informações importantes sobre os desejos do mercado (que inclui não apenas consumidores, mas também fornecedores e concorrentes).

Como exemplo, empresas como Facebook, Netflix, Apple e Google buscam tirar conclusões sobre os padrões e necessidades existentes do mercado observando o fluxo de dados, 
além de identificar oportunidades e desenvolver novos modelos de negócios (MAZZEI; NOBLE, 2017).

Facebook e Netflix são usados neste trabalho porque existem dados disponíveis sobre os pontos de vista de seus stakeholders para sistemas de big data.

O Facebook é uma empresa cuja abordagem de negócios envolve ferramentas e serviços que ampliam a capacidade das pessoas de criar e manter relacionamentos umas com as outras. O foco inicial desta empresa era criar um ecossistema que coleta dados e aumenta constantemente o fluxo desses dados, possibilitando rastrear os perfis dos usuários e a subsequente seleção de anúncios de produtos e tecnologias (MAZZEI; NOBLE, 2017). O core business da Netflix sempre esteve ligado a prever o que as pessoas gostariam de assistir e, além de analisar o histórico dos filmes de seus usuários, a empresa aplica, por exemplo, um algoritmo que também analisa as cores das capas dos filmes assistidos pelo usuário para propor conteúdo relacionado os filmes com capas de cores similares, acreditando que as cores nas capas podem despertar nos usuários o mesmo interesse de filmes já assistidos (SIMON, 2014).

Essas empresas do tipo 3 observam o fluxo de dados de modo estratégico e são capazes de experimentar novos projetos inovadores sem inicialmente considerar benefícios financeiros, além de buscar formas inovadoras de ter uma percepção apurada dos desejos do mercado (Facebook e realidade virtual, navegação Apple e carros etc.).

A Figura 27 apresenta a modelagem obtida dos pontos de vista deste tipo de empresa para o big data.

Respondendo às questões propostas por Horkoff e Yu (2011), o modelo resultante é analisado e a Tabela 4 apresenta as respostas obtidas.

Por meio da comparação do modelo na Figura 27 com o modelo em (ERIDAPUTRA; HENDRADJAYA; DANAR SUNINDYO, 2014), observa-se que o modelo apresentado aqui pode ser melhorado pela inclusão de requisitos detalhando as características que os fluxos de dados devem ter, por exemplo a qualidade, a veracidade, o valor e a segurança esperada nos dados. Neste estudo essas melhorias não foram realizadas pois se entende que os modelos obtidos a partir da metodologia KAOS já estão suficientemente detalhados e abordam os requisitos e expectativas suficientes para a finalidade esperada (i.e. a especificação da arquitetura de aquisição de big data).

Os modelos obtidos (Figuras 25, 26 e 27) contêm as características esperadas pelos stakeholders para os sistemas de big data. Usando o trabalho de Horkoff e Yu (2011), foi possível analisar estes modelos, verificando os modelos KAOS resultantes, e que esses refletem os pontos de vista das partes interessadas. 
Figura 27 - Empresas onde os dados motivam a estratégia competitiva.

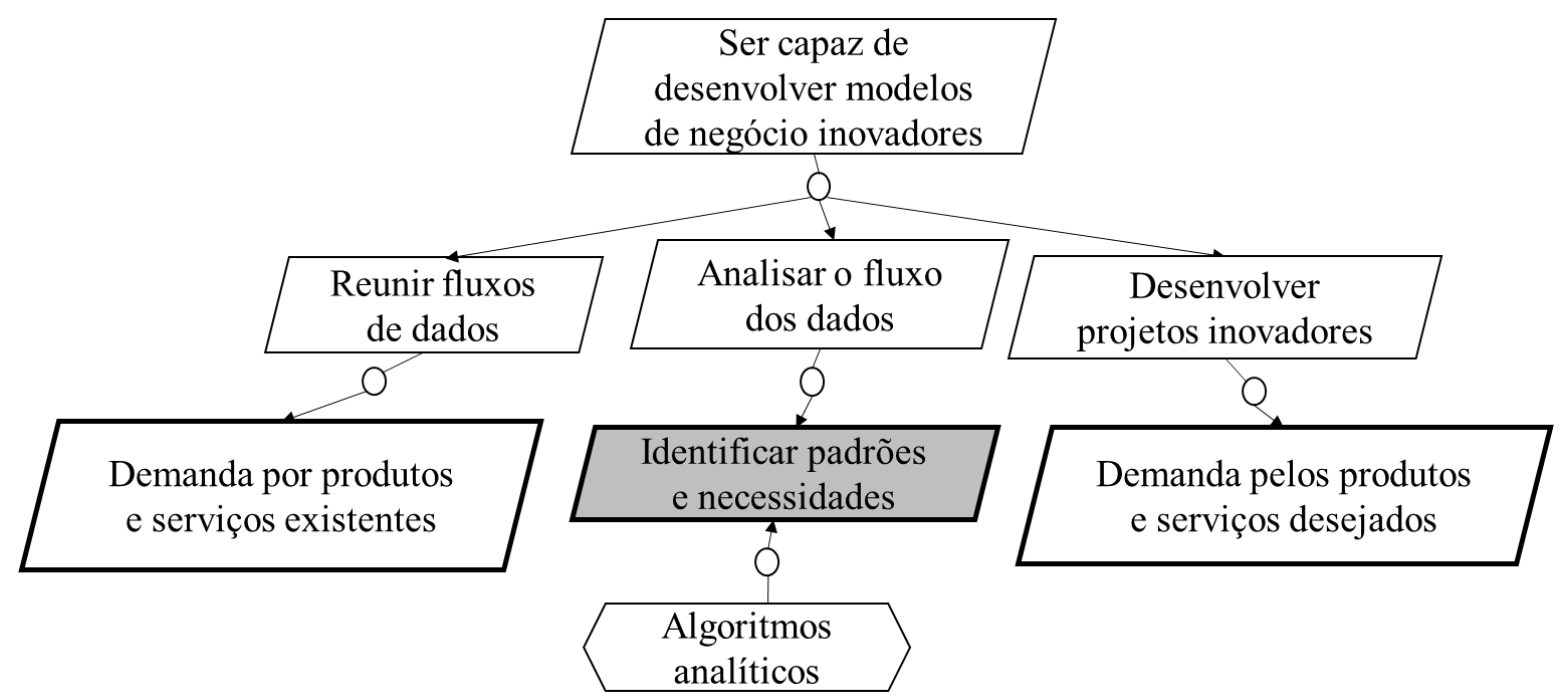

Fonte: Adaptado de Coda et al. (2018).

Tabela 4 - Análise do modelo em KAOS da Figura 27 (tipo 3).

\begin{tabular}{|c|c|}
\hline Categoria & Tipo 3 \\
\hline \multirow{2}{*}{$\begin{array}{l}\text { Compreensão } \\
\text { do domínio }\end{array}$} & $\begin{array}{l}\text { QU1: O modelo oferece uma visão das semelhantes necessidades e expectativas de } \\
\text { stakeholders de múltiplos domínios de atuação, mas não um detalhamento de } \\
\text { particularidades de cada domínio específico. }\end{array}$ \\
\hline & $\begin{array}{l}\text { QU2: Não, a proposta do modelo neste momento é apenas a modelagem das } \\
\text { características e requisitos de stakeholders com interesses semelhantes para sistemas de } \\
\text { big data. }\end{array}$ \\
\hline Com & $\begin{array}{l}\text { QC1: Sim, a comunicação das propriedades do modelo para stakeholders envolvidos é } \\
\text { importante na validação e adequação do modelo. }\end{array}$ \\
\hline \multirow{2}{*}{$\begin{array}{l}\text { Melhoria } \\
\text { do modelo }\end{array}$} & $\begin{array}{l}\text { QM1: A modelagem inclui as semelhanças nos interesses para sistemas de big data em } \\
\text { domínios diferentes. O modelo pode ser detalhado para representar domínios } \\
\text { específicos conforme a necessidade. }\end{array}$ \\
\hline & $\begin{array}{l}\text { QM2: Não, durante esta primeira etapa de concepção das características do sistema, não } \\
\text { é necessária a verificação das propriedades críticas. }\end{array}$ \\
\hline Escopo & $\begin{array}{l}\text { QS1: A modelagem busca encontrar semelhanças em domínios diferentes para sistemas } \\
\text { de big data. Espera-se que um sistema que contenha as características do modelo atenda } \\
\text { diferentes áreas de atuação. O escopo pode ser determinado no detalhamento do modelo } \\
\text { com os interesses específicos de stakeholders de determinada empresa. }\end{array}$ \\
\hline $\begin{array}{c}\text { Elicitação } \\
\text { dos Requisitos }\end{array}$ & $\begin{array}{l}\text { QE1: Não. A modelagem realizada visa encontrar semelhanças nos interesses de } \\
\text { stakeholders, possibilitando o desenvolvimento de sistemas que atendam às exigências } \\
\text { de diversos sistemas produtivos. Requisitos de mais alto nível podem ser usados para } \\
\text { detalhar o modelo com as necessidades de processos produtivos específicos. }\end{array}$ \\
\hline
\end{tabular}




\begin{tabular}{|c|c|}
\hline & $\begin{array}{l}\text { QE2: Não, apenas quando existir interesse em elaborar modelos dedicados a sistemas } \\
\text { produtivos específicos, representando suas particularidades. }\end{array}$ \\
\hline & $\begin{array}{l}\text { QE3: Não, requisitos não-funcionais detalham não o que um sistema deve fazer, mas } \\
\text { como ele deve fazer. Estes devem ser considerados nas etapas efetivas de } \\
\text { desenvolvimento dos sistemas. }\end{array}$ \\
\hline & $\begin{array}{l}\text { QE4: O modelo não contém uma descrição de um domínio específico, mas uma } \\
\text { interseção entre domínios diferentes. }\end{array}$ \\
\hline \multirow{2}{*}{$\begin{array}{c}\text { Melhoria } \\
\text { dos Requisitos }\end{array}$} & $\begin{array}{l}\text { QR1: Nesta etapa da modelagem não foram consideradas essas propriedades. O modelo } \\
\text { deve ser melhor detalhado para as conter conforme as especificações de cada empresa. }\end{array}$ \\
\hline & $\begin{array}{l}\text { QR2: É necessário que as propriedades do modelo sejam revistas por stakeholders de } \\
\text { processos produtivos específicos. }\end{array}$ \\
\hline \multirow{4}{*}{ Projeto } & $\begin{array}{l}\text { QD1: Não, nesta etapa não foi considerado o projeto específico de um sistema, mas os } \\
\text { interesses nele. }\end{array}$ \\
\hline & $\begin{array}{l}\text { QD2: Não nesta etapa do projeto. Espera-se que durante o desenvolvimento dos } \\
\text { sistemas considerem-se alternativas de projeto que melhor se encaixem nas expectativas } \\
\text { de stakeholders de áreas diferentes. }\end{array}$ \\
\hline & $\begin{array}{l}\text { QD3: Sim, devem-se encontrar processos aceitáveis que possibilitem o } \\
\text { desenvolvimento de sistemas com as características do modelo. }\end{array}$ \\
\hline & $\begin{array}{l}\text { QD4: Nesta fase, tem-se a concepção do sistema. A simulação da operação do sistema } \\
\text { deve ser considerada durante seu desenvolvimento. }\end{array}$ \\
\hline
\end{tabular}

Fonte: Adaptado de Coda et al. (2018).

Os resultados obtidos indicam que, se necessário, os modelos podem ser detalhados para incluir as particularidades nos requisitos de uma empresa específica e seu processo produtivo. Esse detalhamento deve ser realizado a partir da percepção de utilidade dos modelos KAOS elaborados aqui por stakeholders dessas empresas.

No presente estudo o foco está em empresas com processos produtivos da área de manufatura que, em geral, caracterizam- se mais como empresas do "Tipo 1" (Figura 25), onde os dados alimentam ferramentas de otimização dos processos industriais. Assim, os requisitos elucidados com base nos pontos de vista de stakeholders do "Tipo 1" são considerados na contextualização do big data na I4.0, e para a elaboração da arquitetura proposta neste trabalho.

\subsection{Síntese do Capítulo}

Este capítulo discutiu os requisitos e desafios do big data sob os pontos de vista dos stakeholders da I4.0. Este é entendido como um primeiro passo essencial para o estudo e 
desenvolvimento de uma especificação de sistema que deve considerar a heterogeneidade das entidades na I4.0.

Nos modelos desenvolvidos, e que também foram publicados em Coda et al. (2018), as empresas foram divididas em três tipos, conforme proposto por Mazzei e Noble (2017), pois se argumenta que o sistema de big data procurado por cada tipo deriva de diferentes perspectivas e deve ter características específicas.

A comparação dos modelos de requisitos para sistemas de big data (Figuras 25, 26 e 27) apresentados neste estudo com os modelos propostos por Eridaputra, Hendradjaya e Sunindyo (2014) mostra que os modelos aqui desenvolvidos são baseados nos pontos de vista de múltiplos stakeholders, e podem ser detalhados com a inclusão das características desejadas por aplicações especificas ou especificando a forma de armazenamento dos dados e procedimentos de segurança.

A avaliação dos requisitos foi realizada com base nas respostas de questões discutidas por Horkoff e Yu (2011) baseadas nas opiniões das partes interessadas e dos usuários finais envolvidos no modelo de negócios específico dentro do contexto da I4.0. Neste caso, mais detalhes podem ser adicionados ao modelo, incorporando novos requisitos ou características procuradas por uma aplicação ou sistema específico aos modelos (Figuras 25, 26 e 27). Entende-se que um processo cíclico deve ser realizado se qualquer ponto não considerado anteriormente for identificado nos modelos resultantes. Uma nova solução deve ser então proposta com uma interpretação corrigida dos requisitos. $\mathrm{O}$ ciclo deve ser executado até que o modelo esteja completamente definido e sem problemas.

Inspirado nos requisitos que refletem os interesses de stakeholders ligados à I4.0, foi concebida e desenvolvida uma arquitetura do processo de aquisição de dados voltado para o big data na I4.0. Essa arquitetura teve suas funcionalidades definidas com base na arquitetura NBDRA e estruturadas com base no RAMI 4.0, visando atender aos requisitos estabelecidos pelos stakeholders associados a empresas do "Tipo 1", uma vez que estes requisitos dizem respeito às atividades necessárias para o processo de aquisição e análise do big data, objeto deste estudo. 


\section{ARQUITETURA PARA A AQUISIÇÃO DE BIG DATA}

A arquitetura do sistema de aquisição de big data proposta aqui foi desenvolvida com base nos conceitos abordados pela NDBRA e pelas arquiteturas que a NDBRA usou como referência. Além disso o RAMI 4.0 é utilizada para assegurar a transição da arquitetura de aquisição de big data proposta para o contexto da I4.0.

Após a apresentação da estrutura geral da arquitetura, o fluxo de dados é detalhado, determinando o procedimento para a coleta, integração, armazenamento e análise dos dados. Este detalhamento também ilustra os comandos a serem enviados de volta aos dispositivos com base na tomada de decisão feita a partir dos dados analisados.

\subsection{Estrutura da arquitetura}

A arquitetura proposta do sistema de aquisição de big data tem como principal característica elucidar e organizar as funcionalidades necessárias em um contexto de sistemas produtivos na I4.0. Para esta finalidade, a arquitetura reúne as funcionalidades dos componentes necessárias para a aquisição de dados organizados conforme as camadas da RAMI 4.0.

Na primeira camada do RAMI 4.0, Ativo técnico, estão os elementos físicos do processo de aquisição de dados (e.g. equipamentos, produtos, pessoas, sensores, atuadores, etc.). Nesta camada tem-se, para um sistema de aquisição de dados, uma referência ao "Fornecedor de dados" discutido na NBDRA, pois nesta camada estão as fontes de dados a serem coletados sobre os ativos a serem monitorados e analisados. Nesta camada estão os sensores responsáveis pela coleta de dados (incluindo os dispositivos de comando que fazer a interface do homem recebe informações/comandos do homem), os dispositivos de controle responsáveis por controlar os processos, e os atuadores responsáveis por exercer alguma ação nos elementos físicos (incluindo os dispositivos de monitoração que fazem a interface para o homem - envia informações/sinais para o homem) (PISCHING, 2018). Cada elemento físico deve possuir meios de comunicação e identificadores únicos, permitindo sua monitoração e supervisão por uma interface de administração integrada (e.g. Adminstration Shell ${ }^{14}$ ) aos dispositivos de controle (ADOLPHS et al., 2015).

${ }^{14}$ O Administration Shell (ADOLPHS et al., 2015) representa uma interface responsável por administrar ativos e recursos. Para Bangemann et al. (2016) o Administration Shell é uma representação virtual de um I4.0C e foi planejado para prover uma representação digital de todas as informações e serviços de um objeto, seja ele hardware ou software (GRANGEL-GONZÁLEZ et al., 2016; PISCHING, 2018). 
$\mathrm{Na}$ segunda camada, Integração, estão as funcionalidades responsáveis pela "virtualização" (i.e., responsáveis por conectar os mundos real e virtual) de todos os ativos da camada inferior (ADOLPHS et al., 2015), que dependem dos dados coletados sobre eles. O conceito de virtualização é abordado nas arquiteturas de referência para o big data utilizadas pelas empresas Oracle, Pivotal, 9Sight e IBM (NBD-PWG, 2015). Nesta camada também associa-se as técnicas de comunicação entre os componentes do sistema (e.g.: Wi-Fi, LTE/5GNR, Bluetooth, etc.) abordadas em Cheng et al. (2018).

Na terceira camada, Comunicação, os dados coletados de todas as fontes são integrados (NBD-PWG, 2015, 2018), filtrados (NBD-PWG, 2018; NEHREY; HNOT, 2019) e limpos, removendo-se outliers e se corrigindo typos (ELITEDATASCIENCE, 2019; NBD-PWG, 2015, 2018) para remover os dados redundantes ou irrelevantes. Nesta camada também estão os protocolos de comunicação usados pelo sistema como "AMQP (Advanced Message Queuing Protocol)" (CHENG et al., 2018; KOMINEK, 2017), "MQTT (Message Queuing Telemetry Transport)" (KOMINEK, 2017) ou OPC-UA (OPC Unified Architecture) (ADOLPHS et al., 2015; KOMINEK, 2017).

Na quarta camada, Informação, os dados são armazenados em uma solução de arquivamento compatível com as necessidades da aplicação (e.g.: NoSQL, HDSF, NewSQL, etc.) abordadas em (STROHBACH et al., 2016) e na NBDRA na forma do "Fornecedor da estrutura de big data". Ainda nesta camada, os dados são analisados e visualizados conforme discutido na NBDRA, seguidos pelo processo de tomada de decisão abordados como o "Fornecedor das aplicações" na NBDRA.

Na quinta camada, Funcional, estão as interfaces para a integração horizontal e a descrição de todas as funcionalidades conforme descrito em (ADOLPHS et al., 2015). Essa camada também é responsável por gerar as regras a serem seguidas e a lógica da tomada de decisão, referenciando o "Consumidor dos dados" na NBDRA.

Na sexta e última camada, Regra de Negócio, estão os conceitos abordados na NBDRA no componente "Orquestrador do sistema". Nesta camada estão as regras a serem seguidas para garantir que as funções sejam executadas mantendo a integridade de todos os ativos. Essa camada é responsável pela orquestração dos serviços na camada Funcional.

A Figura 28 apresenta a estrutura da arquitetura aqui proposta para a aquisição de big data. 
Figura 28 - Estrutura da arquitetura sobre o eixo Camadas do RAMI 4.0.

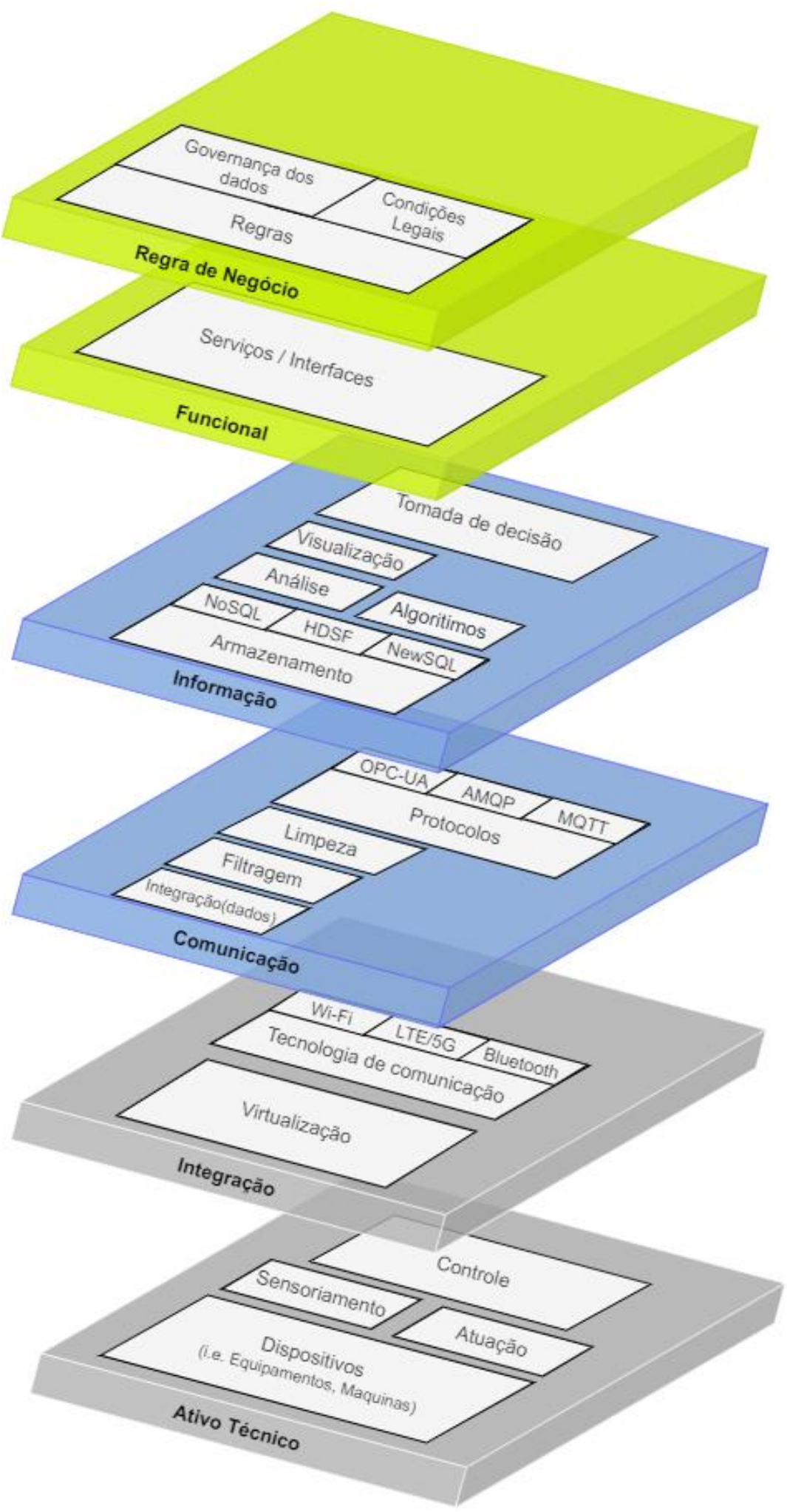

Fonte: autor. 


\subsection{Interação entre os componentes da arquitetura}

Nesta seção o fluxo dos dados e o retorno dos comandos aos dispositivos no nível de "ativos técnicos" é detalhado, mostrando a interatividade entre os componentes da arquitetura, e que facilitam a visualização do processo de aquisição de big data na I4.0.

A sincronização de um DAQ em relação a um evento externo é um critério importante em muitas das suas aplicações. Por exemplo, a coleta de dados pode ter início após o recebimento de um pulso de um codificador quando a temperatura em algum ponto da máquina ou processo exceder um valor crítico. Nesses casos o DAQ deve ser configurado para iniciar o procedimento de aquisição de dados assim que um evento externo ocorre (trigger) (NATIONAL INSTRUMENTS, 2019). Analogamente, no contexto de um sistema de manufatura industrial, o evento que inicia a coleta de dados pode ser o início de uma operação de usinagem, transporte, movimentação, montagem, etc.

A Figura 29 ilustra o processo de aquisição de dados pela interação dos componentes da arquitetura proposta (Figura 28) com o início na ocorrência de um evento onde os fluxos de informações na Figura 29 correspondem à:

- Fluxo 1 - Um sensor monitora a variável física, coletando dados sobre a sua operação;

- Fluxo 2 - Os dados são enviados ao dispositivo de controle do processo que pode intervir no processo caso alguma condição crítica tenha sido alcançada;

- Fluxo 3 - O dispositivo de controle envia os dados do processo físico para que seja feita a "ponte" entre o seu processo físico e o modelo virtual;

- Fluxo 4 - Os dados são encaminhados para a associação com a tecnologia de comunicação;

- Fluxo 5 - Todos os dados monitorados pelos diversos sensores são encaminhados para que eles sejam integrados, reunindo medições de todos os sensores;

- Fluxo 6 - O dataset formado após a integração dos dados é encaminhado para filtragem, depurando as medições que possam ter sido realizadas em duplicidade por dispositivos diferentes ou medições irrelevantes;

- Fluxo 7 - O dataset é limpo, corrigindo erros estruturais (e.g.: typos), removendo-se outliers e rotulando lacunas no conjunto de dados;

- Fluxo 8 - O dataset é encaminhado para a associação com os protocolos de comunicação; 
- Fluxo 9-O dataset é enviado para a solução de armazenamento adequada para as suas dimensões (i.e., volume, velocidade, variedade, veracidade e valor);

- Fluxo 10 - O dataset é disposto para o processo de análise;

- Fluxo 11 - As funcionalidades (e.g.: software, algoritmos) a serem utilizadas para analisar os dados são enviados para que a análise ocorra in situ;

- Fluxo 12 - São utilizadas técnicas adequadas para a visualização dos resultados alcançados pelos métodos de análise;

- Fluxo 13 - Os resultados visualizados são dispostos para que sejam tomadas as decisões em relação ao processo físico;

- Fluxo a - São consultados os serviços e interfaces disponíveis;

- Fluxo b - São consultadas as regras de atuação;

- Fluxo 14 - Com base na análise dos dados, a tomada de decisão gera comandos a serem enviados de volta aos dispositivos. Este fluxo ilustra o envio desses comandos para a solução de armazenagem, uma vez que os comandos enviados também são fontes de dados de interesse para análise e devem ser arquivados;

- Fluxo 15 -São definidos os protocolos de comunicação para os comandos;

- Fluxo 16 - São definidas as tecnologias de comunicação para os comandos;

- Fluxo 17 - Os comandos são enviados ao modelo virtual do dispositivo monitorado;

- Fluxo 18 - Os comandos são enviados ao dispositivo de controle;

- Fluxo 19 - O dispositivo de controle coordena o funcionamento dos atuadores segundo as instruções contidas nos comandos recebidos;

- Fluxo 20 - Os atuadores intervêm, isto é, afetam o estado do sistema/processo de onde os dispositivos coletaram os dados iniciais.

Ainda sobre a arquitetura apresentada nas Figuras 28 e 29 entende-se que a estrutura do processo de aquisição de big data está em conformidade com os requisitos elucidados utilizando a metodologia KAOS com base em empresas do Tipo 1 (i.e., indústrias de fabricação comprometidas em coletar dados relevantes) no capítulo anterior. Nesse contexto, a arquitetura proposta visa orientar as atividades do processo de coleta de dados industriais na I4.0 de uma maneira que possibilite a análise de big data e, consequentemente, a otimização e monitoramento dos processos produtivos atendendo aos principais requisitos das empresas deste tipo. 
Figura 29 - Detalhamento do fluxo de dados.
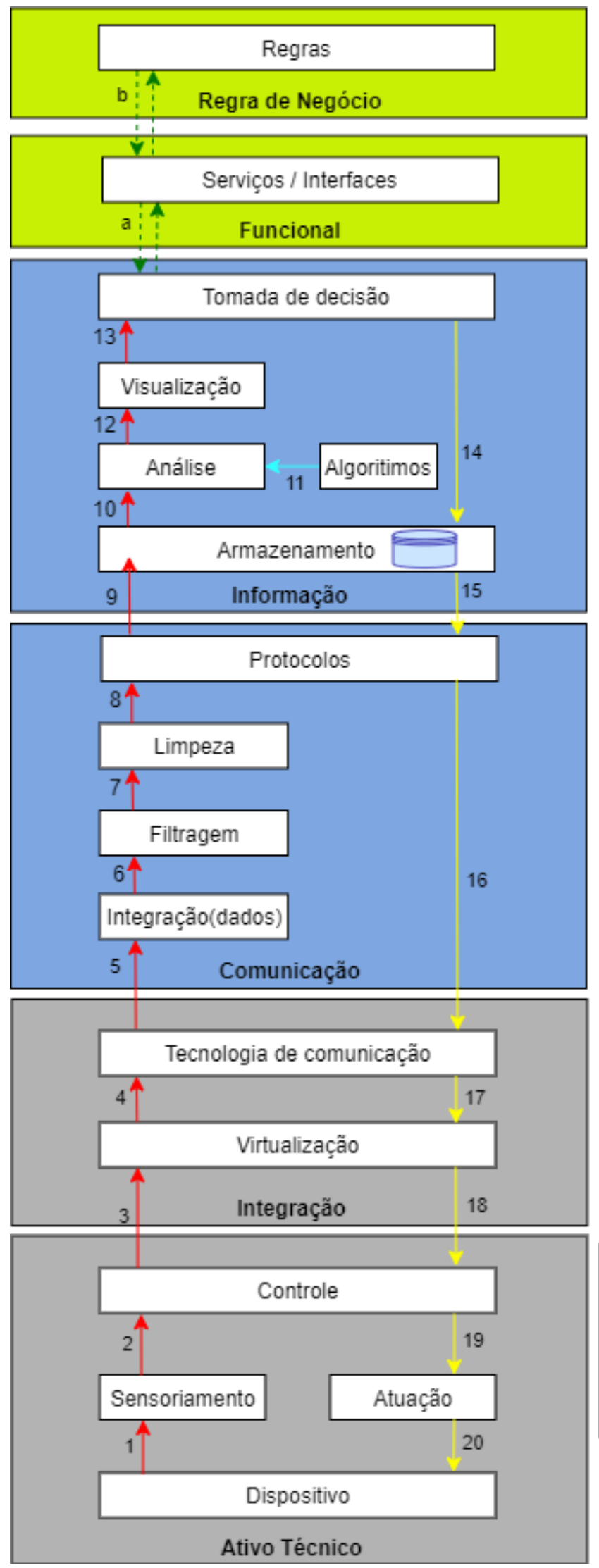

Algoritimos -....Acesso Comandos Dados

Fonte: autor. 


\subsection{Síntese do Capítulo}

A arquitetura aqui proposta segue a estrutura do RAMI 4.0, com o objetivo de manter a conformidade nos sistemas associados a I4.0. Além do RAMI 4.0, a arquitetura também considera os conceitos discutidos em outras iniciativas para lidar com big data, incluindo a NBDRA e arquiteturas utilizadas por empresas conceituadas na área de ciência dos dados e soluções de ICT. A arquitetura proposta aqui é baseada em soluções discutidas tanto nos meios acadêmicos quanto empresariais onde se assegura que a estrutura e a interatividade entre os componentes propostos são funcionais.

Neste estudo, não foram levadas em consideração tecnologias restritas a um tipo de empresa ou solução específica. O objetivo desta abordagem foi conceber uma arquitetura que seja ampla e capaz de ser aplicada na maior quantidade de sistemas existentes possíveis.

No contexto da I4.0 observa-se que muitos dos seus aspectos ainda são expectativas, incluindo o RAMI 4.0, que é um trabalho em progresso. Nesse aspecto, na medida que o RAMI 4.0 é progressivamente detalhado, a arquitetura aqui proposta também deve ser revisada e/ou detalhada.

Destaca-se que, com a arquitetura proposta, é possível confrontar sistemas de aquisição de dados existentes, mapeando suas funcionalidades. Esta prática contribui para elucidar (nos sistemas existentes) as oportunidades de modernização e implementação, além da sua adequação aos paradigmas da I4.0.

A arquitetura e seus componentes apresentados nesta seção foram verificados e validados por meio de modelos desenvolvidos com a técnica PFS/RdP. Considerando que a arquitetura considera processos característicos de SED, a técnica formal PFS/RdP é adotada para a especificação do sistema por meio da sua modelagem conceitual e funcional e que será apresentada no próximo capítulo. 


\section{MODELAGEM E ANÁLISE DO PROCESSO DE AQUISIÇÃO DE BIG}

\section{DATA}

Neste capitulo é apresentada a modelagem do processo de aquisição de big data conforme a arquitetura proposta no capitulo anterior. A modelagem foi realizada utilizando a técnica PFS/RdP dividida nas próximas seções entre: (1) o detalhamento progressivo do processo de aquisição de big data em PFS na I4.0; (2) o modelo RdP derivado do PFS, (3) a análise das propriedades da $\mathrm{RdP}$ e (4) a discussão dos resultados.

\subsection{Modelagem Conceitual do Processo de Aquisição de Big Data}

Segundo Liu e Jiang (2016), o processo de aquisição de dados industriais pode ter duas fontes: dados coletados em tempo real de dispositivos de campo (ou seja, dispositivos de detecção e máquinas no chão-de-fábrica); ou dados históricos do sistema coletados dos sistemas de controle e supervisão da produção (por exemplo: ERP, MRP) ${ }^{15}$.

Os dados coletados em tempo real pelos dispositivos de detecção são usados no controle de máquinas e supervisão de processos, tornando estes subsistemas auto adaptativos e autoconscientes. Além disso, na prática, a otimização de processos tem como base as técnicas de análise de dados em tempo real em conjunto com dados históricos de sistemas de controle e supervisão. A Figura 30 apresenta o modelo resultante desta forma de interpretar o processo de uso de dados em processos industriais.

Lyko, Nitzschke e NgongaNgomo (2016) detalham o processo de aquisição de dados em tempo real. Os autores afirmam que a aquisição de dados consiste no processo de coletar, filtrar e limpar os dados antes de encaminhá-los para um data warehouse ou qualquer outra solução de armazenamento.

A Figura 31 ilustra o detalhamento do processo de aquisição de dados em tempo real.

De acordo com os manuais de empresas como a Omega Engineering INC (2000) e a Measurement Computing Corporation (2012), a coleta de dados dos ativos envolve o uso de transdutores de variáveis físicas. Uma variável física é percebida e convertida em um sinal elétrico analógico que requer amplificação, condicionamento e remoção de ruído. Finalmente, o sinal pode ser convertido de analógico para digital (isto é, tem-se a discretização do sinal

15 A discussão das propriedades e a modelagem dos sistemas ERP e MRP não são foco deste trabalho, assim, estes sistemas serão apenas discutidos brevemente 
contínuo medido para um valor dentro de uma escala discreta). Esta etapa permite que o sinal seja armazenado e exibido em computadores para aplicar os algoritmos de análise.

Figura 30 - Uso de dados industriais.

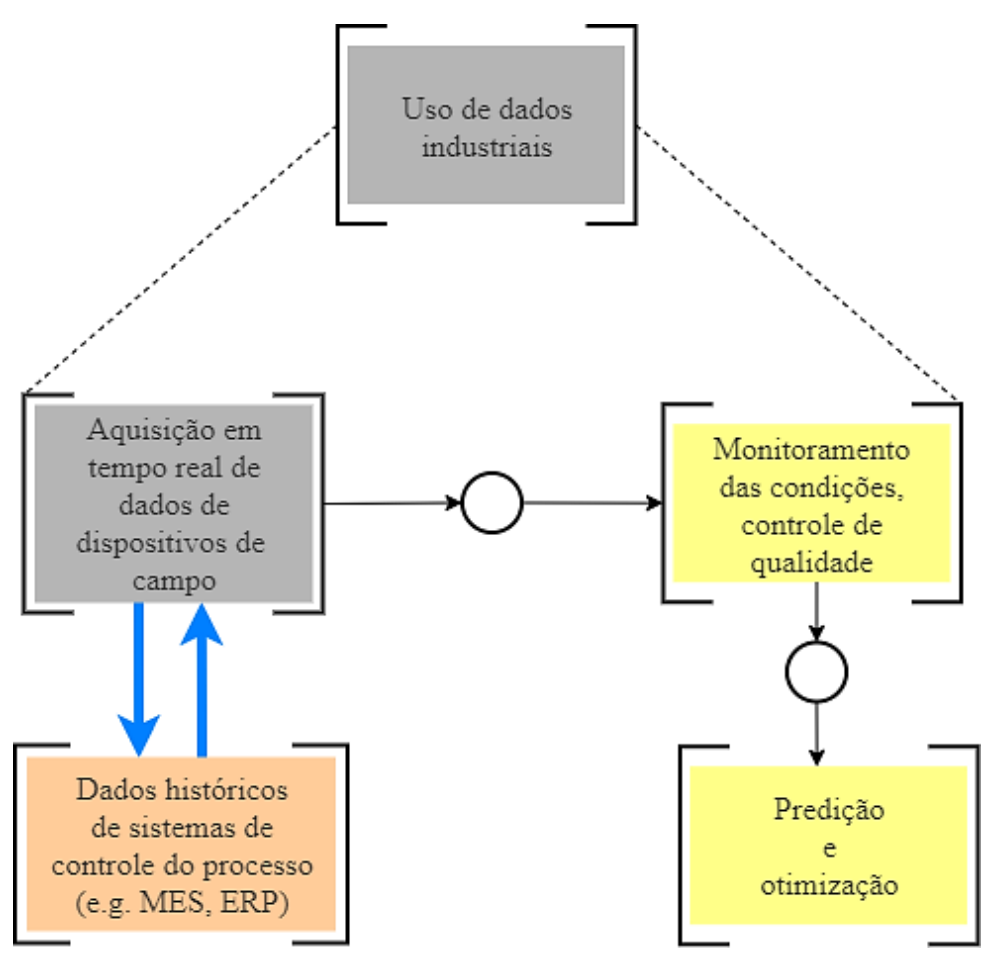

Fonte: autor.

Figura 31 - Detalhamento da aquisição de dados em tempo real.

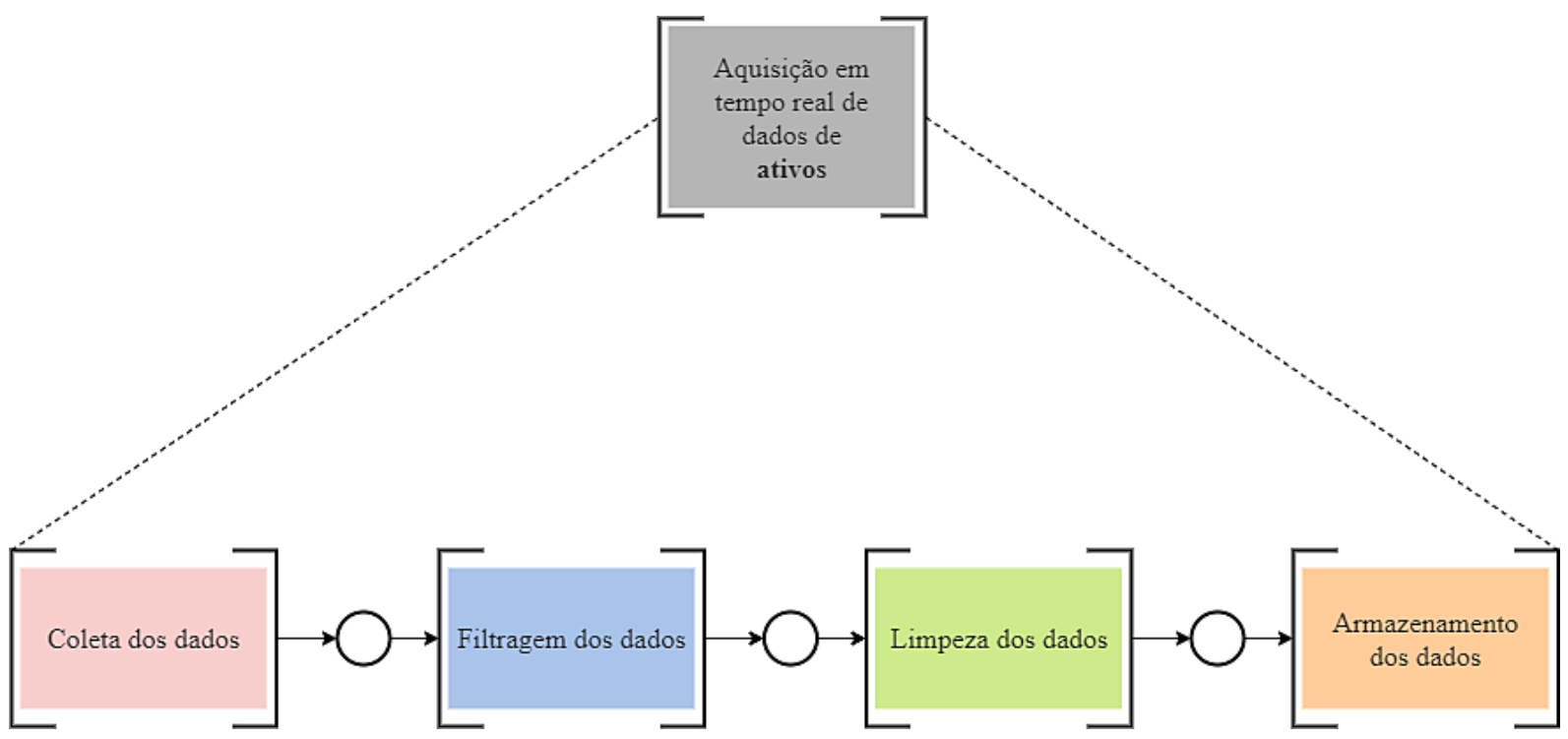

Fonte: autor. 
A Figura 32 apresenta o modelo gerado do processo de coleta de dados.

Figura 32 - Coleta de dados.

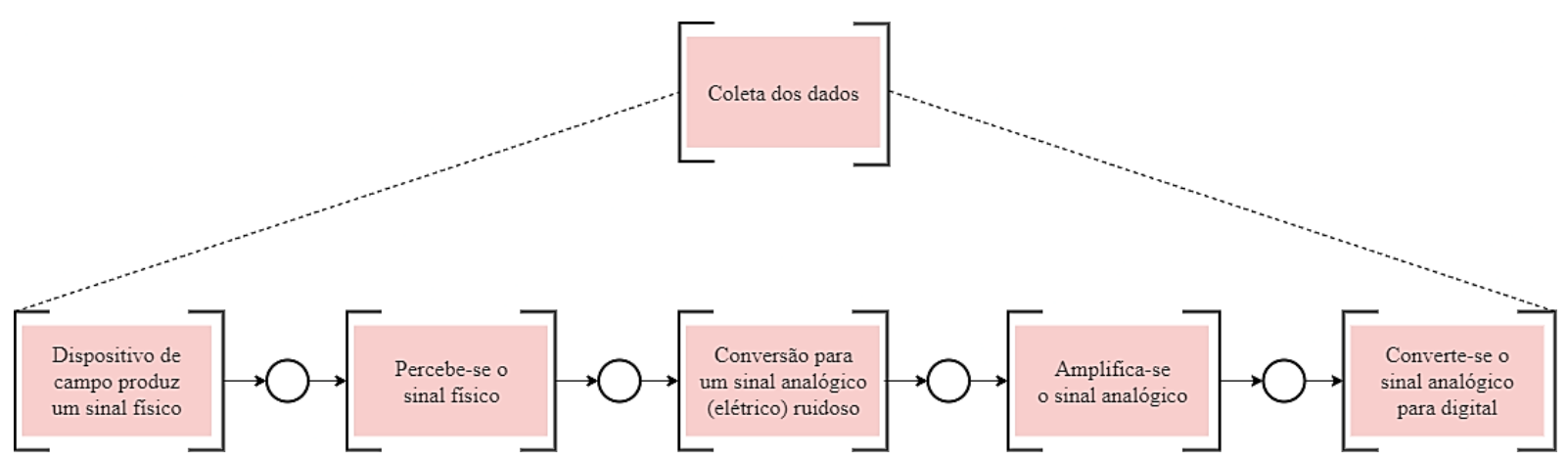

Fonte: autor.

Nehrey e Hnot (2019) descrevem o processo de filtragem de dados como a utilização de estratégias para refinar conjuntos de dados. Após a coleta de todos os dados, nesta etapa eles são integrados e depurados de modo que se identifique apenas os que são, de fato, necessários, isto é, excluindo os dados repetidos, redundantes e irrelevantes além de separar os considerados confidenciais, rotulando-os com regras de acesso. A Figura 33 apresenta o modelo do processo de filtragem de dados.

Figura 33 - Filtragem dos dados.

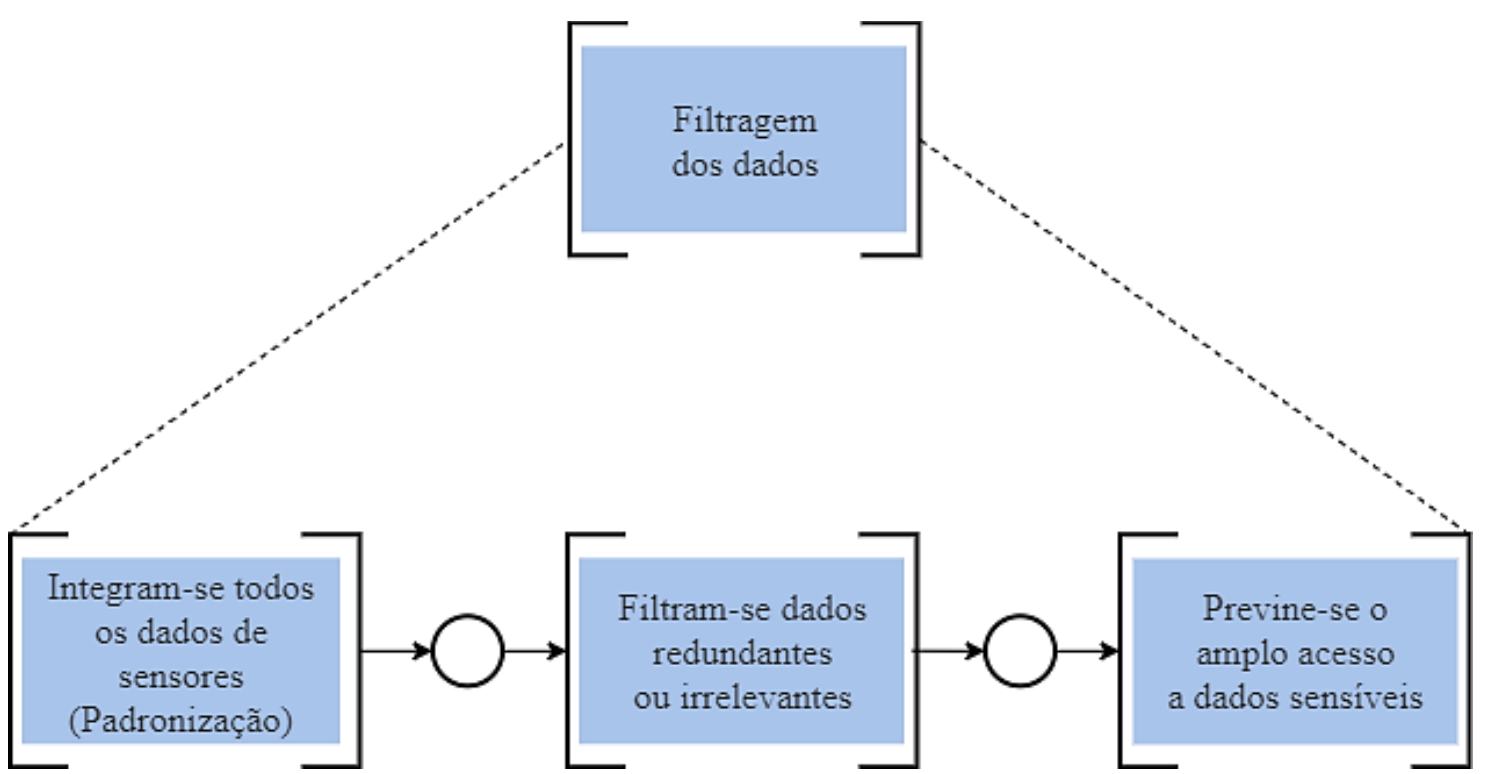

Fonte: autor. 
A limpeza é também um passo crucial na preparação dos dados a serem analisados. Um conjunto de dados confiável tem um valor maior que o algoritmo empregado em sua análise. Práticas para limpeza de dados envolvem (ELITEDATASCIENCE, 2019):

- Corrigir erros de digitação ou formatação (e.g. "N/A" e "não aplicável" podem indicar classes diferentes de dados);

- Filtrar "outliers" removendo os dados considerados como uma medida suspeita e que não reflete os dados reais;

- Rotular "lacunas" no conjunto de dados, referenciando dados que estão faltando.

A Figura 34 apresenta a modelagem do processo de limpeza de dados.

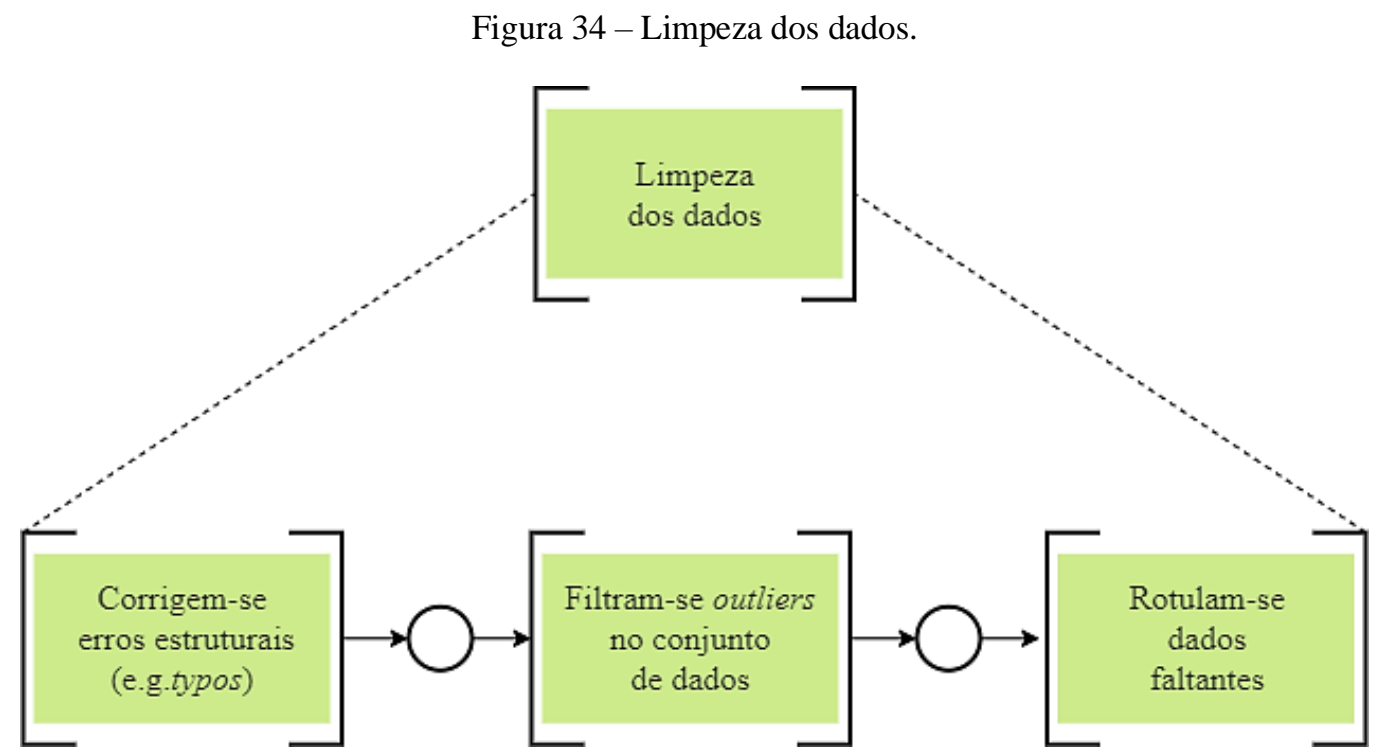

Fonte: autor.

Uma "solução de armazenamento" de big data diz respeito ao armazenamento e ao gerenciamento dos dados em uma forma escalável, satisfazendo as necessidades das aplicações que requerem acesso a esses dados. O sistema ideal de armazenagem de big data deve: (i) permitir o armazenamento de uma quantidade muito grande de dados; (ii) suportar taxas altas e aleatórias de acesso para gravação e leitura; (iii) tratar de forma flexível e eficiente uma grande variedade de tipos de dados; (iv) ter suporte tanto para dados estruturados como para os não estruturados; e (v) por questões de privacidade, trabalhar com dados encriptados (STROHBACH et al., 2016).

A Figura 35 ilustra como o processo de armazenamento de dados compreende a utilização de uma ou mais soluções de armazenamento, conforme as necessidades da aplicação. 
Figura 35 - Armazenamento de dados.

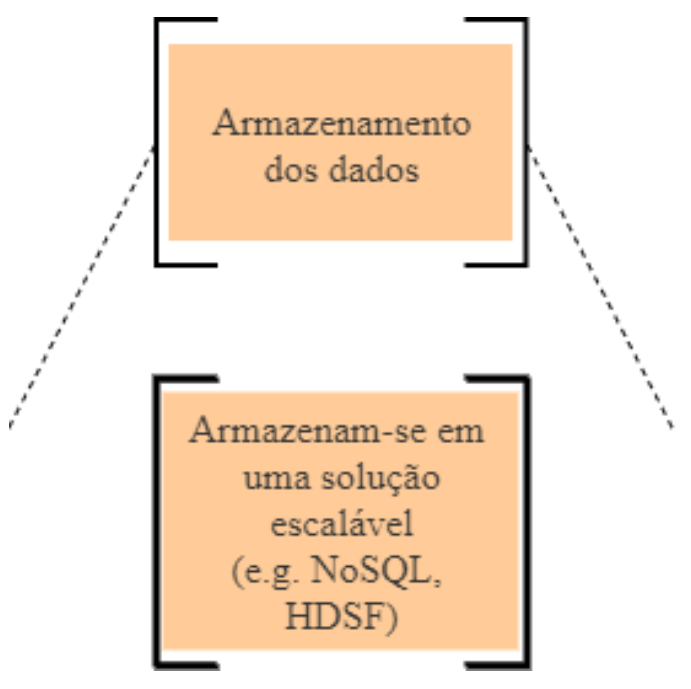

Fonte: autor.

Liu e Jiang (2016) afirmam que os dados históricos sobre equipamentos ou processos relevantes são extraídos de sistemas de controle e supervisão corporativos (ERP, MRP, etc.). Estes sistemas interagem com as soluções de armazenamento utilizadas pela empresa, reunindo vários conjuntos de dados históricos sobre os processos produtivos que podem ser analisados para aplicações de predição e otimização da produção. A Figura 36 mostra a interação entre a solução de armazenamento e os sistemas de controle e supervisão corporativos.

Figura 36 - Interação entre sistemas de controle e supervisão corporativos e a "solução de armazenamento" de dados.

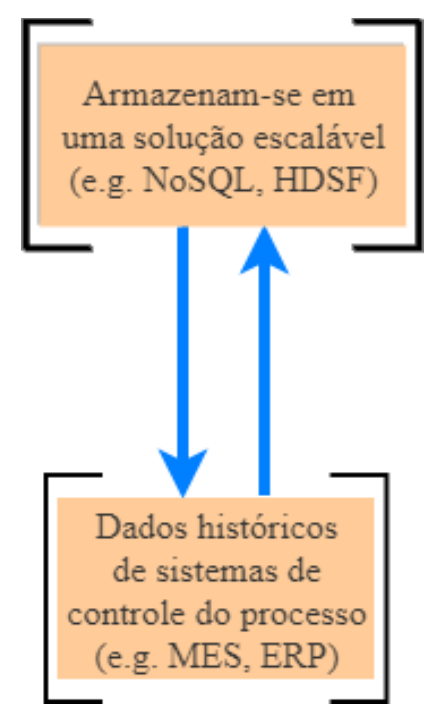

Fonte: autor. 
Van Der Veen, Van Der Waaij e Meijer (2012) argumentam que o formato de um banco de dados ideal para armazenar dados dos dispositivos de detecção seria um banco de dados com "bom" desempenho para gravações singulares (ou seja, onde cada dispositivo de detecção poderia solicitar individualmente uma permissão para gravar dados na base), e múltiplas leituras (ou seja, cada sistema de análise de dados teria permissão para realizar múltiplos acessos para ler o banco de dados).

A Figura 37 apresenta o modelo em PFS do processo geral de aquisição de big data.

Nesse contexto, é possível associar o modelo em PFS do processo de aquisição de big data à I4.0, mapeando as etapas do processo nas camadas do RAMI 4.0. Interpreta-se aqui que um sistema de aquisição de dados na I4.0 está refletido em todas as camadas do RAMI 4.0:

- Regra de negócio: são consultadas as regras de operação dos dispositivos;

- Funcional: são consultados os serviços e interfaces disponíveis para a realização das operações, orientando a lógica da tomada de decisão;

- Informação: os dados são armazenados em uma solução compatível com as necessidades, analisados e visualizados, extraindo deles as informações desejadas e necessárias para a tomada de decisão em relação a operação dos dispositivos;

- Comunicação: os dados são convertidos de sinais analógicos para digitais, integrados, filtrados, e limpos, garantindo sua integridade e os preparando para serem armazenados nos bancos de dados. Nesta camada também são associados os protocolos de comunicação (e.g. OPC-UA);

- Integração: os dados coletados sobre os dispositivos são usados para os virtualizar (i.e., relacionando o processo físico real ao seu modelo virtual) e são definidas as tecnologias de comunicação necessárias para sua integração com outras entidades reis e virtuais;

- Ativo técnico: a operação dos ativos produz sinais físicos capazes de serem sensoriados, convertendo esses sinais físicos em sinais elétricos que por sua vez podem ser mensurados e analisados.

Assim, a Figura 37 apresenta a modelagem do processo de aquisição de dados voltado para as funcionalidades exigidas no processo de aquisição e análise de big data da forma como ele é descrito pela literatura correlata e a Figura 38 ilustra a transição desse processo para o contexto da I4.0 via RAMI 4.0.

A Figura 38 ilustra o processo de aquisição de dados associado ao RAMI 4.0. 


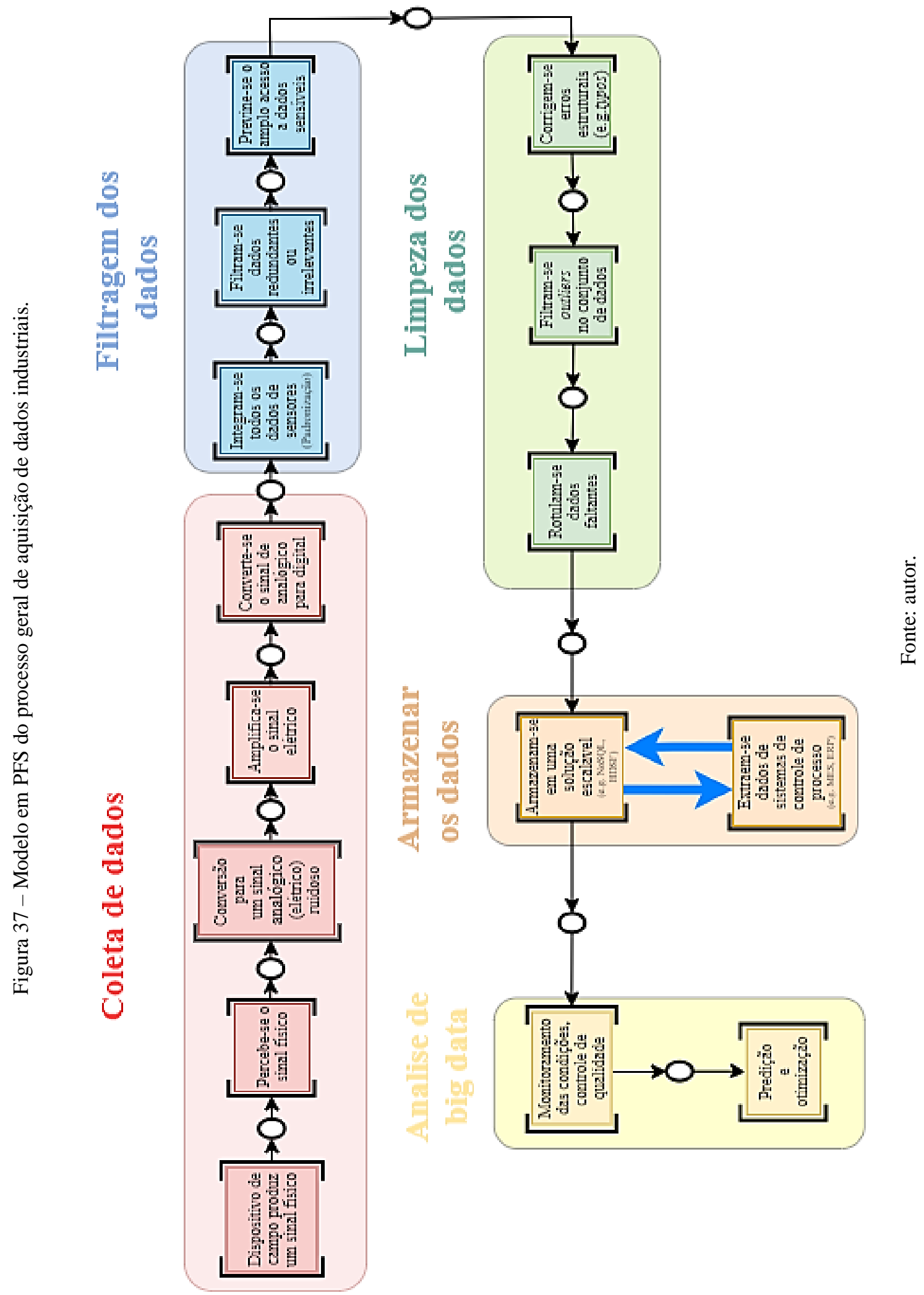




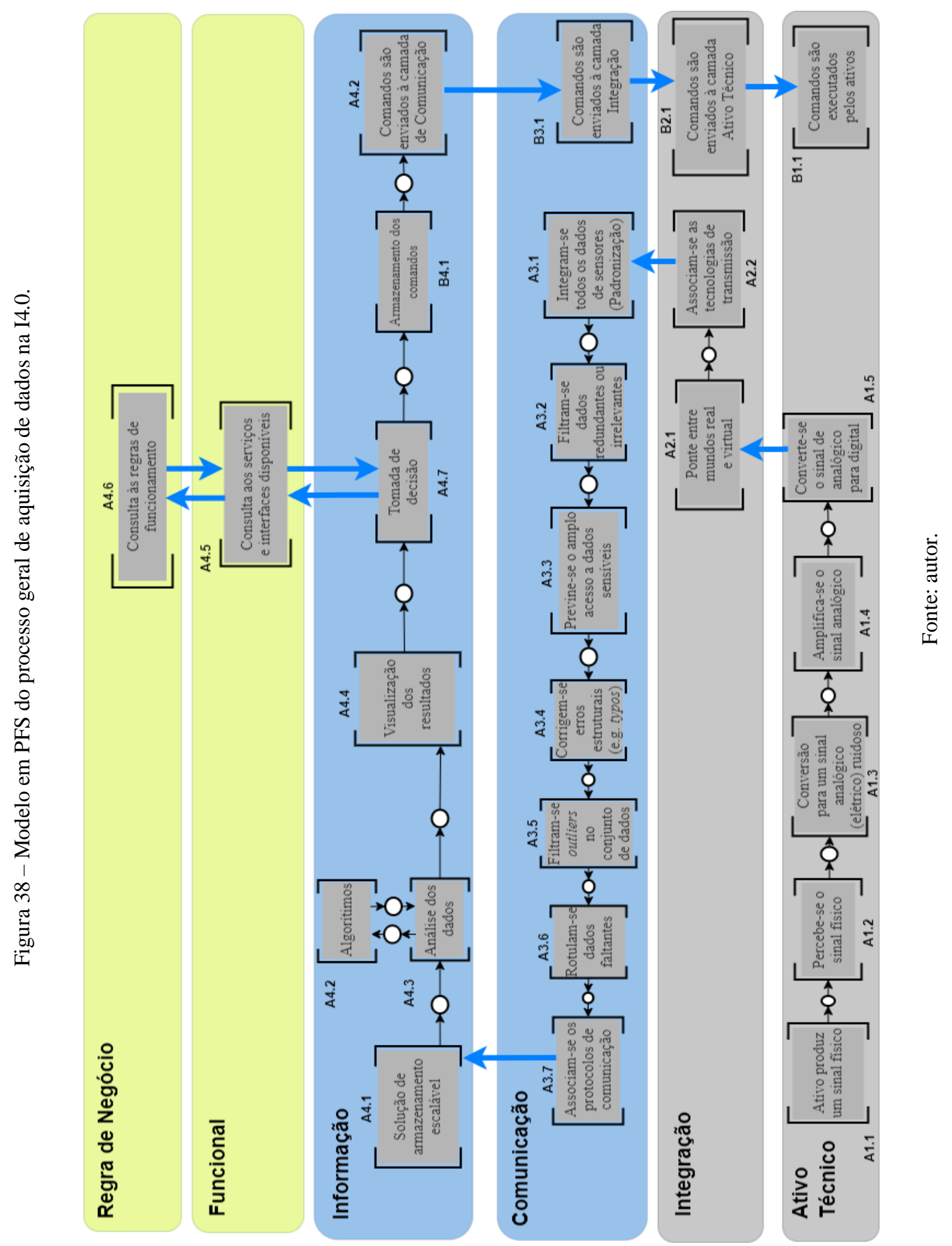




\subsection{Modelagem Funcional da Arquitetura Proposta}

A partir dos modelos em PFS e em nível conceitual do processo de aquisição de big data derivam-se modelos funcionais em $\mathrm{RdP}$ desse processo no contexto da arquitetura proposta no Capítulo 4. Os modelos em RdP são utilizados na validação do processo modelado, garantindo que este se comporta como previsto, isto é, determinando se a arquitetura proposta atende e opera segundo as condições impostas. A modelagem apresentada aqui foi elaborada e os processos foram analisados via técnica de simulação utilizando a ferramenta PIPE ${ }^{16}$ (Platform

\section{Independent Petri net Editor)}

Pisching (2018) cita alguns dos aspectos que podem ser verificados de uma arquitetura de sistemas a partir da simulação do seu modelo em RdP, como deadlocks ${ }^{17}$, ou o seu comportamento dinâmico, assegurando que as funcionalidades do sistema foram projetadas corretamente.

O modelo em RdP do processo elaborado a partir do detalhamento da arquitetura (Figura 29) e do modelo em PFS (Figura 39) é apresentado progressivamente a seguir.

Na camada "Ativo Técnico" do RAMI 4.0 são representadas as funcionalidades de sensoriamento das variáveis físicas produzidas pelo dispositivo de campo - atividades de [A1.1] a [A1.4] no PFS, retratadas na Figura 33 na seção 5.1. A Figura 39 ilustra o modelo em RdP da coleta de dados, enquanto a Tabela 5 identifica os elementos do modelo e as referências consideradas na sua elaboração.

Figura 39 - Modelo em RdP da coleta de dados na camada "Ativo Técnico".

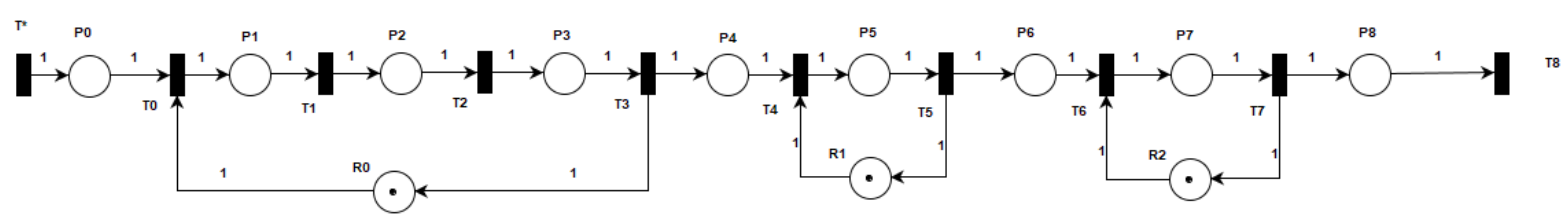

Fonte: autor.

\footnotetext{
${ }^{16} \mathrm{http}: / /$ pipe.sourceforge.net/

${ }^{17}$ Um deadlock ocorre quando um processo entra em espera permanente (i.e., incapaz de mudar seu estado indefinidamente), pois os recursos exigidos por ele estão sendo utilizados por outro processo também em espera permanentemente (SILBERSCHATZ; GALVIN; GAGNE, 2006). Ezpeleta, Colom e Martinez (1995) definem um deadlock como um impasse do sistema, onde seus processos nunca podem ser finalizados.
} 
Tabela 5 - Legenda do modelo na Figura 39.

\begin{tabular}{|c|c|c|c|c|}
\hline Lugares & Significado & Transições & Função & Referências \\
\hline $\mathrm{P} 0$ & Variável física produzida & $\mathrm{T}^{*}$ & Transição inicial & \multirow{12}{*}{$\begin{array}{c}\text { (PISCHING, 2017) } \\
\text { (NBD-PWG, 2017) } \\
\text { (OMEGA ENGINEERING, 2000) } \\
\text { (M. C. CORPORATION, 2012) }\end{array}$} \\
\hline $\mathrm{P} 1$ & Sinal fisíco percebido & T0 & Processamento da variável física & \\
\hline $\mathrm{P} 2$ & Sinal analógico & $\mathrm{T} 1$ & Conversão para sinal analógico & \\
\hline P3 & Sinal analógico amplificado & $\mathrm{T} 2$ & Amplificação do sinal analógico & \\
\hline P4 & Sinal analógico aguarda conversão para digital & $\mathrm{T} 3$ & Sensor liberado & \\
\hline $\mathrm{P} 5$ & Processo de conversão do sinal analógico & $\mathrm{T} 4$ & Conversão para sinal digital & \\
\hline P6 & Fim do sensoriamento & T5 & $\begin{array}{l}\text { Recurso para conversão de sinal digital } \\
\text { liberado }\end{array}$ & \\
\hline P7 & Disp. Controle recebe os dados & T6 & Dados transmitidos ao Disp. Controle & \\
\hline $\mathrm{P} 8$ & Dados aguardam acesso para virtualização & $\mathrm{T} 7$ & Disp. Controle liberado & \\
\hline R0 & Sensor disponível & $\mathrm{T} 8$ & Acesso Ativo/Integração & \\
\hline R1 & Recurso para conversão de sinal digital & & & \\
\hline $\mathrm{R} 2$ & Disp. Controle disponível & & & \\
\hline
\end{tabular}

Fonte: autor.

Na camada "Integração" do RAMI 4.0 o modelo em RdP reflete as funcionalidades necessárias para a "ponte" entre os modelos virtual e real dos sistemas físicos e o processo de associação da tecnologia de comunicação (ADOLPHS et al., 2015; CHENG et al., 2018; PISCHING, 2018) - atividades [A2.1] e de [A2.2] no PFS. A Figura 41 apresenta o modelo em RdP das funcionalidades na camada "Integração", enquanto a Tabela 6 identifica os elementos do modelo e as referências consideradas na sua elaboração.

Figura 40 - Modelo em RdP da virtualização dos ativos na camada "Integração".

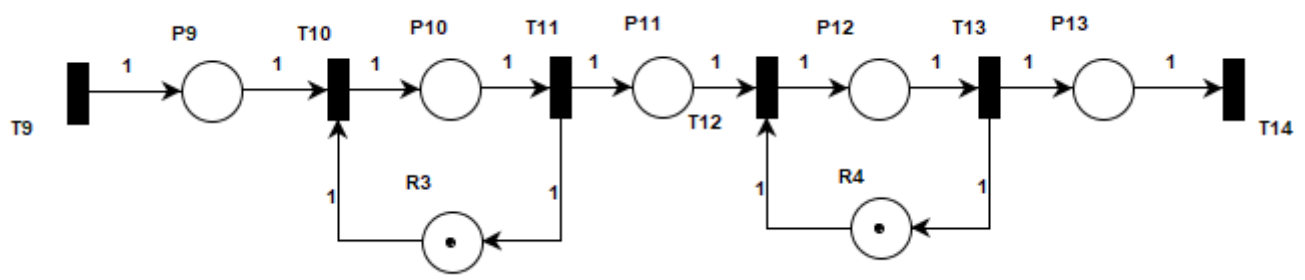

Fonte: autor.

Na camada "Comunicação" do RAMI 4.0 estão as funcionalidades ligadas à integração, filtragem, limpeza e a associação dos protocolos de comunicação aos dados (ADOLPHS et al., 2015; CHEN; LI; WANG, 2015; NBD-PWG, 2018; NEHREY; HNOT, 2019) - atividades [A3.1] e de [A3.8] no PFS, retratadas nas Figura 33, 41 e 42 na secção 5.1. A Figura 41 apresenta o modelo em RdP das funcionalidades na camada "Comunicação", enquanto a Tabela 7 identifica os elementos do modelo e as referências consideradas na sua elaboração. 
Tabela 6 - Legenda do modelo na Figura 40.

\begin{tabular}{|l|l|l|l|l|}
\hline Lugares & Significado & Transições & Função & Referências \\
\hline P9 & Dados acessados na camada Integração & T9 & Acesso Integração/Ativo & \\
\hline P10 & Processo de formação do modelo virtual & T10 & Formação do modelo virtual & (PISCHING, 2017) \\
\hline P11 & Modelo virtual & T11 & Recurso para virtualização liberado & (ADOLPHS et al., 2015) \\
P12 & $\begin{array}{l}\text { Dados aguardam associação da tecnologia de } \\
\text { comunicação }\end{array}$ & T12 & Associação da tecnologia de comunicação & (KOMENG et al., 2018) \\
P13 & $\begin{array}{l}\text { Dados com tecnologia de comunicação } \\
\text { associada }\end{array}$ & T13 & $\begin{array}{l}\text { Recurso para associação da tecnologia de } \\
\text { comunicação liberado }\end{array}$ & \\
\hline R3 & Recurso de virtualização & T14 & Acesso Integração/Comunicação & \\
\hline R4 & Recurso para associação do protocolo & & & \\
\hline
\end{tabular}

Fonte: autor.

Figura 41 - Modelo em RdP da transferência dos dados na camada "Comunicação".

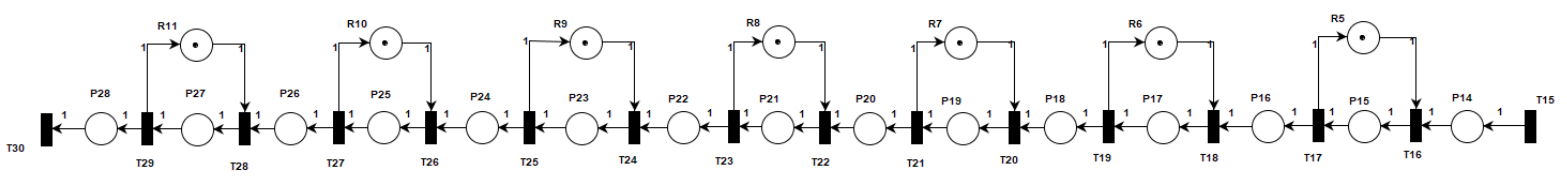

Fonte: autor.

Tabela 7 - Legenda do modelo na Figura 41.

\begin{tabular}{|c|c|c|c|c|}
\hline Lugares & Significado & Transições & Função & Referências \\
\hline P14 & Dados acessados na camada Comunicação & $\mathrm{T} 15$ & Acesso Comunicação/Integração & \multirow{22}{*}{$\begin{array}{c}\text { (CHEN, LI, WANG, 2015) } \\
\text { (NBD-PWG, 2015) } \\
\text { (NBD-PWG, 2017) } \\
\text { (NEHREY, HNOT, 2019) } \\
\text { (ADOLPHS et al., 2015) } \\
\text { (ELITEDATASCIENCE, 2019) }\end{array}$} \\
\hline P15 & Processo de integração dos dados & T16 & Integração dos dados & \\
\hline P16 & Dados integrados (formação de um dataset) & T17 & Recurso para integração liberado & \\
\hline P17 & Processo de filtragem & T18 & Filtragem dos dados & \\
\hline P18 & Dataset filtrado & T19 & Recurso para filtragem liberado & \\
\hline P19 & Processo de prevenção ao acesso & $\mathrm{T} 20$ & Prevenção ao acesso & \\
\hline $\mathrm{P} 20$ & Dataset com acesso restrito & $\mathrm{T} 21$ & Recurso para prevenção ao acesso liberado & \\
\hline P21 & Processo de correção de erros estruturais & $\mathrm{T} 22$ & Correção de erros estruturais & \\
\hline $\mathrm{P} 22$ & Dataset sem erros & $\mathrm{T} 23$ & $\begin{array}{l}\text { Recurso de correção de erros estruturais } \\
\text { liberado }\end{array}$ & \\
\hline $\mathrm{P} 23$ & Processo de remoção de outliers & $\mathrm{T} 24$ & Remoção de outliers & \\
\hline $\mathrm{P} 24$ & Dataset sem outliers & $\mathrm{T} 25$ & Recurso de remoção de outliers liberados & \\
\hline $\mathrm{P} 25$ & $\begin{array}{l}\text { Processo de classificação de dados faltantes } \\
\text { (lacunas) }\end{array}$ & T26 & Classificação de dados faltantes (lacunas) & \\
\hline P26 & Dataset com lacunas referenciadas & T27 & Recurso de classificação de lacunas liberado & \\
\hline P27 & Processo de associação de protocolo & T28 & Associação do protocolo & \\
\hline P28 & Dataset com protocolo associado & T29 & Recurso de associação de protocolo liberado & \\
\hline R5 & Recurso para integração & T30 & Acesso Comunicação/Informação (comandos) & \\
\hline R6 & Recurso para filtragem & & & \\
\hline R7 & Recurso de prevenção de acesso & & & \\
\hline R8 & Recurso de correção de erros estruturais & & & \\
\hline R9 & Recurso de remoção de outliers & & & \\
\hline R10 & Recurso de classificação de lacunas & & & \\
\hline R11 & Recurso de associação de protocolo & & & \\
\hline
\end{tabular}

Fonte: autor.

Na camada "Informação" do RAMI 4.0 estão as funcionalidades de armazenamento, os algoritmos utilizados, o processo de análise a visualização dos resultados e o processo de tomada de decisão - atividades [A4.1] à [A4.4] e [A4.7], retratadas na Figura 37 na seção 5.1. Após a tomada de decisão, comandos de atuação a serem enviados de volta aos ativos são 
armazenados e enviados à camada inferior - atividades [B4.1] e [B4.2] (CHEN; LI; WANG, 2015; NBD-PWG, 2018; STROHBACH et al., 2016). A Figura 42 apresenta o modelo em RdP das funcionalidades na camada "Informação" e a Tabela 8 identifica os elementos utilizados na sua elaboração.

Figura 42 - Modelo em RdP das funcionalidades na camada "Informação".

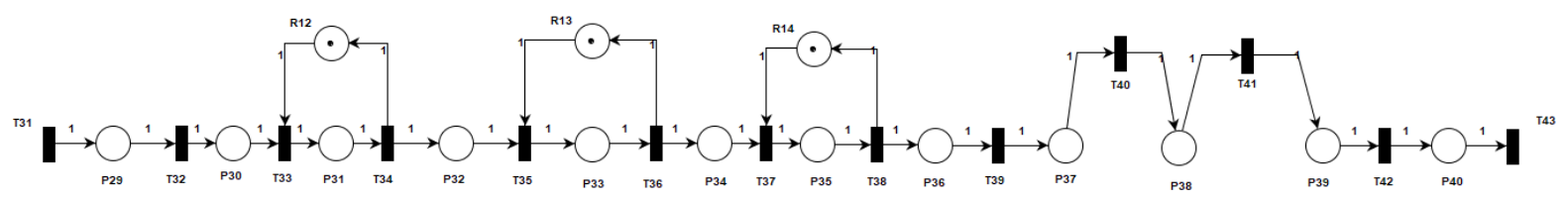

Fonte: autor.

Tabela 8 - Legenda do modelo na Figura 42.

\begin{tabular}{|c|c|c|c|c|}
\hline Lugares & Significado & Transições & Função & Referências \\
\hline P29 & Dataset acessado na camada Informação & $\mathrm{T} 31$ & Acesso Informação/Comunicação & \multirow{15}{*}{$\begin{array}{c}\text { (LIU, JIANG, 2016) } \\
\text { (NBD-PWG, 2015) } \\
\text { (NBD-PWG, 2017) } \\
\text { (STROHBACH } \text { et al. , 2016), } \\
\text { (CHEN, LI, WANG, 2015) }\end{array}$} \\
\hline P30 & Dataset aguarda armazenamento & $\mathrm{T} 32$ & Dataset encaminhado para armazenamento & \\
\hline $\mathrm{P} 31$ & Processo de armazenamento & $\mathrm{T} 33$ & Armazenamento do dataset & \\
\hline $\mathrm{P} 32$ & Dataset armazenado & $\mathrm{T} 34$ & Solução de armazenamento liberada & \\
\hline P33 & Processo de análise in situ & T35 & Analise do Dataset & \\
\hline P34 & Análise do Dataset realizada & $\mathrm{T} 36$ & Algoritmo liberado & \\
\hline P35 & Processo de visualização dos dados & $\mathrm{T} 37$ & Visualização dos resultados & \\
\hline P36 & Visualização dos dados realizada & T38 & $\begin{array}{l}\text { Recurso para visualização dos dados } \\
\text { liberado }\end{array}$ & \\
\hline P37 & Aguarda processo de tomada de decisão & $\mathrm{T} 39$ & $\begin{array}{l}\text { Resultados encaminhados para tomada de } \\
\text { decisão }\end{array}$ & \\
\hline P38 & Processo de tomada de decisão & $\mathrm{T} 40$ & Acesso Informação/Funcional & \\
\hline P39 & Tomada de decisão realizada & T41 & Acesso Funcional/Informação & \\
\hline $\mathrm{P} 40$ & Comandos aguardam envio para a camada & $\mathrm{T} 42$ & Comandos de atuação gerados & \\
\hline R12 & Solução de armazenamento & T43 & $\begin{array}{l}\text { Acesso Informação/Comunicação } \\
\text { (comandos) }\end{array}$ & \\
\hline R13 & Algoritmos & & & \\
\hline R14 & Recurso de visualização & & & \\
\hline
\end{tabular}

Fonte: autor.

Na camada "Funcional" do RAMI 4.0 estão as funcionalidades para consulta dos serviços e interfaces disponíveis para a tomada de decisão (ADOLPHS et al., 2015) - atividade [A4.5]. A Figura 43 apresenta o modelo em RdP das funcionalidades na camada "Funcional" e a Tabela 9 identifica os elementos da e as referências utilizadas na sua elaboração. 
Figura 43 - Modelo em RdP das funcionalidades na camada "Funcional".

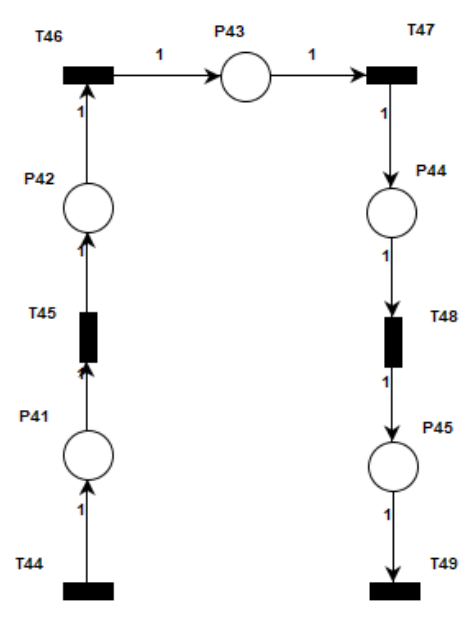

Fonte: autor.

Tabela 9 - Legenda do modelo na Figura 43.

\begin{tabular}{|l|l|l|l|l|}
\hline Lugares & Significado & Transições & Função & Referências \\
\hline P41 & $\begin{array}{l}\text { Resultados confrontados com a descrição das } \\
\text { funcionalidades }\end{array}$ & T44 & Camada Informação é acessada & \\
\hline P42 & Aguarda consulta às regras de funcionamento & T45 & Requisição das regras de funcionamento & (LIU, JIANG, 2016) \\
\hline P43 & Consulta à camada Regra de Negócio & T46 & Acesso Funcional/Regra de Negócio & (ADOLPHS et al., 2015) \\
(NBD-PWG, 2017)
\end{tabular}

Fonte: autor.

Na camada "Regra de Negócio" estão as funcionalidades responsáveis pela consulta às regras de operação dos ativos (ADOLPHS et al., 2015; NBD-PWG, 2018; ZHANG et al., 2017) - atividade [A4.6]. A Figura 44 apresenta o modelo em RdP das funcionalidades nesta camada e a Tabela 10 identifica os elementos e as referências utilizadas na sua elaboração.

Após a tomada de decisão na camada "Informação" os comandos a serem enviados aos dispositivos físicos são enviados a camada "Comunicação" para que sejam associados protocolos de comunicação aos comandos (ADOLPHS et al., 2015; CHEN; LI; WANG, 2015; NBD-PWG, 2018; NEHREY; HNOT, 2019). A Figura 45 apresenta o modelo em RdP do envio dos comandos na camada “Comunicação" e a Tabela 11 identifica os elementos e as referências utilizadas na sua elaboração. 
Figura 44 - Modelo em RdP das funcionalidades na camada "Regra do Negócio".

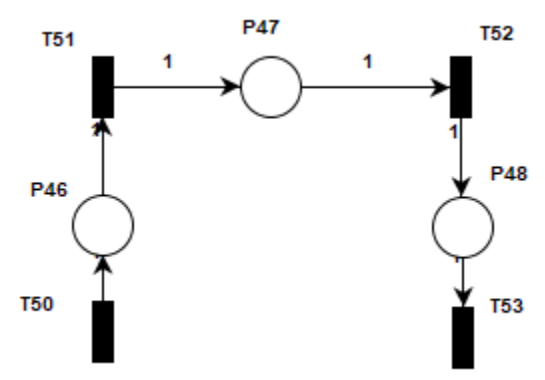

Fonte: autor.

Tabela 10 - Legenda do modelo na Figura 44.

\begin{tabular}{|c|c|c|c|c|}
\hline Lugares & Significado & Transições & Função & Referências \\
\hline P46 & Aguarda consulta às regras de funcionamento & T50 & Funcional acessa a camada Regra de & \multirow{4}{*}{$\begin{array}{c}\text { (ZHANG et al, 2017) } \\
\text { (PISCHING, 2017) } \\
\text { (ADOLPHS } \text { et al., 2015) } \\
\text { (NBD-PWG, 2017) }\end{array}$} \\
\hline P47 & $\begin{array}{l}\text { Aguarda consulta às condições ideais de carga } \\
\text { de trabalho }\end{array}$ & T51 & Consulta às regras de funcionamento & \\
\hline P48 & $\begin{array}{l}\text { Aguarda envio das informações à camada } \\
\text { funcional }\end{array}$ & T52 & Consulta às cargas de trabalho & \\
\hline & & T53 & Funcional libera a camada Regra de negócio & \\
\hline
\end{tabular}

Fonte: autor.

Figura 45 - Modelo em RdP do envio de comandos na camada "Comunicação".

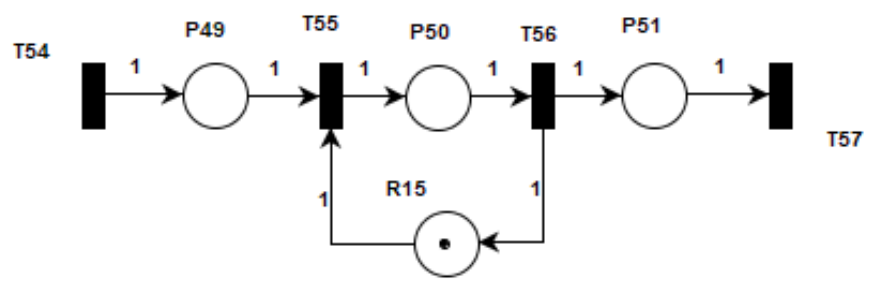

Fonte: autor.

Na camada "Integração" são associadas as tecnologias de comunicação aos comandos e eles são direcionados aos ativos para a modificação dos seus parâmetros (ADOLPHS et al., 2015; PISCHING, 2018) - atividade [A2.1]. A Figura 46 apresenta o modelo em RdP do envio dos comandos na camada "Integração" e a Tabela 12 identifica os elementos da e as referências utilizadas na sua elaboração. 
Tabela 11 - Legenda do modelo na Figura 45.

\begin{tabular}{|l|l|l|l|l|}
\hline Lugares & Significado & Transiçães & Função & Referências \\
\hline P49 & Comandos enviados à camada Comunição & T54 & $\begin{array}{l}\text { Acesso Comunicação/Informação } \\
\text { (comandos) }\end{array}$ & (CHEN, LI, WANG, 2015) \\
P50 & $\begin{array}{l}\text { Processo de associação de protocolo } \\
\text { (comandos) }\end{array}$ & T55 & Associação dos protocolos (comandos) & $\begin{array}{r}\text { (NBD-PWG, 2015) } \\
\text { (NBD-PWG, 2017) }\end{array}$ \\
\hline P51 & Protocolos associados aos comandos & T56 & $\begin{array}{l}\text { Recurso de associação de protocolo liberado } \\
\text { (comandos) } \\
\text { (ADOLPHS et al., 2015) }\end{array}$ \\
\hline R15 & $\begin{array}{l}\text { Recurso de associação de protocolo } \\
\text { (comandos) }\end{array}$ & T57 & $\begin{array}{l}\text { Acesso Comunicação/Integração } \\
\text { (comandos) }\end{array}$ & \\
\hline
\end{tabular}

Fonte: autor.

Figura 46 - Modelo em RdP do envio de comandos na camada "Integração".

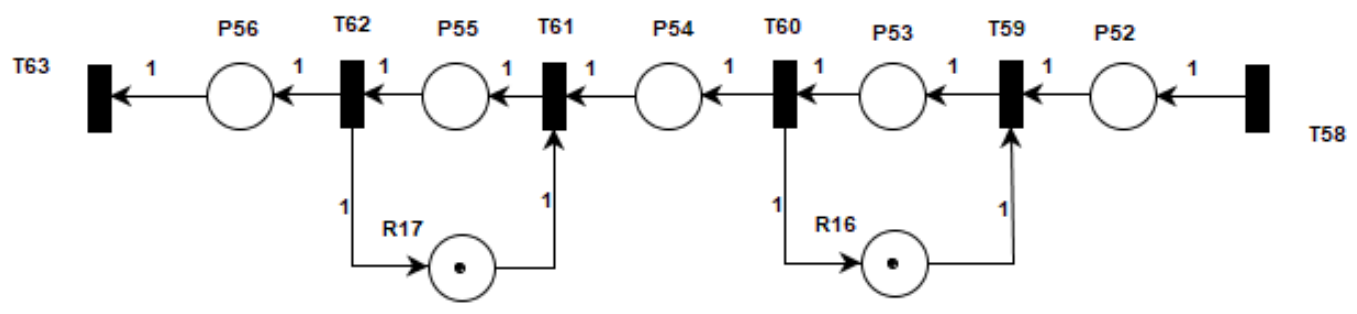

Fonte: autor.

Tabela 12 - Legenda do modelo na Figura 46.

\begin{tabular}{|c|c|c|c|c|}
\hline Lugares & Significado & Transições & Função & Referências \\
\hline $\mathrm{P} 52$ & Comandos enviados à camada Comunição & T58 & Acesso Integração/Comunicação (comandos) & \multirow{7}{*}{$\begin{array}{c}\text { (PISCHING, 2017) } \\
\text { (ADOLPHS et al., 2015) }\end{array}$} \\
\hline P53 & $\begin{array}{l}\text { Processo de associação da tecnologia de } \\
\text { comunicação (comandos) }\end{array}$ & T59 & $\begin{array}{l}\text { Associação da tecnologia de comunicação } \\
\text { (comandos) }\end{array}$ & \\
\hline P54 & Tecnologia de comunicação associada & T60 & $\begin{array}{l}\text { Recurso para associação da tecnologia de } \\
\text { comunicação liberado (comandos) }\end{array}$ & \\
\hline P55 & Comandos aguardam interação virtual/real & T61 & Interação virtual/real & \\
\hline P56 & Interação virtual/real realizada & T62 & Recurso de virtualização liberado (comandos) & \\
\hline R16 & $\begin{array}{l}\text { Recurso de associação de tecnologia de } \\
\text { comunicação (comandos) }\end{array}$ & T63 & $\begin{array}{l}\text { Acesso Integração/Ativo Técnico } \\
\text { (comunicação) }\end{array}$ & \\
\hline $\mathrm{R} 17$ & Recurso de virtualização (comandos) & & & \\
\hline
\end{tabular}

Fonte: autor.

Na camada "Ativo Técnico" os comandos retornam ao dispositivo de controle que orienta o funcionamento dos atuadores que intervém na operação dos ativos (CHEN; LI; WANG, 2015; PISCHING, 2018) - atividade [B1.1] no PFS. A Figura 47 apresenta o modelo em RdP da execução dos comandos na camada "Ativo Técnico" e a Tabela 13 identifica os elementos da e as referências utilizadas na sua elaboração. 
Figura 47 - Modelo em RdP do envio de comandos na camada "Ativo Técnico".

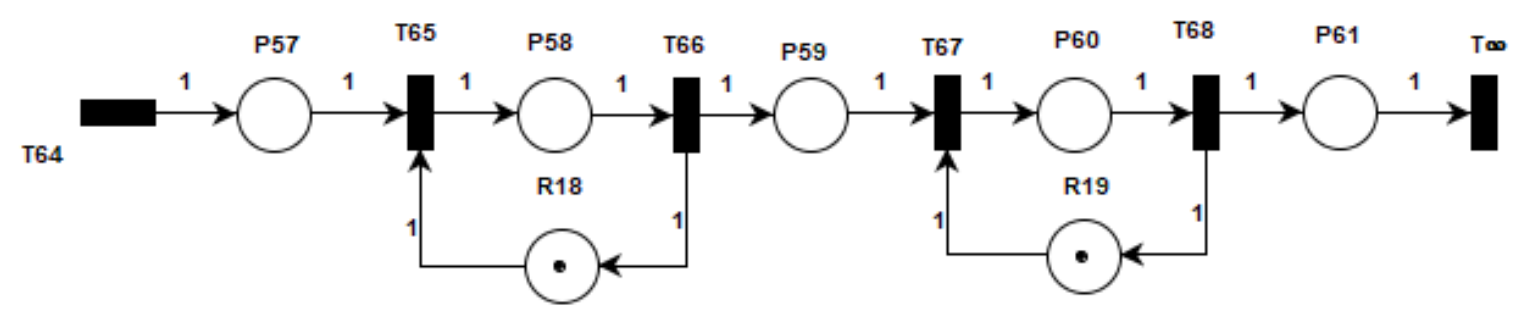

Fonte: autor.

Tabela 13 - Legenda do modelo na Figura 47.

\begin{tabular}{|l|l|l|l|l|}
\hline Lugares & Significado & Transiçães & Função & Refe rências \\
\hline P57 & Comandos enviados à camada Ativo técnico & T64 & Acesso Ativo Técnico/Integração & \\
\hline P58 & $\begin{array}{l}\text { Processo de recebimento dos comandos pelo } \\
\text { Disp. Controle }\end{array}$ & T65 & Envio dos comandos ao Disp. Controle & \\
\hline P59 & Disp. Controle com comandos recebidos & T66 & Disp. Controle liberado (comandos) & (PISCHING, 2017) \\
\hline P60 & Processo de atuação nos dispositivos & T67 & Atuação nos dispositivos & 2015) \\
\hline P61 & Dispositivos com novos parâmetros de atuação & T68 & Recurso de atuação liberado (comandos) & (CHEN, WANG, \\
\hline R18 & Recurso do Dispositivo de controle (comandos) & To & Transição final & \\
\hline R19 & Recurso de atuação (comandos) & & & \\
\hline R* & Recurso de limite da quantidade de marcas & & & \\
\hline
\end{tabular}

Fonte: autor.

A Figura 48 apresenta o modelo em RdP de todo o processo de aquisição de dados considerando a estrutura de camadas do RAMI 4.0. Graficamente, foi adicionado um recurso $\left(\mathrm{R}^{*}\right)$, que garante que apenas uma marca exista no sistema e que este seja reversível.

As transições que ligam as camadas (e.g. T8 e T9) foram separadas para facilitar o entendimento, mas conforme o conceito de fusão de transições onde, para efeito de simulação da evolução do sistema, elas compõem uma única transição.

\subsection{Análise dos Modelos em RdP}

Apresenta-se aqui a análise do modelo em RdP que representa o processo de aquisição de big data na I4.0 (Figura 48) pela identificação das suas características, propriedades e classificação. Para tal, foram utilizados os recursos de análise qualitativa e quantitativa que a ferramenta PIPE (utilizada na edição/construção dos modelos) dispõe. 


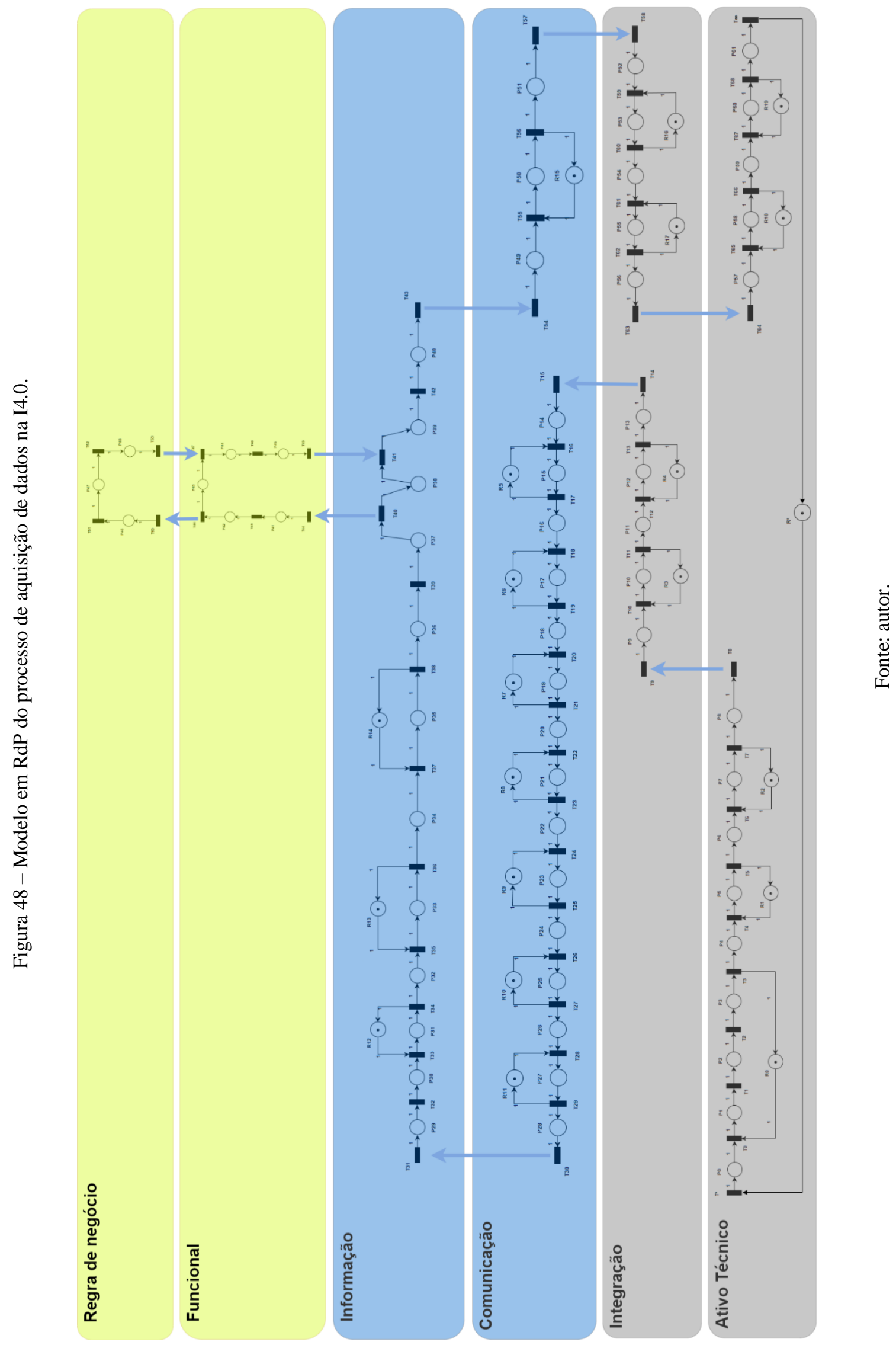




\subsubsection{Análise das características estruturais do modelo em $\mathrm{RdP}$}

Com base nas características estruturais do modelo em RdP, o comportamento dinâmico dos processos (i.e., sua parte física, desconsiderando as transições inicial e final para que a simulação dos modelos corresponda a um ciclo, ou seja, do início ao fim de uma instância do processo) dentro da arquitetura proposta podem ser avaliados.

As características estruturais que podem ser percebidas no modelo são:

\section{- $\quad \underline{\text { Sequência }}$}

Como esperado para um processo tipificado pela sequência de atividades como é a aquisição de dados, o seu modelo em RdP possui diversas estruturas em sequência. Estas estruturas asseguram a dinâmica linear do processo, com uma sequência de atividades a serem executadas desde a coleta dos dados, até o retorno de informações aos ativos físicos.

A Figura 49 indica as sequências de atividades no modelo em RdP.

Figura 49 - Atividades em sequência no modelo em RdP.

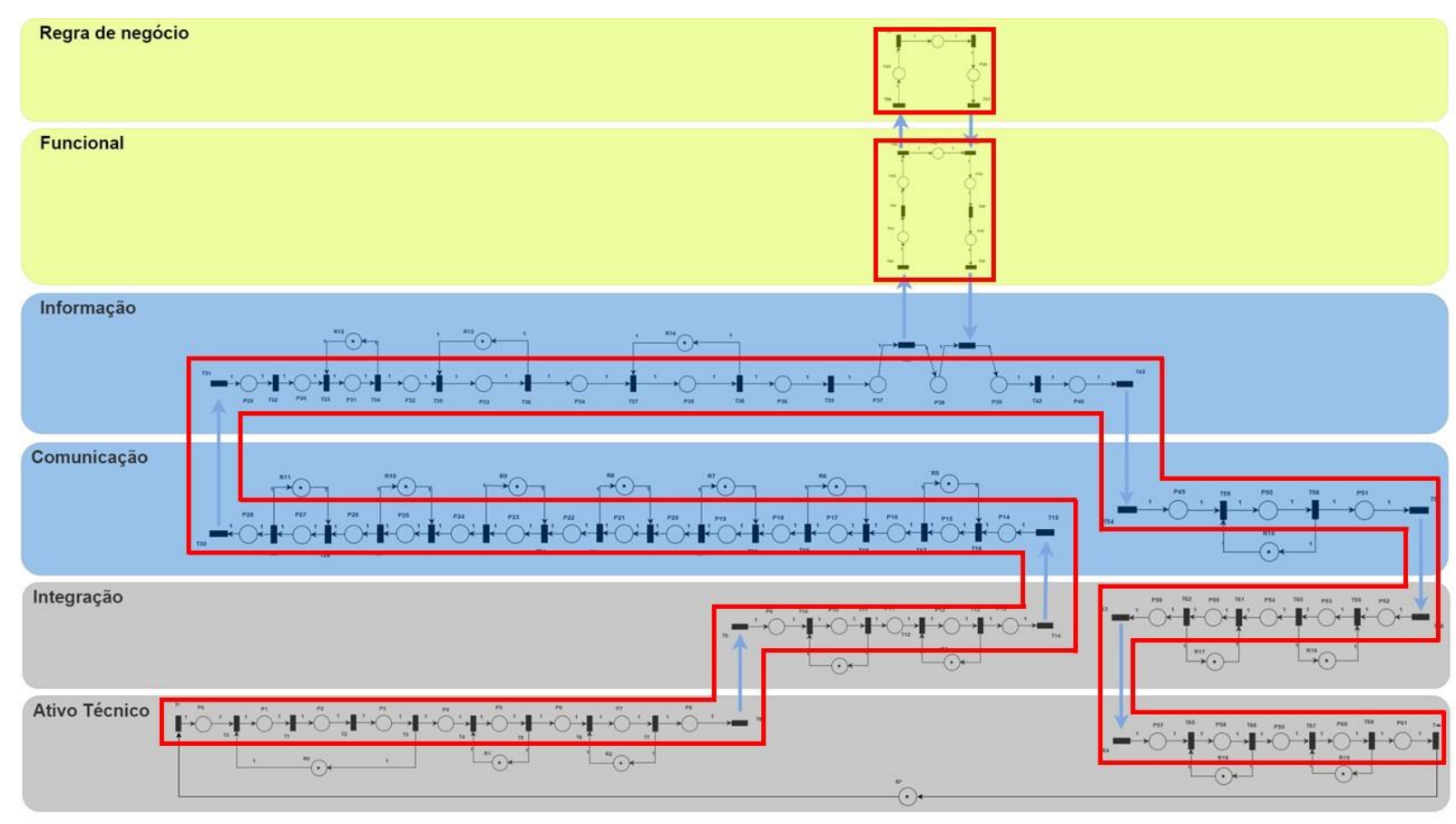

Fonte: autor.

A modelagem representa assim o sequenciamento das atividades da aquisição de dados e como isso ocorre no contexto da I4.0. 
Como definido na seção 2.3, uma arquitetura de um sistema deve envolver todas as funcionalidades da aplicação considerada. Nesse contexto, as partes do modelo onde existe sequenciamento comprovam a evolução do processo de aquisição de big data e como as atividades e funcionalidades estão relacionadas às camadas do RAMI 4.0 e, consequentemente, a I4.0.

\section{- Paralelismo}

O paralelismo no modelo ocorre nas atividades de consulta às interfaces disponíveis e às regras de atuação, respectivamente nas camadas "Funcional" e "Regra de Negócio". A consulta às camadas está relacionada à tomada de decisão, onde o processo fica em estado de espera até que a consulta seja finalizada.

Encerrada a tomada de decisão, o paralelismo é utilizado para representar a independência entre as atividades de envio dos comandos de atuação (i.e., a continuidade do processo de aquisição de dados) e as atividades de organização dessas camadas para novas consultas.

A Figura 50 indica o paralelismo nas atividades no modelo em RdP.

Figura 50 - Atividades em paralelismo no modelo em RdP.

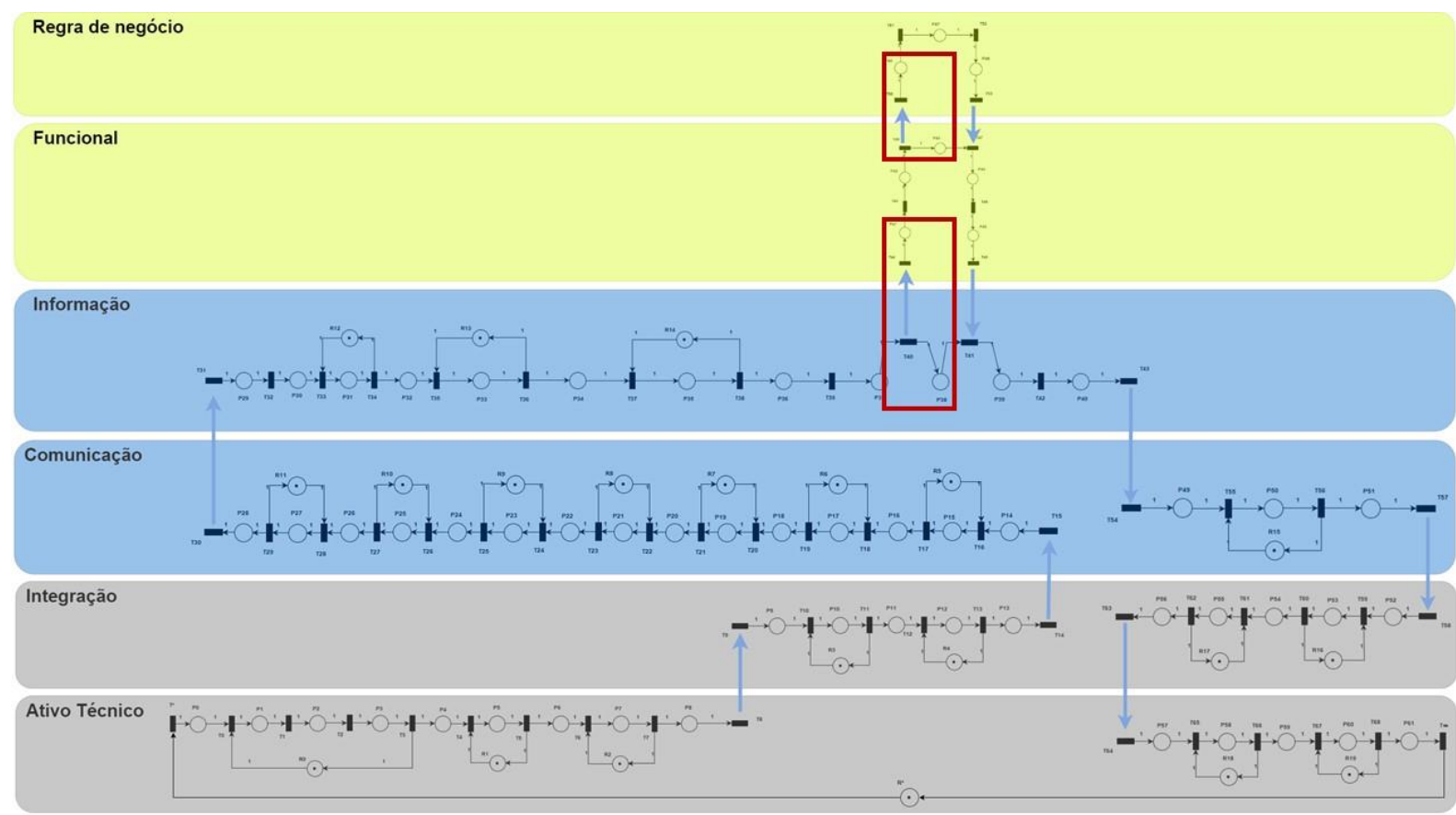

Fonte: autor. 


\section{- $\quad$ Sincronização}

A sincronização no modelo aparece quando se tem combinação da inteligência adquirida pela consulta às interfaces disponíveis na camada "Funcional" e das regras de atuação na camada "Regra de Negócio".

A Figura 51 indica a sincronização no modelo RdP.

Figura 51 - Atividades em sincronismo no modelo em RdP.

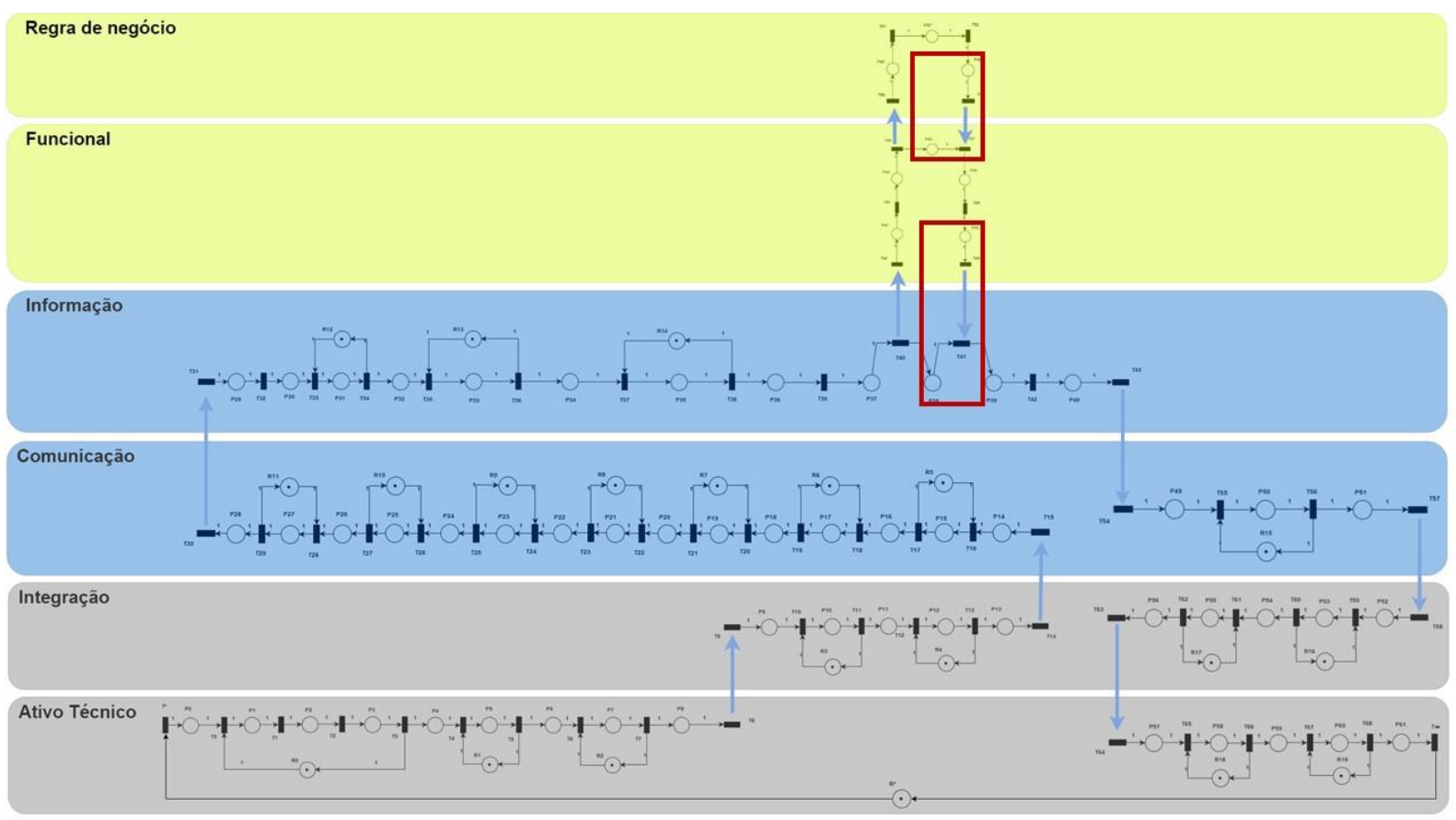

Fonte: autor.

\section{- Conflito}

A partir da análise da evolução do processo de aquisição de big data em um modelo RdP, observa-se que não existem situações de conflito entre atividades estruturadas e organizadas de acordo com a arquitetura proposta.

Entende-se que como a arquitetura especifica as atividades necessárias para a aquisição de big data, situações de conflito não são desejadas, uma vez que o processo foi descrito de modo que todas as atividades devem ser acionadas para completar a coleta das informações devidas. 
- Compartilhamento de recursos

O compartilhamento de recursos representa situações em que existe um limitado número de entidades com disponibilidade para realizar uma ou mais atividades de um processo. Assim, esta entidade se mantem comissionada durante a execução de cada atividade.

A Figura 52 indica as atividades que requerem recursos para sua execução.

Figura 52 - Atividades com recursos em compartilhamento no modelo em RdP.

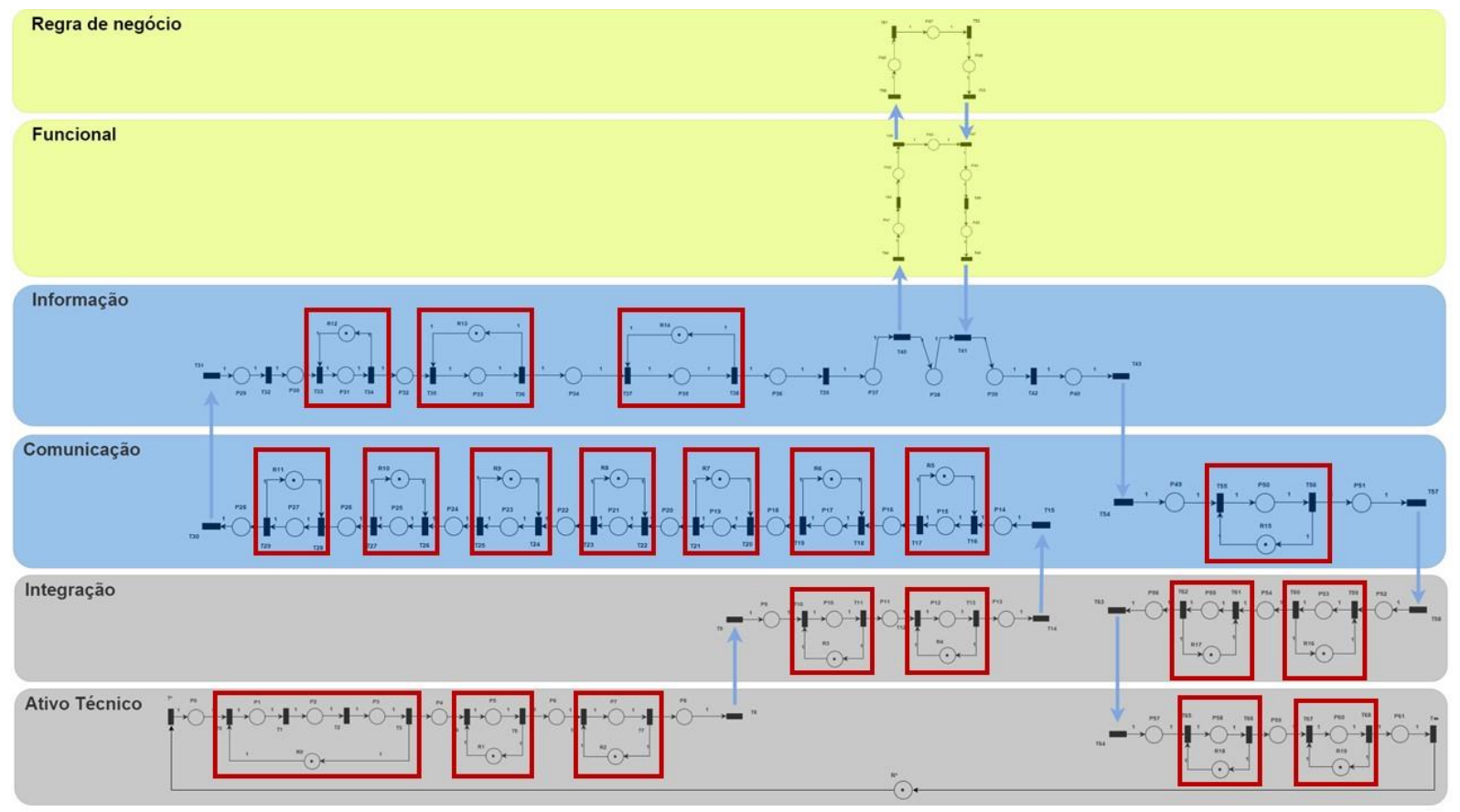

Fonte: autor.

Ainda sobre a Figura 52, percebe-se que mesmo existindo atividades no modelo RdP que são realizadas utilizando recursos específicos, não há compartilhamento de recursos no modelo, fato já evidenciado pela ausência de conflitos.

A partir da análise das características estruturais do modelo RdP, a organização das atividades da arquitetura, e a evolução do processo de aquisição de big data podem ser avaliadas.

Percebe-se que a maior parte das atividades do modelo está em sequência. Esta característica está de acordo com a literatura relacionada ao contexto da aquisição e análise de big data, onde trabalhos como os de Lyko; Nitzschke; Ngonga Ngomo (2016) e NBD-PWG (2018) retratam estas atividades da mesma maneira. 
A análise das atividades também mostra que existe um "fluxo principal" das atividades, marcado pelo fluxo de dados desde a atividade de coleta pelos dispositivos físicos até a tomada de decisão e, seguida pelo envio de informações de volta ao ativo (i.e. as atividades das camadas Ativo Técnico, Integração, Comunicação e Informação).

As atividades de consulta nas camadas "Funcional" e "Regra de Negócio" são atividades de apoio à tomada de decisão, formando um fluxo secundário de informações. Assim, para manter a independência entre as atividades de cada fluxo, o modelo conta com situações de paralelismo.

\subsubsection{Análise das propriedades do modelo em RdP}

Com base na análise das propriedades do modelo em RdP, é possível avaliar tanto qualitativa quanto quantitativamente outros aspectos da arquitetura proposta. A análise das propriedades do modelo em RdP segue:

\section{- $\quad$ Alcancabilidade}

Em relação à alcançabilidade do modelo em RdP, a análise desta propriedade permite a caracterização dos processos que ocorrem na arquitetura proposta, considerando os estados que estes processos podem alcançar e como o processo evolui entre estes estados.

No contexto do processo de aquisição de big data, tanto este estudo como a literatura correlata confirmam que a evolução das atividades segue um padrão linear, ou seja, a execução da próxima atividade está relacionada ao término da atividade anterior.

O modelo completo do processo (apresentado na Figura 48) possui 61 estados alcançáveis, com 65 situações / cenários que descrevem a evolução entre estes estados.

A Figura 53 mostra a árvore de alcançabilidade do modelo RdP (relativos às Figuras de 39 à 47) entre o estado inicial $S 0$ e o estado final $S 60$, o último antes do início de um novo ciclo (respectivamente destacados pelas setas verde e vermelha) e as transições responsáveis por alterar os estados do modelo. Observando a alcançabilidade do modelo em RdP é possível confirmar a linearidade do processo de aquisição de dados.

\section{- $\quad$ Limitabilidade e Seguranca}

Observa-se que em nenhum dos estados alcançados no modelo RdP existe a possibilidade de acúmulo de marcas. Além disso, para qualquer estado alcançável, nenhum dos 
111

lugares do modelo ultrapassa um número maior que uma única marca. Logo, o modelo em RdP é 1-limitada e, portanto, o modelo que representa o processo de aquisição de big data também é dito seguro.

Figura 53 - Árvore de alcançabilidade dos componentes do modelo RdP.

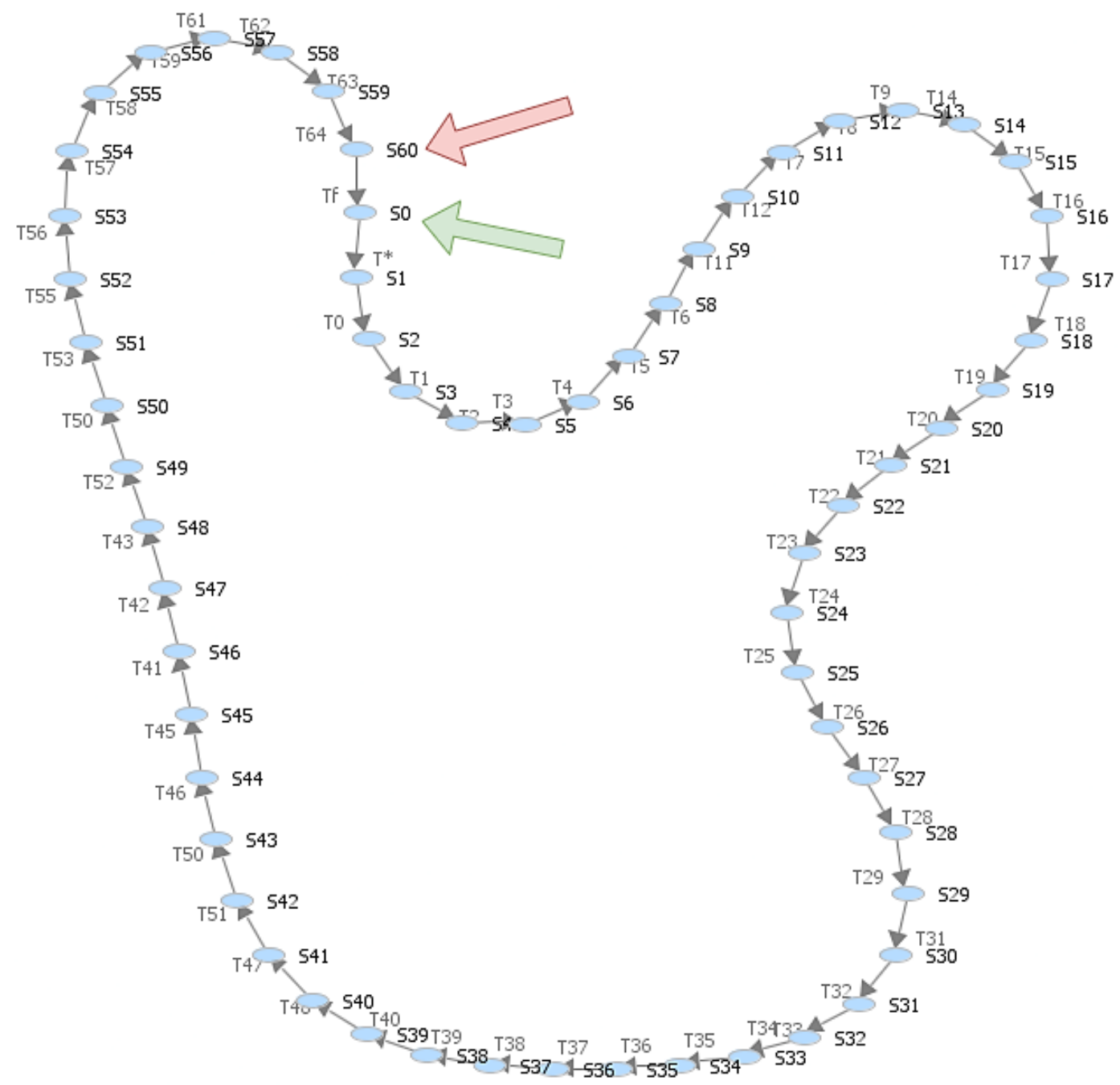

Fonte: autor.

\section{- $\quad$ Vivacidade}

Pela observação da sequência de disparos de cada transição e como os seus disparos interagem com as demais transições, chega-se à conclusão de que o modelo em RdP é L3-vivo, uma vez que o processo é cíclico. 
Além disso, os experimentos de simulação demonstram que não existem deadlocks na evolução dos processos, assim, o modelo comprova que os processos na arquitetura proposta alcançam o estado final a partir do estado inicial sem nenhum problema de impasse e/ou travamento e permitindo o recomeço do ciclo.

\section{- Reversibilidade}

A modelagem da arquitetura proposta foi realizada com base nas atividades que definem um processo que evolui do seu estado inicial (i.e., o sensoriamento de uma variável física), até seu estado final (i.e., o retorno de comandos de atuação aos dispositivos físicos).

Entende-se que o processo de aquisição de dados deve ser reversível, uma vez que é importante que o sistema volte para o estado inicial para que um novo ciclo possa ser iniciado. Essa propriedade é alcançada no modelo pela utilização das transições inicial e final (respectivamente $T^{*}$ e $T \infty$ ) e pelo recurso $\left(R^{*}\right)$, que garantem tanto a reversibilidade do sistema quanto a limitação do processo a apenas uma marca, mantendo a segurança do modelo.

\section{- $\quad \underline{\text { Persistência }}$}

O modelo em RdP é persistente, uma vez que nele, o disparo de uma transição não desabilita o disparo de outras transições. Isto é, entende-se que as atividades modeladas não possuem situações de conflito e que o processo de aquisição de big data foi modelado de maneira que todas as suas atividades são de alguma forma acionadas em algum momento entre o início e o fim do processo. Assim, a modelagem é consistente com a estrutura e funcionalidades consideradas na arquitetura proposta.

\section{- Equidade}

Na modelagem do processo de aquisição de dados assumiu-se que cada atividade ocorre uma única vez. Assim, após disparo de qualquer transição do modelo é necessário um disparo das transições seguintes para que o modelo complete seu ciclo e essa transição seja habilitada novamente. Neste caso, as transições do modelo em RdP comprovam ser "incondicionalmente iguais".

A análise desta propriedade do modelo RdP está condizente com a evolução esperada do processo de aquisição de big data. 


\subsubsection{Análise dos tipos do modelo em RdP}

A ferramenta de análise PIPE conta com alguns módulos de análise que, em consonância com o trabalho de Bonet e Lladó (2007), permitem a classificação do tipo do modelo RdP com base nas conexões entre seus lugares e transições.

A Figura 54 mostra os resultados do módulo de classificação de tipos do PIPE para o modelo em RdP (explicados na Seção 2.5.4 e ilustrados na Figura 24).

Figura 54 - Resultado do módulo de classificação de tipos no modelo em RdP.

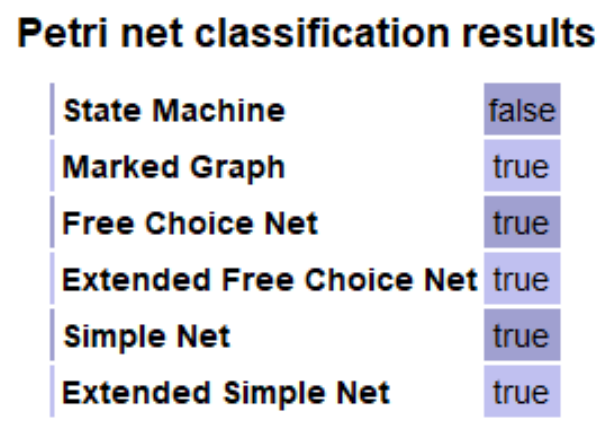

Fonte: autor.

A partir dos resultados obtidos, a Figura 55 ilustra a percepção do modelo RdP proposto em relação às suas classificações:

Figura 55 - Interpretação do módulo de classificação de tipos no modelo em RdP.

- State Machine

- Marked Graph

- Free Choice Net

- Extended Free Choice Net

- Simple Net

- Extended Simple Net

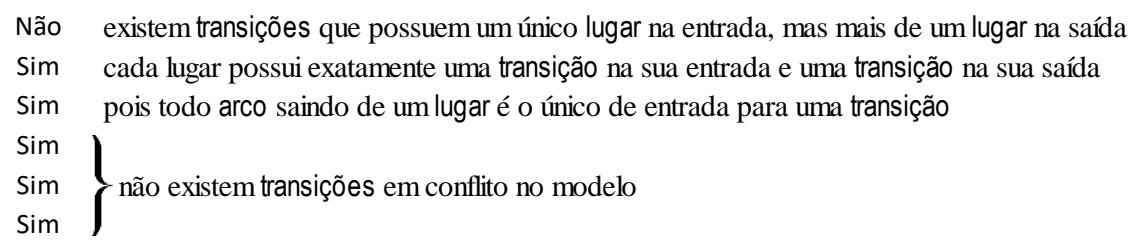

Fonte: autor.

\subsection{Resultados da Avaliação do Modelo}

A modelagem do processo de aquisição de big data no contexto da arquitetura proposta baseou-se na literatura correlata que identifica as principais etapas do processo. Essas etapas foram interpretadas de modo a se modelar o processo de forma abrangente, considerando as funcionalidades necessárias para um DAQ de big data. 
O uso da técnica do PFS para modelagem do processo confirmou ser eficaz para a visualização conceitual e estrutural dos fluxos de dados através do sistema por meio de uma linguagem intuitiva, facilitando seu entendimento entre diferentes especialistas e, sistematizando a derivação de modelos em RdP. Assim, a abordagem adotada no presente trabalho mostrou-se aderente ao cenário da I4.0, colaborando para a integração de conhecimentos de profissionais de diferentes áreas.

Os modelos em RdP obtidos neste estudo são refinamentos do modelo conceitual desenvolvido em PFS. A partir da análise dos modelos em RdP, isto é, da caracterização de propriedades e simulação de cenários, tem-se a comprovação de que o processo do DAQ modelado é funcional, logo, o sistema é capaz de evoluir do seu estado inicial até o estado final sem nenhum impasse.

No contexto da I4.0, os modelos obtidos são entendidos como um passo para a especificação e desenvolvimento de sistemas capazes de coletar dados que permitam alcançar a eficiência descrita por seus idealizadores. Com base nos modelos e o detalhamento dos processos, tem-se um estudo detalhado das funcionalidades e do desempenho das atividades envolvidos na aquisição de big data de modo que se tem assim os fundamentos para uma arquitetura de DAQ em consonância com o RAMI 4.0 que é a referência assumida para a implantação da I4.0.

Em relação à avaliação e análise, os modelos em RdP foram interpretados e analisados com base em diversos aspectos. A partir das suas características, propriedades, classificação e simulação, pôde-se verificar pontos importantes da modelagem, como a ausência de impasses que impeçam o progresso da aquisição de big data ou a quantidade de atividades no processo e como elas se comportam em diferentes cenários. 


\section{CONCLUSÕES}

Com foco na Indústria 4.0, foi possível observar neste estudo a necessidade de uma solução prática para a implementação de sistemas que efetivamente atuam na coleta de big data e processam esses dados de modo efetivo, isto é, do ponto de vista macro se necessita conceber uma arquitetura de um sistema para este fim. Como já existem arquiteturas de referência correlatas ou, que estão em desenvolvimento, estas foram adotadas como base para orientar as possíveis soluções. Desta forma, este trabalho foi capaz de chegar ao resultado esperado, isto é, a proposta de uma arquitetura para a aquisição de big data capaz de relacionar todo o processo de aquisição de dados ao contexto da I4.0.

O RAMI 4.0 e a NBDRA foram as principais referências para a estruturação do processo de aquisição de big data associado a um sistema produtivo. A partir da NBDRA foi possível conceituar o processo de aquisição de dados e as suas funcionalidades. O RAMI 4.0 por sua vez foi utilizada na conversão do processo para o contexto da I4.0. Isto é, assumiu-se que no contexto da I4.0, o desenvolvimento de sistemas a partir do RAMI 4.0 deve seguir a estrutura em camadas para a especificação dos processos envolvidos na aquisição de dados.

A utilização da técnica PFS/RdP se mostrou adequada para a modelagem de todo o processo de aquisição de dados, desde sua conceitualização até o seu detalhamento e a análise estrutural e funcional das entidades e atividades envolvidas.

As técnicas e métodos empregados para a avaliação dos modelos em RdP se mostraram adequados. A partir da sua utilização foi possível analisar as características, propriedades, classificações e simular diferentes situações nos modelos RdP. Por este procedimento de avaliação, a arquitetura proposta foi revisitada e aprimorada, garantindo que as características desejadas do processo de aquisição de big data estão devidamente consideradas e retratadas da forma esperada para este estudo.

A análise via caracterização de propriedades e simulação de cenários dos modelos em RdP indica também como uma arquitetura de DAQ para o big data pode ser especificada.

A I4.0, pela heterogeneidade nos conceitos envolvidos e a interdisciplinaridade dos seus sistemas, tem a necessidade de adotar soluções efetivas para a composição e interação entre sistemas que conciliem o conhecimento de diversos especialistas, facilitando o desenvolvimento desses mesmos sistemas a partir do entendimento mútuo entre os profissionais envolvidos. Com base nesse contexto, entende-se que a arquitetura do DAQ aqui proposta pode ser um guia para orientar os envolvidos nos setores produtivos sobre a aquisição de big data na I4.0. 
O estudo e a proposição de uma arquitetura neste estudo seguiu, de forma abrangente, o mesmo procedimento utilizado na elaboração da NBDRA (taxonomia, elicitação dos requisitos e usos de caso, a construção e detalhamento da arquitetura e, finalmente, sua verificação).

A arquitetura proposta provê um formato compreensivo, capaz de confrontar as funcionalidades de uma solução de coleta de big data com as questões abordadas neste estudo, elucidando oportunidades de modernização, auxiliando em aspectos da I4.0 como a autonomia da tomada de decisões, a personalização da produção e a otimização dos sistemas de produção.

\subsection{Trabalhos Futuros}

A seguir se destaca os pontos que orientam o desenvolvimento de trabalhos futuros.

- A implementação da arquitetura proposta em um sistema real composto por dispositivos e recursos distribuídos, de modo que mais comprovações podem ser somadas àqueles apresentados neste estudo para a validação da arquitetura.

- Um estudo aprofundado sobre os tempos de execução e resposta e do desempenho das atividades do processo de aquisição de big data, de modo que os modelos desenvolvidos neste estudo podem ser mais detalhados, e com isto mais situações e cenários podem ser avaliados. 


\section{APÊNDICE}

Para ilustrar de uma forma mais objetiva os processos e o fluxo de informações descrito pela arquitetura proposta, nesta seção são apresentados exemplos de aplicação de um componente I4.0 (I4.0C), incluindo os seus ativos e seus Administration Shells. Além disso, também é apresentada a estrutura de uma base de dados no contexto da I4.0. Entende-se que os exemplos apresentados aqui auxiliam na compreensão da magnitude dos dados referenciados na I4.0.

\subsection{Componente 4.0 (I4.0C)}

Nesta seção é realizada uma revisão mais detalhada dos conceitos da I4.0. Assim, o I4.0C é desdobrado em seus subelementos (Ativos, propriedades, submodelos e views), além disso, são apresentados também os conceitos que um Ativo deve preencher para ser compatível com a I4.0.

O RAMI 4.0, apresentado na seção 2.3.1 deste estudo, contém uma descrição estruturada dos requisitos fundamentais dos sistemas compatíveis com a I4.0, explorando o ciclo de vida dos sistemas, hierarquias e camadas funcionais.

O componente I4.0 (I4.0 Component - I4.0C) foi proposto/desenvolvido como uma forma de se consolidar o RAMI 4.0. Sua principal característica é a combinação de características dos mundos físico e digital, oferecendo funcionalidades padronizadas e serviços flexíveis, dentro e fora da rede de componentes da Indústria 4.0. Desta forma o Componente I4.0 deve possuir um identificador único e capacidade de comunicação (YE; HONG, 2019).

A Figura 56 ilustra a base conceitual de um I4.0C. Em termos da sua estrutura um I4.0C é composto por dois elementos básicos: o Ativo (Asset) e o Asset Administration Shell (AAS). O Ativo pode ser algo físico (máquinas e seus componentes, materiais, peças e produtos) ou digital (ordens de fabricação, documentos, desenhos técnicos, contratos, pedidos) para uma empresa. O AAS compreende o Manifesto (Manifest) e o Gerenciador de Componentes (CM - Component Manager). Nesse Contexto, o AAS é a representação virtual, digital e ativa do Ativo, contendo todas as suas informações e funcionalidades técnicas e sendo a entidade responsável por gerenciar a comunicação com os demais I4.0C (YE; HONG, 2019).

Em resumo, a ideia básica do I4.0C é envolver os Ativos da I4.0 com um AAS, capaz de fornecer uma descrição mínima, única, mas suficiente, do Ativo (contendo suas 
características, funcionalidades, propriedades etc.) de acordo com os casos de uso da I4.0 (BEDENBENDER et al., 2017a; GAYKO, 2018).

Figura 56 - O conceito de I4.0C.

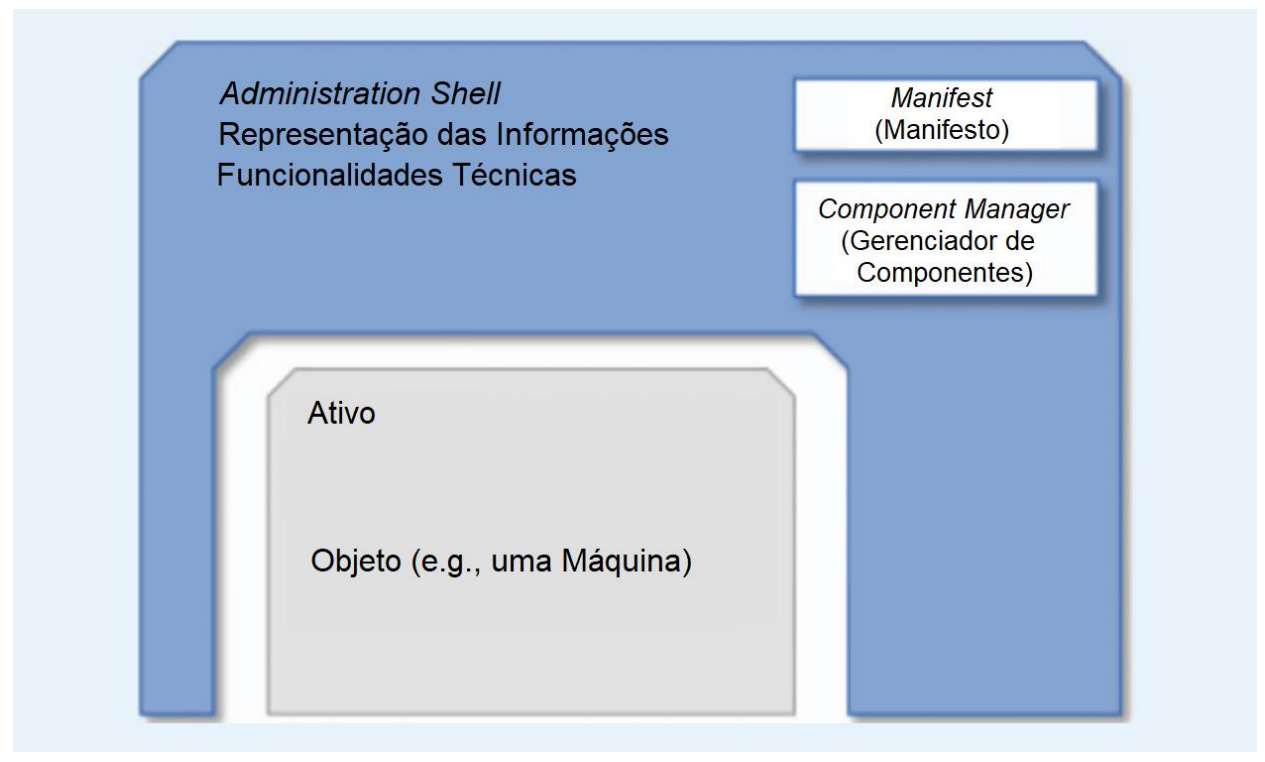

Fonte: Adaptado de (BEDENBENDER et al., 2017a; YE; HONG, 2019).

Segundo Ye e Hong (2019), em (BEDENBENDER et al., 2017a) foram definidos os conjuntos de requisitos estruturais, funcionais e relacionados à informação dos I4.0C. Para facilitar o uso dos I4.0C em processos produtivos, de forma prática, o estudo em (RÖPKE $e t$ al., 2016) apresentou um modelo hierárquico de sistemas de produção considerando as estruturas existentes do sistema e explicou como identificar o I4.0C e atribuir às camadas específicas. O trabalho foi estendido em (HELL et al., 2016).

A Figura 57 ilustra um I4.0C e seus principais elementos, o Ativo e o AAS (BEDENBENDER et al., 2017a). Em um I4.0C podem estar representados um ou mais Ativos, de acordo com o nível de abstração adotado (e.g. um atuador pode ser visto como Ativo, da mesma maneira que a máquina que contêm este atuador pode ser vista como um conjunto de Ativos). Já com relação ao AAS, um Ativo pode ter diferentes AAS de acordo com o seu ciclo de vida, bem como o I4.0C pode ter um conjunto de AAS quando este se refere a um conjunto de Ativos e seus respectivos AASs. A figura também apresenta um tipo específico de componente, o Sistema I4.0 (I4.0S - I4.0 System) (BEDENBENDER et al., 2017a). 
Figura 57 - Representação de um I4.0C, seu relacionamento com os Ativos, AAS e um tipo particular de I4.0C, o I4.0S.

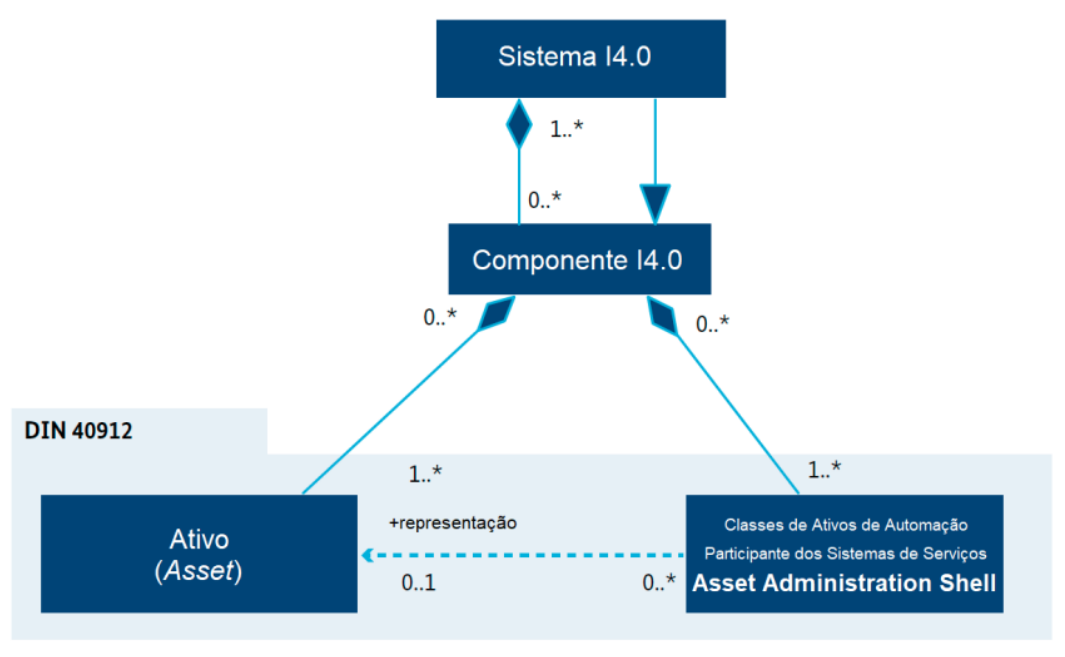

Fonte: Adaptado de (BEDENBENDER et al., 2017b).

O I4.0S é componente especializado que tem a função de gerenciar os demais componentes subordinados a ele. Deve-se ter claro que o I4.0S não é sinônimo de ERP (Enterprise Resource Planning). O próprio ERP deve ser revisto no contexto da Indústria 4.0 uma vez que muitas de suas funcionalidades devem migrar para os I4.0C (representadas como Ativo e AAS).

Na Figura 58, Bedenbender et al., (2017a) apresentam uma visão mais detalhada do I4.0C, mais especificamente dos elementos que compõem o AAS: Manifesto (Manifest), Gerenciador de Componentes (CM - Component Manager), Submodelos (Submodels), Propriedades (Properties) e Views. Cada um destes elementos é apresentado nos próximos itens.

\subsubsection{Ativo}

O Ativo pode ser algo físico (como uma máquina e seus componentes, materiais, partes e produtos) ou digital (ordens de fabricação, documentos, desenhos técnicos, contratos, pedidos) para uma empresa. Bader et al. (2019) sintetizam o conceito de Ativo como: qualquer objeto que tenha um valor para uma empresa, que seja importante. Assim, os Ativos na I4.0 podem assumir quase qualquer forma, como apresentado anteriormente. Além destes exemplos de Ativos, são apresentados alguns outros exemplos em (BEDENBENDER et al., 2017c): 
Figura 58 - Essência do AAS
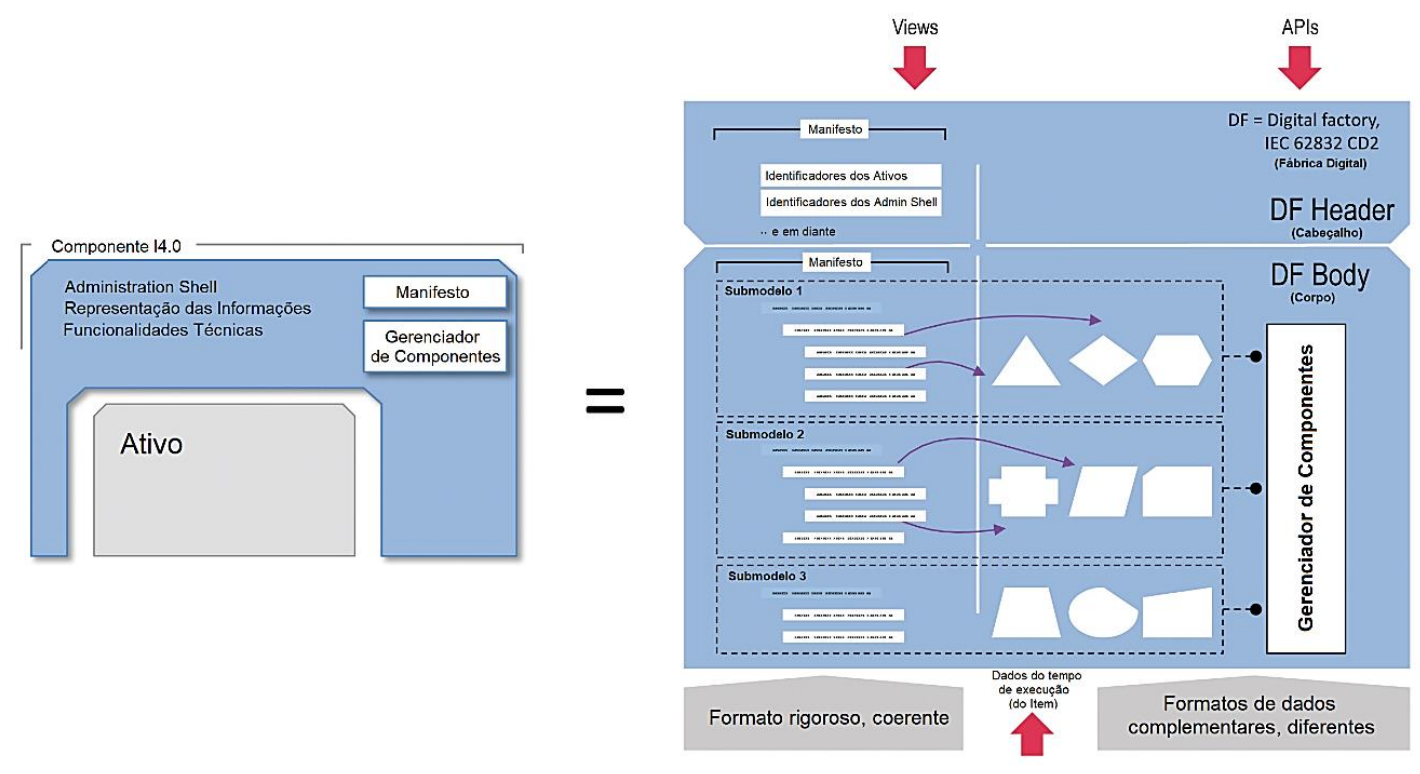

Fonte: Adaptado de (BEDENBENDER et al., 2017a).

- Local é um Ativo, pois nele são estabelecidas relações entre outros Ativos. Então se pode ter uma região (espaço físico) de uma planta/empresa, e ter também um agrupamento de máquinas ali, formando uma célula de manufatura, por exemplo;

- Tempo é um Ativo, pois em um determinado período de tempo pode-se estabelecer uma relação entre diferentes Ativos. Um Ativo "ordem de serviço" poderia relacionar um Ativo “equipamento" com um Ativo “operador" em um Ativo "planta de tratamento de efluentes" em um Ativo "período designado para realizar a atividade programada". Este Ativo contém todas as informações relevantes para um horário específico. Este pode ser o tempo do mundo físico, mas também pode ser um tempo virtual, por exemplo, para fins de simulação;

- Estado (de um Ativo) é um Ativo, e compreende todas as informações relevantes sobre o estado de um Ativo. Isso pode refletir o estado do mundo físico, mas também pode ser um estado virtual, por exemplo, para fins de simulação;

- Seres humanos, que agem como parte de um I4.0S, só podem se relacionar com outros Ativos se forem vistos, isto é, modelados como Ativos;

- Relacionamentos entre Ativos também são Ativos, pois os relacionamentos precisam ser estabelecidos, mantidos, rompidos e modificados, e desta forma também necessitam de um AAS para tanto. 
Ao considerar tudo o que é relevante para o sistema como um Ativo, tem-se a tentativa de padronização de uma estrutura para organização das informações dentro dos I4.0C, uma forma de estabelecer relacionamentos entre os I4.0C, e uma forma de interação entre os I4.0C.

\subsubsection{Asset Administration Shell (AAS)}

O AAS é uma representação digital do Ativo da I4.0, contendo todas as informações e funcionalidades técnicas do mesmo, e estabelece e gerencia uma comunicação padronizada, controlada e segura com os demais I4.0C (PLATTFORM INDUSTRIE 4.0, 2019; YE; HONG, 2019). Ou seja, como comentado anteriormente, o AAS fornece uma descrição mínima, única, mas suficiente, do Ativos (suas características, funcionalidades, propriedades, etc.) de acordo com os casos de uso da I4.0 (BEDENBENDER et al., 2017a; GAYKO, 2018). Ele pode ser usado tanto para integrar Ativos inteligentes ou não, ou seja, passivos (sem uma interface de comunicação) como, por exemplo, aqueles que apenas mantêm códigos de barras, QR-Code ou RFID (Radio-Frequency IDentification) (PLATTFORM INDUSTRIE 4.0, 2019).

AAS (i) organiza as informações (por exemplo, manuais, dados de tempo de execução) do Ativo em um banco de dados, formando a base para que as empresas atuem com algum grau de autonomia e apliquem mecanismos de inteligência artificial, e (ii) padroniza as interfaces de comunicação do Ativo, viabilizando a interoperabilidade entre os componentes, inclusive os de outras empresas (GAYKO, 2018; PLATTFORM INDUSTRIE 4.0, 2019). Isso viabiliza o funcionamento descentralizado (GAYKO, 2018), permitindo que a produção se torne modular, autônoma e suficientemente flexível para lidar com situações inesperadas e anormais; e produtos personalizados para o cliente, portanto, reduzindo seu custo frente aos praticados atualmente (YE; HONG, 2019).

As informações de produção geradas ao longo do ciclo de vida do Ativo são digitalizadas no AAS (YE; HONG, 2019). Em (PLATTFORM INDUSTRIE 4.0, 2019) é apresentado um exemplo de como esta característica é explorada:

- Durante a fase de projeto de engenharia (fase de Tipo), as funcionalidades são planejadas. Por exemplo, um motor (Ativo) com certo torque e comprimento de eixo. As propriedades do motor são colocadas no AAS;

- Na etapa seguinte é escolhido um motor específico, ainda na fase de Tipo, de um fabricante, e mais informações contidas no Tipo deste motor são adicionadas ao AAS; 
- O fabricante do motor fornece um "componente" para calcular e simular o motor (um “digital twin”), permitindo que a escolha possa ser avaliada (usando, por exemplo, técnicas de simulação) e confirmada;

- Depois, durante o comissionamento, o motor é solicitado, então vai se deixar de utilizar o Tipo referente ao motor e será utilizada a Instância do motor, com um número de série, e com dados específicos para esse motor individual, e estas informações também são armazenadas no $\mathbf{A A S}$;

- Parâmetros operacionais (temperatura, vibrações, etc.) são medidos durante a operação do motor e são gravados no AAS;

- As manutenções feitas no motor são registradas no AAS;

- Após o fim da vida útil, o motor é substituído por um novo. Essa alteração e todas as informações sobre os novos Tipo e Instância referentes ao novo motor são registradas;

- As informações contidas no AAS podem ser trocadas entre todos os parceiros envolvidos na cadeia de valor: fornecedores, engenheiros, integradores de sistemas, operadores e prestadores de serviço.

Consequentemente, todas as informações essenciais, digitalizadas e armazenadas em um AAS, podem ser usadas para aperfeiçoar os processos, interações e integração da cadeia de valor (PLATTFORM INDUSTRIE 4.0, 2019; YE; HONG, 2019).

Em relação à estrutura de um AAS, esta pode ser organizada entre um cabeçalho (Header) e um Corpo (Body), termos herdados do conceito de "Fábrica Digital" (YE; HONG, 2019).

O Cabeçalho apresenta uma lista de propriedades compatíveis com a I4.0, como a identificação única para o ativo físico e para o AAS (ADOLPHS et al., 2016; YE; HONG, 2019). Essa lista de propriedades é denominada Manifesto, definido como um conjunto de metadados, acessíveis externamente, que fornece informações sobre as propriedades funcionais e não funcionais do I4.0C (ADOLPHS et al., 2016; YE; HONG, 2019).

O Corpo é como um contêiner para as propriedades, Views suportadas, serviços e referências. Ele pode ser considerado a principal fonte de informações do AAS, e contém todas as informações e funções para executar aplicativos do Ativo (BEDENBENDER et al., 2017a).

Ele contém um Gerenciador de Componentes $(\mathbf{C M})$ responsável pelo gerenciamento e acesso a serviços em submodelos individuais (ADOLPHS et al., 2016; YE; HONG, 2019). 
Este $\mathbf{C M}$ consiste em um conjunto de serviços projetados para realizar a manutenção das informações ao longo da vida do Ativo. Em princípio, os recursos desse serviço devem, por meio da arquitetura orientada a serviços (SOA) serem compatíveis com a I4.0, disponibilizando comunicação compatível com a I4.0 a todos os participantes, levando em consideração requisitos de segurança (ADOLPHS et al., 2016). O AAS também deve garantir a aquisição contínua de dados gerados pelos Ativo como, por exemplo, dados de posição, velocidade, temperatura de atuadores mecânicos (ADOLPHS et al., 2016; YE; HONG, 2019).

Ainda em relação ao Corpo, cada submodelo é composto por um conjunto de propriedades organizadas hierarquicamente, vinculadas a vários dados ou funções. A totalidade das propriedades de todos os submodelos constitui o Manifesto no Corpo (ADOLPHS et al., 2016) e devem seguir um formato de dados padronizado, como o do eCl@ss ou o Common Data Dictionary, conforme especificado em (BEDENBENDER et al., 2019).

A Figura 59 apresenta a estrutura do AAS (BEDENBENDER et al., 2017a) discutida até o momento.

A partir de trabalhos como (ADOLPHS et al., 2016) e (YE; HONG, 2019) as principais características e requisitos do AAS podem ser sintetizadas em:

- O AAS é composto por um Cabeçalho e um Corpo;

- O Cabeçalho contém informações sobre a utilização do Ativo associado ao AAS;

- O Corpo contém informações referentes ao Ativo associado ao AAS;

- O Corpo consiste em um Manifesto (dos submodelos, isto é, dos diferentes aspectos do Ativo) e um CM;

- As informações do AAS são acessíveis por meio de uma solução baseada em arquitetura orientada a serviços (SOA), na forma de uma API (Application Programming Interface);

- O AAS representa as informações relativas a diferentes aspectos do Ativo;

- O AAS fornece as funcionalidades técnicas relacionadas ao papel do Ativo nas atividades produtivas;

- O AAS pode ser estruturado na forma de Views;

- O AAS possui um identificador (ID) único;

- O Ativo possui um ID único;

- Uma fábrica também pode ser vista como um Ativo, possuindo um AAS e sendo acessada por meio de um ID;

- O AAS pode ser identificado nas fases de Tipo e/ou Instância; 
Figura 59 - Estrutura atual do AAS

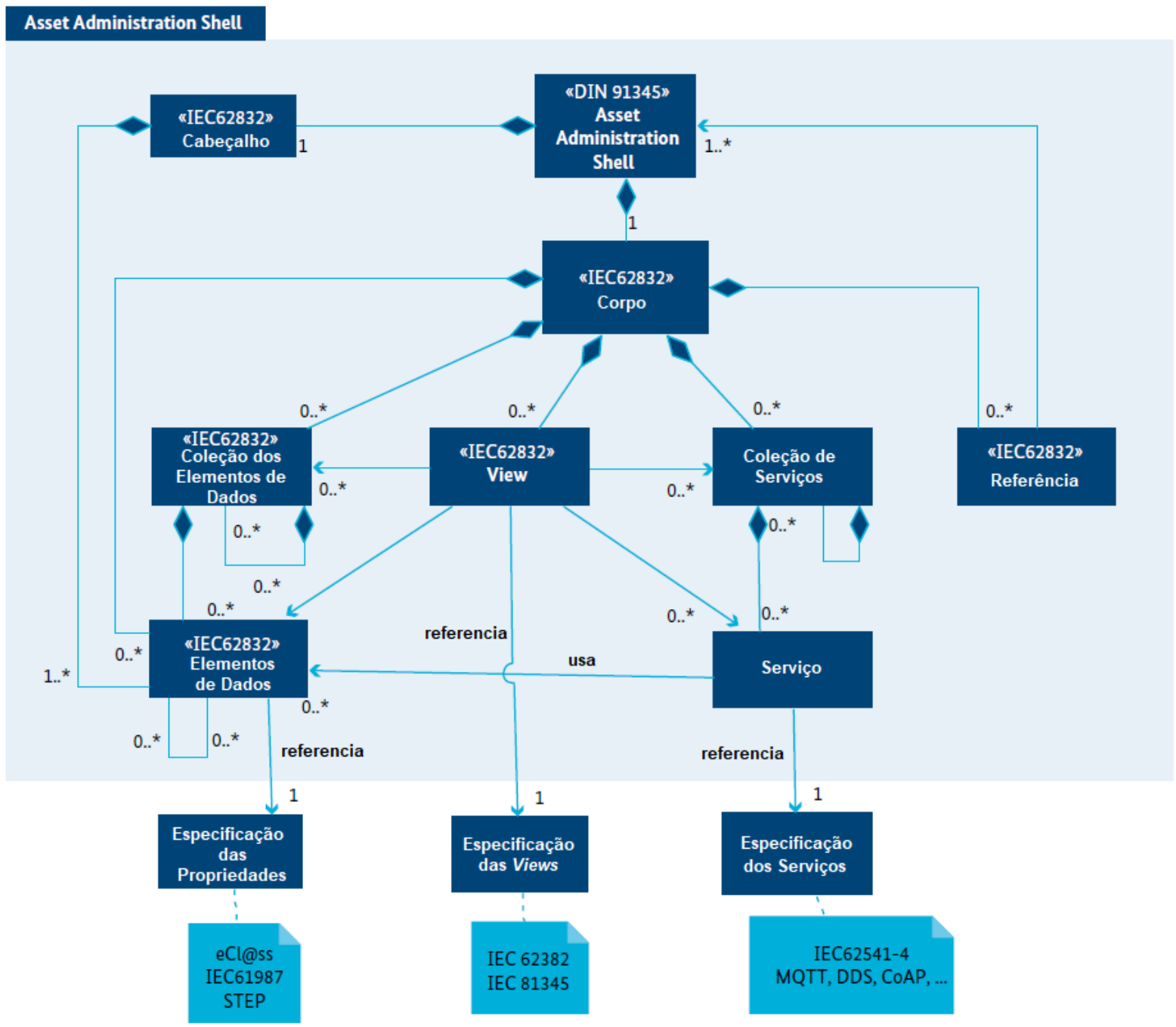

Fonte: Adaptado de (BEDENBENDER et al., 2017a).

- O AAS pode conter referências a outros AASs ou informações da I4.0;

- Cada AAS deve poder ser combinado em um AAS geral, sem perder a sua estrutura;

- Cada AAS deve ser capaz de estabelecer comunicação com outros AASs, ativa ou passivamente;

- Os AASs devem apresentar um entendimento semântico comum das informações trocadas;

- Propriedades adicionais, como por exemplo, informações específicas de um fabricante, também são contempladas;

- Uma quantidade mínima e confiável de propriedades deve ser definida para todos os AAS; 
- Cada AAS pode e deve operar em um estágio do ciclo de vida do Ativo durante um determinado período.

Ye e Hong (2019) destacam os impactos da implantação do AAS:

- $\quad \mathrm{Na}$ fase de engenharia, deve-se prezar pela engenharia multidisciplinar. Isso aumenta a eficiência do planejamento e do comissionamento quando comparado aos métodos de engenharia convencionais ${ }^{18}$;

- $\quad$ Na fase de operação, por um lado, os dados operacionais do Ativo são monitorados e registrados pelos respectivos AASs. Esses dados são fundamentais para controle de dispositivos, gerenciamento e atividades de diagnóstico e manutenção do sistema. Por outro lado, a implementação de AASs é a espinha dorsal do "plug and produce" na automação dos processos produtivos. A implantação de AASs reduz os esforços necessários para reconfigurações;

- Como os ativos envolvidos por AASs são autônomos, eles podem negociar entre si para garantir conexão, configuração e programação ideais de novos agrupamentos de AASs. No futuro, o AAS deve ser projetado para ter capacidades de inteligência distribuída em virtude de tecnologias como "gêmeo digital". Isso será usado para implementar processos produtivos totalmente descentralizados e modulares.

\subsubsection{Propriedades}

Segundo Bader et al. (2019) a norma IEC 61360 fornece uma estrutura e um modelo de informação para dicionários de produtos. O conceito de tipo de produto é representado por "classes" e as características do produto são representadas por "propriedades". Tais propriedades são elementos de dados padronizados. As definições destas propriedades podem ser encontradas em vários repositórios, como IEC CDD (Common Data Dictionary - dicionário de dados comuns) ou eCl@ss. A definição de uma propriedade associa um identificador exclusivo (e reconhecido mundialmente) a uma definição, que é um conjunto de atributos bem definidos.

Esta estrutura e modelo de informação para dicionários de produtos são aqui transferidos para o caso de Ativos de modo que atributos relevantes da propriedade para o AAS são, entre

\footnotetext{
${ }^{18}$ Que trabalham isolados ou com pouca interação.
} 
outros: o nome preferido, o símbolo, a unidade de medida e uma definição textual legível por seres humanos.

Segundo Adolphs et al. (2016) e Gayko (2018), são requisitos com relação às propriedades:

- As propriedades e outros elementos de informação no AAS devem ser adequados para os Ativos nas fases de Tipo e Instância;

- Deve haver uma capacidade de estruturação hierárquica e contável das propriedades;

- As propriedades devem poder fazer referência a outras propriedades, também em outros AASs;

- As propriedades devem ser capazes de referenciar dados e funções do AAS (no mínimo as internas a este);

- As propriedades devem levar em consideração aspectos da segurança da informação garantindo disponibilidade, integridade, confidencialidade, visibilidade e autenticidade.

As propriedades são classificadas em quatro classes distintas (ADOLPHS et al., 2016), conforme apresentada na Tabela 14:

- Básicas e mandatórias - são referentes a uma quantidade respectivamente pequena de propriedades que devem existir para, por exemplo, garantir a interoperabilidade dos componentes ou que podem descrever os índices de um componente específico (por exemplo, de acordo com a DIN ISO 61551-3). As propriedades básicas são obrigatórias e padronizadas para os AASs, enquanto a propriedades mandatórias são padronizadas para submodelos dos AASs;

- Opcionais - são propriedades padronizadas para os submodelos, mas não obrigatórias;

- Livres - podem ser formadas por uma ampla variedade de formatos de dados ou padrões de um fabricante. Estas propriedades podem ser formadas de maneira rápida e fácil, e também podem atender às especificidades de Ativos do fabricante.

\subsubsection{Referência}

O AAS pode fazer referência a outros AASs para determinados casos de uso. Pode ser útil saber à quais outros Ativos o Ativo em questão está conectado, em qual segmento da planta está localizado e de qual outro Ativo é derivado. Essas referências podem mudar 
dinamicamente durante a operação do Ativo, pois, por exemplo, o layout da fábrica pode mudar (BEDENBENDER et al., 2017a). A Figura 60 ilustra as possíveis referências associadas ao AAS. Nota-se também que a semântica associada a elas ainda deve ser definida e validada.

Tabela 14 - Classes de propriedades utilizadas

\begin{tabular}{ll}
\hline Propriedades Básicas & $\begin{array}{l}\text { Propriedades que são mandatórias e padronizadas } \\
\text { para todos os Administration Shells. }\end{array}$ \\
\hline Propriedades Mandatórias & $\begin{array}{l}\text { Propriedades que são mandatórias e padronizadas } \\
\text { para submodelos de Administration Shells. }\end{array}$ \\
\hline Propriedades Opcionais & $\begin{array}{l}\text { Propriedades que são padronizadas mas não } \\
\text { mandatórias para submodelos de Administration } \\
\text { Shells. }\end{array}$ \\
\hline Propriedades Livres & $\begin{array}{l}\text { Propriedades que são não padronizadas e não } \\
\text { compulsorias para submodelos de Administration } \\
\text { Shells, e.g. Propriedades especificas de fabricantes. }\end{array}$ \\
\hline
\end{tabular}

Fonte: Adaptado de (ADOLPHS et al., 2016).

\subsubsection{Submodelo}

O AAS é a representação digital padronizada do Ativo, e é a peça chave para garantir interoperabilidade entre os aplicativos que gerenciam os sistemas produtivos. Portanto, ele precisa fornecer uma descrição mínima, mas suficiente, de acordo com os diferentes cenários de aplicação na I4.0.

Muitos padrões (internacionais) diferentes podem contribuir para essa descrição (BADER et al., 2019). Como apresentado na Figura 61, informações de diferentes domínios técnicos podem ser associadas a um Ativo e, portanto, é necessário que propriedades diferentes sejam representadas nos AASs dos futuros I4.0C. Para gerenciar esse conjunto complexo de informações, os submodelos fornecem uma forma de organização. O AAS é, portanto, composto de uma série de submodelos. Eles representam diferentes aspectos do Ativo em questão.

O objetivo é ter um submodelo padronizado para cada aspecto do Ativo. Com isso, seria possível encontrar, por exemplo, uma furadeira quando se está procurando um AAS contendo um submodelo "Perfuração". Um segundo submodelo, "Eficiência energética", poderia identificar a furadeira com menor consumo de eletricidade. Ou seja, deve-se desenvolver um submodelo para cada aspecto funcional (PLATTFORM INDUSTRIE 4.0, 2019).

Ainda, cada submodelo contém uma quantidade estruturada de propriedades que podem se referir a dados e funções. Um formato padronizado baseado na IEC61360 é necessário para 
as propriedades. Dados e funções podem estar disponíveis em vários formatos complementares (BEDENBENDER et al., 2017a). A Figura 61 apresenta alguns dos possíveis submodelos para um AAS.

Figura 60 - Diferentes tipos de referências

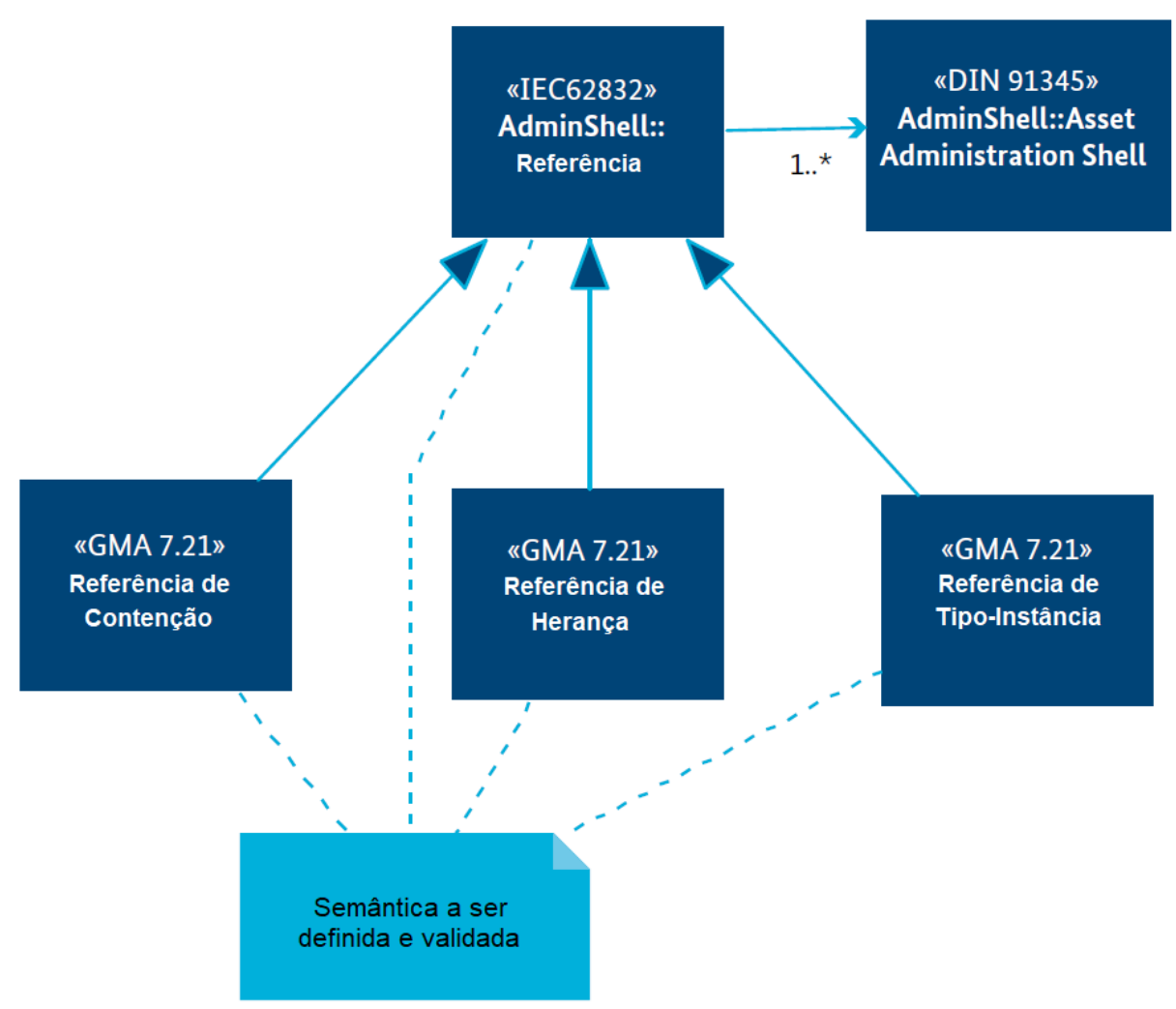

Fonte: Adaptado de (BEDENBENDER et al., 2017a).

Os submodelos contêm elementos que representam (PLATTFORM INDUSTRIE 4.0, 2019):

- Propriedades do Ativo em termos de IEC61360-1 e ecl@ss;

- Variáveis e parâmetros do processo, dados de telemetria;

- Referências a fontes ou arquivos de dados externos;

- Referências a outros AASs e suas partes (submodelos, propriedades), mesmo de parceiros externos que fazem parte da cadeia de valor;

- Capacidades do Ativo, descrição de chamadas de método;

- Conjuntos de propriedades. 
Figura 61 - Possíveis submodelos de um AAS

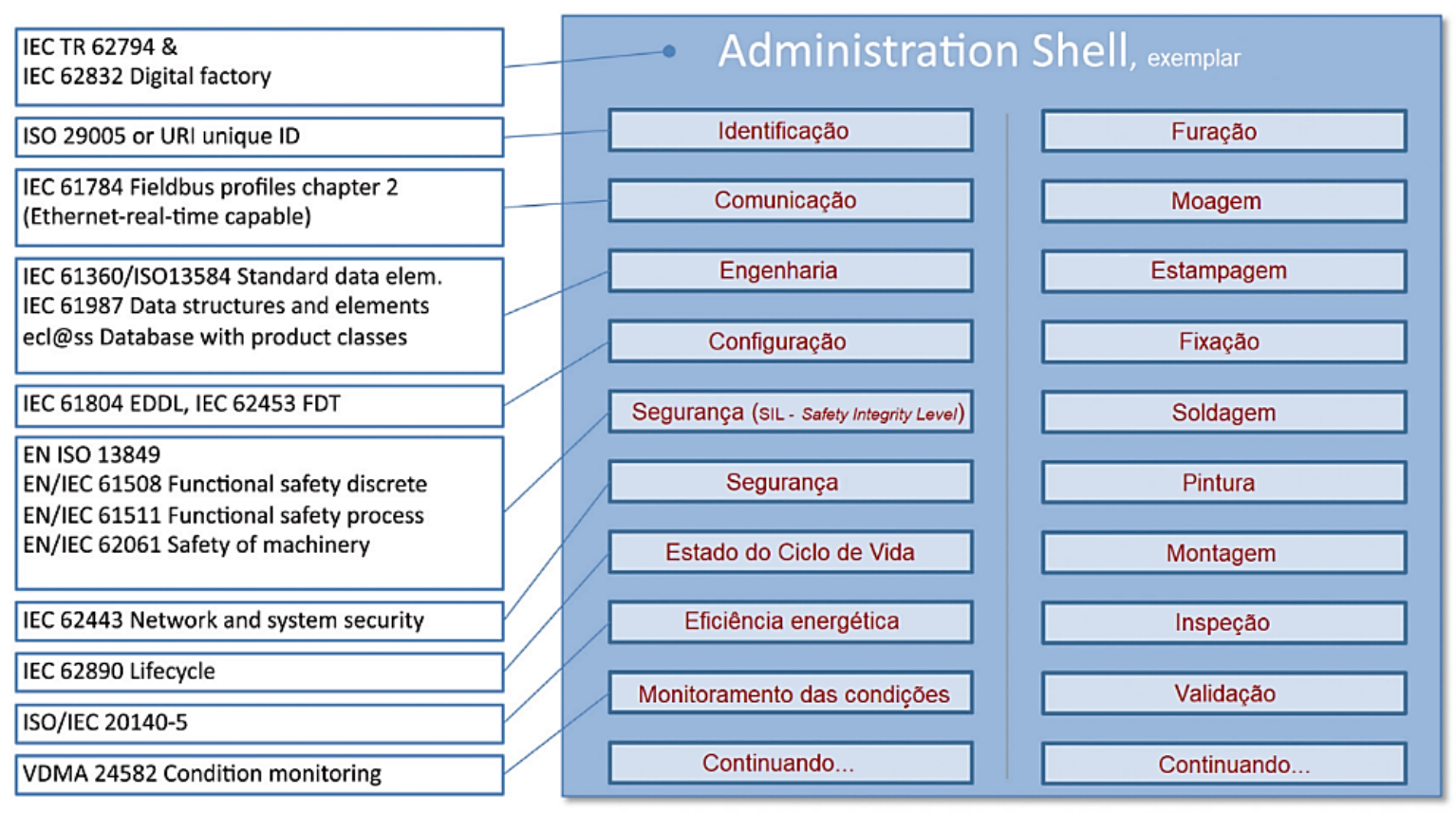

Fonte: Adaptado de (BEDENBENDER et al., 2017a).

De forma geral, os submodelos podem ser definidos como genéricos (para todos os Ativos), ou específicos para cada Ativo, dependendo das informações gerenciadas (YE; HONG, 2019).

Um submodelo genérico é um submodelo básico, padronizado, aplicável a uma ampla variedade de Ativos. Todos os AASs devem incluir submodelos genéricos para representar informações obrigatórias sobre os Ativos. No trabalho de Ye e Hong (2019) foram formulados quatro tipos de submodelos genéricos: (i) índice de dados; (ii) declaração de valor da propriedade; (iii) documentação; e (iv) comunicação. Todos são estáticos, e as propriedades são armazenadas e denominadas "dados".

A seguir são apresentados os quatro submodelos tratados em (YE; HONG, 2019).

\section{- $\underline{\text { Índice de dados }}$}

Este submodelo é o ponto de entrada/acesso para todos os outros submodelos. Ele contém um índice listando os IDs (identificadores) de outros submodelos em um formato, como o GUID (Globally Unique ID). Isso significa que é essencialmente um índice que permite a pesquisa eficiente de todos os submodelos (YE; HONG, 2019). 


\section{- Declaracão de valor da propriedade}

Este submodelo contém as propriedades estáticas do Ativo em questão. Ele também registra e gerencia metadados, que permitem aos usuários descobrir os atributos do Ativo. Essas propriedades podem incluir nomes, versões, históricos de revisões, fabricantes e símbolos. Algumas dessas propriedades podem mudar ao longo do ciclo de vida do Ativo, como históricos de revisão. Portanto, esse submodelo deve ser atualizado regularmente (YE; HONG, 2019).

\section{- $\quad$ Comunicacão}

Este submodelo armazena informações sobre os recursos de comunicação do Ativo. Normalmente, pelo menos um mecanismo de comunicação deve ser suportado por um AAS para trocar dados. Múltiplas capacidades de comunicação permitem que os Ativos executem várias funções, mas isso não é obrigatório (YE; HONG, 2019).

\section{- Documentação}

Este submodelo é um arquivo de parâmetros de configuração, dados de tempo de execução, e estágios do ciclo de vida do Ativo. Além disso, este submodelo pode conter dados sobre relacionamentos ou referências a informações dentro ou fora do AAS (YE; HONG, 2019).

\subsubsection{View}

View é parte do I4.0C que fornece meios para filtrar o conteúdo do AAS, para que sejam mostradas apenas as informações relevantes para cada tipo específico de usuário.

O número de elementos e serviços de dados para um Ativo industrial típico pode estar na faixa de centenas ou mesmo milhares, de modo que as Views permitem que humanos ou ferramentas restrinjam esta complexidade ao explorar ou interagir com o AAS. Por exemplo, poderia haver Views para tarefas de manutenção ou Views relacionadas apenas ao local físico de instalação do Ativo.

Diferentes Views podem fazer referência aos mesmos elementos de dados e serviços, não havendo uma separação estrita entre eles (BEDENBENDER et al., 2017a), conforme é apresentado na Figura 62 (ADOLPHS et al., 2016). 


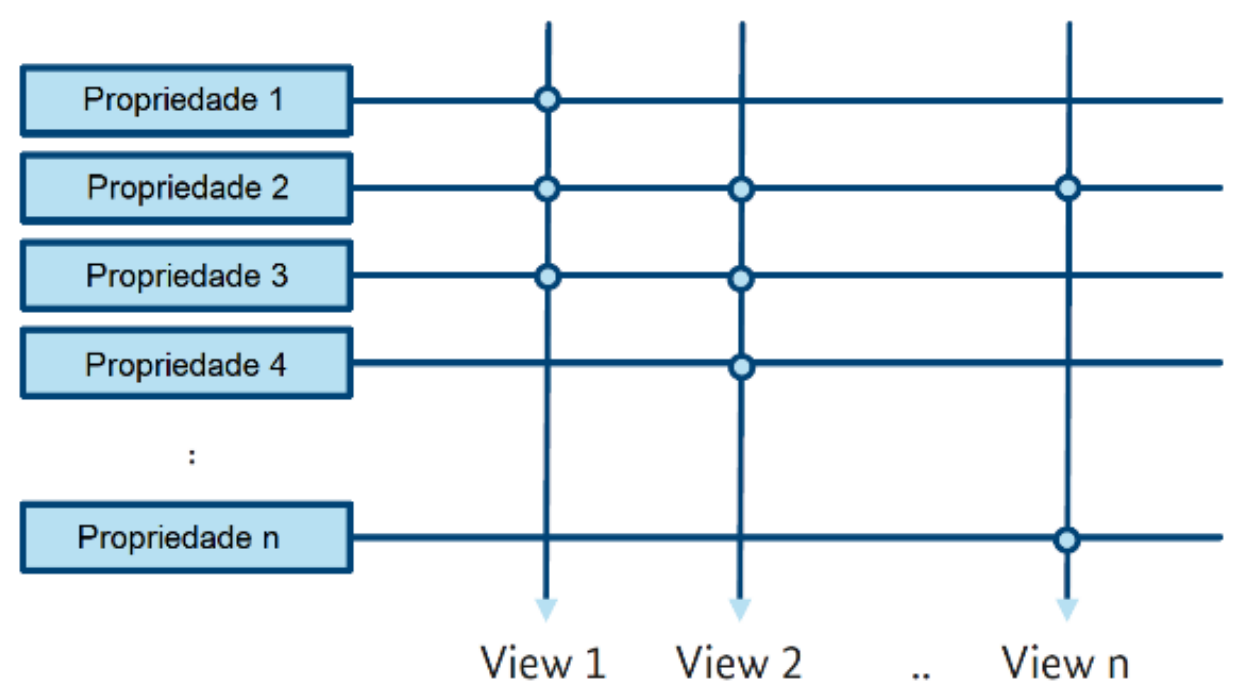

Fonte: Adaptado de (ADOLPHS et al., 2016).

A Tabela 15 apresenta as Views básicas e propõe exemplos apropriados em cada caso (ADOLPHS et al., 2016).

\subsection{Exemplo 1}

O exemplo a seguir foi apresentado em (BEDENBENDER et al., 2017a). Sua estrutura foi confrontada com a última publicação técnica sobre padronização, apresentada em (BADER et al., 2019). Entretanto, os autores alertam que ele pode conter discrepâncias frente às padronizações que ainda estão sendo desenvolvidas. Mesmo assim, ele foi mantido por ser um exemplo muito significativo de como o AAS deve ser organizado para promover a I4.0.

Este exemplo considera um Ativo denominado "MES" que deve decidir entre três I4.0Cs com funcionalidades similares (estações de trabalho de perfuração) e que competem por uma ordem de fabricação. Para isso, o MES consulta as propriedades destes três Ativo por meios de suas Views. Com isso os autores ilustram os conceitos de propriedades, submodelos e Views.

No entanto, ressalta-se que o conceito de MES e suas funções nos sistemas produtivos correntes não devem ser as mesmas que se espera para ele no contexto da I4.0. A Figura 63 ilustra este cenário, e os submodelos considerados, que são descritos a seguir:

- Submodelo "Conexão MES" - Conecta a estação de trabalho a um sistema MES por meio de um número relativamente pequeno de propriedades. Especifica se a estação está (i) produzindo, (ii) pronta para produção, (iii) está em estado de falha ou, (iv) está em manutenção, por exemplo; 


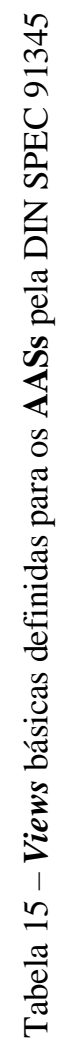

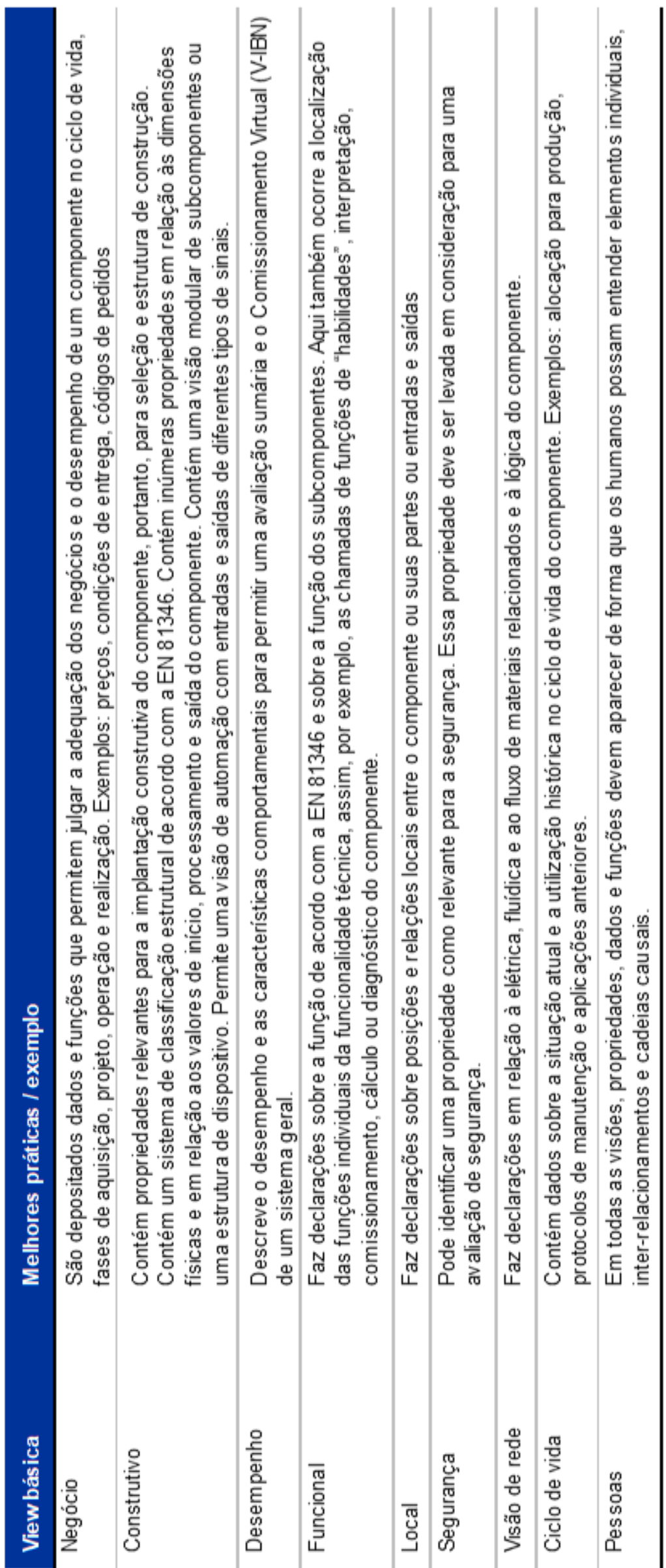

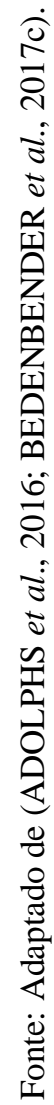


- Submodelo "Documentação" - Armazena os documentos como dados em formato PDF (não mostrado na figura);

- Submodelo "Eficiência energética" - Específica certos detalhes/dados sobre eficiência energética, por exemplo. Estes dados também podem ser fornecidos por sensores;

- Submodelo "Furação" - Contém um relativamente pequeno número de propriedades e funções para iniciar, finalizar ou simular o processo de furação.

Figura 63 - Exemplo de submodelos para o cenário apresentado em (BEDENBENDER et al., 2017a).

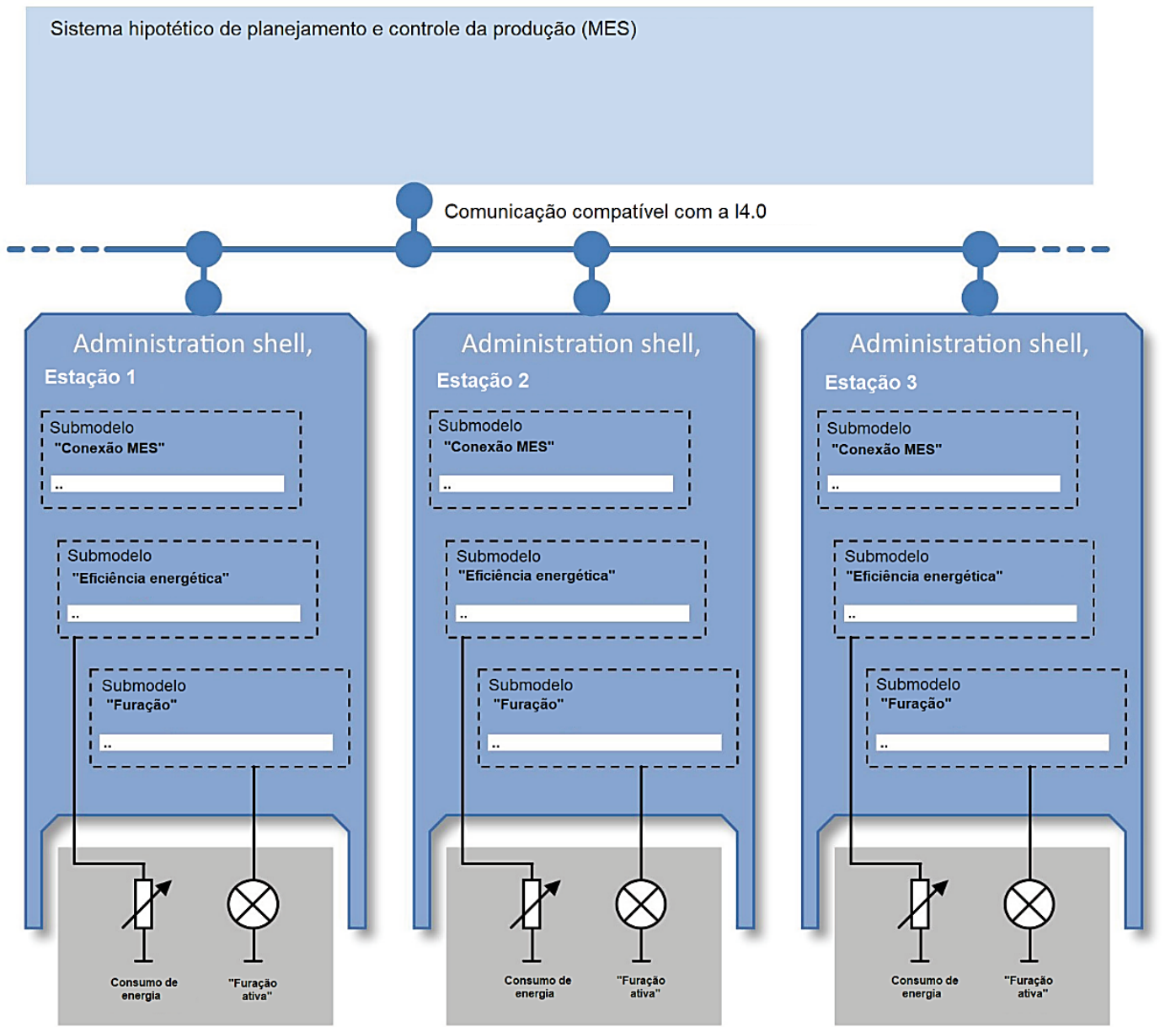

Fonte: Adaptado de (BEDENBENDER et al., 2017a).

Segundo (BEDENBENDER et al., 2017a), para este exemplo são consideradas propriedades hipotéticas com apenas alguns campos de dados, de acordo com a IEC61360. Definições adicionais devem ser feitas quando essas propriedades forem necessárias em submodelos reais. 
A Tabela 16 apresenta as informações "básicas" referentes ao AAS de cada um dos I4.0C do exemplo. Todos os principais elementos precisam ter uma identificação. Neste caso o AAS é um dos elementos que deve apresentar um "ID". Este exemplo desconsiderou a propriedade "idType" que pode informar que o "ID" é um identificador global ou "personalizado", ou seja, conhecido apenas em um contexto restrito, como de uma empresa, por exemplo. Os números da versão e revisão são opcionais, mas servem para ter controle das alterações. Em seguida é apresentado um conjunto de propriedades que ajudam a caracterizar o AAS. Com exceção da "Nome (preferido)", todas as demais são opcionais em (BADER et al., 2019).

Tabela 16 - Campos de dados para propriedades.

\begin{tabular}{|c|c|c|c|c|}
\hline Campo & Tradução & Explicação & Requerimento & Exemplo \\
\hline ID (Kennung) & ID & $\begin{array}{l}\text { Identificador de acordo com a ISO } 29002-5 \text {, } \\
\text { geralmente hipotético para este documento. Em } \\
\text { casos individuais, podem ser usadas definições } \\
\text { de propriedade real. Identificadores também } \\
\text { podem ser definidos como URIs }\end{array}$ & Mandatório & BAA120 \\
\hline Versionsnummer & $\begin{array}{l}\text { Número da } \\
\text { versão }\end{array}$ & $\begin{array}{l}\text { Número para distinguir a versão de um tipo de } \\
\text { elemento de dados }\end{array}$ & Mandatório & 007 \\
\hline Änderungsnummer & $\begin{array}{l}\text { Número de } \\
\text { revisão }\end{array}$ & $\begin{array}{l}\text { Número para distinguir a revisão de um tipo de } \\
\text { elemento de dados }\end{array}$ & Mandatório & 01 \\
\hline (bevorzugter) Name & $\begin{array}{l}\text { Nome } \\
\text { (preferido) }\end{array}$ & $\begin{array}{l}\text { Um nome que consiste em uma ou mais } \\
\text { palavras atribuídas a um tipo de elemento de } \\
\text { dados }\end{array}$ & Mandatório & Velocidade Max. \\
\hline Kurzbezeichung & Nome curto & $\begin{array}{l}\text { Exibição abreviada do nome preferido para o } \\
\text { tipo de elemento de dados }\end{array}$ & Mandatório & \\
\hline $\begin{array}{l}\text { Symbol des } \\
\text { Formelzeichens }\end{array}$ & $\begin{array}{l}\text { Simbolo de } \\
\text { letra } \\
\text { preferido }\end{array}$ & $\begin{array}{l}\text { Símbolo de fórmula do tipo de elemento de } \\
\text { dados }\end{array}$ & Opcional & "n" para rotações \\
\hline Definition & Definição & $\begin{array}{l}\text { Informações que descrevem exclusivamente o } \\
\text { significado de um tipo de elemento de dados e } \\
\text { permitem que ele seja diferenciado de todos os } \\
\text { outros tipos de elementos de dados }\end{array}$ & Mandatório & $\begin{array}{l}\text { Maxima velocidade permitida } \\
\text { na qual o motor ou unidade } \\
\text { de fornecimento pode ser } \\
\text { operada. }\end{array}$ \\
\hline $\begin{array}{l}\text { Quellendokument für } \\
\text { die Definition des } \\
\text { Datentypelements }\end{array}$ & $\begin{array}{l}\text { Documento } \\
\text { de origem da } \\
\text { definição }\end{array}$ & $\begin{array}{l}\text { Referência a outros documentos que contêm a } \\
\text { definição }\end{array}$ & Opcional & $\begin{array}{l}\text { http://industrie-i40. } \\
\text { org/2016/interaction/ } \\
\text { negotiation/property_ } \\
\text { type/task_ref_number }\end{array}$ \\
\hline Datentyp & $\begin{array}{l}\text { Tipo de } \\
\text { dados }\end{array}$ & $\begin{array}{l}\text { Tipo de dados que uma implementação de } \mathrm{TI} \\
\text { usa para representar valores desse elemento } \\
\text { de tipo de dados }\end{array}$ & Mandatório & $\begin{array}{l}\text { INTEGER } \\
\text { MEASURE }\end{array}$ \\
\hline Werteformat & $\begin{array}{l}\text { Formato do } \\
\text { valor }\end{array}$ & $\begin{array}{l}\text { Especifica o tipo e a duração para exibir os } \\
\text { valores desse elemento de tipo de dados }\end{array}$ & Mandatório & NR1..5 ou outra \\
\hline Maßeinheit & $\begin{array}{l}\text { Unidade de } \\
\text { medida }\end{array}$ & $\begin{array}{l}\text { Especifica a unidade na qual o valor de um tipo } \\
\text { de elemento de dados qualificado deve ser } \\
\text { fornecido }\end{array}$ & $\begin{array}{l}\text { Mandatório, } \\
\text { "n.a." } \\
\text { Permitido }\end{array}$ & $1 / \min$ \\
\hline Werteliste & $\begin{array}{l}\text { Lista de } \\
\text { valores }\end{array}$ & $\begin{array}{l}\text { Especifica os valores permitidos para um tipo } \\
\text { de elemento de dados }\end{array}$ & $\begin{array}{l}\text { Mandatório, } \\
\text { "n.a." } \\
\text { Permitido }\end{array}$ & $0 . .8000$ \\
\hline
\end{tabular}

Fonte: Adaptado de (BEDENBENDER et al., 2017a). 
Os termos da coluna "Campo" foram mantidos na língua alemã para manter o campos de identificação da forma como ele é descrito no exemplo. A tradução destes termos, assim como sua explicação e demais propriedades seguem traduzidas nas outras colunas.

Já na Tabela 17 é apresentada uma estruturação para os submodelos do AAS. Bader et al. (2019) não fazem referência a uma "Hierarquia". Assim como na Tabela 16, o "ID" e o "Nome (preferido)" são obrigatórios. Novamente faltou a propriedade "idType". As propriedades que contemplam de "Definição" até "Valor" são opcionais.

Tabela 17 - Campos de dados para submodelos.

\begin{tabular}{|c|c|c|c|c|}
\hline Campo & Tradução & Explicação & Requerimento & Exemplo \\
\hline Hierarchie & Hierarquia & $\begin{array}{l}\text { Permite a indicação das estruturas hierárquicas e } \\
\text { contáveis das propriedades no submodelo por requisito }\end{array}$ & Mandatório & +-+ \\
\hline ID (Kennung) & ID & (Ver tabela anterior) & Mandatório & \\
\hline (bevorzugter) Name & $\begin{array}{l}\text { Nome } \\
\text { (preferido) }\end{array}$ & (Ver tabela anterior) & Mandatório & \\
\hline Definition & Definição & (Ver tabela anterior) & Mandatório & \\
\hline Maßeinheit & $\begin{array}{l}\text { Unidade de } \\
\text { medida }\end{array}$ & (Ver tabela anterior) & $\begin{array}{l}\text { Mandatório, } \\
\text { "n.a." } \\
\text { Permitido }\end{array}$ & \\
\hline Datentyp & Tipo de dados & (Ver tabela anterior) & Mandatório & \\
\hline Werteliste & $\begin{array}{l}\text { Lista de } \\
\text { valores }\end{array}$ & (Ver tabela anterior) & $\begin{array}{l}\text { Mandatório, } \\
\text { "n.a." } \\
\text { Permitido }\end{array}$ & \\
\hline Wert & Valor & $\begin{array}{l}\text { Valor atual que pode ser especificado através de um } \\
\text { submodelo instanciado (por exemplo, na estação 2) ou } \\
\text { através do ativo }\end{array}$ & Opcional & $22501 / \mathrm{min}$ \\
\hline Ausprägungsaussage & $\begin{array}{l}\text { Expressão } \\
\text { semântica }\end{array}$ & $\begin{array}{l}\text { Especifica qual papel a propriedade desempenha em } \\
\text { uma interação, ou seja, qual expressão o provedor da } \\
\text { propriedade pretende. } \\
\text { Os valores válidos são: } \\
\text { - Requisito (para solicitações que devem ser confirmadas } \\
\text { ou rejeitadas) } \\
\text { - Confirmações (para respostas a solicitações que } \\
\text { descrevem a capacidade de um ativo) } \\
\text { - Medição (se um valor medido ou real for fornecido) }\end{array}$ & $\begin{array}{l}\text { Mandatório, } \\
\text { "n.a." } \\
\text { Permitido }\end{array}$ & $\begin{array}{l}\text { Requerimento, } \\
\text { Confirmação, } \\
\text { Medição }\end{array}$ \\
\hline Ausprägungslogik & $\begin{array}{l}\text { Expressão } \\
\text { lógica }\end{array}$ & $\begin{array}{l}\text { Especifica qual função deve ser usada se diferentes } \\
\text { lógicas de expressão forem comparadas entre si. }\end{array}$ & Opcional & $\begin{array}{l}\text { Igual, maior ou igual a, } \\
\text { menor ou igual a, entre } \\
\text { os valores }\end{array}$ \\
\hline Sicht & Visão & $\begin{array}{l}\text { Indica a quais visualizações a propriedade está } \\
\text { associada }\end{array}$ & Mandatorio & Negócio \\
\hline$R / D / F / A /-$ & $R / D / F / A /-$ & $\begin{array}{l}\text { Indica se uma referência, conteúdo de dados complexo } \\
\text { ou funcionalidade é especificada nas colunas } \\
\text { subseqüentes. "A" significa Anmerkung (Comentário) }\end{array}$ & $\begin{array}{l}\text { Mandatório, } \\
\text { "n.a." } \\
\text { Permitido }\end{array}$ & $\mathbf{F}$ \\
\hline Inhalt & Conteudo & $\begin{array}{l}\text { Descrição da referência ( } O \text { que é referenciado?), do } \\
\text { conteúdo dos dados ( } O \text { que é referido e em que } \\
\text { formato?), ou da funcionalidade (Onde isso é } \\
\text { implementado? Como é representado? O que essa } \\
\text { funcionalidade inclui?). Se o indicador }=A \text {, basta inserir } \\
\text { um comentário sobre o conteúdo da linha. }\end{array}$ & $\begin{array}{l}\text { Mandatório, desde } \\
\text { que "-" não seja } \\
\text { inserido acima }\end{array}$ & $\begin{array}{l}\text { Biblioteca de módulos } \\
\text { funcionais de acordo } \\
\text { com a IEC } 61131 \text { que } \\
\text { deve ser implementada } \\
\text { no próximo controle } \\
\text { compativel com } 61131 .\end{array}$ \\
\hline
\end{tabular}

Fonte: Adaptado de (BEDENBENDER et al., 2017a). 
Não foram encontradas menções às demais propriedades. Faz-se uma observação quanto à propriedade "View", pois não é no submodelo que se apresenta a View na qual será usada, mas é sim, na View, que são referenciadas as propriedades a serem utilizadas.

Outra observação é quanto ao "Valor", onde no exemplo deveria constar apenas "2250", sem unidade, visto que existe uma propriedade para especificar a unidade de medição.

Na Tabela 18 é apresentado um exemplo de aplicação da organização dos dados para os submodelos. A primeira linha apresenta uma informação quanto ao funcionamento do Ativo, enquanto a segunda linha apresenta uma informação quanto ao total de segundos trabalhados.

Tabela 18 - Submodelo "Conexão MES”.

\begin{tabular}{|c|c|c|c|c|c|c|c|c|c|c|c|c|}
\hline \multirow[b]{2}{*}{ Hierarquia } & \multirow[b]{2}{*}{ ID } & \multirow[b]{2}{*}{$\begin{array}{c}\text { Nome } \\
\text { (preferido) }\end{array}$} & \multirow[b]{2}{*}{ Definição } & \multicolumn{3}{|c|}{ Definição das propriedades } & \multicolumn{3}{|c|}{ Caracterização das propriedades } & \multirow[b]{2}{*}{ Views } & \multirow[b]{2}{*}{$\mathrm{R} / \mathrm{D} / \mathrm{F} / \mathrm{A}-$} & \multirow[b]{2}{*}{ Conteudo } \\
\hline & & & & $\begin{array}{c}\begin{array}{c}\text { Unidade de } \\
\text { medida }\end{array} \\
\end{array}$ & Tipo de dado & \begin{tabular}{|l} 
Lista de Valores \\
\end{tabular} & Valor & $\begin{array}{l}\text { Expressão } \\
\text { semântica }\end{array}$ & Expressão lógica & & & \\
\hline 1 & AAA020 & $\begin{array}{c}\text { Estado de } \\
\text { produção do Ativo }\end{array}$ & $\begin{array}{l}\text { Esta propriedade determina, se } \\
\text { o ativo associado é capaz de } \\
\text { executar una tarefa de } \\
\text { produção no momento }\end{array}$ & & ENUM & $\begin{array}{l}\text { \{Ocioso, } \\
\text { Operando, } \\
\text { Falha, } \\
\text { Contido, } \\
\text { Programado, } \\
\text { Não programado\} }\end{array}$ & Operando & Medição & Igual & Negócio & D & - \\
\hline 1 & AAA021 & Horas de operação & $\begin{array}{l}\text { Esta propriedade determina, } \\
\text { quanto tempo cumulativamante } \\
\text { o ativo associado foi ligado à } \\
\text { fonte de energia. }\end{array}$ & s & INT64 & $0 .{ }^{*}$ & $153453 \mathrm{~s}$ & Medição & Igual & Desempenho & D & - \\
\hline
\end{tabular}

Fonte: Adaptado de (BEDENBENDER et al., 2017a).

O exemplo da Tabela 19 serve para ilustrar a organização das propriedades de forma hierárquica. AAB010 e AAB020 indicam os topos das hierarquias. O primeiro para energia elétrica e o segundo para energia pneumática. Novamente, a unidade não deveria estar na coluna "Valor".

Na Tabela 20 é interessante notar as propriedades AAC007, AAC008, e AAC011. Na propriedade AAC007 o campo "Tipo de dado" faz referência a uma tabela de materiais (Tabela 21), que são organizados hierarquicamente, sendo CAA001 o topo da hierarquia. Deve-se ressaltar que é uma forma simplificada de referência a um elemento externo, visto que seria necessário informar a localização desta tabela, seu ID, e aí sim a propriedade de interesse. O mesmo pode ser dito do campo "Valor".

Na Tabela 22 é exemplificada uma forma de organizar a documentação associada a um AAS ou Ativo. Chamam a atenção as propriedades AAD003 e AAD007. Em AAD003 faz-se referência à Tabela 23, de documentação. Já a propriedade AAD007 apresenta a referência para a tabela de tipos de documentos (“Tipo de dado" é CAD001), mas "Valor" deveria ser CAD002 (Tabela 24) ao invés de utilizar uma comparação em um campo de valor (CAD001 == PDF). 
Tabela 19 - Submodelo "Eficiência energética".

\begin{tabular}{|c|c|c|c|c|c|c|c|c|c|c|c|c|}
\hline \multirow[b]{2}{*}{ Hierarquia } & \multirow[b]{2}{*}{ ID } & \multirow[b]{2}{*}{$\begin{array}{c}\text { Nome } \\
\text { (preferido) }\end{array}$} & \multirow[b]{2}{*}{ Definiçăo } & \multicolumn{3}{|c|}{ Definição das propriedades } & \multicolumn{3}{|c|}{ Caracterização das propriedades } & \multirow[b]{2}{*}{ Views } & \multirow[b]{2}{*}{$R / D / F / A-$} & \multirow[b]{2}{*}{ Conteudo } \\
\hline & & & & $\begin{array}{c}\text { Unidade de } \\
\text { medida }\end{array}$ & Tipo de dado & Lista de Valores & Valor & $\begin{array}{l}\text { Expressäo } \\
\text { semântica }\end{array}$ & Expressão lógica & & & \\
\hline+- & AAB010 & Energia elétrica & $\begin{array}{l}\text { Este é um grupo de } \\
\text { propriedades relacionadas ao } \\
\text { consumo de energia elétrica. }\end{array}$ & $\cdot$ & - & - & - & - & - & Desempenho & & \\
\hline-1 & AAB011 & $\begin{array}{c}\text { Consumo elétrico } \\
\text { real }\end{array}$ & Consumo elétrico atual, real. & w & Real & $0 .{ }^{*}$ & $93.6[\mathrm{~W}]$ & Medição & Igual & Desempenho & & \\
\hline-1 & AAB012 & $\begin{array}{c}\text { Consumo de } \\
\text { energia elétrica } \\
\text { acumulada }\end{array}$ & $\begin{array}{c}\text { Consumo elétrico integrado ao } \\
\text { longo do tempo. }\end{array}$ & Wh & Real & $0 . .^{*}$ & $118.86[\mathrm{Wh}]$ & Medição & Igual & Desempenho & & \\
\hline-1 & AAB013 & $\begin{array}{c}\text { Data de inicio do } \\
\text { consumo de } \\
\text { energia elétrica } \\
\text { acumulada }\end{array}$ & $\begin{array}{c}\text { Data e hora em que a } \\
\text { integraçāo do consumo elétrico } \\
\text { foi iniciada. }\end{array}$ & - & $\begin{array}{c}\text { UTC Hora \& } \\
\text { Data }\end{array}$ & n/a & $\begin{array}{l}\text { 2002-05- } \\
\text { 30T09:30:10Z }\end{array}$ & Medição & Igual & Desempenho & A & $\begin{array}{c}\text { Para o XML como } \\
\text { formato de horário } \\
\text { UTC ver: } \\
\text { http } \mathrm{p} / \text { www.w3schools.c } \\
\text { om/xml/schema_dtypes } \\
\text { ddate.asp }\end{array}$ \\
\hline+- & AAB020 & $\begin{array}{c}\text { Energia } \\
\text { pneumática }\end{array}$ & $\begin{array}{c}\text { Este é um grupo de } \\
\text { propriedades relacionadas ao } \\
\text { consumo de energia } \\
\text { pneumática. }\end{array}$ & - & - & - & - & - & - & Desempenho & & \\
\hline-1 & AAB021 & $\begin{array}{l}\text { Pressão real de } \\
\text { alimentação }\end{array}$ & $\begin{array}{l}\text { Pressão fornecida ao ativo } \\
\text { detectada na sua entrada. }\end{array}$ & bar & Real & $0 . .{ }^{*}$ & $8[\mathrm{bar}]$ & Mediçāo & Igual & Desempenho & & \\
\hline-1 & AAB022 & $\begin{array}{c}\text { Consumo } \\
\text { pneumático real }\end{array}$ & $\begin{array}{l}\text { Consumo pneumático atual, } \\
\text { real. }\end{array}$ & $\mathrm{L} / \mathrm{h}$ & Real & $0 .{ }^{*}$ & $212[\mathrm{LLh}]$ & Medição & Igual & Desempenho & & \\
\hline-1 & AAB023 & \begin{tabular}{|c|} 
Consumo \\
pneumatico de \\
energia acumulada
\end{tabular} & $\begin{array}{l}\text { Consumo pneumático integrado } \\
\text { ao longo do tempo. }\end{array}$ & L & Real & $0 . .{ }^{*}$ & $3424[$ [L] & Mediçāo & Igual & Desempenho & & \\
\hline-1 & AAB024 & $\begin{array}{c}\text { Data de inicio do } \\
\text { consumo de } \\
\text { energia } \\
\text { pneumatica } \\
\text { acumulada }\end{array}$ & $\begin{array}{l}\text { Data e hora em que a } \\
\text { integração do consumo } \\
\text { pneumático fol iniciado. }\end{array}$ & - & $\begin{array}{c}\text { UTC Hora \& } \\
\text { Data }\end{array}$ & n/a & $\begin{array}{l}\text { 2002-05- } \\
\text { 30T09:30:10Z }\end{array}$ & Mediçāo & Igual & Desempenho & & \\
\hline
\end{tabular}

Fonte: Adaptado de (BEDENBENDER et al., 2017a).

Tabela 20 - Submodelo "Furação".

\begin{tabular}{|c|c|c|c|c|c|c|c|c|c|c|c|c|}
\hline & & & & Definic & ao das prop & riedades & ract & ção das pr & priedades & & & \\
\hline Hierarquia & ID & $\begin{array}{c}\text { Nome } \\
\text { (preferido) }\end{array}$ & Definiçăo & $\begin{array}{c}\text { Unidade de } \\
\text { medida }\end{array}$ & Tipo de dado & \begin{tabular}{|l} 
Lista de Valores \\
\end{tabular} & Valor & $\begin{array}{l}\text { Expressãa } \\
\text { semantica }\end{array}$ & Expressão lógica & Views & RIDFF/A- & Conteudo \\
\hline I & AAC001 & $\begin{array}{c}\text { Diâmetro da broca } \\
\text { de furaçăo max. }\end{array}$ & $\begin{array}{l}\text { Diâmetro máximo da ferramenta } \\
\text { de furaçáa que pode ser } \\
\text { usinada }\end{array}$ & $\mathrm{mm}$ & Real & $0 . . *$ & $12[\mathrm{~mm}]$ & Confirmação & Menor que & Desempenho & - & \\
\hline I & AAC002 & 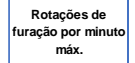 & $\begin{array}{c}\text { Rotaçōes máximas por minuto } \\
\text { para a furaçăo }\end{array}$ & $1 /$ min & Real & $0 . . *$ & 2000 [1/min] & Confirmaçăo & Menor que & Desempenho & - & \\
\hline$F==$ & AAC003 & $\begin{array}{c}\text { Simulacăa do do } \\
\text { tempo de furação }\end{array}$ & $\begin{array}{c}\text { Determinado por simulaçăo ou } \\
\text { estimando o tempo do processo } \\
\text { para todo o processo de } \\
\text { furação }\end{array}$ & sec & Real & $0 . . *$ & $0.21[\mathrm{sec}]$ & Confirmaçăo & Menor que & Desempenho & $\mathbf{F}$ & $\begin{array}{c}\text { Chamada de função sincrona, } \\
\text { utilizando os parâmetros de } \\
\text { entrada (AAC000 . . AAC007) e } \\
\text { retornando u m REAL }\end{array}$ \\
\hline-1 & AAC004 & $\begin{array}{c}\text { Diâmetro da broca } \\
\text { de furaçấo }\end{array}$ & Diâmetro da ferramenta a usar & $\mathrm{mm}$ & Real & $0 . .{ }^{*}$ & $5[\mathrm{~mm}]$ & Requisito & Igual & Desempenho & $\cdot$ & \\
\hline-1 & AAC005 & $\begin{array}{l}\text { Taxa de } \\
\text { alimentaçăo da } \\
\text { broca }\end{array}$ & Taxa de alimentaçăo a usar & mm/sec & Real & $0 . .{ }^{*}$ & $3[\mathrm{~mm} / \mathrm{sec}]$ & Requisito & Igual & Desempenho & - & \\
\hline-1 & AAC006 & $\begin{array}{l}\text { Profundidade da } \\
\text { broca }\end{array}$ & Profundidade a ser perfurada & $\mathrm{mm}$. & Real & $0 .{ }^{*}$ & $8.2[\mathrm{~mm}]$ & Requisito & Igual & Desempenho & - & \\
\hline-1 & AAC007 & $\begin{array}{l}\text { Material da peça } \\
\text { de trabalho }\end{array}$ & $\begin{array}{l}\text { Classe de material para } \\
\text { perfurar }\end{array}$ & . & $\rightarrow$ CAA001 & - & CAA005 & . & . & Desempenho & . & \\
\hline$F=$ & AAC008 & $\begin{array}{l}\text { Iniciar programa } \\
\text { de furaçâa }\end{array}$ & $\begin{array}{l}\text { Iniciando o programa de } \\
\text { furação pré-configurado }\end{array}$ & - & $\rightarrow$ CAB001 & - & - & - & . & Desempenho & $\mathrm{F}$ & $\begin{array}{c}\text { Inicia assincronamente o } \\
\text { programa de furacacoe e etorna } \\
\text { imediatamente sucesso / erro }\end{array}$ \\
\hline-1 & AAC004 & $\begin{array}{c}\text { Diâmetro da broca } \\
\text { de furaçâao }\end{array}$ & Diâmetro da ferramenta a usar & $\mathrm{mm}$ & Real & $0 .{ }^{*}$ & $5[\mathrm{~mm}]$ & Requisito & Igual & Desempenho & - & \\
\hline-1 & AAC005 & $\begin{array}{l}\text { Taxa de } \\
\text { alimentaçăo da } \\
\text { broca }\end{array}$ & Taxa de alimentaçăo a usar & $\mathrm{mm} / \mathrm{sec}$ & Real & $0 . .{ }^{*}$ & $3[\mathrm{~mm} / \mathrm{sec}]$ & Requisito & Igual & Desempenho & - & \\
\hline-1 & AAC006 & $\begin{array}{l}\text { Profundidade da } \\
\text { broca }\end{array}$ & Profundidade a ser perfurada & $\mathrm{mm}$ & Real & $0 . . *$ & $8.2[\mathrm{~mm}]$ & Requisito & Igual & Desempenho & - & \\
\hline-1 & AAC007 & $\begin{array}{c}\text { Material da peça } \\
\text { de trabalho }\end{array}$ & $\begin{array}{l}\text { Classe de material para } \\
\text { perfurar }\end{array}$ & - & $\rightarrow$ CAA001 & - & CAA007 & Requisito & Igual & Desempenho & - & \\
\hline-1 & AAC009 & Posiçăo da broca $\mathrm{X}$ & Coordenada $\mathrm{X}$ para perfurar & $\mathrm{mm}$ & Real & $0 .{ }^{*}$ & $12[\mathrm{~mm}]$ & Requisito & Igual & Desempenho & - & \\
\hline-1 & AAC010 & Posiçāo da broca Y & Coordenada $Y$ para perfurar & $\mathrm{mm}$ & Real & $0 . .^{*}$ & $42[\mathrm{~mm}]$ & Requisito & Igual & Desempenho & - & \\
\hline$F=$ & AAC011 & $\begin{array}{l}\text { Interromper o } \\
\text { programa de } \\
\text { furaçâo }\end{array}$ & $\begin{array}{l}\text { Interromper o programa de } \\
\text { perfuraçâo atual }\end{array}$ & - & $\rightarrow$ CAB001 & - & . & . & . & Desempenho & $\mathrm{F}$ & $\begin{array}{l}\text { Interrompe assincronamente o } \\
\text { programa de furaçäo e retorna } \\
\text { imediatamente sucesso / erro }\end{array}$ \\
\hline
\end{tabular}

Fonte: Adaptado de (BEDENBENDER et al., 2017a) 
Tabela 21 - Exemplo de classificação de materiais, utilizado na Tabela 20.

\begin{tabular}{|c|c|c|c|}
\hline Hierarquia & ID & Nome & Definição \\
\hline+ & CAA001 & Material & \\
\hline+-+ & CAA002 & Metal & \\
\hline +-+-+ & CAA003 & Liga não metálica & \\
\hline +-+-+-+ & CAA004 & Aço & \\
\hline +-+-+-+-I & CAA005 & S275JR & \\
\hline +-+-+-+ & CAA006 & Alumínio & \\
\hline +-+-+-+-I & CAA007 & AW-6060 & \\
\hline +-+-+-+-I & CAA008 & AW-7020 & \\
\hline +-+-+ & CAA009 & Liga metálica & \\
\hline +-+-+-+ & CAA010 & Cobre & \\
\hline +-+-+-+-I & CAA011 & CR004A & \\
\hline
\end{tabular}

Fonte: Adaptado de (BEDENBENDER et al., 2017a).

Novamente, para referenciar propriedades em outros locais seriam necessárias mais orientações quanto à localização da propriedade.

Tabela 22 - Submodelo "Documentações".

\begin{tabular}{|c|c|c|c|c|c|c|c|c|c|c|c|c|}
\hline \multirow[b]{2}{*}{ Hierarquia } & \multirow[b]{2}{*}{ ID } & \multirow[b]{2}{*}{$\begin{array}{c}\text { Nome } \\
\text { (preferido) }\end{array}$} & \multirow[b]{2}{*}{ Definiçăo } & \multicolumn{3}{|c|}{ Definição das propriedades } & \multicolumn{3}{|c|}{ Caracterização das propriedades } & \multirow[b]{2}{*}{ Views } & \multirow[b]{2}{*}{ RID/F/A- } & \multirow[b]{2}{*}{ Conteudo } \\
\hline & & & & $\begin{array}{c}\text { Unidade de } \\
\text { medida }\end{array}$ & \begin{tabular}{|l} 
Tipo de dado \\
\end{tabular} & Lista de Valores & Valor & $\begin{array}{l}\begin{array}{l}\text { Expressäo } \\
\text { semântica }\end{array} \\
\end{array}$ & Expressāo lógica & & & \\
\hline+- & AAD001 & $\begin{array}{c}\text { Item de } \\
\text { documentação }\end{array}$ & $\begin{array}{l}\text { Agrupa várias propriedades } \\
\text { para um item. }\end{array}$ & . & $\begin{array}{l}\text { Conjunto de } \\
\text { propriedades }\end{array}$ & . & . & . & - & Design & A & $\begin{array}{l}\text { Vários itens como mesmo ID } \\
\text { "ADD001" deve ser possivel. }\end{array}$ \\
\hline-1 & AAD002 & ID do recurso & $\begin{array}{c}\text { ID do ativo respectivo do item } \\
\text { de documentaçăo }\end{array}$ & . & STRING & - & $\begin{array}{l}\text { http://pk.festo.co } \\
\text { m3S7PLFDRS35 }\end{array}$ & Confirmaçăo & Igual & Design & A & $\begin{array}{l}\text { "'?'por padräo, se apenas um } \\
\text { ativo no Administration Shell. }\end{array}$ \\
\hline-1 & AAD003 & $\begin{array}{c}\text { Item do documento } \\
\text { Tipo }\end{array}$ & Tipo de documentação & - & $\rightarrow$ CAC001 & - & & Confirmação & Igual & Design & - & \\
\hline-1 & AAD004 & $\begin{array}{c}\text { Item do documento } \\
\text { Titulo }\end{array}$ & Titulo da documentaçăo & - & STRING & - & $\begin{array}{c}\text { "Módulos } \\
\text { analógicos para } \\
. . .\end{array}$ & Confirmaçäo & Igual & Design & - & \\
\hline-1 & AAD005 & $\begin{array}{c}\text { Item do documento } \\
\text { Nome do arquivo }\end{array}$ & $\begin{array}{l}\text { Nome do arquivo associado ao } \\
\text { arquivo de dados, contorme } \\
\text { fornecido pelo fornecedor }\end{array}$ & - & STRING & - & "CPX_AM01.PDF" & Confirmação & Igual & Design & - & \\
\hline-1 & AAD006 & $\begin{array}{c}\text { Item do documento } \\
\text { Versäo }\end{array}$ & Versão da documentação & . & STRING & $" 1.1 "$ & 2.0 .0 & Confirmaçăo & Igual & Design & - & \\
\hline-1 & AAD007 & $\begin{array}{l}\text { Item do documento } \\
\text { Formato dos dados }\end{array}$ & $\begin{array}{l}\text { Formato dos dados do objeto } \\
\text { de dados complexos }\end{array}$ & & $\rightarrow$ CAD001 & CAD001 & CAD001 $==$ PDF & Confirmação & Igual & Design & $\cdot$ & \\
\hline-1 & AAD008 & \begin{tabular}{|c|} 
Item do documento \\
BLOB \\
(Binary Large \\
OBject)
\end{tabular} & $\begin{array}{l}\text { Objeto de dados complexos do } \\
\text { item de documentaçăo }\end{array}$ & . & BLOB & - & - & Confirmaçăo & Igual & Design & - & \\
\hline
\end{tabular}

Fonte: Adaptado de (BEDENBENDER et al., 2017a).

A Figura 64 ilustra como as propriedades seriam apresentadas em um cliente OPC-UA. Isso é similar ao que ocorreria se um Ativo consultasse as propriedades de outro, autonomamente. 
Tabela 23 - Exemplo de classificação dos tipos de campo de documento, utilizado na Tabela 22.

\begin{tabular}{|c|c|c|c|}
\hline Hierarquia & ID & Nome & Definição \\
\hline+ & CAA001 & Documentação & Todo tipo de documentação \\
\hline+-+ & CAA002 & Documentos técnicos & \\
\hline+-+-1 & CAA003 & Especificação técnica & $\begin{array}{l}\text { Folha de registro de dados, análise de } \\
\text { tensão, folha de especificações,.... }\end{array}$ \\
\hline+-+-1 & CAAOO4 & Desenhos / Esquemas & Vista explodida, modelo 3D, ... \\
\hline+-+-1 & CAA005 & Lista de materiais & Lista de materiais \\
\hline+-+-1 & CAA006 & Certificações & $\begin{array}{l}\text { Certificado Atex, declaração de } \\
\text { conformidade,.. }\end{array}$ \\
\hline+-+ & CAA007 & $\begin{array}{c}\text { Documentos relacionados } \\
\text { à atividade }\end{array}$ & \\
\hline+-+-1 & CAA008 & $\begin{array}{c}\text { Montagem / Implementação } \\
\text { / Desmontagem }\end{array}$ & $\begin{array}{l}\text { Instruções de montagem, planta do } \\
\text { chão de fábrica,... }\end{array}$ \\
\hline+-+-1 & CAA009 & Operação & Instrução de uso, instrução IBN \\
\hline+-+-1 & CAA010 & Segurança & Instruções de segurança \\
\hline+-+-1 & CAA011 & $\begin{array}{l}\text { Inspeção / Manutenção / } \\
\text { Avaliação }\end{array}$ & $\begin{array}{l}\text { Horário de manutenção, instruções de } \\
\text { calibração, .. }\end{array}$ \\
\hline+-+-1 & CAA012 & Reparo / Serviço & $\begin{array}{c}\text { Instruções de reparo, lista de peças de } \\
\text { reposição, ... }\end{array}$ \\
\hline+-+ & CAA013 & Documentos de contrato & \\
\hline+-+-1 & CAA014 & Documentos de contrato & Nota de entrega, fatura,... \\
\hline
\end{tabular}

Fonte: Adaptado de (BEDENBENDER et al., 2017a).

Nesse contexto, o exemplo 1 se refere a um estudo de caso hipotético da estrutura de um ativo na I4.0 responsável pelo processo de decisão entre três alternativas para executar um processo de fabricação.

$\mathrm{Na}$ Figura 65 tem-se as indicações na arquitetura proposta das atividades que foram descritas (em verde), no exemplo de Bedenbender et al. (2017a).

Tabela 24 - Exemplo de classificação de tipos de arquivos para itens do documento utilizados na Tabela 22.

\begin{tabular}{|l|c|c|c|}
\hline Hierarquia & ID & Nome & Definição \\
\hline+ & CAD001 & $\begin{array}{c}\text { Documentação formatos } \\
\text { de dados }\end{array}$ & $\begin{array}{c}\text { Formatos de dados permitidos para } \\
\text { documentações na I4.0 }\end{array}$ \\
\hline--1 & CAD002 & PDF & Arquivo PDF, padrão "frio" \\
\hline--1 & CAD003 & HTML & Arquivo único, arquivo HTML \\
\hline
\end{tabular}

Fonte: Adaptado de (BEDENBENDER et al., 2017a). 
Figura 64 - Exemplo de visualização de um submodelo em um cliente OPC-UA.

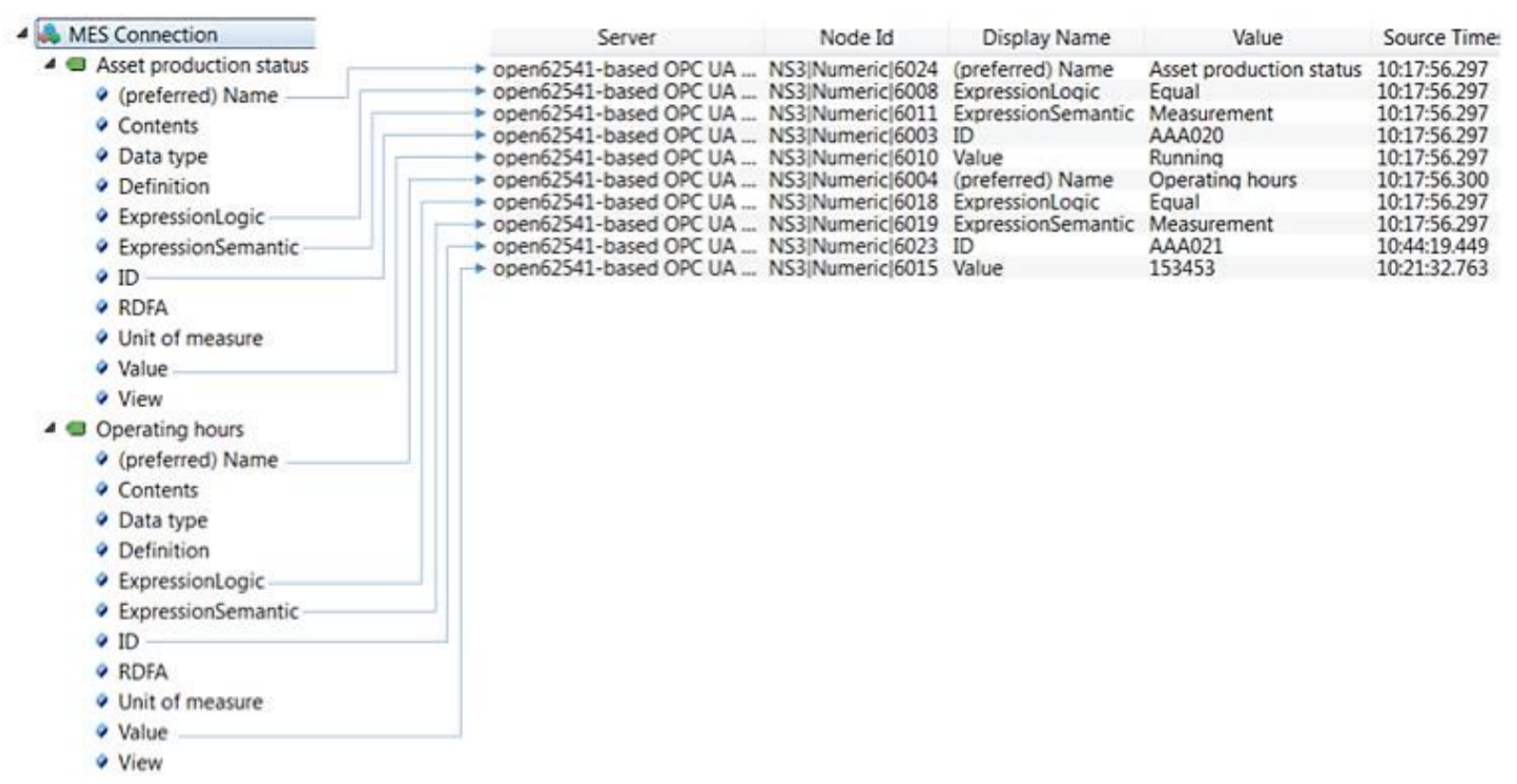

Fonte: (BEDENBENDER et al., 2017a).

\subsection{Composição e cooperação entre ativos}

Para que os Ativos cooperem entre si eles devem estar conectados. Na forma tradicional, atual, os Ativos são compostos usando um processo de engenharia padrão, ou seja, que geram composições estáticas. No entanto, o comportamento dinâmico da I4.0, que permite que os Ativos se localizem e se auto organizem, não pode ser alcançado com os métodos de engenharia atuais (BEDENBENDER et al., 2017c).

Como um Ativo composto representa por si só um novo Ativo, ele está sujeito às mesmas regras de mapeamento de cada Ativo isolado. Portanto, os Ativos compostos exibem automaticamente a mesma estrutura relacionada aos dados com semântica unificada das informações que os Ativos isolados. Portanto, eles também são componentes da I4.0 com seu próprio AAS.

A Figura 66 mostra essa situação (BEDENBENDER et al., 2017c). Nela é exemplificada a composição de 3 eixos acionados eletricamente (eixo elétrico) e uma garra, cada um destes Ativos com seu próprio AAS, para montar um manipulador cartesiano, um novo Ativo, com seu próprio AAS.

Como os recursos de um Ativo podem ser descritos em qualquer nível de granularidade, a tarefa de engenharia para gerar Ativos compostos pode ser iniciada assim que uma quantidade mínima de informações estiver disponível (Figura 67). Posteriormente, a modelagem pode ser estendida para incluir outras partes dos Ativos que porventura tenham sido definidas 
posteriormente ao processo inicial de composição. Isso dá uma grande flexibilidade ao projeto de sistemas.

Figura 65 - Atividades do Exemplo 1 na arquitetura proposta.
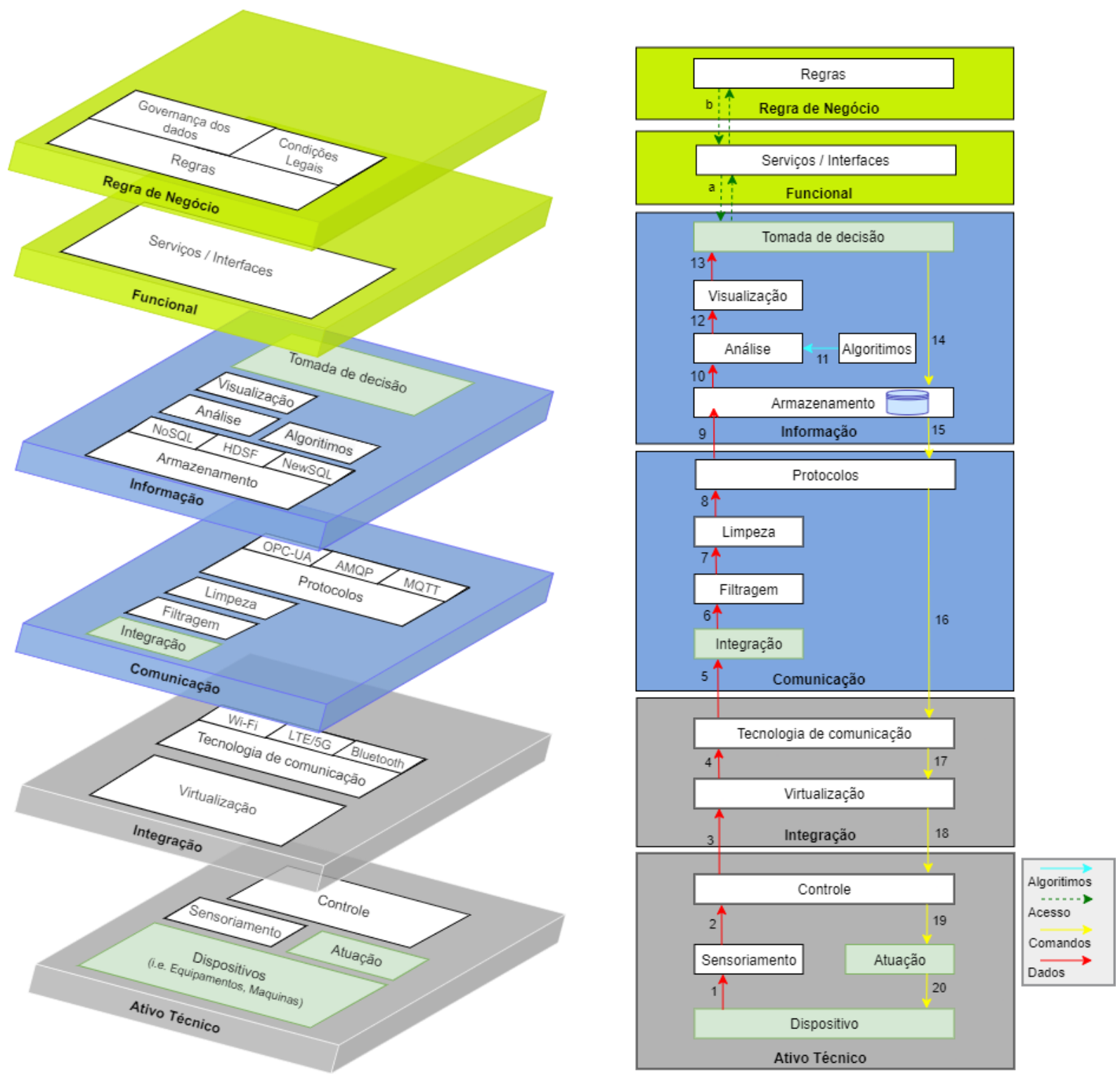

Fonte: autor

Da mesma forma, os Ativos podem ser agrupados e representados por um Ativo de nível superior (agregação). Nesse caso, a soma dos recursos de dois Ativos interconectados é maior que a soma de seus recursos individuais. Este novo Ativo apresenta seu próprio AAS, criandose, assim, um novo I4.0C (Figura 68) (BEDENBENDER et al., 2017c). 
Na Figura 68 também é destacado que o relacionamento entre os Ativos é feito por meio do relacionamento entre propriedades (BEDENBENDER et al., 2017c).

Figura 66 - Vários I4.0Cs com relacionamentos constituem um novo I4.0C com um AAS próprio.

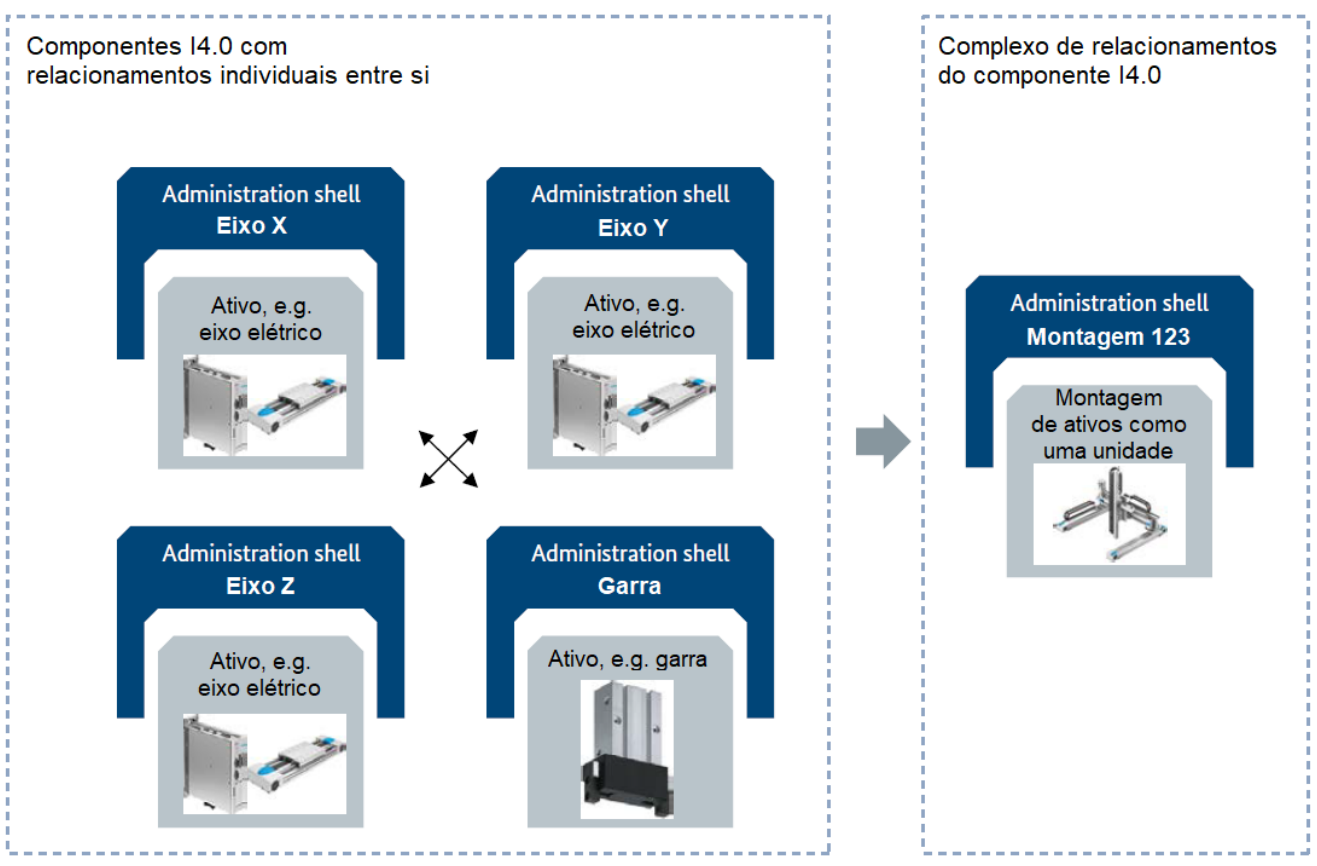

Fonte: Adaptado de (BEDENBENDER et al., 2017c).

Figura 67 - A estrutura de um sistema em diferentes níveis de granularidade.

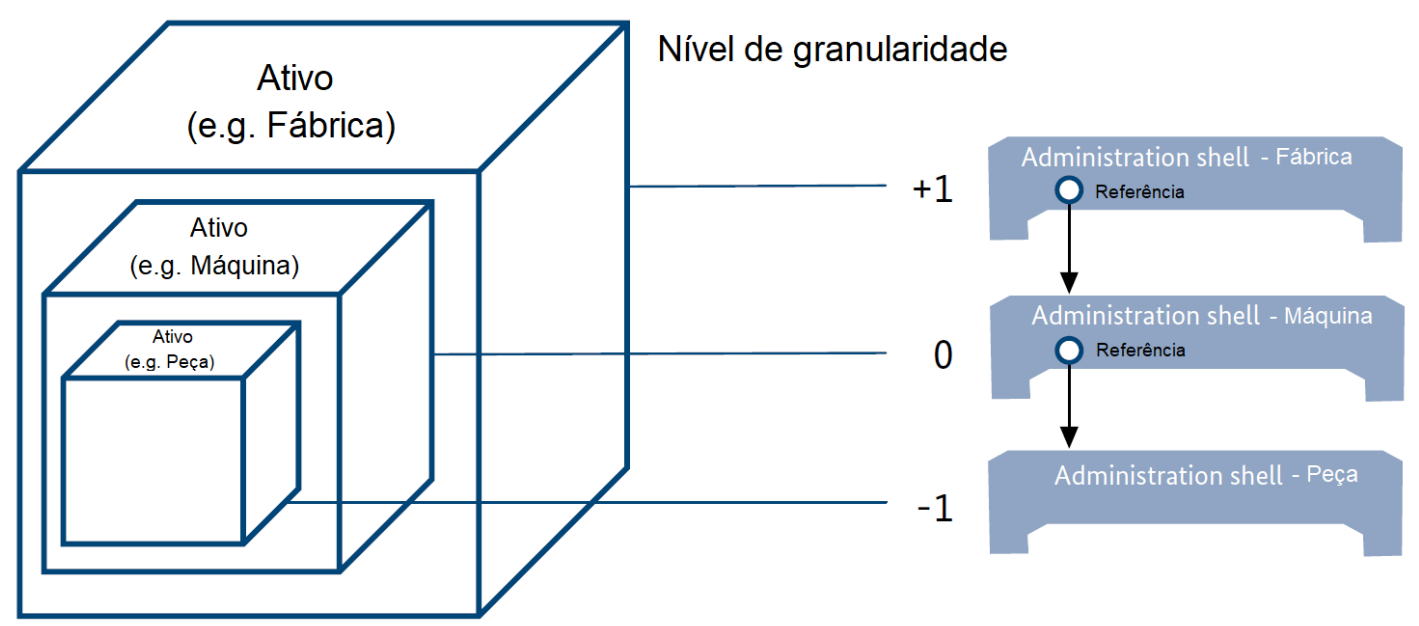

Fonte: Adaptado de (BEDENBENDER et al., 2017c). 
Na Figura 69 Bedenbender et al. (2017c) mostram três Ativos interconectados no mundo físico, na abordagem atual, tradicional.

Figura 68 - As relações entre Ativos são descritas por meio de relações de propriedade.

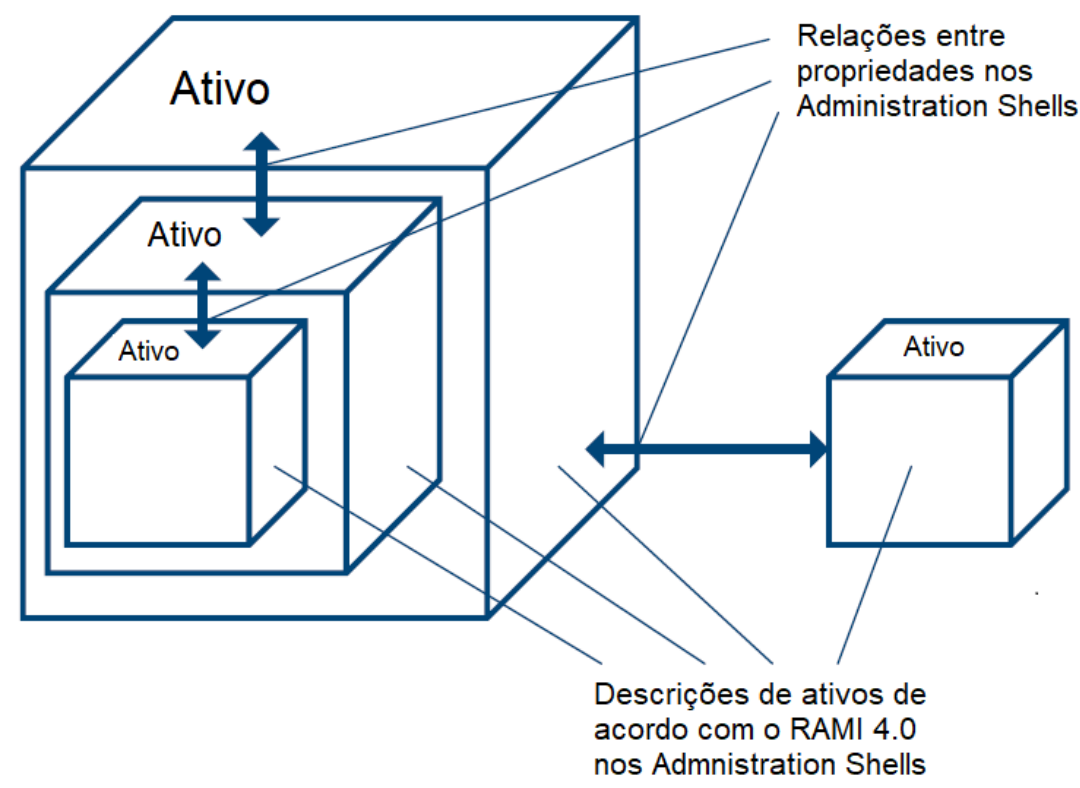

Fonte: Adaptado de (BEDENBENDER et al., 2017c).

As propriedades que descrevem exclusivamente cada uma das interfaces de cada Ativo estão inter-relacionadas (linhas verdes na Figura 69). Essa situação geralmente não é descrita explicitamente, mas é importante no contexto da I4.0. Uma forma de imaginar estas conexões no mundo físico é por meio, por exemplo, de uma rede de comunicação.

No mundo digital, as conexões entre os Ativos, que foram estabelecidas fisicamente na Figura 69, são expressas por relações entre propriedades correspondentes entre si (linhas laranjas na Figura 70). As conexões entre os termos que representam Ativos no mundo físico se tornam relações de propriedades no AAS, que são devidamente mapeadas para serem processáveis por máquina. Isso se aplica a todos os tipos de relacionamentos (BEDENBENDER et al., 2017c): (a) estáticos, que descrevem o arranjo físico, como um componente composto, como na Figura 67; ou (b) dinâmico, que descreve a cooperação entre os I4.0Cs durante, por exemplo, uma intervenção.

O principal objetivo dos relacionamentos é permitir a cooperação entre Ativos. No entanto, esses relacionamentos não podem ser configurados sem a infraestrutura apropriada. Os relacionamentos podem ser estabelecidos, mantidos, rompidos e modificados. 
Consequentemente, esse tipo de infraestrutura no mundo digital também constitui um I4.0C com seu próprio AAS, ou seja, os relacionamentos também são Ativos (BEDENBENDER et al., 2017c).

Figura 69 - No mundo físico, os Ativos são conectados $\left(c_{i}\right)$ por meio de suas propriedades $(M n)$ no mundo digital.

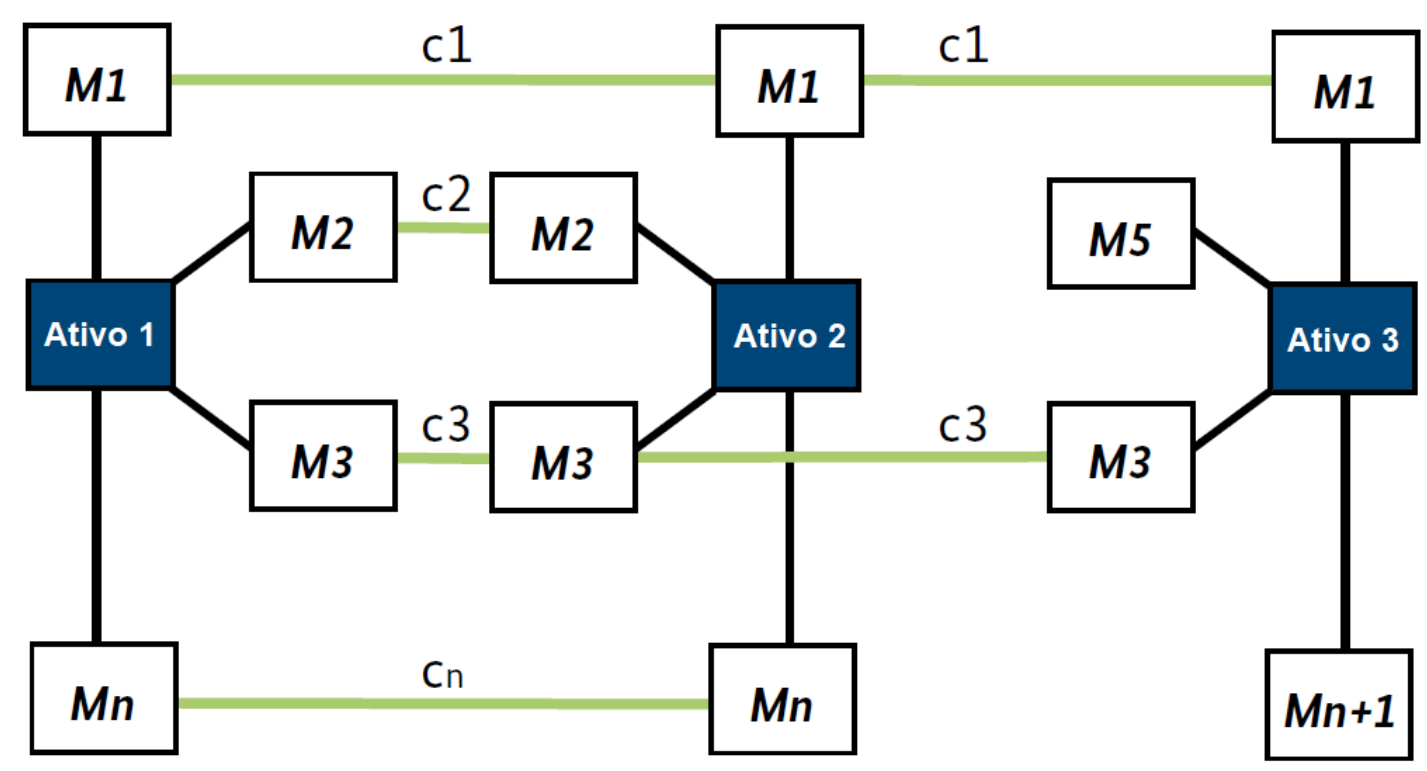

$\mathrm{Bn}=$ termo $\mathrm{n}, \mathrm{c}=$ conexão

Fonte: Adaptado de (BEDENBENDER et al., 2017c).

A grande vantagem dos AASs que são estruturados identicamente de acordo com o RAMI 4.0 é que a consideração de separação entre os mundos físico e digital, em termos de Ativos e de representação digital do I4.0C, respectivamente, é substituída por um visão homogênea. Isso ocorre porque o Ativo do mundo físico sempre deve ser considerado juntamente com sua representação no mundo digital, seu(s) AAS(s).

Consequentemente, as conexões entre os Ativos do mundo físico devem ser refletidas no mundo digital de acordo com regras claras, usando relacionamentos entre os AASs relacionados.

Graças à estruturação uniforme dos AASs e seu conteúdo semântico, as composições podem ser geradas a partir dos I4.0Cs. Essas composições são compatíveis entre si, tanto como Ativos no mundo físico quanto como AASs no mundo digital. Isso se aplica não apenas quando se gera uma um I4.0C composto, mas também durante toda a sua vida útil. Cada alteração em 
um Ativo no mundo físico resulta em alterações correspondentes no AAS e possivelmente também no AAS de toda a composição, que também é um I4.0C com AAS (BEDENBENDER et al., 2017c).

Figura 70 - No mundo digital, as conexões entre os Ativos são representadas pelos relacionamentos $(r)$ entre propriedades $(M n)$ registradas nos AASs dos I4.0C.
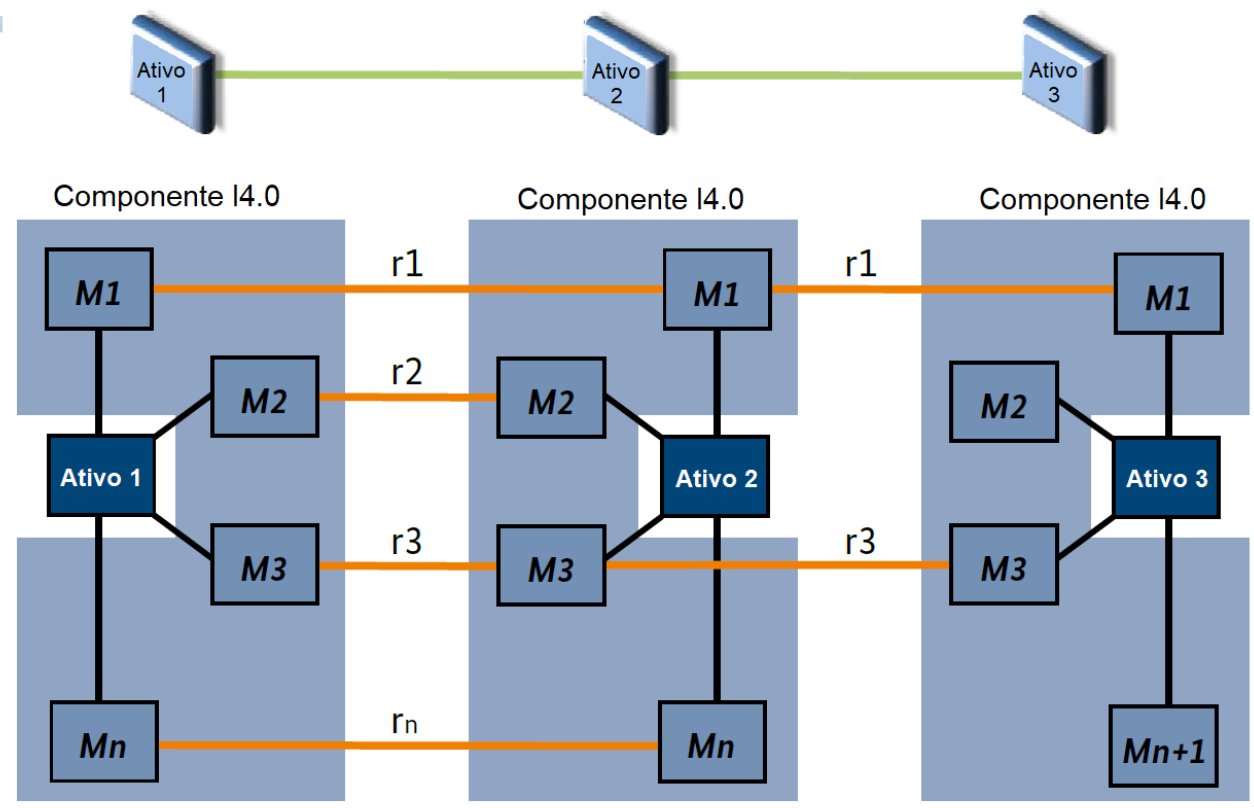

$\mathrm{Mn}=$ propriedade $\mathrm{n}, \mathrm{r}=$ relação

Fonte: Adaptado de (BEDENBENDER et al., 2017c).

Como já comentado anteriormente, componentes compostos são criados quando pelo menos dois I4.0Cs são conectados um ao outro. Nesse processo, pelo menos uma propriedade de um dos I4.0Cs é configurada em relação a pelo menos uma propriedade correspondente do outro I4.0C. Esse tipo de componente composto possui novos recursos em comparação com os I4.0Cs individuais.

Ao mesmo tempo, um componente composto também é um I4.0C, isto é, o componente composto também possui um AAS (BEDENBENDER et al., 2017c).

A Figura 71 retoma o exemplo apresentado na Figura 66. Aqui pode ser observado que cada um dos Ativos possui seu próprio AAS, e pode ser acessado por meio do barramento de comunicação compatível com a I4.0, e o componente composto também apresenta o seu próprio AAS. Desta forma, quando se quer a informação específica de cada Ativo, pode-se acessá-lo diretamente. 
Figura 71 - Exemplo de uma montagem que conecta vários componentes para formar um sistema Pick \& Place.

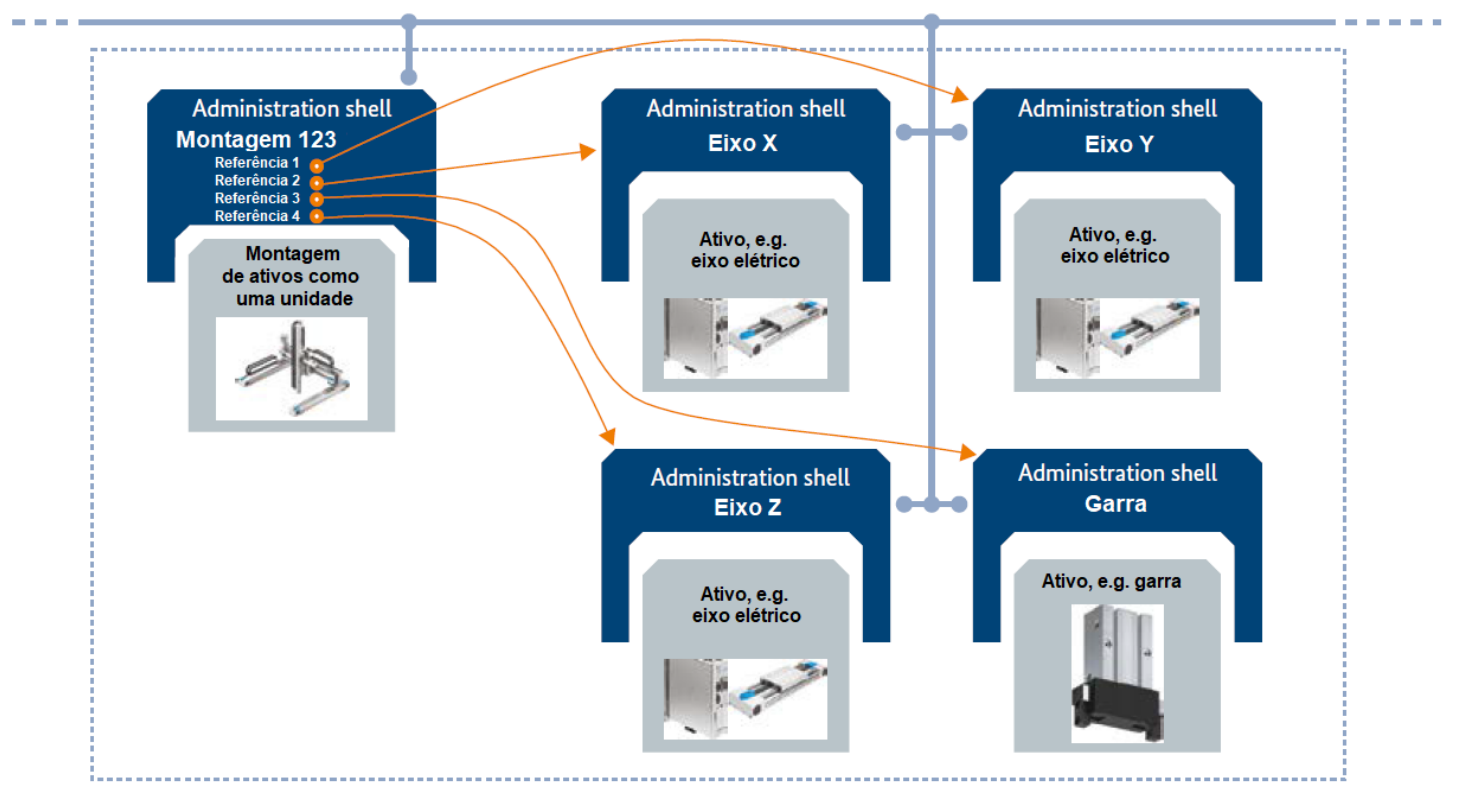

Fonte: Adaptado de (BEDENBENDER et al., 2017c).

Quando se quer uma informação do conjunto ou enviar um comando para a máquina (o componente composto), acessa-se o AAS da mesma. Da mesma forma, pensado na análise de dados, o AAS de cada Ativo individualmente já armazena e análise dados específicos dele. O Ativo composto não tem necessidade de replicar estes dados e repetir estas análises. Para ele é apenas necessário criar relacionamento para as propriedades pertinentes de cada Ativo individual e usar estes dados em novas análises, pertinentes para o Ativo composto.

Ainda com relação à Figura 71, para atender a uma meta de produção específica, os I4.0 Cs de diferentes fabricantes são combinados em uma unidade direcionada a atender uma meta específica de produção. Muitas vezes, essa integração dos diferentes componentes é sugerida pelos fabricantes das máquinas ou dos equipamentos.

Em geral, o fabricante da máquina utiliza a flexibilidade dos componentes para indicar as possíveis montagens que, em princípio, melhor exploram as vantagens de sua máquina. $\mathrm{O}$ fabricante da máquina então relaciona as diferentes disciplinas de engenharia de todos os componentes da máquina, ou seja, fluxos de materiais, mecânica, fluídos, elétrico-eletrônica e programação. Esse tipo de montagem geralmente é obtido a partir de uma ou mais arranjos físicos de Ativos, que juntos formam as possibilidades do sistema da montagem. Assim, o conjunto como um todo novamente se torna um Ativo, no qual dados e funções específicas, 
complexas, podem ser atribuídas e representadas pelo respectivo AAS (BEDENBENDER et al., 2017c).

O objetivo de introduzir um componente composto é fornecer informações importantes sobre o relacionamento entre os componentes individuais na forma de elementos de informação compatíveis com a I4.0 e, assim, permitir que essas informações sejam usadas por outros I4.0 Cs e sistemas de nível superior. Dessa forma, especificações importantes, por exemplo, da fase de engenharia, podem ser disponibilizadas para um grupo extenso de empresas (BEDENBENDER et al., 2017c).

A montagem (ou seja, o Ativo do componente composto) é adequadamente descrita por várias disciplinas de engenharia e seus documentos relevantes. Nem toda disciplina de engenharia leva em conta a realidade completa; o diagrama elétrico de um equipamento, por exemplo, não trata das fixações dos parafusos dos eixos mecânicos desse equipamento.

Portanto, é necessária uma combinação de vários submodelos para produzir uma descrição suficientemente precisa da realidade geral da montagem. Cada submodelo deve descrever os relacionamentos para o subconjunto dos Ativos da montagem (BEDENBENDER et al., 2017c).

A Tabela 25 apresenta algumas das diferentes disciplinas de engenharia e lista alguns exemplos de propriedades que podem ser consideradas na elaboração dos submodelos, enquanto a Tabela 26 apresenta algumas considerações quanto aos valores que as propriedades podem assumir tendo-se em vista as diferentes disciplinas de engenharia.

Em geral, apenas os formatos de dados abertos reconhecidos pela arquitetura de referência da I4.0 podem ser considerados nos submodelos do componente composto. Para uso interno da empresa, um formato de dados não aberto também pode ser incorporado (BEDENBENDER et al., 2017c).

\subsection{Exemplo de aplicação de relacionamento entre ativos}

Este exemplo serve para ilustrar alguns tipos de relacionamento. Nele são apresentados os relacionamentos de uma unidade CLP (Controlador Lógico Programável) com uma impressora 3D (Figura 72). Deve-se observar que a imagem mostrada no diagrama é simplificada, pois os Ativos referentes aos relacionamentos são apresentados como linhas simples e não como Ativos. Este caso foi extraído de (BEDENBENDER et al., 2017c). 
Tabela 25 - Classificações de propriedades para diferentes disciplinas de engenharia.

\begin{tabular}{ll}
\hline Disciplina de engenharia & Exemplos de relacionamentos classificados por propriedades \\
\hline Construção mecânica & $\begin{array}{l}\text { Junta permanente, junta prismática, junta articulada, junta cilíndrica, junta esférica, cada uma } \\
\text { incorporando atrito, molas ou amortecimento }\end{array}$ \\
\hline Engenharia elétrica & $\begin{array}{l}\text { Conexão elétrica monopolar, conexão elétrica multipolar, conexão de barramento de dados, } \\
\text { conexão de potenciais, conexão entre módulos terminais }\end{array}$ \\
\hline Fluidos & $\begin{array}{l}\text { Conexão de tubulações, conexão direta a parafuso ou plugue, conector terminal entre } \\
\text { componentes, conexão em espaço aberto (absorvedor de som) }\end{array}$ \\
\hline $\begin{array}{l}\text { Planejamento de tubulações } \\
\text { Cadeia de blocos funcionais em }\end{array}$ & $\begin{array}{l}\text { Conexão de tubulações, conexão de sensor e atuador } \\
\text { tecnologia de automação } \\
\text { (61131-CFC / FBD) }\end{array}$ \\
$\begin{array}{l}\text { Interconexão de componentes de de sinal, conexão de evento, conexão de barramento } \\
\text { software (Diagrama de comunicação } \\
\text { UML) }\end{array}$ & $\begin{array}{l}\text { Tempo de vida (vita) na conexão de comunicação } \\
\text { Nota: Mensagens individuais podem ser modeladas como propriedades desse relacionamento }\end{array}$ \\
\hline $\begin{array}{l}\text { Layout do chão de fábrica } \\
\text { Linha de transporte (contínua), linha de transporte (discreta), infraestrutura elétrica, infraestrutura } \\
\text { pneumática, infraestrutura de mídia, intralogística, rota de tráfego para pedestres, rota de tráfego } \\
\text { de veículos }\end{array}$ \\
\hline
\end{tabular}

Fonte: Adaptado de (BEDENBENDER et al., 2017c).

Tabela 26 - Possíveis declarações de valor de propriedade.

\begin{tabular}{|c|c|}
\hline Designações de referência & $\begin{array}{l}\text { Os planos de várias disciplinas de engenharia frequentemente atribuem suas próprias } \\
\text { designações de referência. No caso de um plano eletrônico, isso pode ser uma designação de } \\
\text { referência de acordo com a DIN EN } 81346 \text {. } \\
\text { Diferentes componentes compostos podem fornecer várias alternativas para a construção de } \\
\text { uma estação de produção, por exemplo. }\end{array}$ \\
\hline Detalhes da localização & $\begin{array}{l}\text { Os detalhes da localização de um ativo podem ser definidos em planos diferentes, por exemplo, } \\
\text { de acordo com uma posição geodésica, em um plano de localização, plano de layout de fábrica } \\
\text { ou plano de linha de produção. } \\
\text { Diferentes componentes compósitos podem, por exemplo, refletir o histórico de compósitos de } \\
\text { plantas ou especificar um plano hipotético, para executar uma simulação de eventos discretos } \\
\text { (SED). }\end{array}$ \\
\hline $\begin{array}{l}\text { Modo de operação, valores } \\
\text { definidos }\end{array}$ & $\begin{array}{l}\text { Um componente composto ou um plano pode fornecer diferentes modos operacionais ou definir } \\
\text { valores para vários produtos ou cenários de produção. }\end{array}$ \\
\hline $\begin{array}{l}\text { ALOP/DLOP/OLOP according } \\
\text { to IEC } 61987-10\end{array}$ & $\begin{array}{l}\text { A Industria } 4.0 \text { tem como objetivo permitir processos de planejamento. Os componentes } \\
\text { compostos podem representar diferentes documentos de planejamento e hipóteses, que } \\
\text { podem, por exemplo, incluir listas de requisitos para ativos planejados, mas ainda não } \\
\text { totalmente definidos. Um exemplo frequentemente usado pode ser o de "papel para uma bomba } \\
\text { com uma saída nominal de } 5001 / \text { min". }\end{array}$ \\
\hline \multicolumn{2}{|c|}{ ALOP: Lista das propriedades administrativas (Administrative List Of Properties) } \\
\hline \multicolumn{2}{|c|}{ DLOP: Lista das propriedades dos dispositivos (Device List Of Properties) } \\
\hline OLOP: Lista de propriedades de oper & eração" (Operating List Of Properties) \\
\hline
\end{tabular}

Fonte: Adaptado de (BEDENBENDER et al., 2017c). 
Figura 72 - Exemplo de relacionamentos entre Ativos baseados em um PLC e uma impressora 3D.

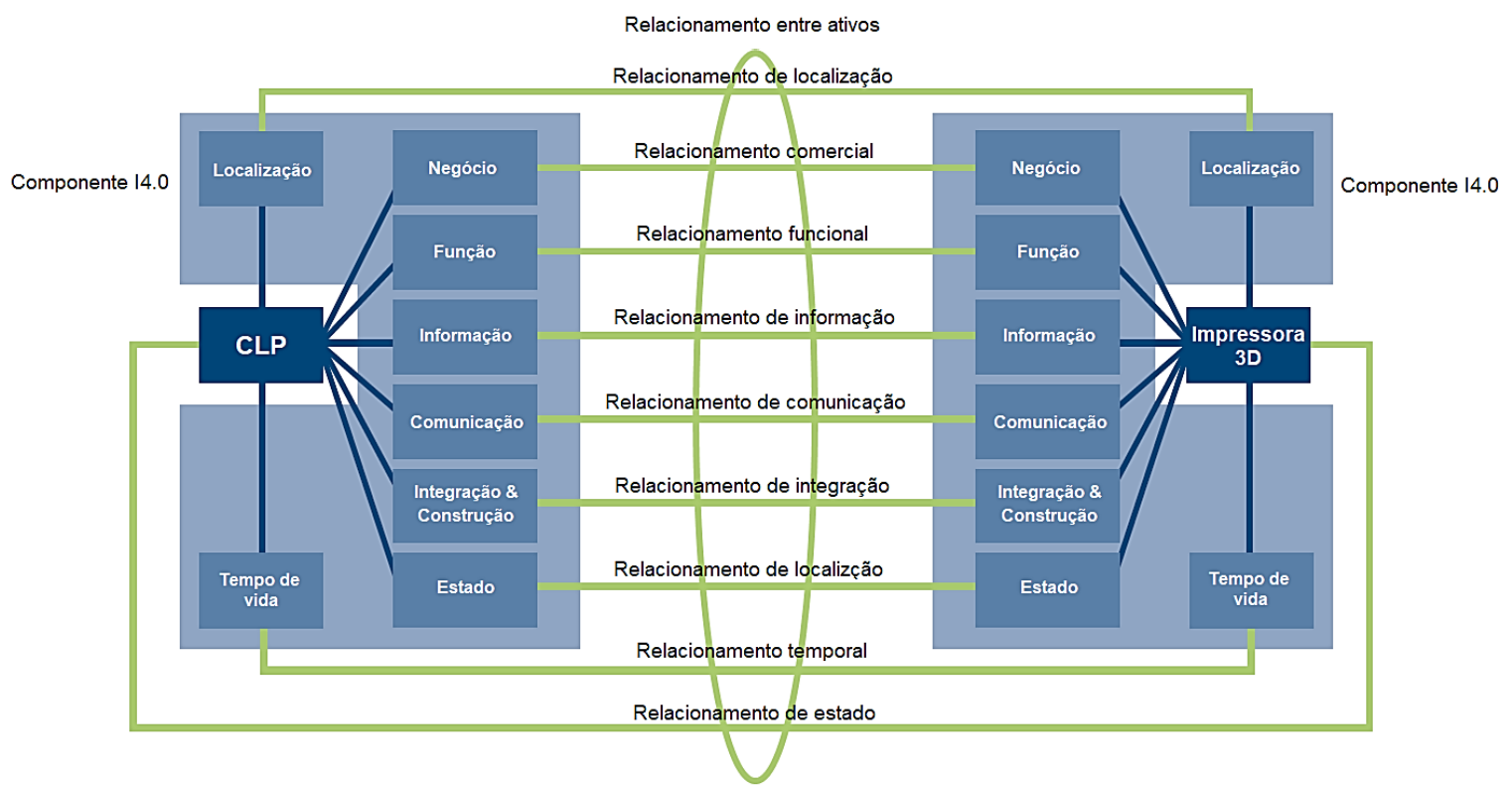

Fonte: Adaptado de (BEDENBENDER et al., 2017c).

\section{Relacionamento comercial}

Do ponto de vista comercial, esse tipo de relacionamento entre o CLP e uma impressora 3D é caracterizado pelo fato de que a impressora 3D fornece um serviço ao CLP e esse serviço requer um pedido, incorre em custos e envolve prazos de entrega, etc. Nesse caso, verifica-se, por exemplo, se a impressora 3D oferece a qualidade desejada pelo preço acordado, os requisitos legais associados à fabricação do produto, etc.

\section{Relacionamento funcional}

O relacionamento funcional é um relacionamento lógico entre funções de cooperação dos Ativos. No caso da impressora 3D, a função "ordem de impressão" no CLP aciona a função “ordem de execução da impressão” na impressora 3D. As informações necessárias no início do pedido são derivadas do relacionamento de informação.

\section{Relacionamento de informação}

Este relacionamento abrange todos os dados e informações necessárias, geradas ou modificadas no nível funcional. É, portanto, usado para executar a cooperação funcional entre os Ativos e para correlacionar dados dos Ativos estabelecidos em um relacionamento, por exemplo, por meio de algoritmos. 


\section{Relacionamento de comunicação}

Os Ativos que cooperam entre si devem compartilhar informações/dados. Um relacionamento de comunicação fornece tudo o que for necessário para troca ou distribuição de dados. Um "canal de comunicação" é configurado para garantir a transferência segura de dados usando protocolos de comunicação compatíveis com a I4.0.

\section{Relacionamento de integração}

Um relacionamento de integração descreve as conexões básicas, como terminais de energia, construção mecânica e fluxos relevantes de materiais entre os Ativos do mundo físico, refletindo assim o mundo físico.

A construção mecânica inclui conexões desde uma simples fixação por parafuso ou um acoplamento de tubo, mas também um Ativo colocado sobre uma mesa ou, em um edifício, uma coluna conectada ao piso acima ou abaixo, etc.

Os Ativos pertencentes à composição podem formar relacionamentos de energia com base em tipos básicos de energia como, por exemplo: energia mecânica; energia elétrica; energia hidráulica; e energia pneumática.

\section{Relacionamento de localização}

Cada Ativo é atribuído a um local físico específico, o que também pode mudar no caso de Ativos móveis. Em outras palavras, esse relacionamento pode mudar ao longo da vida útil do Ativo. O relacionamento de localização descreve as informações geográficas para dois ou mais Ativos em um relacionamento. Como o local em si também é um Ativo, qualquer I4.0C em um local específico tem um relacionamento com um I4.0C de localização.

\section{Relacionamento temporal}

O relacionamento temporal descreve as informações temporais para dois ou mais Ativos em um relacionamento.

Como o próprio tempo também é um Ativo, qualquer I4.0C em um determinado momento tem um relacionamento com um I4.0C temporal. O Ativo temporal compreende todas as informações relevantes para o horário (intervalo de tempo) específico. Este pode ser o tempo do mundo físico, mas também pode ser um tempo virtual, por exemplo, para fins de simulação. 


\section{Relacionamento de estado}

O relacionamento do estado descreve todas as informações relacionadas ao estado de dois ou mais Ativos em um relacionamento. Como o próprio estado também é um Ativo, qualquer I4.0C em um determinado momento tem um relacionamento com um I4.0C de estado. O Ativo "estado" compreende todas as informações relevantes sobre o estado de um Ativo. Isso pode refletir o estado do mundo físico, mas também pode ser um estado virtual, por exemplo, para fins de simulação.

\section{Relacionamento ativo-ativo}

Um relacionamento ativo-ativo representa a conexão entre dois Ativos no mundo físico. É também um I4.0C com um AAS que compreende os AASs de outros relacionamentos.

\section{Relacionamento humano-ativo}

Este relacionamento permite que os seres humanos intervenham em um I4.0S de fora. Os seres humanos que agem como parte de um I4.0S só podem estar envolvidos nos relacionamentos anteriores da mesma maneira que todos os outros Ativos no I4.0S.

Por fim, o seguinte se aplica a todos os tipos de relacionamento (BEDENBENDER et al., 2017c):

- Os relacionamentos descrevem conexões específicas do aplicativo entre Ativos ou seus I4.0Cs;

- Um ponto de conexão é caracterizado por estar relacionado a um I4.0C e pelas propriedades relevantes, incluindo seus valores, serem compatíveis com os dois I4.0Cs;

- Os relacionamentos sempre têm um identificador único;

- Para permitir que Ativos cooperem entre si com base em relacionamentos, é necessária uma linguagem de interação comum, principalmente baseada em propriedades.

\subsection{Critérios para um ativo ser considerado compatível com a I4.0}

A ZVEI desenvolveu critérios gerais e universais para os produtos considerados compatíveis com a I4.0. Esses critérios visam ajudar o mercado a decidir quais produtos já podem ser rotulados como compatíveis com a I4.0. Ao mesmo tempo, as empresas podem usar 
esses critérios como um guia para o desenvolvimento de produtos para a I4.0. Para os interessados em implantar soluções baseadas em I4.0, a definição da ZVEI assegura maior clareza sobre o desempenho e os recursos que os produtos I4.0 devem apresentar. Indiretamente, também fica claro o que não é compatível com a I4.0 (BEDENBENDER et al., 2019).

Entende-se que esses critérios ainda estão sendo estabelecidos, de modo que aqui se discute o que se pode considerar para o presente momento.

Cada critério é dividido quanto às características do produto, grau de cumprimento dos requisitos e as fases do seu ciclo de vida. Algumas características são obrigatórias enquanto outras são opcionais (dependentes do caso de uso).

\section{- Identificação}

Identificação global única de todos os Ativos na I4.0. Para esse fim, cada Ativo requer um identificador que possa ser usado para a sua identificação em todo o mundo.

O mesmo se aplica aos dados, funções padronizadas, AAS, etc. que pertencem ao Ativo. Um identificador global exclusivo também é necessário para que o relacionamento entre os dados e as funções possa ser estabelecido entre diferentes fabricantes.

\section{- Comunicação}

A I4.0 segue uma arquitetura orientada a serviços (SOA), na qual os serviços podem ser fornecidos, e os dados trocados. Para esse fim, foram formulados requisitos para a transferência de mensagens entre dois componentes da I4.0.

As especificações para a comunicação da I4.0 ainda estão sendo definidas (BEDENBENDER et al., 2019). No RAMI 4.0, a comunicação da I4.0 é especificada na camada de "Comunicação", utilizando OPC-UA. Todos os outros tipos de comunicação e protocolos estão na camada de "Integração".

\section{- Semântica}

Componentes, máquinas, instalações industriais e sistemas de TI requerem um idioma comum para entendam uns aos outros, independentemente do fabricante. Isso envolve um vocabulário compartilhado na forma de dados e funções, e uma sintaxe comum, que cria o contexto correto para os dados. No RAMI 4.0, a semântica da I4.0 está na camada de "Informações". Todos os dados e funções que não são padronizados de acordo com a I4.0 estão na camada de "Integração". 


\section{- Descrição virtual}

A descrição virtual reflete todo o conteúdo da representação digital do Ativo. Há uma compilação digital de dados importantes na semântica da I4.0, além de outras informações, como descrições de Ativos, páginas de catálogo técnico, imagens, recursos técnicos, folhas de dados, recursos de segurança, modelos de simulação, etc. Essas informações fornecem uma descrição digital dos Ativos, sendo que algumas partes também estão acessíveis para os clientes. As informações podem ser acessadas no Ativo, disponibilizadas gratuitamente na Internet, conectadas ao produto ou recuperadas on-line.

\section{- Serviços e estados}

Componentes, sistemas e máquinas devem poder fazer parte da I4.0 e conduzir uma negociação inicial comunicando-se entre si. Isso também inclui trocas de dados, funções e recursos disponíveis. Uma vez alcançado um acordo nessas negociações, os primeiros dados podem ser trocados. Os serviços básicos são necessários para esses processos e os dois parceiros de comunicação devem poder operá-los. Portanto, esses serviços no contexto da I4.0 devem ser descritos e implementados independentemente dos fabricantes, para que a I4.0 possa funcionar.

\section{- Funções padronizadas}

Certas funções devem ser padronizadas para todos os componentes e sistemas. Se os valores iniciais forem padronizados para todos os fabricantes, é muito mais fácil implementar a monitoração das condições dos ativos entre fabricantes distintos. Tais funções, que devem estar na camada "Funcional" do RAMI 4.0, estão atualmente sendo padronizadas/normatizadas e certamente serão um critério importante para os produtos I4.0 no futuro.

\section{- Segurança}

A segurança é um dos tópicos centrais da I4.0 e deve ser assegurada durante todo o ciclo de vida em todas as camadas da arquitetura e níveis hierárquicos. No futuro, o modelo de segurança descreverá os recursos necessários e opcionais dos componentes da I4.0 que precisam ser levados em consideração para os Ativos. Além disso, os recursos de segurança (patrimonial e física), privacidade, resiliência e confiabilidade, deverão ser as propriedades características de um componente da I4.0 (BEDENBENDER et al., 2019).

A Tabela 27 apresenta uma síntese destes critérios. 
Tabela 27 - Características determinadas para os Ativos compatíveis com a Indústria 4.0.

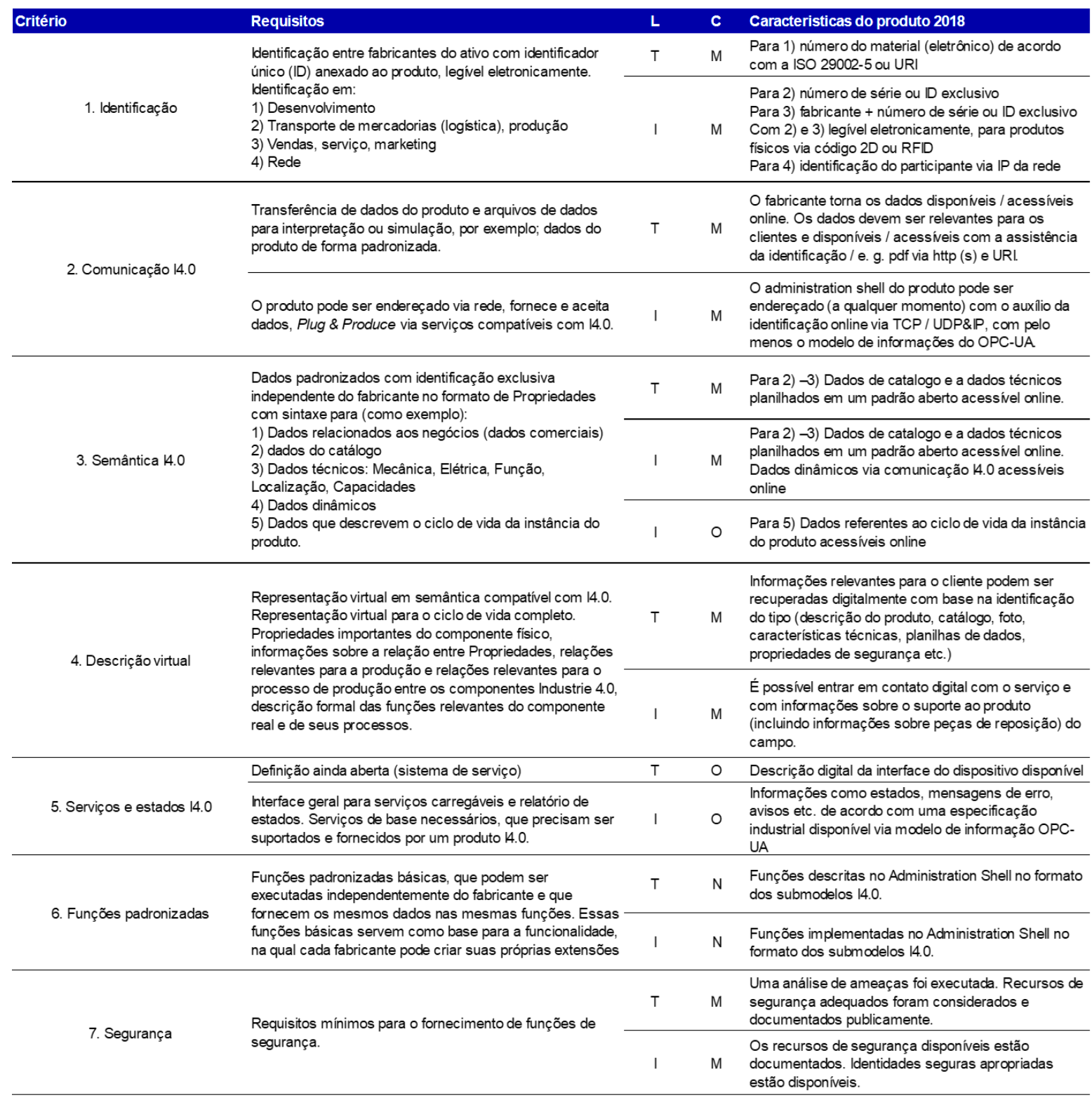

Características do produto para os critérios

L: Ciclo de Vida com T: Tipo e I: Instância

C: Cobertura com M: Obrigatório, O: Opcional, dependendo do caso de uso, pode ser obrigatório e N: Não relevante

Fonte: Adaptado de (BEDENBENDER et al., 2019).

\subsection{Exemplo 2}

O exemplo 1, apesar de estar defasado frente às especificações mais atuais, ilustra o potencial de se utilizar a estrutura de dados proposta para a I4.0. Neste exemplo 2 é mostrada uma estrutura atualizada, que está sendo adotada como base para a especificação de uma base de dados para o presente projeto. Este exemplo foi extraído de (BADER et al., 2019) e foi apresentado originalmente no formato XML. Para este documento ele é apresentado 
considerando o metamodelo apresentado nas Figuras 73 e 74 . Este metamodelo foi utilizado para analisar o quão atualizado está o exemplo 1.

O significado de cada um dos atributos de cada uma das classes da UML utilizadas neste exemplo estão todos estão devidamente detalhados em (BADER et al., 2019).

Neste exemplo o Ativo é um servo motor de corrente contínua, e seus atributos mínimos são apresentadas na Figura 75.

A este Ativo está associado um AAS, conforme apresentado na Figura 76, também com seus atributos mínimos.

Para relacionar o AAS ao Ativo, é necessário o uso de uma referência. A sua representação pode ser observada na Figura 77. É por meio do atributo "string" que ocorre o relacionamento.

Este AAS apresenta três submodelos: documentação; dados técnicos; dados de operação. Por simplificação, é detalhado apenas o de dados técnicos (Figura 78). De forma similar ao que ocorreu na Figura 77. Na Figura 79 é apresentado o relacionamento entre o AAS e o submodelo.

Na Figura 80 é apresentada uma referência a um elemento externo (global), que não faz parte do contexto deste AAS, para uma definição da propriedade "semanticId" da Figura 78.

Na Figura 81 é apresentado um exemplo de elemento de submodelo. Neste caso está sendo especificada a propriedade "velocidade máxima de rotação" do motor. Uma referência a um elemento do contexto do AAS, para dar uma definição o atributo "semanticId" da Figura 81 é apresentada na Figura 82. Esta referência relaciona a propriedade "velocidade máxima de rotação" com um dicionário de conceitos (Figura 83). Este dicionário, por sua vez, está referenciando um elemento externo (global) com esta definição.

Uma das vantagens de se ter estas referências externas (globais) é que elas servem de repositório para todos os fabricantes e integradores de Ativos.

A Figura 84 apresenta o diagrama completo para este exemplo.

Neste exemplo, tem-se o procedimento de identificação de um ativo (i.e., o servomotor) e todas as suas propriedades, assim, tanto dados do próprio ativo quanto das suas propriedades são devidamente registrados para a gestão e operação dos ativos. Além disso, este exemplo também considera um repositório de referências externas para os fabricantes e integradores de ativos. 


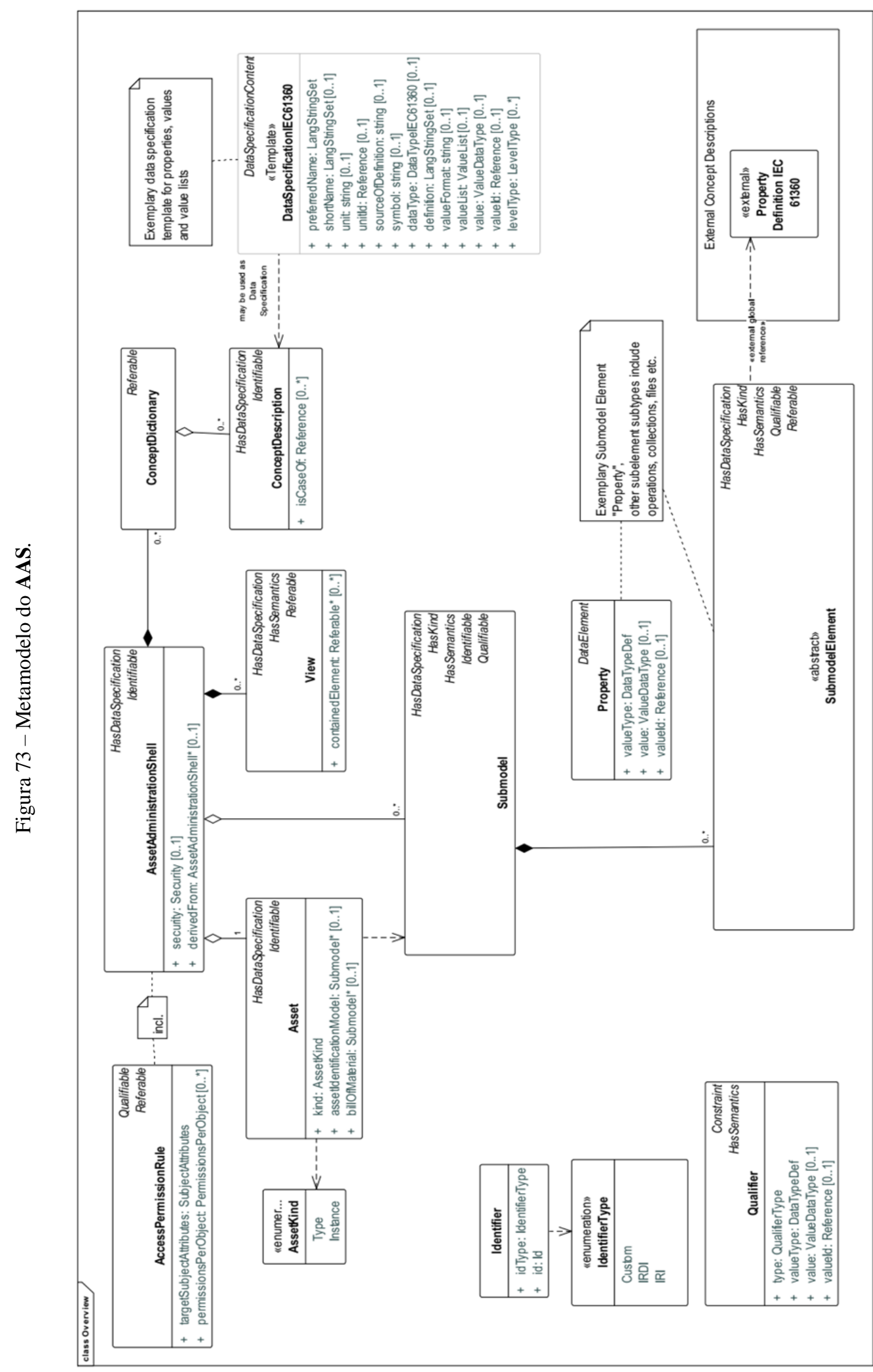

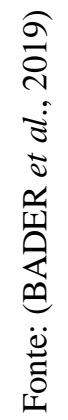




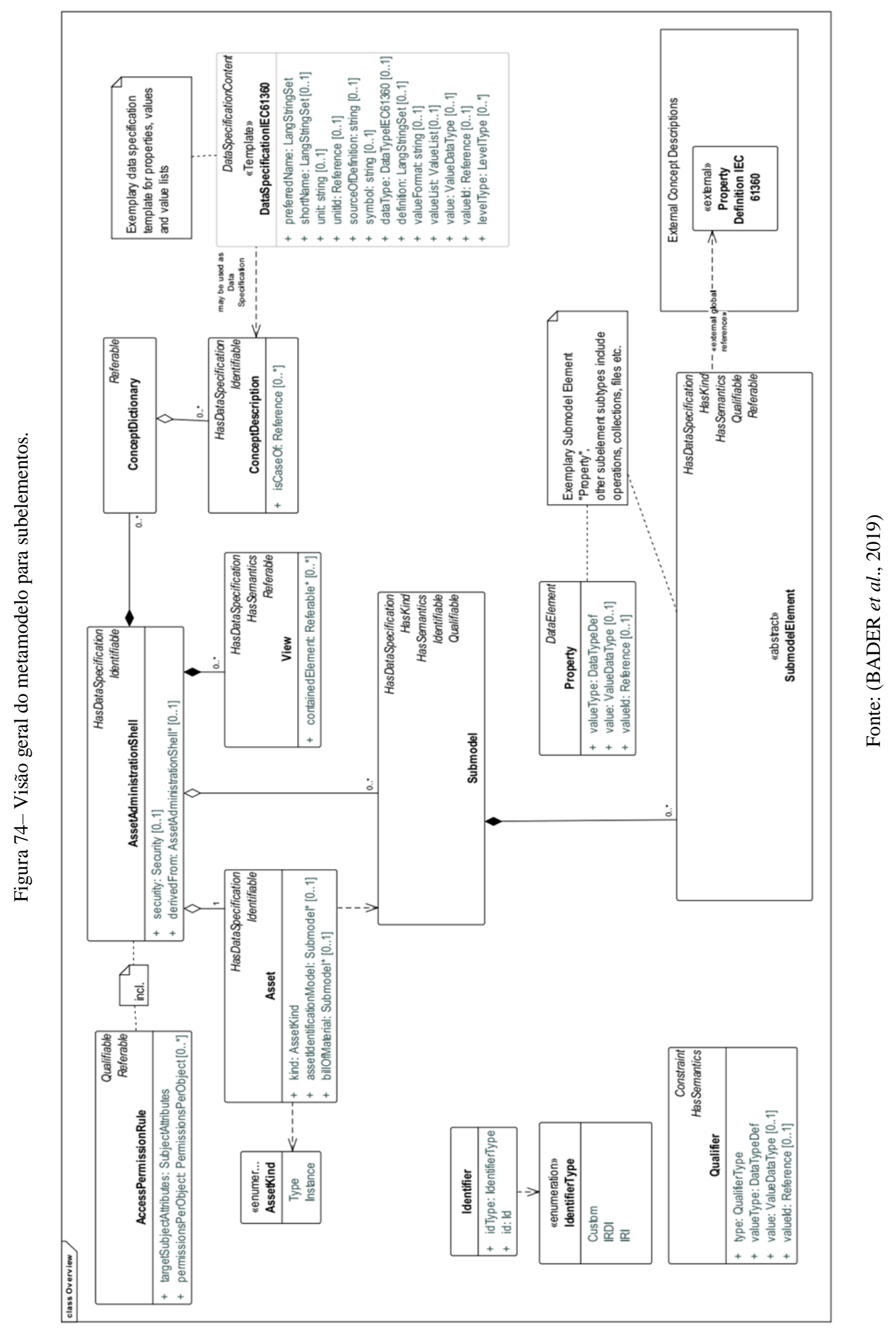


Figura 75 - Representação dos atributos mínimos do Ativo "servo motor de corrente contínua", utilizando uma classe UML.

\begin{tabular}{|l|}
\hline asset \\
\hline idShort: ServoDCMotor \\
idType: IRI \\
id: http://customer.com/assets/KHBVZJSQKIY \\
kind: Instance
\end{tabular}

Fonte: autor.

Figura 76 - Representação dos atributos mínimos do AAS relacionado ao Ativo da Figura 74, utilizando uma classe UML.

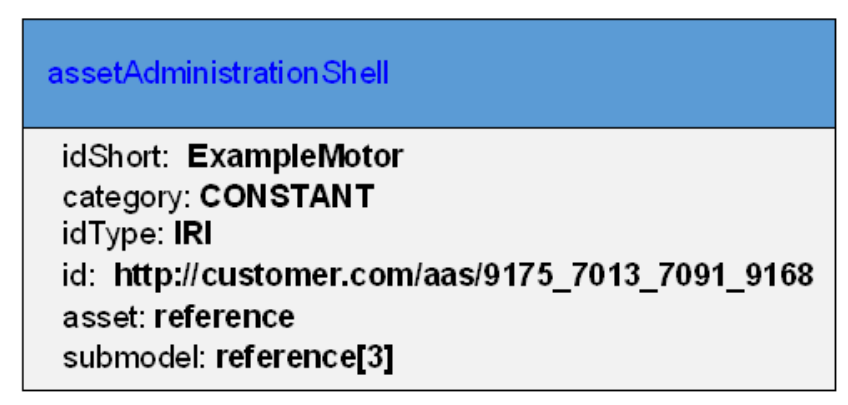

Fonte: autor.

Figura 77 - Referência entre o AAS (Figura 76) e seu Ativo (Figura 75), utilizando um diagrama UML.

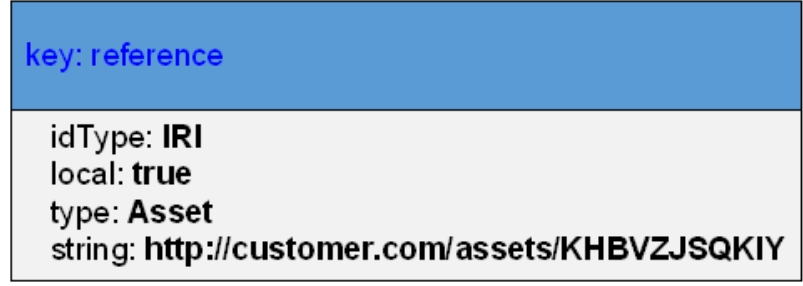

Fonte: autor 
Figura 78 - Representação dos atributos mínimos do submodelos de dados técnicos do AAS da Figura 76, utilizando um diagrama UML.

\begin{tabular}{|l|}
\hline submodel \\
\hline idShort: TechnicalData \\
category: CONSTANT \\
idType: IRI \\
id: http://i40.customer.com/type/1/1/7A7104BDAB57E184 \\
kind: Instance \\
semanticld: reference \\
\hline
\end{tabular}

Fonte: autor.

Figura 79 - Referência entre o AAS (Figura 76) e seu submodelo (Figura 78), utilizando um diagrama UML.

\begin{tabular}{|l|}
\hline key: reference \\
\hline idType: IRI \\
local: true \\
type: Submodel \\
string: http://i40.customer.com/type/1/1/7A7104BDAB57E184
\end{tabular}

Fonte: autor.

Figura 80 - Referência a um elemento que não faz parte do contexto deste AAS para dar uma definição à propriedade "semanticId" da Figura 78, utilizando um diagrama UML.

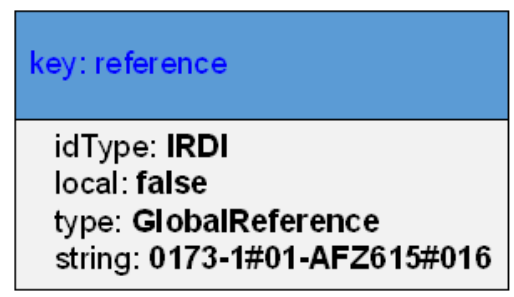

Fonte: autor. 
Figura 81 - Propriedade "velocidade máxima de rotação" referente ao submodelo "dados técnicos", utilizando um diagrama UML.

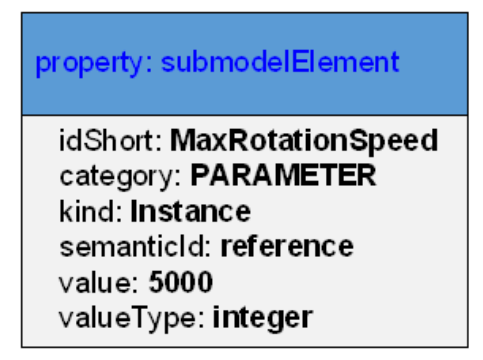

Fonte: autor.

Figura 82 - Referência a um elemento do contexto deste AAS para dar uma definição à propriedade "semanticId" da Figura 81, utilizando um diagrama UML.

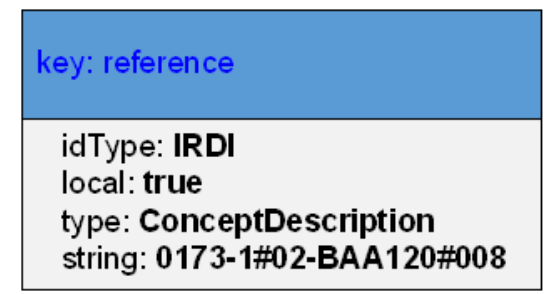

Fonte: autor.

Figura 83 - Descrição do conceito "velocidade máxima de rotação", pertencente a um dicionário de conceitos do AAS, utilizando um diagrama UML.

\begin{tabular}{|l|}
\hline conceptDescription \\
\hline idShort: MaxRotationSpeed \\
category: PROPERTY \\
idType: IRDI \\
id: 0173-1\#02-BAA120\#008 \\
version: 2 \\
revision: 0 \\
\hline
\end{tabular}

Fonte: autor. 
Figura 84 - Representação de todos os elementos que compõem o exemplo do motor de passo de corrente contínua.

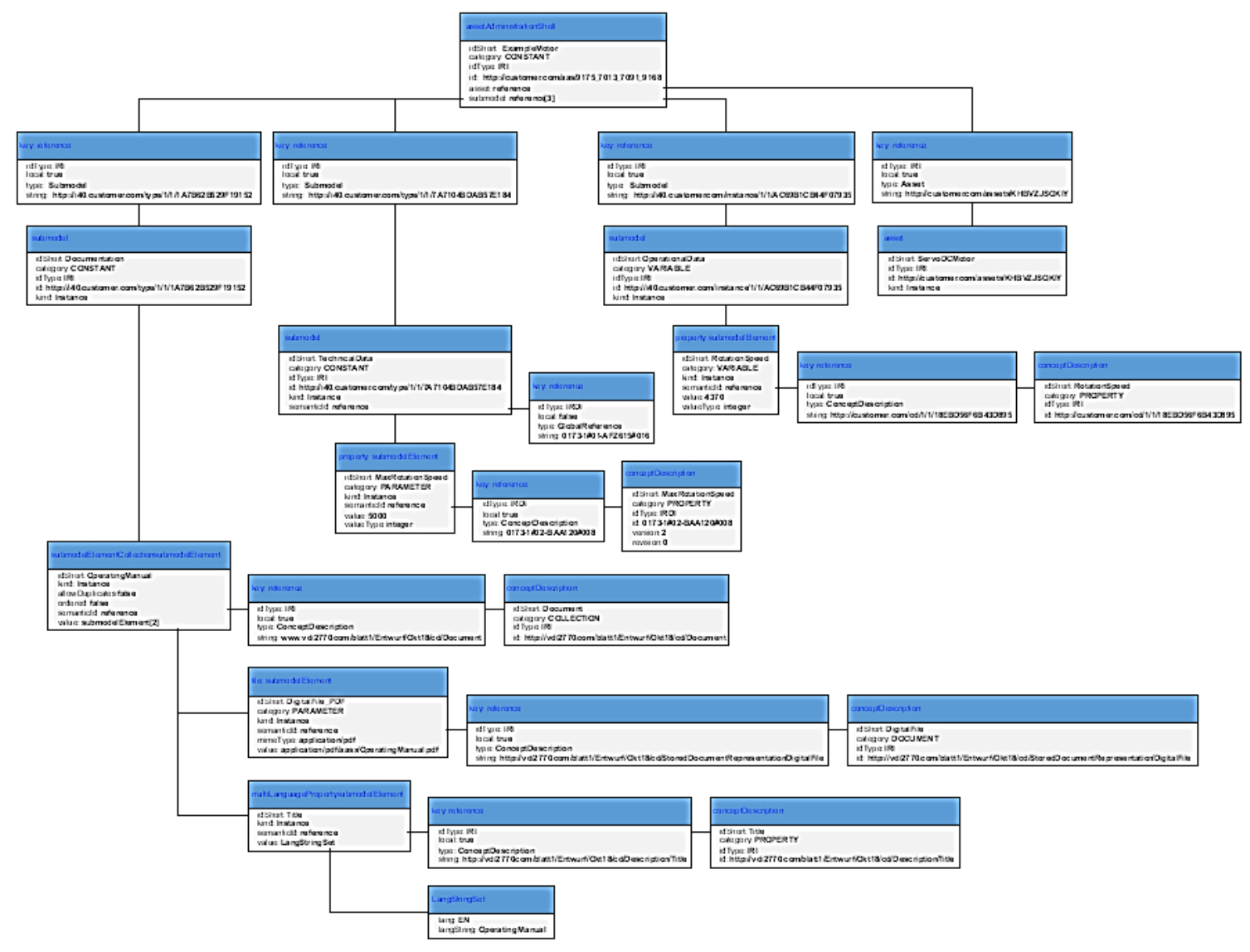

Fonte: autor.

Na Figura 85 têm-se as indicações na arquitetura proposta das atividades descritas no Exemplo 2, isto é, as atividades que foram especificamente descritas (em verde), as atividades que estão relacionadas (em amarelo) e as atividades que são entendidas como necessárias, mas que não foram abordadas (em vermelho).

\subsection{Estrutura de uma base de dados}

Com base no exemplo 2 é possível apresentar a estrutura inicial para uma base de dados (Figura 86) em consonância com a I4.0, e consequentemente, com a arquitetura proposta neste estudo.

Ao longo da sua aplicação em estudos de caso, e tendo como referências (BADER et al., 2019) e publicações mais atuais da Plattform Industrie 4.0, esta estrutura será refinada. 
Figura 85 - Atividades do Exemplo 2 na arquitetura proposta.
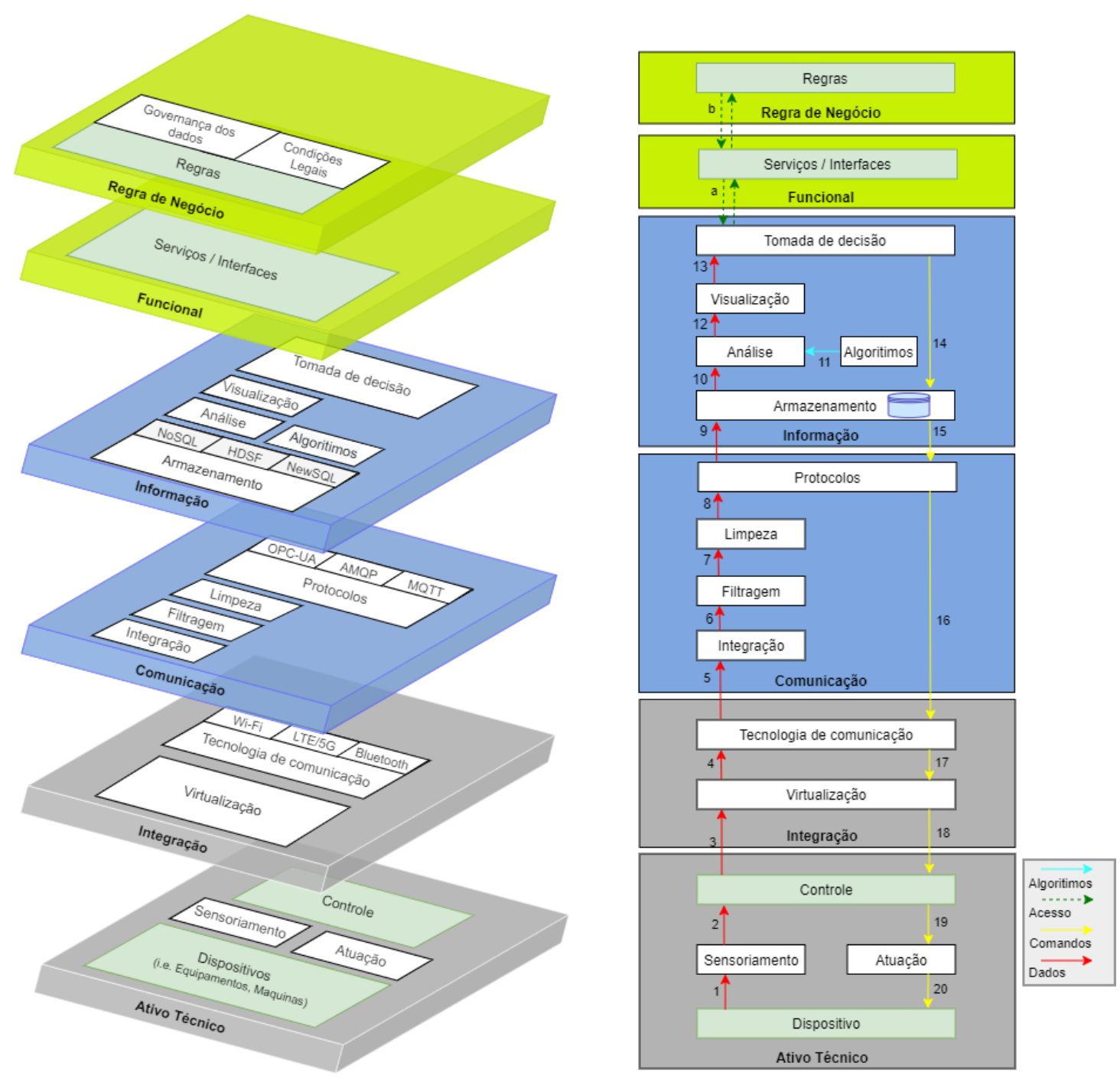

Fonte: autor.

A base de dados é composta (até o momento) por 7 tabelas:

- UniqueId (Tabela 28) - responsável por garantir uma chave externa única para a tabela Attributes;

- IdentifiableElements (Tabela 29) - é a tabela com o registro de apenas quatro tipos de elementos que possuem um identificador único: Ativo, AAS, submodel (submodelo) e conceptDescription (descrição do conceito);

- SubModelElement (Tabela 30) - esta tabela é para o cadastramento de elementos adicionais para caracterizar os submodelos; 
- Reference (Tabela 31) - faz referência entre elementos do modelo ou com elementos externos;

- Attributes (Tabela 32) - esta tabela apresenta os atributos utilizados para descrever os principais elementos dos I4.0Cs;

- Data (Tabela 33) - contém os valores associados aos atributos; se um atributo receber um novo valor, o valor anterior não será apagado, ficando o histórico;

- LangStringSet (Tabela 34) - no exemplo 2 esta tabela se mostrou necessária para registrar informações associadas ao idioma; com a evolução do projeto outras tabelas devem ser criadas para atender os metamodelos da I4.0.

Figura 86 - Estrutura inicial para a base de dados.

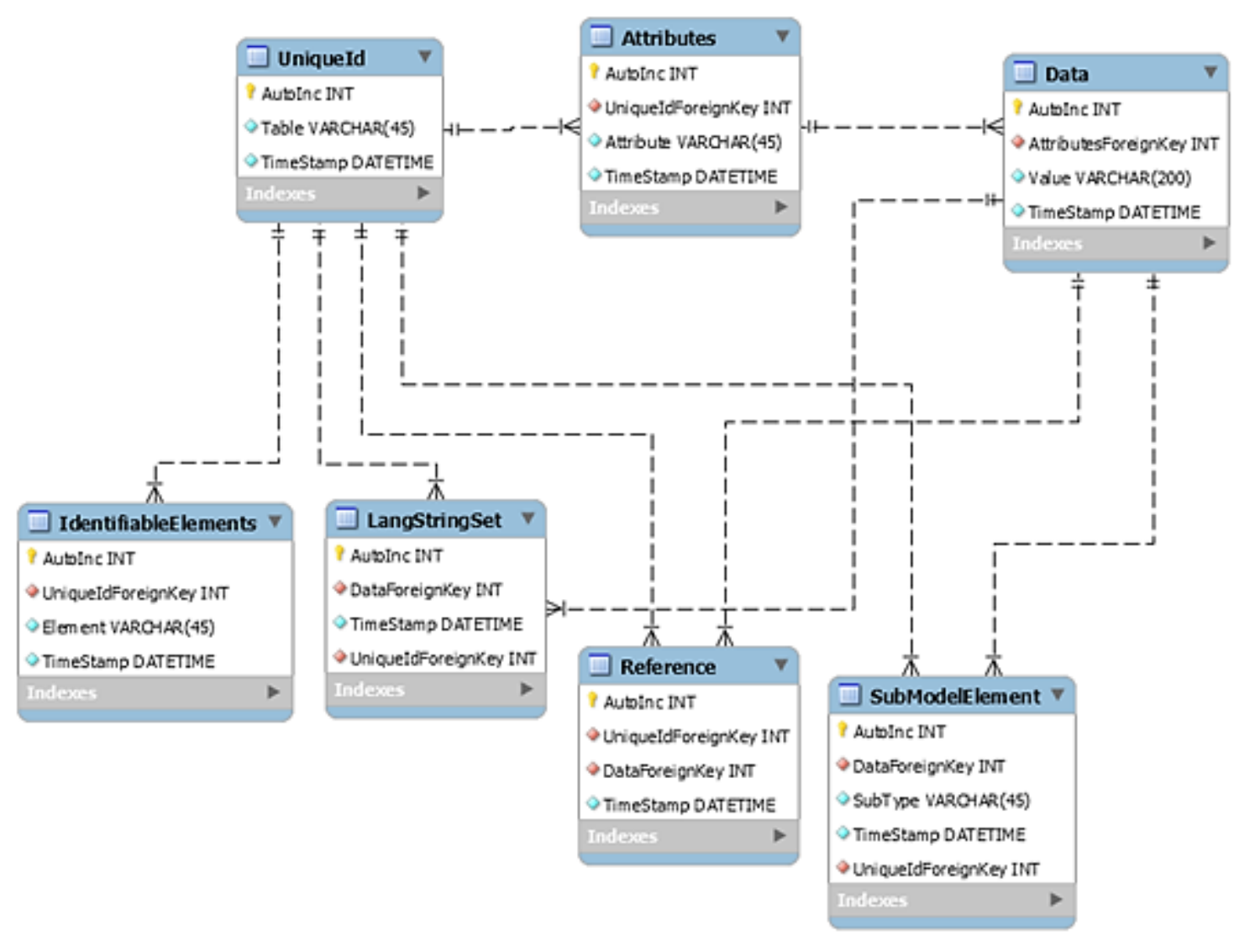

Fonte: autor.

Todas as tabelas apresentam o campo "TimeStamp" para registrar a data e hora em que o registro foi criado.

Nesse contexto, as tabelas da estrutura da base de dados preenchidas para o exemplo 2 preenchidas seguem (Tabelas 28 a 34): 
Tabela 28 - Tabela UniqueId da base de dados.

\begin{tabular}{|c|c|c|}
\hline AutoInc & Table & TimeStamp \\
\hline 1 & IdentifiableElements & \\
\hline 2 & IdentifiableElements & \\
\hline 3 & IdentifiableElements & \\
\hline 4 & IdentifiableElements & \\
\hline 5 & IdentifiableElements & \\
\hline 6 & IdentifiableElements & \\
\hline 7 & IdentifiableElements & \\
\hline 8 & IdentifiableElements & \\
\hline 9 & IdentifiableElements & \\
\hline 10 & IdentifiableElements & \\
\hline 11 & SubModelElement & \\
\hline 12 & SubModelElement & \\
\hline 13 & SubModelElement & \\
\hline 14 & SubModelElement & \\
\hline 15 & SubModelElement & \\
\hline 16 & Reference & \\
\hline 17 & Reference & \\
\hline 18 & Reference & \\
\hline 19 & Reference & \\
\hline 20 & Reference & \\
\hline 21 & Reference & \\
\hline 22 & Reference & \\
\hline 23 & Reference & \\
\hline 24 & Reference & \\
\hline 25 & Reference & \\
\hline 26 & LangStringSet & \\
\hline
\end{tabular}

Fonte: autor. 
Tabela 29 - Tabela IdentifiableElements da base de dados.

\begin{tabular}{|c|c|c|c|}
\hline AutoInc & UniqueIdForeignKey & Element & TimeStamp \\
\hline 1 & 1 & assetAdministrationShell & \\
\hline 2 & 2 & asset & \\
\hline 3 & 3 & Submodel & \\
\hline 4 & 4 & Submodel & \\
\hline 5 & 5 & conceptDescription & \\
\hline 6 & 6 & conceptDescription & \\
\hline 7 & 7 & conceptDescription & \\
\hline 8 & 8 & conceptDescription & \\
\hline 9 & 9 & conceptDescription & \\
\hline 10 & 10 & &
\end{tabular}

Fonte: autor.

Tabela 30 - Tabela SubModelElement da base de dados.

\begin{tabular}{|c|c|c|l|l|}
\hline AutoInc & UniqueIdForeignKey & DataForeignKey & SubType & TimeStamp \\
\hline 1 & 11 & 16 & submodelElementCollection & \\
\hline 2 & 12 & 57 & file & \\
\hline 3 & 13 & 57 & multiLanguageProperty & \\
\hline 4 & 14 & 23 & property & \\
\hline 5 & 15 & 29 & property & \\
\hline
\end{tabular}

Fonte: autor. 
Tabela 31 - Tabela Reference. da base de dados

\begin{tabular}{|c|c|c|c|}
\hline AutoInc & UniqueIdForeignKey & DataForeignKey & TimeStamp \\
\hline 1 & 16 & 5 & \\
\hline 2 & 17 & 6 & \\
\hline 3 & 18 & 6 & \\
\hline 4 & 19 & 6 & \\
\hline 5 & 20 & 56 & \\
\hline 6 & 21 & 66 & \\
\hline 7 & 22 & 22 & \\
\hline 8 & 23 & 71 & \\
\hline 9 & 24 & 77 & \\
\hline 10 & 25 & & \\
\hline
\end{tabular}

Fonte: autor.

Tabela 32- Tabela Attributes da base de dados.

\begin{tabular}{|c|c|c|c|}
\hline AutoInc & UniqueIdForeignKey & Attribute & TimeStamp \\
\hline 1 & 1 & id & \\
\hline 2 & 1 & idType & \\
\hline 3 & 1 & idShort & \\
\hline 4 & 1 & category & \\
\hline 5 & 1 & asset & \\
\hline 6 & 1 & submodel & \\
\hline 7 & 2 & id & \\
\hline 8 & 2 & idType & \\
\hline 9 & 2 & idShort & \\
\hline 10 & 2 & kind & \\
\hline 11 & 3 & id & \\
\hline 12 & 3 & idType & \\
\hline 13 & 3 & idShort & \\
\hline 14 & 3 & category & \\
\hline 15 & 3 & kind & \\
\hline 16 & 3 & SubModeloElement & \\
\hline 17 & 4 & id & \\
\hline 18 & 4 & idType & \\
\hline 19 & 4 & idShort & \\
\hline
\end{tabular}




\begin{tabular}{|c|c|c|}
\hline 20 & 4 & category \\
\hline 21 & 4 & kind \\
\hline 22 & 4 & semanticId \\
\hline 23 & 4 & SubModeloElement \\
\hline 24 & 5 & id \\
\hline 25 & 5 & idType \\
\hline 26 & 5 & idShort \\
\hline 27 & 5 & category \\
\hline 28 & 5 & kind \\
\hline 29 & 5 & SubModeloElement \\
\hline 30 & 6 & id \\
\hline 31 & 6 & idType \\
\hline 32 & 6 & idShort \\
\hline 33 & 6 & category \\
\hline 34 & 6 & version \\
\hline 35 & 6 & revision \\
\hline 36 & 7 & id \\
\hline 37 & 7 & idType \\
\hline 38 & 7 & idShort \\
\hline 39 & 7 & category \\
\hline 40 & 8 & id \\
\hline 41 & 8 & idType \\
\hline 42 & 8 & idShort \\
\hline 43 & 8 & category \\
\hline 44 & 9 & id \\
\hline 45 & 9 & idType \\
\hline 46 & 9 & idShort \\
\hline 47 & 9 & category \\
\hline 48 & 10 & id \\
\hline 49 & 10 & idType \\
\hline 50 & 10 & idShort \\
\hline 51 & 10 & category \\
\hline 52 & 11 & idShort \\
\hline 53 & 11 & kind \\
\hline 54 & 11 & allowDuplicates \\
\hline 55 & 11 & ordered \\
\hline 56 & 11 & semanticId \\
\hline 57 & 11 & value \\
\hline 58 & 12 & idShort \\
\hline
\end{tabular}




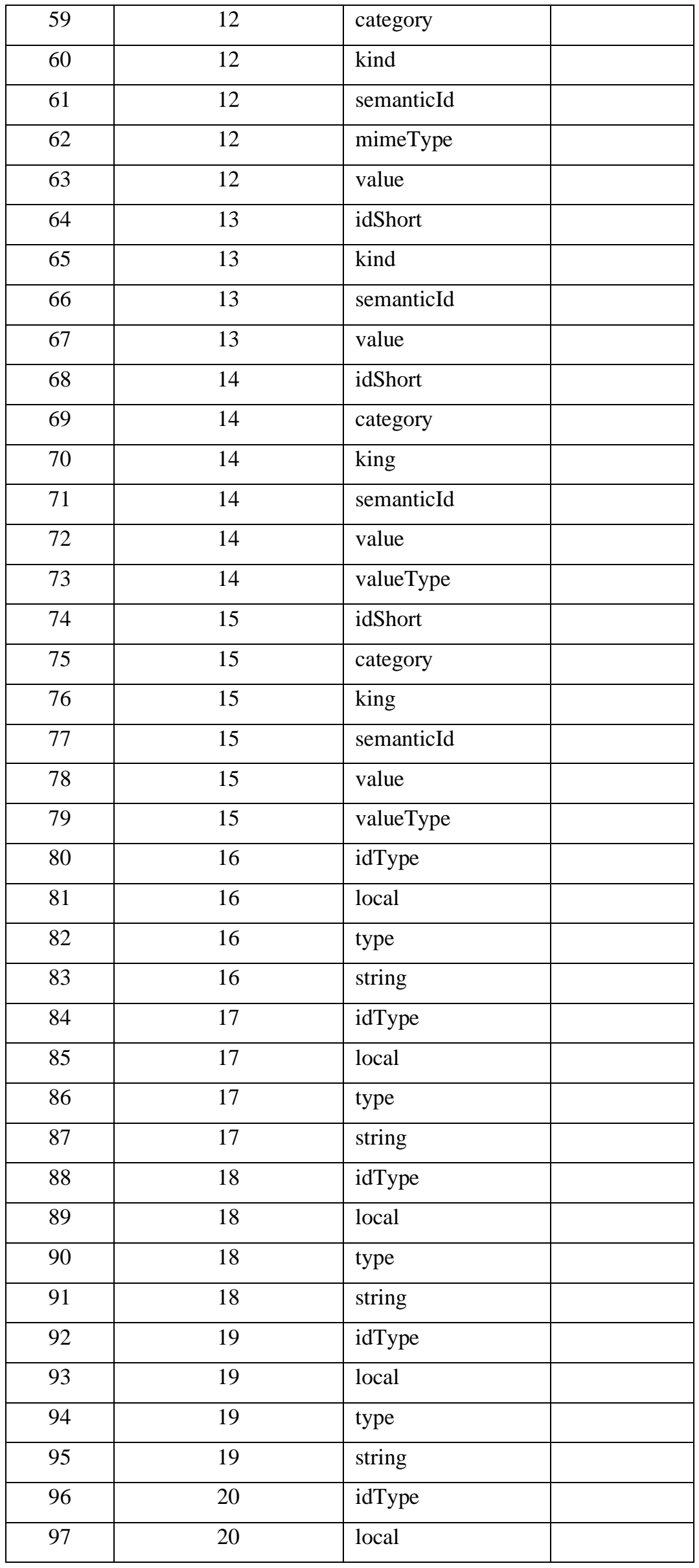




\begin{tabular}{|c|c|c|}
\hline 98 & 20 & type \\
\hline 99 & 20 & string \\
\hline 100 & 21 & idType \\
\hline 101 & 21 & local \\
\hline 102 & 21 & type \\
\hline 103 & 21 & string \\
\hline 104 & 22 & idType \\
\hline 105 & 22 & local \\
\hline 106 & 22 & type \\
\hline 107 & 22 & string \\
\hline 108 & 23 & idType \\
\hline 109 & 23 & local \\
\hline 110 & 23 & type \\
\hline 111 & 23 & string \\
\hline 112 & 24 & idType \\
\hline 113 & 24 & local \\
\hline 114 & 24 & type \\
\hline 115 & 24 & string \\
\hline 116 & 25 & idType \\
\hline 117 & 25 & local \\
\hline 118 & 25 & type \\
\hline 119 & 25 & string \\
\hline 120 & 26 & lang \\
\hline 121 & 26 & langString \\
\hline
\end{tabular}

Fonte: autor. 
Tabela 33 - Tabela Data da base de dados.

\begin{tabular}{|c|c|c|c|}
\hline AutoInc & AttributesForeignKey & Value & TimeStamp \\
\hline 1 & 1 & http://customer.com/aas/9175_7013_7091_9168 & \\
\hline 2 & 2 & IRI & \\
\hline 3 & 3 & ExampleMotor & \\
\hline 4 & 4 & CONSTANT & \\
\hline 5 & 5 & REFERENCE & \\
\hline 6 & 6 & REFERENCE & \\
\hline 7 & 7 & http://customer.com/assets/KHBVZJSQKIY & \\
\hline 8 & 8 & IRI & \\
\hline 9 & 9 & ServoDCMotor & \\
\hline 10 & 10 & Instance & \\
\hline 11 & 11 & $\begin{array}{l}\text { http://i40.customer.com/type/1/1/1A7B62B529F1 } \\
9152\end{array}$ & \\
\hline 12 & 12 & IRI & \\
\hline 13 & 13 & Documentation & \\
\hline 14 & 14 & CONSTANT & \\
\hline 15 & 15 & Instance & \\
\hline 16 & 16 & SubModelElementReference & \\
\hline 17 & 17 & $\begin{array}{l}\text { http://i40.customer.com/type/1/1/7A7104BDAB5 } \\
\text { 7E184 }\end{array}$ & \\
\hline 18 & 18 & IRI & \\
\hline 19 & 19 & TechnicalData & \\
\hline 20 & 20 & CONSTANT & \\
\hline 21 & 21 & Instance & \\
\hline 22 & 22 & REFERENCE & \\
\hline 23 & 23 & SubModelElementReference & \\
\hline 24 & 24 & $\begin{array}{l}\text { http://i40.customer.com/instance/1/1/AC69B1CB } \\
\text { 44F07935 }\end{array}$ & \\
\hline 25 & 25 & IRI & \\
\hline 26 & 26 & OperationalData & \\
\hline 27 & 27 & VARIABLE & \\
\hline 28 & 28 & Instance & \\
\hline 29 & 29 & SubModelElementReference & \\
\hline 30 & 30 & 0173-1\#02-BAA120\#008 & \\
\hline 31 & 31 & IRDI & \\
\hline 32 & 32 & MaxRotationSpeed & \\
\hline 33 & 33 & PROPERTY & \\
\hline
\end{tabular}




\begin{tabular}{|c|c|c|}
\hline 34 & 34 & 2 \\
\hline 35 & 35 & 0 \\
\hline 36 & 36 & $\begin{array}{l}\text { http://vdi2770.com/blatt1/Entwurf/Okt18/cd/Desc } \\
\text { ription/Title2 }\end{array}$ \\
\hline 37 & 37 & IRI \\
\hline 38 & 38 & Title \\
\hline 39 & 39 & PROPERTY \\
\hline 40 & 40 & http://customer.com/cd/1/1/18EBD56F6B43D895 \\
\hline 41 & 41 & IRI \\
\hline 42 & 42 & RotationSpeed \\
\hline 43 & 43 & PROPERTY \\
\hline 44 & 44 & $\begin{array}{l}\text { http://vdi2770.com/blatt1/Entwurf/Okt18/cd/Doc } \\
\text { ument }\end{array}$ \\
\hline 45 & 45 & IRI \\
\hline 46 & 46 & Document \\
\hline 47 & 47 & COLLECTION \\
\hline 48 & 48 & $\begin{array}{l}\text { http://vdi2770.com/blatt1/Entwurf/Okt18/cd/Stor } \\
\text { edDocumentRepresentation/DigitalFile }\end{array}$ \\
\hline 49 & 49 & IRI \\
\hline 50 & 50 & DigitalFile \\
\hline 51 & 51 & DOCUMENT \\
\hline 52 & 52 & OperatingManual \\
\hline 53 & 53 & Instance \\
\hline 54 & 54 & false \\
\hline 55 & 55 & false \\
\hline 56 & 56 & REFERENCE \\
\hline 57 & 57 & SubModelElementReference \\
\hline 58 & 58 & DigitalFile_PDF \\
\hline 59 & 59 & PARAMETER \\
\hline 60 & 60 & Instance \\
\hline 61 & 61 & REFERENCE \\
\hline 62 & 62 & application/pdf \\
\hline 63 & 63 & application/pdf/aasx/OperatingManual.pdf \\
\hline 64 & 64 & Title \\
\hline 65 & 65 & Instance \\
\hline 66 & 66 & REFERENCE \\
\hline 67 & 67 & LangStringSet \\
\hline 68 & 68 & MaxRotationSpeed \\
\hline 69 & 69 & PARAMETER \\
\hline
\end{tabular}




\begin{tabular}{|c|c|c|}
\hline 70 & 70 & Instance \\
\hline 71 & 71 & REFERENCE \\
\hline 72 & 72 & 5000 \\
\hline 73 & 73 & integer \\
\hline 74 & 74 & RotationSpeed \\
\hline 75 & 75 & VARIABLE \\
\hline 76 & 76 & Instance \\
\hline 77 & 77 & REFERENCE \\
\hline 78 & 78 & 4370 \\
\hline 79 & 79 & integer \\
\hline 80 & 80 & IRI \\
\hline 81 & 81 & true \\
\hline 82 & 82 & Asset \\
\hline 83 & 83 & http://customer.com/assets/KHBVZJSQKIY \\
\hline 84 & 84 & IRI \\
\hline 85 & 85 & true \\
\hline 86 & 86 & Submodel \\
\hline 87 & 87 & $\begin{array}{l}\text { http://i40.customer.com/instance/1/1/AC69B1CB } \\
\text { 44F07935 }\end{array}$ \\
\hline 88 & 88 & IRI \\
\hline 89 & 89 & true \\
\hline 90 & 90 & Submodel \\
\hline 91 & 91 & $\begin{array}{l}\text { http://i40.customer.com/type/1/1/1A7B62B529F1 } \\
9152\end{array}$ \\
\hline 92 & 92 & IRI \\
\hline 93 & 93 & true \\
\hline 94 & 94 & Submodel \\
\hline 95 & 95 & $\begin{array}{l}\text { http://i40.customer.com/type/1/1/7A7104BDAB5 } \\
\text { 7E184 }\end{array}$ \\
\hline 96 & 96 & IRI \\
\hline 97 & 97 & true \\
\hline 98 & 98 & ConceptDescription \\
\hline 99 & 99 & $\begin{array}{l}\text { www.vdi2770.com/blatt1/Entwurf/Okt18/cd/Doc } \\
\text { ument }\end{array}$ \\
\hline 100 & 100 & IRI \\
\hline 101 & 101 & true \\
\hline 102 & 102 & ConceptDescription \\
\hline 103 & 103 & $\begin{array}{l}\text { http://vdi2770.com/blatt1/Entwurf/Okt18/cd/Stor } \\
\text { edDocumentRepresentation/DigitalFile }\end{array}$ \\
\hline
\end{tabular}




\begin{tabular}{|c|c|c|}
\hline 104 & 104 & IRI \\
\hline 105 & 105 & true \\
\hline 106 & 106 & ConceptDescription \\
\hline 107 & 107 & $\begin{array}{l}\text { http://vdi2770.com/blatt1/Entwurf/Okt18/cd/Desc } \\
\text { ription/Title }\end{array}$ \\
\hline 108 & 108 & IRDI \\
\hline 109 & 109 & false \\
\hline 110 & 110 & GlobalReference \\
\hline 111 & 111 & 0173-1\#01-AFZ615\#016 \\
\hline 112 & 112 & IRDI \\
\hline 113 & 113 & true \\
\hline 114 & 114 & ConceptDescription \\
\hline 115 & 115 & 0173-1\#02-BAA120\#008 \\
\hline 116 & 116 & IRI \\
\hline 117 & 117 & true \\
\hline 118 & 118 & ConceptDescription \\
\hline 119 & 119 & http://customer.com/cd/1/1/18EBD56F6B43D895 \\
\hline 120 & 120 & EM \\
\hline 121 & 121 & Operating Manual \\
\hline
\end{tabular}

Fonte: autor.

Tabela 34 - Tabela LangStringSet da base de dados.

\begin{tabular}{|c|c|c|c|}
\hline AutoInc & UniqueIdForeignKey & DataForeignKey & TimeStamp \\
\hline 1 & 26 & 67 & \\
\hline
\end{tabular}

Fonte: autor. 


\section{REFERÊNCIAS}

AAZAM, Mohammad; ZEADALLY, Sherali; HARRAS, Khaled A. Deploying Fog Computing in Industrial Internet of Things and Industry 4.0. IEEE Transactions on Industrial Informatics, [S. 1.], 2018. DOI: 10.1109/TII.2018.2855198.

ADOLPH, Lars; ANLAHR, Thomas; BEDENBENDER, Heinz; BENTKUS, Alexander; BRUMBY, Lennart; DIEDRICH, Christian; DIRZUS, Dagmar; ELMAS, Filiz; EPPLE, Ulrich; FRIEDRICH, Jochen; FRITZ, Jessica; GEBHARDT, Hansjürgen; GEILEN, Jan; HECKER, Christoph; HEIDEL, Roland; HEMBERGER, Klaus; HIENSCH, Stefan; HILGENDORF, Eric; HÖRCHER, Günter; KLEMM, Eckerhardt; MEHRFELD, Jens; METZGER, Theo; MIDDELKAMP, Stephan; MOSCH, Christian; NICKEL, Peter; PICHLER, Reinhold; PRINZ, Christopher; RAUCHHAUPT, Lutz; ROLLE, Ingo; SASAKI, Felix; SEIDEL, Uwe; STEIN, Johannes; TIEVES-SANDER, Daniela; ULLRICH, Carsten; WEBER, Ingo; WEI, Wei; WINKEL, Ludwig; . German Standardization Roadmap - Industry 4.0. German Institue for Standardization \& German Commission for Electrical, Electronic \& Information Technologies of German Institute for Standardization and Association for Electrical, Electronic \& Information Technologies, [S. 1.], 2016.

ADOLPHS, Peter; AUER, Sören; BEDENBENDER, Heinz; BILLMANN, Meik; HANKEL, Martin; HEIDEL, Roland; HOFFMEISTER, Michael; HUHLE, Haimo; JOCHEM, Michael; KIELE, Markus; KOSCHNICK, Gunther; KOZIOLEK, Heiko; LINKE, Lukas; PICHLER, Reinhold; SCHEWE, Frank; SCHNEIDER, Karsten; BERND, Waser. Structure of the administration shell. continuation of the development of the reference model for the industrie 4.0 component. ZVEI and VDI, Status Report, [S. 1.], 2016.

ADOLPHS, Peter; BEDENBENDER, Heinz; DIRZUS, Dagmar; EHLICH, Martin; EPPLE, Ulrich; HANKEL, Martin; HEIDEL, Roland; HOFFMEISTER, Michael; HUHLE, Haimo; KÄRCHER, Bernd; KOZIOLEK, Heiko; PICHLER, Reinhold; POLLMEIER, Stefan; SCHEWE, Frank; WALTER, Armin; WASER, Bernd; WOLLSCHLAEGER, Martin. Reference Architecture Model Industrie 4.0 (RAMI4.0) Igarss 2014. [s.l: s.n.]. DOI: 10.1007/s13398-014-0173-7.2, 2015.

ALHARTHI, Abdulkhaliq; KROTOV, Vlad; BOWMAN, Michael. Addressing barriers to big data. Business Horizons, [S. 1.], 2017. DOI: 10.1016/j.bushor.2017.01.002.

ALMISNED, Faisal; KEPPENS, Jeroen. Requirements Analysis: Evaluating KAOS Models. 
Journal of Software Engineering and Applications, [S. 1.], 2010. DOI: 10.4236/jsea.2010.39101.

ANTON, Annie I.; POTTS, Colin. Use of goals to surface requirements for evolving systems.

Proceedings - international conference on software engineering 1998, DOI: 10.1109/icse.1998.671112.

BADER, Sebastian; BARNSTEDT, Erich; BEDENBENDER, Heinz; BILLMANN, Meik; BOSS, Birgit; BRAUNMANDL, André; CLAUER, Erich; DEPPE, Torben; DIEDRICH, Christian; FLUBACHER, Björn; FRITSCHE, Wolfgang; GARRELS, Kai; GATTERBURG, Andreas Graf; HANKEL, Martin; HILLERMEIER, Oliver; HOFFMEISTER, Michael; JOCHEM, Michael; KOGAN, Yevgen; KOZIOLEK, Heiko; LEGAT, Christoph; LÜDER, Arndt; MAHNKE, Wolfgang; MENDES, Marco; NEIDIG, Jörg; ORZELSKI, Andreas; PETHIG, Florian; SAUER, Manuel; SCHIER, Marc; SCHLEIPEN, Miriam; SCHMITT, Michael; SCHRÖDER, Tizian; STOJANOVIC, Ljilijana; UHL, André; USLÄNDER, Thomas; WALLOSCHKE, Thomas; WASER, Bernd; WENDE, Jörg; WIEGAND, Mathias; ZIESCHE, Constantin. Details of the Asset Administration Shell. Part 1 - The exchange of information between partners in the value chain of Industrie 4.0 (Version 2.0). Berlin, Germany. Disponível em:

https://www.plattformi40.de/PI40/Redaktion/EN/Downloads/Publikation/vws-in-detail-presentation.pdf.

BANGEMANN, Thoma; BAUER, Christian; BEDENBENDER, Heinz; DIESNER, Markus; EPPLE, Ulrich; ELMAS, Filiz; FRIEDRICH, Jens; GOLDSCHMIDT, Thomas; GÖBE, Florian; GRÜNER, Sten; HANKEL, Martin; SCHLICH, Bastian; HEIDEL, Roland; HESSELMANN, Klaus; HÜTTEMANN, Guido; KEHL, Heinrich; LÖWEN, Ulrich; PFROMMER, Julius; SCHLEIPEN, Miriam; USLÄNDER, Thomas; WESTERKAMP, Clemens; WINTER, Albrecht; WOLLSCHLAEGER, Martin. Industrie 4.0 Technical Assets: Basic terminology concepts, life cycles and administration models. [s.l: s.n.]. Disponível em: https://www.vdi.de/fileadmin/vdi_de/redakteur_dateien/gma_dateien/6092_PUB_E_T W_GMA_Status_Report_ZVEI_-_Industrie_4_0_-_Technical_Assets_Internet.pdf.

BASSI, Alessandro; BAUER, Martin; FIEDLER, Martin; KRANENBURG, Rob Van. Enabling things to talk. [s.1.]: Springer-Verlag GmbH, 2013.

BAUSE, Falko; KRITZINGER, Pieter S. Stochastic Petri nets: An introduction to the theory. ACM SIGMETRICS Performance Evaluation Review, [S. 1.], v. 26, n. 2, pp. 2-3, 1998. 
BEDENBENDER, Heinz; BILLMANN, Meik; EPPLE, Ulrich; HADLICH, Thomas; HANKEL, Martin; HEIDEL, Roland; HILLERMEIER, Oliver; HOFFMEISTER, Michael; HUHLE, Haimo; JOCHEM, Michael; KIELE-DUNSCHE, Markus; KOSCHNICK, Gunther; KOZIOLEK, Heiko; LINKE, Lukas; LOHMANN, Steffen; PALM, Florian; PICHLER, Reinhold; POLLMEIER, Stefan; RAUSCHER, Benedikt; SCHEWE, Frank; SCHNEIDER, Karsten; WASER, Bernd; WEBER, Ingo; WOLlSCHLAEGER, Martin; ZINN, Marcus. Examples for the Asset Administration Shell for Industrie 4.0 Components - Basic Part. Frankfurt am Main, Germany. Disponível em: https://www.zvei.org/fileadmin/user_upload/Presse_und_Medien/Publikationen/2017/ April/Asset_Administration_Shell/ZVEI_WP_Verwaltungschale_Englisch_Download _03.04.17.pdf.

BEDENBENDER, Heinz; BENTKUS, Alexander; EPPLE, Ulrich; HADLICH, Thomas; HEIDEL, Roland; HILLER-MEIER, Oliver; HOFFMEISTER, Michael; HUHLE, Haimo; KIELE-DUNSCHE, Markus; KOZIOLEK, Heiko; LOHMANN, Steffen; MENDES, Marco; NEIDIG, Jörg; PALM, Florian; POLLMEIER, Stefan; RAUSCHER, Benedikt; SCHEWE, Frank; WASER, Bernd; WEBER, Ingo; WOLLSCHLAEGER, Martin. Industrie 4.0 Plug-and-Produce for Adaptable Factories: Example Use Case Definition, Models, and Implementation. Berlin, Germany. Disponível em: https://www.zvei.org/fileadmin/user_upload/Presse_und_Medien/Publikationen/2017/J uni/Industrie_4.0_Plug_and_produce/Industrie-4.0-_Plug-and-Produce-zvei.pdf.

BEDENBENDER, Heinz; BENTKUS, Alexander; EPPLE, Ulrich; HADLICH, Thomas; HANKEL, Martin; HEIDEL, Roland; HILLERMEIER, Oliver; HOFFMEISTER, Michael; HUHLE, Haimo; KIELE-DUNSCHE, Markus; KOZIOLEK, Heiko; LOHMANN, Steffen; MENDES, Marco; NEIDIG, Jörg; PALM, Florian; POLLMEIER, Stefan; RAUSCHER, Benedikt; SCHEWE, Frank; WASER, Bernd; WEBER, Ingo; WOLLSCHLAEGER, Martin. Relationships between I4.0 Components - Composite Components and Smart Production. Berlin, Germany. Disponível em: https://www.plattformi40.de/PI40/Redaktion/EN/Downloads/Publikation/hm-2018-relationship.pdf.

BEDENBENDER, Heinz; BILLMANN, Meik; BOSS, Birgit; EPPLE, Ulrich; GARRELS, Kai; HADLICH, Thomas; HANKEL, Martin; HEIDEL, Roland; HILLERMEIER, Oliver; JOCHEM, Michael; HOFFMEISTER, Michael; KIELE-DUNSCHE, Markus; KOZIOLEK, Heiko; WOLLSCHLAEGER, Martin; WEBER, Ingo; WASER, Bernd; 
RAUCHER, Benedikt; POLLMEIER, Stefan; PALM, Florian; NEIDIG, Jörg; MENDES, Marco. Which criteria do Industrie 4.0 products need to fulfil? Berlin, Germany. Disponível em: https://www.plattformi40.de/PI40/Redaktion/EN/Downloads/Publikation/criteria-industrie-40-products.pdf.

BERNARDINELLO, Luca; CINDIO, Fiorella. A survey of basic net models and modular net classes. In: [s.1: s.n.]. DOI: 10.1007/3-540-55610-9_177.

BKCASE EDITORIAL BOARD. Guide to the Systems Engineering Body of Knowledge. Guide to the Systems Engineering Body of Knowledge (SEBoK), [S. 1.], 2016.

BLUNCK, Erskin; WERTHMANN, Hedwig. Industry 4.0-an opportunity to realize sustainable manufacturing and its potential for a circular economy. DIEM: Dubrovnik International Economic Meeting. Sveučilište u Dubrovniku, 2017. p. 644-666.

BONET, Pere; LLADÓ, CM. PIPE v2. 5: A Petri net tool for performance modelling. Proc. of 23rd Latin American Conference on Informatics (CLEI 2007), [S. 1.], 2007.

BORNSCHLEGL, Martin; DRECHSEL, Michael; KREITLEIN, Sven; BREGULLA, Markus; FRANKE, Jorg. A new approach to increasing energy efficiency by utilizing cyberphysical energy systems. In: PROCEEDINGS OF THE 11TH INTERNATIONAL WORKSHOP ON INTELLIGENT SOLUTIONS IN EMBEDDED SYSTEMS, WISES 2013

BRETTEL, Malte; FRIEDERICHSEN, Niklas; KELLER, Michael; ROSENBERG, Marius. How Virtualization, Decentralization and Network Building Change the Manufacturing Landscape: An Industry 4.0 Perspective. International Journal of Mechanical, Aerospace, Industrial, Mechatronic and Manufacturing Engineering, [S. 1.], 2014.

BROY, Manfred. Cyber-Physical Systems Innovation durch Software-Intensive eingebettet Systeme. acatech Diskutiert, [S. 1.], 2010. DOI: 10.1007/978-3-642-14901-6.

CASSANDRAS, Christos G.; LAFORTUNE, Stéphane. Introduction to discrete event systems. [s.l: s.n.]. DOI: 10.1007/978-0-387-68612-7.

CHANTANAYINGYONG, Fon Mathuros. What is the theme of Davos 2016? 2016. Disponível em: https://www.weforum.org/agenda/2015/11/what-is-the-theme-ofdavos-2016/. Acesso em: 3 jun. 2019.

CHEN, Kun; LI, Xin; WANG, Huaiqing. On the model design of integrated intelligent big data analytics systems. Industrial Management and Data Systems, [S. 1.], 2015. DOI: 10.1108/IMDS-03-2015-0086.

CHEN, Min; MAO, Shiwen; LIU, Yunhao. Big data: A survey. Mobile networks and applications, [S. 1.], v. 19, n. 2, pp. 171-209, 2014. 
CHENG, Betty H. C.; ATLEE, Joanne M. Research directions in requirements engineering. In: FOSE 2007: FUTURE OF SOFTWARE ENGINEERING 2007, DOI: 10.1109/FOSE.2007.17.

CHENG, Bo; ZHANG, Jingyi; HANCKE, Gerhard P.; KARNOUSKOS, Stamatis; COLOMBO, Armando Walter. Industrial Cyberphysical Systems: Realizing CloudBased Big Data Infrastructures. IEEE Industrial Electronics Magazine, [S. 1.], 2018. DOI: 10.1109/MIE.2017.2788850.

CHUNG, Christopher A. Simulation modeling handbook: a practical approach. [s.1.]: CRC press, 2003.

CHUNG, Lawrence; NIXON, Brian A.; YU, Eric; MYLOPOULOS, John. Non-functional requirements in software engineering. [s.1.]: Springer Science \& Business Media, 2012. v. 5

CODA, Felipe A.; DE SALLES, Rafael M.; JUNQUEIRA, Fabricio; SANTOS FILHO, Diolino J.; SILVA, José R.; MIYAGI, Paulo E. Big data systems requirements for Industry 4.0. In: 2018 13TH IEEE INTERNATIONAL CONFERENCE ON INDUSTRY APPLICATIONS (INDUSCON) 2018, pp. 1230-1236.

CODA, Felipe A.; SALlES, Rafael M.; VITOI, Henrique A.; PESSOA, Marcosiris A. O.; MOSCATO, Lucas A.; SANTOS FILHO, Diolino J.; JUNQUEIRA, Fabrl'licio; MIYAGI, Paulo E. Big Data on Machine to Machine Integration's Requirement Analysis Within Industry 4.0. In: DOCTORAL CONFERENCE ON COMPUTING, ELECTRICAL AND INDUSTRIAL SYSTEMS 2019, pp. 247-254.

CURY, José Eduardo Ribeiro. Teoria de controle supervisório de sistemas a eventos discretos.

V Simpósio Brasileiro de Automaçao Inteligente, [S. 1.], 2001.

DAVENPORT, Thomas H.; BARTH, Paul; BEAN, Randy. How "big data" is different. MIT Sloan Management Review, [S. 1.], 2012.

DE MAURO, Andrea; GRECO, Marco; GRIMALDI, Michele. What is big data? A consensual definition and a review of key research topics. In: AIP CONFERENCE PROCEEDINGS 2015, DOI: 10.1063/1.4907823.

DEUTSCHLAND MAGAZINE. Industry 4.0 at Hannover Messe. 2014. Disponível em: https://www.deutschland.de/en/topic/business/globalization-world-trade/industry-40at-hannover-messe. Acesso em: 1 dez. 2018.

DOMBROWSKI, Uwe; WAGNER, Tobias; RIECHEL, Christoph. Concpt for a Cyber Physical Assembly System. In: PROCEEDINGS - 2013 IEEE INTERNATIONAL SYMPOSIUM ON ASSEMBLY AND MANUFACTURING, ISAM 2013, DOI: 
10.1109/ISAM.2013.6643461.

DORST, Wolfgang; GLOHR, Carsten; HAHN, Thomas; KNAFLA, Frank; LOEWEN, lrich; ROSEN, Roland; SCHIEMANN, Thomas; VOLLMAR, Friedrich; WINTERHALTER, Christoph; DIEGNER, Bernhard; DIEMER, Johannes; KALHOFF, Johannes; DÜMMLER, Mathias; ERKER, Stefan; HERFS, Werner; HILGER, Claus; JÄNICKE, Lutz; JASPERNEITE, Jürgen; KUBACH, Uwe; LÖWEN, Ulrich; MATTIS, Georg; MENGES, Georg; MILDNER, Frank; QUETSCHLICH, Mathias; STEFFENS, ErnstJoachim; STIEDL, Thomas; ADOLPHS, Peter; BEDENBENDER, Heinz; EHLICH, Martin; EPPLE, Ulrich; HANKEL, Martin; HEIDEL, Roland; HOFFMEISTER, Michael; HUHLE, Haimo; KÄRCHER, Bernd; KOZIOLEK, Heiko; PICHLER, Reinhold; POLLMEIER, Stefan; SCHEWE, Frank; SCHULZ, Thomas; SCHWEICHHART, Karsten; WALTER, Armin; WASER, Bernd; WOLLSCHLAEGER, Martin; JÄNICKE, Lutz; JOCHEM, Michael; KAISER, Hartmut; KISCH, Marcel; KLASEN, Wolfgang; LEHMANN, Jörn; LINKE, Lukas; MEHRFELD, Jens; SANDNER, Michael. Implementation Strategy Industrie 4.0 Report on the results of the industrie 4.0 Platform. [s.l: s.n.].

ELITEDATASCIENCE. Chapter 3: Data Cleaning Steps and Techniques. 2019. Disponível em: https://elitedatascience.com/data-cleaning. Acesso em: 6 jun. 2019.

ELKOUTBI, Mohammed; KELLER, Rudolf K. Modeling interactive systems with hierarchical colored petri nets. In: PROC. OF 1998.

ERIDAPUTRA, Hanif; HENDRADJAYA, Bayu; DANAR SUNINDYO, Wikan. Modeling the requirements for big data application using goal-oriented approach. In: PROCEEDINGS OF 2014 INTERNATIONAL CONFERENCE ON DATA AND SOFTWARE ENGINEERING, ICODSE 2014 2014, DOI: 10.1109/ICODSE.2014.7062702.

EVANS, Peter C.; ANNUNZIATA, Marco. Industrial Internet: Pushing the Boundaries of Minds and Machines. General Electric, [S. 1.], 2012.

EZPELETA, Joaquin; COLOM, Jose Manuel; MARTINEZ, Javier. A Petri Net Based Deadlock Prevention Policy for Flexible Manufacturing Systems. IEEE Transactions on Robotics and Automation, [S. 1.], 1995. DOI: 10.1109/70.370500.

FATTORI, Caio Cesar; KANO, Célia Hanako; JUNQUEIRA, Fabrício; MIYAGI, Paulo Eigi; JORGE, André Antunes. Rede de Petri e o aplicativo Platform Independent Petri net Editor (PIPE). [S. 1.], 2019.

FERRERO MARTÍN, F. J.; VALLEDOR LLOPIS, M.; CAMPO RODRÍGUEZ, J. C.; BLANCO GONZÁLEZ, J. R.; MENÉNDEZ BLANCO, J. Low-cost open-source 
multifunction data acquisition system for accurate measurements. Measurement: Journal of the International Measurement Confederation, [S. 1.], 2014. DOI: 10.1016/j.measurement.2014.05.010.

GANTZ, John; REINSEL, David; SHADOWS, Bigger Digital. The Digital Universe in 2020. IDC iView "Big Data, Bigger Digital Shadows, and Biggest Growth in the Far East", [S. 1.], 2012.

GARTNER. Gartner Says Cloud Computing Will Be As Influential As E-business. 2008. GAYKO, Jens E. The Reference Architectural Model RAMI 4.0 and the Standardization Council as an element of success for Industry 4.0. [s.l: s.n.]. Disponível em: https://www.din.de/blob/271306/340011c12b8592df728bee3815ef6ec2/06-smartmanufacturing-jens-gayko-data.pdf.

GERACI, Anne; KATKI, Freny; MCMONEGAL, Louise; MEYER, Bennett; PORTEOUS, Hugh. IEEE Standard Computer Dictionary. A Compilation of IEEE Standard Computer Glossaries. [s.l: s.n.]. DOI: 10.1109/IEEESTD.1991.106963.

GIERSBERG, Georg. Die Vernetzung der Welt. 2014. Disponível em: https://www.deutschland.de/de/topic/wirtschaft/innovation-technik/die-vernetzungder-welt. Acesso em: 6 maio. 2019.

GIL, David; SONG, Il Yeol. Modeling and Management of Big Data: Challenges and opportunitiesFuture Generation Computer Systems, 2016. DOI: 10.1016/j.future.2015.07.019.

GITTLER, Thomas; GONTARZ, Adam; WEISS, Lukas; WEGENER, Konrad. A fundamental approach for data acquisition on machine tools as enabler for analytical Industrie 4.0 applications. In: PROCEDIA CIRP 2019, DOI: 10.1016/j.procir.2019.02.088.

GORECKY, Dominic; SCHMITT, Mathias; LOSKYLL, Matthias; ZÜHLKE, Detlef. Humanmachine-interaction in the Industry 4.0 era. In: PROCEEDINGS - 2014 12TH IEEE INTERNATIONAL CONFERENCE ON INDUSTRIAL INFORMATICS, INDIN 2014 2014, DOI: 10.1109/INDIN.2014.6945523.

GØTZE, John. Reference Architectures for Industry 4.0. 2016. Disponível em: https://coe.qualiware.com/reference-architectures-for-industry-4-0/. Acesso em: 10 jun. 2018.

GRANGEL-GONZÁLEZ, Irlán; HALILAJ, Lavdim; COSKUN, Gökhan; AUER, Sören; COLLARANA, Diego; HOFFMEISTER, Michael. Towards a semantic administrative shell for industry 4.0 components. In: 2016 IEEE TENTH INTERNATIONAL CONFERENCE ON SEMANTIC COMPUTING (ICSC) 2016, pp. 230-237. 
HANKEL, Martin. Industrie 4.0: Das Referenzarchitekturmodell Industrie 4.0 (RAMI 4.0). Zentralverband Elektrotechnik-und Elektronikindustrie eV， [S. 1.], 2015. Disponivel em: https://www.zvei.org/fileadmin/user_upload/Presse_und_Medien/Publikationen/2015/a pril/Das_Referenzarchitekturmodell_Industrie_4.0__RAMI_4.0_/FaktenblattIndustrie4_0-RAMI-4_0.pdf. Acesso em: 28 ago. 2018

HASEGAWA, Kensuke; TAKAHASHI, Kouji; MIYAGI, Paulo Eigi. Application of the Mark Flow Graph to Represent Discrete Event Production Systems and System Control. Transactions of the Society of Instrument and Control Engineers, [S. 1.], 1988. DOI: 10.9746/sicetr1965.24.69.

HAUSE, Matthew. The OMG Systems Modeling Language (SysML). In: EUROPEAN SPACE AGENCY, (SPECIAL PUBLICATION) ESA SP 2007.

HELL, Kristofer; HILLMANN, Robin; LÜDER, Arndt; RÖPKE, Hannes; ZAWISZA, Jacek; SCHMIDT, Nicole; CALÀ, Ambra. Demands on Virtual Representation of Physical Industrie 4.0 Components. In: CIISE 2016, pp. 65-71.

HEWLETT PACKARD ENTERPRISE. What is a Reference Architecture? 2018. Disponível em: https://www.hpe.com/us/en/what-is/reference-architecture.html\#. Acesso em: 28 ago. 2018.

HORKOFF, Jennifer; YU, Eric. Analyzing goal models: Different approaches and how to choose among them. In: PROCEEDINGS OF THE ACM SYMPOSIUM ON APPLIED COMPUTING 2011, DOI: 10.1145/1982185.1982334.

IMTIAZ, Jahanzaib; JASPERNEITE, Jurgen. Scalability of OPC-UA down to the chip level enables "internet of Things". In: IEEE INTERNATIONAL CONFERENCE ON INDUSTRIAL INFORMATICS (INDIN) 2013, DOI: 10.1109/INDIN.2013.6622935.

INTERNATIONAL ORGANIZATION OF STANDARDIZATION. ISO/IEC/IEEE 42010:2011 - Systems and software engineering -- Architecture description. ISOIECIEEE 420102011E Revision of ISOIEC 420102007 and IEEE Std 14712000 , [S. 1.], 2011. DOI: 10.1109/IEEESTD.2011.6129467.

ISA. ISA-95 Enterprise Control Systems. 2019. Disponível em: https://isa-95.com/isa-95enterprise-control-systems. Acesso em: 12 jun. 2019.

JAZDI, Nasser. Cyber physical systems in the context of Industry 4.0. In: PROCEEDINGS OF 2014 IEEE INTERNATIONAL CONFERENCE ON AUTOMATION, QUALITY AND TESTING, ROBOTICS, AQTR 2014 2014, DOI: 10.1109/AQTR.2014.6857843. JUNQUEIRA, Fabrício. Modelagem e simulação distribuída de sistemas produtivos. 2006. 
Tese (Doutorado em Engenharia Mecânica) - Escola Politécnica, Universidade de São Paulo, São Paulo, 2006. doi:10.11606/T.3.2006.tde-11122006-150356. Acesso em: 2020-11-13.

JUNQUEIRA, Fabrício; VILLANI, Emília; MIYAGI, Paulo E. A platform for distributed modeling and simulation of productive systems based on petri nets and object-oriented paradigm. In: IEEE INTERNATIONAL CONFERENCE ON EMERGING TECHNOLOGIES AND FACTORY AUTOMATION, ETFA 2005, DOI: 10.1109/etfa.2005.1612621.

KAGERMANN, Henning. Wir haben als erstes Land eine Vision. 2014. Disponível em: https://www.deutschland.de/de/topic/wirtschaft/globalisierung-welthandel/wir-habenals-erstes-land-eine-vision. Acesso em: 30 ago. 2018.

KAGERMANN, Henning; WAHLSTER, Wolfgang; HELBIG, Johannes. Recommendations for implementing the strategic initiative INDUSTRIE 4.0Final report of the Industrie 4.0 WG. [s.l: s.n.].

KANG, Hyoung Seok; LEE, Ju Yeon; CHOI, Sangsu; KIM, Hyun; PARK, Jun Hee; SON, Ji Yeon; KIM, Bo Hyun; NOH, Sang Do. Smart manufacturing: Past research, present findings, and future directions. International Journal of Precision Engineering and Manufacturing - Green Technology, [S. 1.], 2016. DOI: 10.1007/s40684-016-0015-5. KOMINEK, Darek. Should I Use OPC UA or MQTT or AMQP? 2017. Disponível em: https://opcconnect.opcfoundation.org/2017/10/should-i-use-opc-ua-mqtt-amqp/. Acesso em: 10 maio. 2019.

LANEY, Doug. 3D Data Management: Controlling Data Volume, Velocity, and Variety. Application Delivery Strategies, [S. 1.], 2001. DOI: 10.1016/j.infsof.2008.09.005.

LAPOUCHNIAN, Alexei. Goal-Oriented Requirements Engineering: An Overview of the Current Research. Requirements Engineering, [S. 1.], 2005. DOI: 10.1007/s00766003-0178-9.

LEE, Jay; ARDAKANI, Hossein Davari; YANG, Shanhu; BAGHERI, Behrad. Industrial Big Data Analytics and Cyber-physical Systems for Future Maintenance \& Service Innovation. In: PROCEDIA CIRP 2015, DOI: 10.1016/j.procir.2015.08.026.

LEE, Jay; KAO, Hung An; YANG, Shanhu. Service innovation and smart analytics for Industry 4.0 and big data environment. In: PROCEDIA CIRP 2014, DOI: 10.1016/j.procir.2014.02.001.

LIEW, Anthony. DIKIW: Data, information, knowledge, intelligence, wisdom and their interrelationships. Business Management Dynamics, [S. 1.], 2013. 
LIU, Chao; JIANG, Pingyu. A Cyber-physical System Architecture in Shop Floor for Intelligent Manufacturing. In: PROCEDIA CIRP 2016, DOI: 10.1016/j.procir.2016.10.059.

LYKO, Klaus; NITZSCHKE, Marcus; NGONGA NGOMO, Axel Cyrille. Big data acquisition. In: New Horizons for a Data-Driven Economy: A Roadmap for Usage and Exploitation of Big Data in Europe. [s.1: s.n.]. DOI: 10.1007/978-3-319-21569-3_4.

MA, Bing-xian; WU, Zhe-hui; XIE, Neng-fu. Modeling agent-based Semantic web services with Petri Nets. Acta Simulata Systematica Sinica, [S. 1.], v. 1, 2005.

MAHMOOD, K.; SHEVTSHENKO, E.; KARAULOVA, T.; OTTO, T. Risk assessment approach for a virtual enterprise of small and medium-sized enterprises. Proceedings of the Estonian Academy of Sciences, [S. 1.], 2018. DOI: 10.3176/proc.2017.4.27.

MAKAROV, Oleg.; LANGMANN, Reinhard.; FRANK, B. Signal time deterministic for process control applications from the cloud. In: PROCEEDINGS OF 2014 11TH INTERNATIONAL CONFERENCE ON REMOTE ENGINEERING AND VIRTUAL INSTRUMENTATION, REV 2014 2014, DOI: 10.1109/REV.2014.6784242.

MAZZEI, Matthew J.; NOBLE, David. Big data dreams: A framework for corporate strategy. Business Horizons, [S. 1.], 2017. DOI: 10.1016/j.bushor.2017.01.010.

MEASUREMENT COMPUTING CORPORATION. Data Acquisition Handbook: A Reference for DAQ And Analog \& Digital Signal Conditioning Measurement Computing Corporation (2004-2012). [s.1: s.n.].

MELO, Jose I. Garci.; SOUIT, Samira; SANTOS FILHO, Diolino J..; JUNQUEIRA, Fabrício; MIYAGI, Paulo E. A systematical approach to expose manufacturing system as a service. In: 2010 9TH IEEE/IAS INTERNATIONAL CONFERENCE ON INDUSTRY APPLICATIONS, INDUSCON 2010, DOI: 10.1109/INDUSCON.2010.5739918.

MENYCHTAS, Andreas; GATZIOURA, Anna; VARVARIGOU, Theodora. A business resolution engine for cloud marketplaces. In: 2011 IEEE THIRD INTERNATIONAL CONFERENCE ON CLOUD COMPUTING TECHNOLOGY AND SCIENCE 2011, pp. $462-469$.

MICHAEL, Haustermann; WAGNER, Thomas; MOLDT, Daniel. Welcome to the Petri Nets World - Frequently Asked Questions with Answers. 2018. Disponível em: http://www.informatik.uni-hamburg.de/TGI/PetriNets/faq/. Acesso em: 28 ago. 2018. MIYAGI, Paulo Eigi. Controle Programável: Fundamentos do Controle de Sistemas a Eventos Discretos. São Paulo: Editora Blucher, 1996. 209 p.

MIYAGI, Paulo Eigi; ARATA, Wilson Munemassa; MOSCATO, Lucas Antonio. Application 
of PFS model (production flow schema) based analysis of manufacturing systems for performance assessment. Revista Brasileira de Ciencias Mecanicas/Journal of the Brazilian Society of Mechanical Sciences, [S. 1.], 1997.

MONOSTORI, László. Cyber-physical production systems: Roots, expectations and R\&D challenges. In: PROCEDIA CIRP 2014, DOI: 10.1016/j.procir.2014.03.115.

MONOSTORI, László. Cyber-Physical Systems. CIRP Encyclopedia of Production Engineering, [S. 1.], pp. 1-8, 2018.

MOORE, Kendra E.; BRENNAN, John E. ALPHA/Sim simulation software tutorial. In: PROCEEDINGS OF THE 28TH CONFERENCE ON WINTER SIMULATION 1996, pp. 522-529.

MURATA, Tadao. Petri Nets: Properties, Analysis and Applications. Proceedings of the IEEE, [S. 1.], 1989. DOI: 10.1109/5.24143.

NATIONAL INSTRUMENTS. DAQmx Data Acquisition Triggering Techniques Using LabVIEW. 2019.

NBD-PWG. NIST Big Data Interoperability Framework: Volume 5, Architectures White Paper Survey NIST Special Publication. [s.1: s.n.]. DOI: 10.6028/NIST.SP.1500-5.

NBD-PWG. NIST Big Data Interoperability Framework: Volume 6, Reference Architecture. NIST Special Publication, [S. 1.], 2018. DOI: 10.6028/NIST.SP.1500-6r1.

NEHREY, Maryna; HNOT, Taras. Data Science Tools Application for Business Processes Modelling in Aviation. In: Cases on Modern Computer Systems in Aviation. [s.1.]: IGI Global, 2019. pp. 176-190.

NIKOLAUS, K. "Self-Organizing Factories", Pictures of the Future Magazine. [S. 1.], 2013.

NIST. About NIST. 2017. Disponível em: https://www.nist.gov/about-nis. Acesso em: 23 jul. 2019 .

NUSEIBEH, Bashar; EASTERBROOK, Steve. Requirements engineering: a roadmap. In: PROCEEDINGS OF THE CONFERENCE ON THE FUTURE OF SOFTWARE ENGINEERING 2000, pp. 35-46.

OMEGA ENGINEERING INC. The Omega Transactions and Master Index Vol. 2. 2000.

Disponível em: www.omega.com/literature/transactions/Transactions_Vol_II.pdf. Acesso em: 20 maio. 2019.

PISCHING, Marcos André. Arquitetura para descoberta de equipamentos em processos de manufatura com foco na indústria 4.0. 2017. Tese (Doutorado em Engenharia de Controle e Automação Mecânica) - Escola Politécnica, Universidade de São Paulo, São Paulo, 2017. doi:10.11606/T.3.2018.tde-05032018-133720. Acesso em: 2020-11-13. 
PISCHING, MARCOS A.; FABRICIO JUNQUEIRA; DIOLINO J. DOS SANTOS FILHO; PAULO E. MIYAGI. AN ARCHITECTURE FOR ORGANIZING AND LOCATING SERVICES TO THE INDUSTRY 4.0. In: PROCEEDINGS OF THE 23RD ABCM INTERNATIONAL CONGRESS OF MECHANICAL ENGINEERING 2015a, DOI: 10.20906/cps/cob-2015-0415.

PISCHING, Marcos A.; JUNQUEIRA, Fabrício; FILHO, Diolino J. Santo.; MIYAGI, Paulo E.

Service composition in the cloud-based manufacturing focused on the industry 4.0. In: IFIP ADVANCES IN INFORMATION AND COMMUNICATION TECHNOLOGY 2015b, DOI: 10.1007/978-3-319-16766-4_7.

PISCHING, Marcos A.; PESSOA, Marcosiris A. O.; JUNQUEIRA, Fabricio; MIYAGI, Paulo

E. PFS/PN Technique to Model Industry 4.0 Systems Based on RAMI 4.0. In: 2018 IEEE 23RD INTERNATIONAL CONFERENCE ON EMERGING TECHNOLOGIES AND FACTORY AUTOMATION (ETFA) 2018, pp. 1153-1156.

PLATTFORM INDUSTRIE 4.0. What is Industrie 4.0? Disponivel em: https://www.plattformi40.de/PI40/Navigation/EN/Industrie40/WhatIsIndustrie40/what-is-industrie40.html, 2020 .

PLATTFORM INDUSTRIE 4.0. Plattform Industrie 4.0. Details of the Administration Shell: from idea to implementation. [s.l: s.n.]. Disponível em: https://www.plattformi40.de/PI40/Redaktion/EN/Downloads/Publikation/vws-in-detail-presentation.html.

PLONER, Leopold. Industry Insiders Report: Industry 4.0. 2014. Disponível em: http://br.renesas.com/edge_ol/global/12/index.jsp.

PORTER, Michael E. Competitive Advantage: Creating and Sustaining Superior Performance. [s.1: s.n.]. DOI: 10.1016/j.neubiorev.2009.11.015.

PRESSMAN, Roger S. Engenharia de Software - Uma Abordagem Profissional. [s.l: s.n.]. DOI: 9788563308337.

REISIG, Wolfgang. Understanding Petri nets: Modeling techniques, analysis methods, case studies. [s.l: s.n.]. DOI: 10.1007/978-3-642-33278-4.

RÖPKE, Hannes; HELL, Kristofer; ZAWISZA, Jacek; LÜDER, Arndt; SCHMIDT, Nicole. Identification of Industrie 4.0 component hierarchy layers. In: 2016 IEEE 21ST INTERNATIONAL CONFERENCE ON EMERGING TECHNOLOGIES AND FACTORY AUTOMATION (ETFA) 2016, pp. 1-8.

RÜSSMANN, Michael; LORENZ, Markus; GERBERT, Philipp; WALDNER, Manuela; JUSTUS, Jan; ENGEL, Pascal; HARNISCH, Michael. Industry 4.0: The Future of Productivity and Growth in Manufacturing Industries. The Boston Consulting Group. 
[s.1: s.n.]. DOI: 10.1007/s12599-014-0334-4.

SCHUH, Günther; POTENTE, Till; VARANDANI, Rawina; HAUSBERG, Carlo; FRÄNKEN, Bastian. Collaboration moves productivity to the next level. In: PROCEDIA CIRP 2014, DOI: 10.1016/j.procir.2014.02.037.

SCHWAB, Klaus. The Fourth Industrial Revolution: what it means and how to respond. World Economic Forum, [S. 1.], 2016.

SCHWEICHHART, Karsten. Reference Architectural Model Industrie 4.0 (RAMI 4.0) - An Introduction. Plattform Industrie 4.0, $[S . \quad 1], 2016$. Disponivel em: https://ec.europa.eu/futurium/en/system/files/ged/a2-schweichhartreference_architectural_model_industrie_4.0_rami_4.0.pdf

SIBUM, Helen. Smart factory. 2014. Disponível em: https://www.deutschland.de/de/topic/wirtschaft/innovation-technik/smart-factory. Acesso em: 13 jan. 2019.

SILBERSCHATZ, Abraham; GALVIN, Peter Baer; GAGNE, Greg. Operating system principles. [s.1.]: John Wiley \& Sons, 2006.

SILVA, Javier Martnez. Using GORE method for requirement engineering of planning \& scheduling. In: 26TH INTERNATIONAL CONFERENCE ON AUTOMATED PLANNING AND SCHEDULING 2016, pp. 137-140.

SIMON, PHIL. Big Data Lessons from Netflix. 2014. Disponível em: https://www.wired.com/in-sights/2014/03/big-data-lessons-netflix/. Acesso em: 12 ago. 2018.

SIMONET, Anthony; FEDAK, Gilles; RIPEANU, Matei. Active Data: A programming model to manage data life cycle across heterogeneous systems and infrastructures. Future Generation Computer Systems, [S. 1.], 2015. DOI: 10.1016/j.future.2015.05.015.

SRINIVASAN, Rajagopalan; VENKATASUBRAMANIAN, Venkat. Automating HAZOP analysis of batch chemical plants: Part II. Algorithms and application. Computers and Chemical Engineering, [S. 1.], 1998. DOI: 10.1016/S0098-1354(98)00019-2.

STATISTA. Volume of data/information created, captured, copied, and consumed worldwide from 2010 to 2024. London, United Kingdom: Statista Ltd. Disponível em: https://www.statista.com/statistics/871513/worldwide-data-created/, 2021.

STEVE, Heath. Embedded Systems Design. EDN Series for Design Engineers, [S. 1.], 2003. STROHBACH, Martin; DAUBERT, Jörg; RAVKIN, Herman; LISCHKA, Mario. Big data storage. In: New Horizons for a Data-Driven Economy: A Roadmap for Usage and Exploitation of Big Data in Europe. [s.1: s.n.]. DOI: 10.1007/978-3-319-21569-3_7. 
SUN, Yunchuan; SONG, Houbing; JARA, Antonio J.; BIE, Rongfang. Internet of Things and Big Data Analytics for Smart and Connected Communities. IEEE Access, [S. 1.], 2016. DOI: 10.1109/ACCESS.2016.2529723.

UNGUREAN, Ioan; GAITAN, Nicoleta Cristina; GAITAN, Vasile Gheorghita. An IoT architecture for things from industrial environment. In: IEEE INTERNATIONAL CONFERENCE ON COMMUNICATIONS 2014, DOI: 10.1109/ICComm.2014.6866713.

VAN DER VEEN, Jan Sipke; VAN DER WAAIJ, Bram; MEIJER, Robert J. Sensor data storage performance: SQL or NoSQL, physical or virtual. In: PROCEEDINGS - 2012 IEEE 5TH INTERNATIONAL CONFERENCE ON CLOUD COMPUTING, CLOUD 2012, DOI: 10.1109/CLOUD.2012.18.

VAN KRANENBURG, Rob. The Internet of Things A critique of ambient technology and the all-seeing network of RFID. DOI: 10.1049/ce:20060603.

VAN LAMSWEERDE, Axel. Requirements engineering in the year 00: a research perspective. In: PROCEEDINGS OF THE 22ND INTERNATIONAL CONFERENCE ON SOFTWARE ENGINEERING 2000, pp. 5-19.

VAN RIJMENAM, Mark. Think bigger: developing a successful big data strategy for your business. Choice Reviews Online, [S. 1.], 2014. DOI: 10.5860/choice.51-6848.

VILLANI, Emília. Modelagem e análise de sistemas supervisórios híbridos. 2003. Tese (Doutorado em Engenharia Mecânica) - Escola Politécnica, Universidade de São Paulo, São Paulo, 2004. doi:10.11606/T.3.2004.tde-08062004-131133. Acesso em: 2020-1113.

WANG, Lihui; TÖRNGREN, Martin; ONORI, Mauro. Current status and advancement of cyber-physical systems in manufacturing. Journal of Manufacturing Systems, [S. 1.], 2015. DOI: 10.1016/j.jmsy.2015.04.008.

YANG, Liqin; GE, Xiaokun; SHANG, Pan; ZHANG, Changlin. STUDY ON A QoS-AWARE AND COLOR PETRI NET BASED WEB SERVICE DYNAMIC COMPOSITION. Jisuanji Yingyong yu Ruanjian, [S. 1.], v. 28, n. 5, pp. 102-105, 2011.

YE, Xun; HONG, Seung Ho. Toward Industry 4.0 Components: Insights Into and Implementation of Asset Administration Shells. IEEE Industrial Electronics Magazine, [S. 1.], v. 13, n. 1, pp. 13-25, 2019.

YIN, Shen; KAYNAK, Okyay. Big Data for Modern Industry: Challenges and Trends Proceedings of the IEEE, 2015. DOI: 10.1109/JPROC.2015.2388958.

YU, Eric S. Social Modeling and i. In: Conceptual modeling: Foundations and applications. 
[s.l: s.n.]. pp. 99-121.

YU, Eric S. K. Towards modelling and reasoning support for early-phase requirements engineering. In: PROCEEDINGS OF THE IEEE INTERNATIONAL CONFERENCE ON REQUIREMENTS ENGINEERING 1997, DOI: 10.1109/isre.1997.566873.

ZEZULKA, F.; MARCON, Petr.; VESELY, Ivo.; SAJDL, Ondrej. Industry 4.0 - An Introduction in the phenomenon. IFAC-PapersOnLine, [S. 1.], 2016. DOI: 10.1016/j.ifacol.2016.12.002.

ZHANG, Shaohua; GAO, Hongmei; YANG, Lin; SONG, Jundian. Research on big data governance based on actor-network theory and Petri nets. In: PROCEEDINGS OF THE 2017 IEEE 21ST INTERNATIONAL CONFERENCE ON COMPUTER SUPPORTED COOPERATIVE WORK IN DESIGN, CSCWD 2017, DOI: 10.1109/CSCWD.2017.8066723. 